\title{
Risk assessment after acute myocardial infarction
}

Citation for published version (APA):

Schellings, D. A. A. M. (2017). Risk assessment after acute myocardial infarction: Role of novel biomarkers and implications for early discharge. [Doctoral Thesis, Maastricht University]. Maastricht University. https://doi.org/10.26481/dis.20170412ds

Document status and date:

Published: 01/01/2017

DOI:

10.26481/dis.20170412ds

Document Version:

Publisher's PDF, also known as Version of record

\section{Please check the document version of this publication:}

- A submitted manuscript is the version of the article upon submission and before peer-review. There can be important differences between the submitted version and the official published version of record.

People interested in the research are advised to contact the author for the final version of the publication, or visit the DOI to the publisher's website.

- The final author version and the galley proof are versions of the publication after peer review.

- The final published version features the final layout of the paper including the volume, issue and page numbers.

Link to publication

\footnotetext{
General rights rights.

- You may freely distribute the URL identifying the publication in the public portal. please follow below link for the End User Agreement:

www.umlib.nl/taverne-license

Take down policy

If you believe that this document breaches copyright please contact us at:

repository@maastrichtuniversity.nl

providing details and we will investigate your claim.
}

Copyright and moral rights for the publications made accessible in the public portal are retained by the authors and/or other copyright owners and it is a condition of accessing publications that users recognise and abide by the legal requirements associated with these

- Users may download and print one copy of any publication from the public portal for the purpose of private study or research.

- You may not further distribute the material or use it for any profit-making activity or commercial gain

If the publication is distributed under the terms of Article $25 \mathrm{fa}$ of the Dutch Copyright Act, indicated by the "Taverne" license above, 
Risk assessment after acute myocardial infarction

Role of novel biomarkers and implications

for early discharge 
ISBN: 978-94-6233-547-9

\section{(C) 2017 D.A.A.M. Schellings}

All rights reserved. No part of this book may be reproduced, stored in a retrieval system, or transmitted, in any form or by any means, electronic, mechanical, photocopying, recording or otherwise, without the prior written permission of the copyright holder.

Cover design:

An electrocardiographic sign of coronary artery obstruction.

First described in a human, by Harold E.B. Pardee in Arch Intern Med (Chic) 1920;26(2):244-257.

Printer: Gildeprint, Enschede 


\title{
Risk assessment after acute myocardial infarction
}

\section{Role of novel biomarkers and implications for early discharge}

\begin{abstract}
Proefschrift
Ter verkrijging van de graad van doctor aan de Universiteit Maastricht op gezag van de rector magnificus, Prof. Dr. Rianne M. Letschert, volgens het besluit van het College van Decanen, in het openbaar te verdedigen op woensdag 12 april 2017 om 12.00 uur
\end{abstract}

door

Dirk Adrianus Alouijsius Maria Schellings geboren op 1 mei 1978 te Almelo 
Promotor

Prof. Dr. J.C.A. Hoorntje

Copromotores

Dr. A.W.J. van 't Hof (Isala Zwolle)

Dr. A. Adiyaman (Isala Zwolle)

Beoordelingscommissie

Prof. Dr. H.P. Brunner-La Rocca (voorzitter)

Prof. Dr. H.J.G.M. Crijns

Prof. Dr. J.P.S. Henriques (Academisch Medisch Centrum Amsterdam)

Prof. Dr. A.H.E.M. Maas (Radboud Universitair Medisch Centrum Nijmegen)

Prof. Dr. G.J. Wesseling 


\section{Contents}

Chapter 1. General introduction 1

Chapter 2. Predictors and importance of prolonged hospital stay after 13

primary PCI for ST-elevation myocardial infarction

Chapter 3. Safety and feasibility of next day discharge after primary

percutaneous coronary intervention for acute myocardial infarction

Chapter 4. Early discharge after primary percutaneous coronary intervention:

the added value of $\mathrm{N}$-terminal pro-brain natriuretic peptide to the

Zwolle Risk Score

Chapter 5. NT-proBNP during and after primary PCI for improved scheduling of early hospital discharge

Chapter 6. Value of serial NT-proBNP measurement in predicting non-fatal adverse events after primary PCI

Chapter 7. Predictive value of NT-proBNP for 30-day mortality in patients with non-ST-elevation acute coronary syndromes: a comparison with the GRACE and TIMI risk scores

Chapter 8. Serial N-terminal pro-brain natriuretic peptide assessments in predicting new-onset atrial fibrillation in ST-elevation myocardial infarction patients who undergo primary percutaneous coronary intervention

Chapter 9. Association of serial high-sensitivity troponin $\mathrm{T}$ with onset of atrial fibrillation in ST-elevation myocardial infarction patients undergoing primary percutaneous coronary intervention

Chapter 10. Effect of pre-hospital tirofiban administration on mortality in relation to NT-proBNP level in patients undergoing primary PCI: Insight from the On-TIME 2 trial

Chapter 11. Summary and General discussion

Chapter 12. Valorisation, Samenvatting, Dankwoord,

List of Publications, About the author 

Voor

Marleen

Pepijn en Justus 

CHAPTER 1

General introduction:

Background and general aims of the thesis 



\section{INTRODUCTION}

Acute myocardial infarction (AMI) is the first clinical manifestation in more than 50\% of patients with ischemic heart disease, the worldwide leading cause of death. ${ }^{1-3}$ AMI is frequently caused by coronary atherosclerotic plaque rupture resulting in coronary thrombus formation and abrupt cessation of coronary blood flow, causing myocardial tissue damage. ${ }^{4}$

According to the manifestation of ST-elevation on the electrocardiogram, there are two subtypes of AMI: non-ST-elevation myocardial infarction (NSTEMI) and ST-elevation myocardial infarction (STEMI). ${ }^{5,6}$

Both circumstances require early hospitalization and pharmacological treatment to limit myocardial damage and to prevent sudden cardiac death. Additionally, in STEMI patients concomitant early revascularization of the culprit coronary artery by primary percutaneous coronary intervention (PPCI) has proven to reduce short- and longer-term mortality risk, incidence of stroke and non-fatal re-infarction when compared to pharmacological reperfusion (thrombolysis). ${ }^{7}$ As a consequence, PPCI has now become the treatment of choice in STEMI patients for almost two decades, while innovation of medication and coronary devices have improved prognosis continually., ${ }^{5,9}$ However, despite these favorable developments, there will always be AMI patients at higher risk for adverse outcomes. As a consequence, accurate risk stratification is of great importance and can be challenging.

\section{RISK STRATIFICATION}

In recent years several established AMI risk models have been developed, particularly to predict the patient's mortality risk.

The Thrombolysis in Myocardial Infarction (TIMI) risk score is based on data of over 14,000 fibrinolytic-eligible patients with STEMI. This bedside risk score consists of independent predictors of 30-day mortality derived from the patient's history and clinical baseline characteristics, with scores ranging from 0 to 14 points. In patients with a score of 0 points, mortality at 30-day follow-up was $<1 \%$ with good prognostic capacity (C-statistic of 0.78$).{ }^{10}$ Although initially this risk score was not developed for patients treated with PPCI, the TIMI risk score demonstrated a prognostic value in this group of patients with C-statistics ranging from 0.72 to $0.84 .{ }^{11-13}$ Additionally, a TIMI risk score for NSTEMI or unstable angina patients was also developed, derived from 1957 patients. $^{14}$ 
The global registry of acute coronary events (GRACE) provided data of 11,389 patients (including 509 in-hospital deaths) with acute coronary syndromes with and without ST elevation. ${ }^{15}$ Based on age, Killip Class, systolic blood pressure, presence of ST segment deviation, cardiac arrest during presentation, serum creatinine concentration, heart rate and presence of elevated serum cardiac enzymes, C-statistic for in-hospital mortality was 0.83 .

At present, the GRACE score provides the most accurate stratification of risk in patients presenting with NSTEMI. ${ }^{6}$ In PPCI patients, different C-statistics for 30-day mortality by the GRACE model have been reported, varying from 0.47 to $0.84 .^{12,16}$

\section{PPCI risk models}

The widespread adoption of PPCI resulted in the development of novel risk strategies.

The Zwolle Risk Score (ZRS) is based on 30-day mortality rates of 1791 patients who underwent PPCI. In this risk model, procedural outcome measures were identified as independent predictors of mortality, including the PCI result (post procedural Thrombolysis in Myocardial Infarction (TIMI) flow) and the number of diseased vessels. In combination with established risk variables including Killip Class, age ( $>60$ years), anterior infarction location and time to treatment (ischemia time $>4 \mathrm{~h}$ ), this score (with a maximum of 16 points) was able to identify a large cohort $(73 \%)$ of patients at low mortality risk (ZRS $\leq 3)$, with a good discriminatory capacity (C-statistic of 0.91$).{ }^{17}$ In patients at low mortality risk, the mortality rate was $0.1 \%$ at 2 days and $0.2 \%$ between 2 and 10 days.

The Controlled Abciximab and Device Investigation to Lower Late Angioplasty Complications (CADILLAC) risk model was derived from 2082 patients. In this risk model baseline left-ventricular ejection fraction (assessed by ventriculography) was identified as the most powerful predictor of 1-year mortality. Additional predictors were renal insufficiency, anemia, Killip Class, TIMI flow, number of vessel disease and age. The CADILLAC risk score demonstrated good prognostic accuracy in both the derivation and validation sets (C-statistics of approximately 0.80 for 30-day and 1year mortality). ${ }^{18}$

The Primary Angioplasty in Myocardial Infarction (PAMI) risk score was derived from several PAMI trials, including 3452 PPCI patients to predict 6-month mortality. ${ }^{19}$ Finally, the APEX-AMI risk model was derived from the largest PPCI patient population until now (5745 patients). Compared to the PAMI and CADILLAC scores, this model also considered patients with cardiogenic shock, to predict 90-day mortality risk; however, external validation has not been performed. ${ }^{20}$ 
In Table 1 risk models, variables and outcome measures are summarized. In addition to conventional risk factors, variables related to left-ventricular dysfunction and procedural success are important representatives.

In comparative studies, major differences in predicting 30-day mortality in STEMI patients treated with PPCI between the TIMI, ZRS, CADILLAC and PAMI risk scores could not be demonstrated. ${ }^{12,13,21}$

\section{Biomarkers}

Biomarkers including cardiac troponin ( $\mathrm{cTn}$ ) or brain natriuretic peptide (BNP) and its $\mathrm{N}$-terminal fragment (NT-proBNP) are emerging tools for diagnosis and treatment in cardiology. ${ }^{5,6,8}$ An increased level of the protein $\mathrm{cTn}$ indicates myocardial necrosis, while the amino-acid polypeptide (NT-pro) BNP is released when myocardial dysfunction occurs.

As a consequence, these biomarkers have demonstrated to be of prognostic value in AMI patients as well. ${ }^{22-24}$

In STEMI patients treated by PPCI, these biomarkers are also associated with procedural outcome and clinical events, and improve prognostication over conventional risk factors. ${ }^{25-28}$ Particularly NT-proBNP measurement provides incremental risk stratification in this patient group. ${ }^{29,30}$ However, novel PPCI risk models that have incorporated NT-proBNP are still limited. ${ }^{30,31}$ Furthermore, it remains underexposed whether routinely use of NT-proBNP beyond established PPCI risk models could improve risk stratification.

In NSTEMI patients, cTn or high-sensitivity (hs)-cTn at present, has important prognostic accuracy and constitutes a key-element of the GRACE risk model. ${ }^{15,32}$ However, the added value of NT-proBNP beyond current risk strategies in NSTEMI is debatable. $^{6}$

\section{Early discharge}

The increase in the number of PPCI patients at low mortality risk has been paralleled by a decrease in hospital stay from approximately 1 week in the thrombolysis era to a recommended early discharge, after 3 days at present. ${ }^{4,33}$

The safety and feasibility of early discharge (particularly $48-72 \mathrm{~h}$ after admission) in suitable low-risk PPCI patients was demonstrated in several studies in which different risk strategies were proposed. ${ }^{34,35}$ 


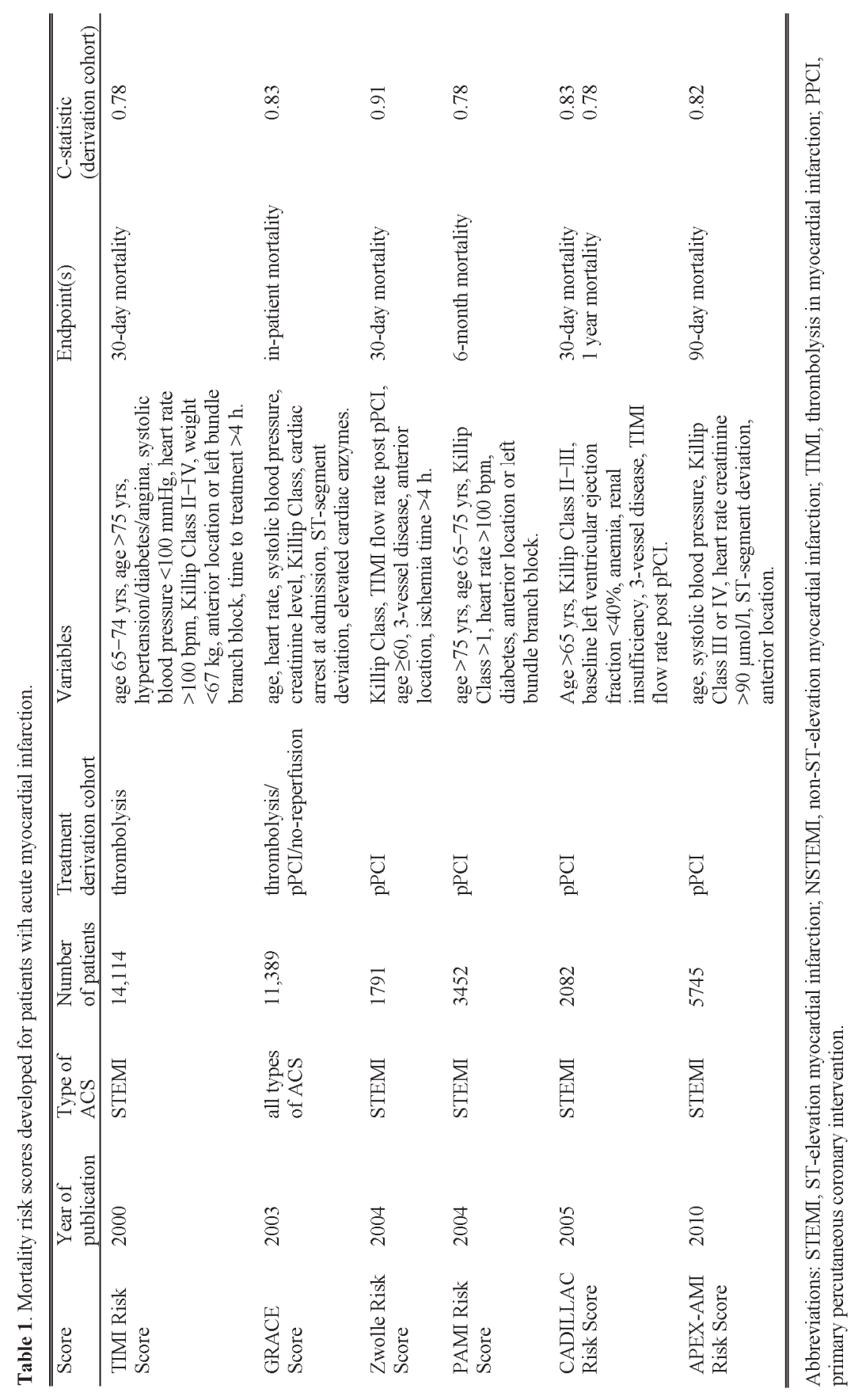


Based on the outcome measures of the Zwolle Risk Score (ZRS), it was suggested that low-risk patients ( $74 \%$ of the study population) could be discharged early (between $48-72 \mathrm{~h}$ ), as a cost-saving alternative for traditional care without increased mortality risk. $^{17}$

The ZRS has been validated in several reports demonstrating that there was no difference in outcome between early discharge compared to traditional care in low-risk PPCI patients, who had a very low occurrence of adverse events. ${ }^{36-38}$

\section{Atrial fibrillation}

New-onset atrial fibrillation (AF), defined as the arrhythmia developing after hospital admission but during inpatient stay, frequently occurs in patients admitted with AMI (incidences to over 20\%). ${ }^{39,40}$

The mechanism of this arrhythmia is supposed to be the result of atrial enlargement, atrial ischemia or atrial wall stretching. Although occurrence of AF is often transiently, AMI patients with new-onset $\mathrm{AF}$ have worse baseline characteristics, more complicated hospital courses and impaired cardiovascular outcome, including a higher mortality risk. ${ }^{41-43 .}$

Although PPCI has decreased the risk of new-onset AF in STEMI patients, it still occurs in about $6 \%$ to $10 \%$ of cases and is associated with higher Killip Class at admission, pre-procedural coronary artery occlusion and post procedural TIMI flow $<3$ and higher risk of 30-day mortality. ${ }^{40,43,44}$ As a consequence, early recognition of patients at risk for developing AF could help to improve outcomes.

In previous reports it was demonstrated that STEMI patients with higher levels of the biomarkers high-sensitivity C-reactive protein (hsCRP) and NT-proBNP were at higher risk for developing AF; with only one report mentioning the predictive value of NTproBNP. $^{45}$

Therefore, more insight in the predictive value of biomarkers including NT-proBNP and $\mathrm{cTn}$ is needed.

\section{Aims of the thesis}

The aims of this thesis are:

1. To improve risk assessment in AMI patients in the present biomarker era.

2. To improve discharge policy in STEMI patients treated with primary PCI.

3. To improve identification of STEMI patients at risk for new-onset AF. 
OUTLINE OF THE THESIS

In CHAPTER 2, we identify the predictors of prolonged hospital stay in STEMI patients treated with PPCI and determine the prognostic importance of a prolonged stay in hospital by evaluating the 1-year mortality rates.

In CHAPTER 3, we investigate the safety and feasibility of next day discharge in lowrisk STEMI patients treated with PPCI, based on the Zwolle Risk Score (ZRS) and protocolized care.

In CHAPTER 4, we investigate whether the Zwolle Risk Score could be improved by adding baseline NT-proBNP determination for prognostication of 30-day mortality in STEMI patients treated with PPCI. Additionally we analysed the occurrence of major adverse cardiac events (MACEs) and major bleeding up to 10 days in low risk patients. In CHAPTER 5, we investigate the optimum time of NT-proBNP determination by performing serial NT-proBNP measurements after PPCI. We also evaluated wether NT-proBNP at the different time points and the ZRS could improve prognostication of 30-day mortality and the scheduling of early hospital discharge.

In CHAPTER 6 serial NT-proBNP measurement after PPCI and its combination with the ZRS is evaluated for prognostication of the occurrence of non-fatal adverse events up to 30 days post PPCI.

In CHAPTER 7, we investigate the predictive value of baseline NT-proBNP for 30-day mortality over and beyond the GRACE and TIMI risk scores in NSTEMI patients.

In CHAPTER 8, the value of serial NT-proBNP assessment in predicting new onset atrial fibrillation in STEMI patients undergoing PPCI is evaluated.

In CHAPTER 9, we investigate the association of serial high-sensitivity troponin $\mathrm{T}$ with the onset of atrial fibrillation in STEMI patients undergoing PPCI.

In CHAPTER 10 we evaluate the association between baseline NT-proBNP levels and long-term mortality in PPCI patients. We also investigate the effect of pre-hospital tirofiban administration on mortality in relation to NT-proBNP levels.

In CHAPTER 11 the outcome of the thesis is summarized, followed by a general discussion with special emphasis on clinical implications and future developments. 


\section{REFERENCES}

1. World Health Organization (http://www.who.int/mediacentre/factsheets/fs310/en/).

2. Herrett E, George J, Denaxas S, Bhaskaran K, Timmis A, Hemingway H, Smeeth L. Type and timing of heralding in ST-elevation and non-ST-elevation myocardial infarction: An analysis of prospectively collected electronic healthcare records linked to the national registry of acute coronary syndromes. Eur Heart J 2013;2:235-245.

3. Herrett E, Bhaskaran K, Timmis A, Denaxas S, Hemingway H, Smeeth L. Association between clinical presentations before myocardial infarction and coronary mortality: a prospective population- based study using linked electronic records. Eur Heart J 2014;35:2363-2371.

4. Virmani R, Burke AP, Farb A, Kolodgie FD. Pathology of the unstable plaque. Prog Cardiovasc Dis 2002;44:349-356.

5. The Task Force on the management of ST-segment elevation myocardial infarction of the European Society of Cardiology (ESC). Steg PhG, James SK, Atar D, Badano LP, BlömstromLundqvist C, Borger MA, Di Mario C, Dickstein K, Ducrocq G, Fernandez-Aviles F, Gershlick AH, Giannuzi P, Halvorsen S, Huber K, Juni P, Kastrati A, Knuuti J, Lenzen MJ, Mahaffey KW, Valgimigli M, van ' $t$ Hof A, Widimsky P, Zahger D. ESC guidelines for the management of acute myocardial infarction in patients presenting with ST-segment elevation. Eur Heart J 2012;33:2569-2619.

6. The Task Force for the manangement of acute coronary syndromes (ACS) in patients presentng without persistent ST-elevation of the European Society of Cardiology (ESC) Roffi M, Patrono C, Collet J-P, Mueller C, Valgimigli M, Andreotti F, Bax JJ, Borger MA, Brotons C, Chew DP, Gencer B, Hasenfuss G, Kjeldsen K, Lancellotti P, Landmesser U, Mehilli J, Mukherjee D, Storey RF, Windecker S. ESC Guidelines for the management of acute coronary syndromes in patients presenting without persistent ST-segment elevation. Eur Heart J 2015;37:267-315.

7. Keeley EC, Boura JA, Grines CL. Primary angioplasty versus intravenous thrombolytic therapy for acute myocardial infarction: a quantitative review of 23 randomised trials. Lancet 2003; 361:13-20.

8. O' Gara PT, Kushner FG, Ascheim DD, Casey DE, Chung MK, de Lemos JA, Ettinger SM, Fang JC, Fesmire FM, Franklin BA, Granger CB, Krumholz HM, Linderbaum JA, Morrow DA, Newby LK, Ornato JP, Ou N, Radford MJ, Tamis-Holland JE, Tommaso CL, Tracy CM, Woo YJ, Zhao DX. 2013 ACCF/AHA Guideline for the management of ST-elevation myocardial infarction. A report of the American College of Cardiology Foundation/ American Heart Association Task Force on Practice Guidelines. J Am Coll Cardiol 2013;61:e78-e140.

9. Roe MT, Messenger JC, Weintraub WS, Cannon CP, Fonarow GC, Dai D, Chen AY, Klein LW, Masoudi FA, McKay C, Hewitt K, Brindis RG, Peterson ED, Rumsfeld JS. Treatment, trends, end outcomes of acute myocardial infarction and percutaneous coronary intervention. J Am Coll Cardiol 2010;56:254.

10. Morrow DA, Antman EM, Charlesworth A, Cairns R, Murphy SA, de Lemos JA, Giugliano RP, McCabe $\mathrm{CH}$, Braunwald E. TIMI Risk Score for ST-elevation myocardial infarction: A convenient, bedside, clinical score for risk assessment at presentation. An intravenous nPA for Treatment of Infarcting Myocardium early II Trial substudy. Circulation 2000;102:2031-2037.

11. Gevaert SA, De Bacquer D, Ervard P, Convens C, Dubois P, Boland J, Renard M, Beauloye C, Coussement P, De Raedt H, De Meester A, Vandecasteele E, Vranckx P, Sinnaeve PR, Claeys MJ. Gender, TIMI risk score and in-hospital mortality in STEMI patients undergoing primary PCI: results from the Belgian STEMI registry. Eurointervention 2014;22:1095-1101.

12. Lev EI, Kornowski R, Vaknin-Assa H, Porter A, Teplitsky I, Ben-Dor I, Brosh D, Fuchs S, Battler A, Assali A. Comparison of the predictive value of four different risk scores for outcomes of patients with ST-elevation acute myocardial infarction undergoing primary percutaneous coronary intervention. Am J Cardiol 2008:102:6-11. 


\section{General introduction}

13. Kozieradzka A, Kaminski KA, Maciorkowska D, Olszewska M, Dobrzycki S, Nowak K, Kralisz P, Prokopczuk P, Musial WJ. GRACE, TIMI, Zwolle and CADILLAC risk scores - do they predict 5-year outcome after ST-elevation myocardial infarction treated invasively? Int J Cardiol 2011;148:70-75.

14. Antmann EM, Cohen M, Bernink PJ, McCabe CH, Horacek T, Papuchis G, Mautner B, Corbalan R, Radley D, Braunwald E. The TIMI risk score for unstable angina/non-ST elevation MI: A method for prognostication and therapeutic decision making. JAMA 2000;284:835-842.

15. Granger CB, Goldberg RJ, Dabbous O, Pieper KS, Eagle KA, Cannon CP, Van de Werf F, Avezum A, Goodman SG, Flather MD, Fox KA. Predictors of hospital mortality in the global registry of acute coronary events. Arch Intern Med 2003;163:2345-2553.

16. Abelin AP, David RB, Gottschall CA, Quadros AS. Accuracy of dedicated risk scores in patients undergoing primary percutaneous coronary intervention in daily clinical practice. Can J Cardiol 2014;30:125-131.

17. De Luca G, Suryapranata H, van 't Hof AW, de Boer MJ, Hoorntje JC, Dambrink JH, Gosselink AT, Ottervanger JP, Zijlstra F. Prognostic assessment of patients with acute myocardial infarction treated with primary angioplasty: implications for early discharge. Circulation 2004;109:2737-2743.

18. Halkin A, Singh M, Nikolsky E, Grines CL, Tcheng JE, Garcia E, Cox DA, Turco M, Stuckey TD, Na Y, Lansky AJ, Gersh BJ, O’Neill WW, Mehran R, Stone GW. Prediction of mortality after primary percutaneous coronary intervention for acute myocardial infarction. The CADILLAC Risk Score. J Am Cardiol 2005;45:1397-1405.

19. Addala S, Grines CL, Dixon SR, Stone GW, Boura JA, Ochoa AB, Pellizzon G, Kahn JK. Predicting mortality in ST elevation myocardial infarction treated with primary angioplasty. Am J Cardiol 2004;93:629-632.

20. Stebbins A, Mehta RH, Armstrong PW, Lee KL, Hamm C, Van de Werf F, James S, ToftegaardNielsen T, Seabra-Gomes R, White HD, Granger CB (APEX AMI Investigators) A model for predicting mortality in acute ST-segment elevation myocardial infarction treated with primary percutaneous coronary intervention. Circ Cardiovasc Interv 2010;3:414-422.

21. Scruth EA, Cheng E, Worrall-Carter L. Risk score comparison of outcomes in patients presenting with ST-elevation myocardial infarction treated with percutaneous coronary intervention. Eur J Cardiovasc Nurs 2013;12:330-336.

22. The GRACE score's performance in predicting in-hospital and 1-year outcome in the era of high sensitivity cardiac troponin assays and B-type natriuretic peptide. Heart 2011;97:1479-1483.

23. Heeschen C, Hamm CW, Mitrovic V, Lantelme NH, White HD. Platelet Receptor Inhibition in Ischemic Syndrome Management (PRISM) investigatigators. N-terminal pro-B-type natriuretic peptide levels for dynamic risk stratification of patients with acute coronary syndromes. Circulation 2004;110:3206-3212.

24. Mega JL, Morrow DA, De Lemos JA, Sabatine MS, Murphy SA, Rifai N, Gibson CM, Antman EM, Braunwald E. B-type natriuretic peptide at presentation and prognosis in patients with STsegment elevation myocardial infarction: an ENTIRE-TIMI-23 substudy. J Am Coll Cardiol 2004;44:335-339.

25. Grabowski M, Fillipiak KJ, Karpinski G, Wretowski, Rdzanek Z, Horszczaruk GJ, Kochman J, Rudowski R, Opolski G. Serum B-type natriuretic peptide levels on admission predict not only short-term death but also angiographic success of procedure in patients with acute ST-elevation myocardial infarction treated with primary PCI. Am Heart J 2004;148:655:655-662.

26. Hong SN, Ahn Y, Hwang SH, Yoon NS, Lee SR, Moon JY, Kim KH, Hong YJ, Park HW, Kim JH, Jeong MH, Cho JG, Park JC, Kang JC. Usefulness of preprocedural N-terminal pre-brain natriuretic peptide in predicting angiographic no-reflow phenomenon during stent implantation in patients with ST-segment elevation acute myocardial infarction. Am J Cardiol 2007;100:631634. 
27. Giannitsis E, Muller-Bardorff M, Lehrke S, Wiegand U, Weidtmann B, Hartmann F, Richardt G, Katus HA. Admission troponin T level predicts clinical outcomes, TIMI flow and myocardial tissue perfusion after primary percutaneous intervention for acute ST-segment elevation myocardial infarction. Circulation 2001;104:630-635.

28. Hall TS, Hallen J, Krucoff MW, Roe MT, Brennan DM, Agewall S, Atar D, Lincoff AM. Cardiac troponin I for the prediction of clinical outcomes and cardiac function through 3-month follow-up after primary percutaneous coronary intervention for ST-segment elevation myocardial infarction. Am Heart J 2015;169:257-265.

29. Velders MA, Wallentin L, Becker RC, Van Boven AJ, Himmelmann A, Husted S, Katus HA, Lindholm D, Morais J, Siegbahn A, Storey RF, Wernroth L, James SK on behalf of the PLATO investigators. Biomarkers for risk stratification of patients with ST-elevation myocardial infarction treated with primary percutaneous coronary intervention: insights from the platelet inhibition and patient outcomes trial. Am Heart J 2015;169:879-889.

30. Damman P, Beijk MAM, Kuijt WJ, Verouden NJW, van Geloven N, Henriques JPS, Baan J, Vis MM, Meeuwissen M, van Straalen JP, Fischer J, Koch KT, Piek JJ, Tijssen JGP, de Winter RJ. Multiple biomarkers at admission significantly improve the prediction of mortality in patients undergoing primary percutaneous coronary intervention for acute ST-segment elevation myocardial infarction. J Am Coll Cardiol 2011;57:29-36.

31. Kampinga MA, Damman P, van der Horst ICC, Woudstra P, Kuijt WJ, Nijsten MWN, Zijlstra F, Tijssen JGP, de Winter RJ, de Smet BJGL. Survival of patients after ST-elevation myocardial infarction: External validation of a predictive biomarker model. Clin Chem 2012;58:1063-1064.

32. Mueller C. Biomarkers and acute coronary syndromes: an update. Eur Heart J 2014;35:552-556.

33. Newby LK, Califf RM, Guerci A, Weaver WD, Col J, Horgan JH, Mark DB, Stebbins A, Van de Werf F, Gore JM, Topol EJ. Early discharge in the thrombolytic era: an analysis of criteria for uncomplicated infarction from the Global Utilization of Streptokinase and t-PA for Occluded Coronary Arteries (GUSTO) trial. J Am Coll Cardiol 1996;27:625-632.

34. Grines CL, Marsalese DL, Brodie B, Griffin J, Donohue B, Costantini CR, Balestrini CR, Stone G, Wharton T, Esente P, Spain M, Moses J, Nobuyoshi M, Ayres M, Jones D, Mason D, Sachs D, Grines LL, O'Neill W. Safety and cost-effectiveness of early discharge after primary angioplasty in low risk patients with acute myocardial infarction. PAMI-II investigators. Primary Angioplasty in Myocardial Infarction. J Am Coll Cardiol 1998;31:967-972.

35. Laarman GJ, Dirksen MT. Early discharge after primary percutaneous coronary intervention. Heart 2010:96:584-587.

36. Kotowycz MA, Cosman TL, Tartaglia C, Afzal R, Syal RP, Natarajan MK. Safety and feasibility of early hospital discharge in ST-segment elevation myocardial infarction - A prospective and randomized trial in low-risk primary percutaneous coronary intervention patients (the Safedepart trial). Am Heart J 2010;159:117.

37. Kotowycz MA, Syal RP, Afzal R, Natarajan MK. Can we improve lenght of hospitalization in ST-elevation myocardial infarction patients treated with primary percutaneous coronary intervention? Can J Cardiol 2009;25:585-588.

38. Melberg T, Jørgensen M, Orn S, Solli T, Edland U, Dickstein K. Safety and health status following early discharge in patients with acute myocardial infarction treated with primary PCI: a randomized trial. Eur J Prev Cardiol 2015;22:1427-1434.

39. Saczynski JS, McManus D, Zhou Z, Spencer F, Yarzebski J, Lessard D, Gore JM, Goldberg RJ. Trends in atrial fibrillation complicating acute myocardial infarction. Am J Cardiol 2009;104:169-174.

40. Schmitt J, Duray G, Gersh BJ, Hohnloser SH. Atrial fibrillation in acute myocardial infarction: a systematic review of the incidence, clinical features and prognostic implications. Eur Heart $\mathrm{J}$ 2009;30:1038-1045. 
41. Jabre P, Roger VL, Murad MH, Chamberlain AM, Prokop L, Adnet F, Jouven X, Mortality associated with atrial fibrillation in patients with myocardial infarction: a systematic review and meta-analysis. Circulation 2011;123:1587-1593.

42. Gorenek B, Kudaiberdieva G. Atrial fibrillation in acute ST-elevation myocardial infarction: clinical and prognostic features. Current Cardiol Rev 2012;8:281-289.

43. Lin CJ, Liu CF, Kung CT. The prognostic value of atrial fibrillation on 30-day clinical outcome in patients with ST-segment elevation myocardial infarction undergoing primary percutaneous coronary intervention. Int Heart J 2011;52:153-158.

44. Mrdovic I, Savic L, Krljanac G. Incidence, predictors, and 30-day outcomes of new-onset atrial fibrillation after primary percutaneous coronary intervention: Insight into the RISK-PCI trial. Coronary Artery Dis 2012;23:1-8.

45. Parashar S, Kella D, Reid KJ, Spertus JA, Tang F, Langberg J, Vaccarino V, Kontos MC, Lopes $\mathrm{RD}$, Lloyd MS. New-onset atrial fibrillation after acute myocardial infarction and its relation to admission biomarkers (from the TRIUMPH registry). Am J Cardiol 2013;112:1390-1395. 


\section{CHAPTER 2}

\section{Predictors and importance of prolonged hospital stay after primary PCI for ST-elevation myocardial infarction}

D.A.A.M. Schellings, J.P. Ottervanger

A.W.J. van 't Hof, M.J. de Boer

J.-H.E. Dambrink, J.C.A. Hoorntje

A.T.M. Gosselink, H. Surypranata

Coronary Artery Disease

2011;22(7):458-462

doi:10.1097/MCA.0b013e3283495d5f 

ABSTRACT

Objective. Although most patients with ST-elevation myocardial infarction treated by primary percutaneous coronary intervention (PCI) have a good prognosis and can be discharged from hospital very soon, some patients must be admitted longer. We performed the current analysis to assess predictors and the prognostic significance of prolonged hospital stay.

Patients and Methods. In this prospective, observational study, individual data from 2323 patients who survived at least 2 days after primary PCI in our hospital were recorded. Patients in the highest tertile of hospital stay were compared with the other patients. Both predictors and prognostic importance of prolonged hospital stay were evaluated.

Results. Mean admission duration was 6.7 days (standard deviation: 6.6). A total of 797 patients had a hospital stay for more than 6 days (highest tertile). Patients with a longer hospital stay were older, more often female, had more often a history of previous myocardial infarction and signs of heart failure on admission, and had more frequently thrombolysis in myocardial infarction flow 0 before PCI. In addition, a low left ventricular ejection fraction was independently associated with prolonged hospital stay [odds ratio: 2.06 (95\% confidence interval: 1.54-2.76)], but with a comparable risk of 1-year mortality [odds ratio: 1.3 (95\% confidence interval: 0.8-2.0)].

Conclusion. According to this study, a low left ventricular ejection fraction is associated with prolonged hospital stay in patients after primary PCI. Predictors of prolonged hospital stay are age, female sex, previous myocardial infarction, heart failure on admission, and thrombolysis in myocardial infarction flow 0 before PCI.

\section{INTRODUCTION}

In the thrombolytic and prethrombolytic era, it was demonstrated that a prolonged hospital stay in patients with ST-elevation myocardial infarction (STEMI) was a strong predictor of both short-term and long-term mortality. ${ }^{1,2}$ Since several years, primary percutaneous coronary intervention (PCI) is the preferred treatment strategy in most patients with STEMI, improving short-term and long-term outcomes ${ }^{3,4}$ and providing a decline in hospital stay. Meanwhile, several studies revealed that an early discharge policy or short hospital stay in uncomplicated STEMI patients treated by primary PCI is feasible with favorable short-term and long-term outcomes. ${ }^{5-12}$

However, in these studies the prognostic importance of a prolonged hospital stay remains unclear. Possibly, after primary PCI, with more frequent complete and 
sustained reperfusion and less bleeding complications, the prognosis of patients with a longer hospital stay is also better. In addition, more frequent use of drugs such as $\beta$ blockers, statins and angiotensin-converting enzyme inhibitors, nowadays, may have improved survival in patients with longer hospital stay. Finally, more insights into predictors of prolonged hospital stay may give opportunities to reduce hospital stay by treating risk factors more aggressively.

To address these issues, we performed a prospective study in patients undergoing primary PCI for STEMI assessing predictors and the prognostic importance of prolonged hospital stay.

\section{PATIENTS AND METHODS}

\section{Population}

During 13 years, individual patient data from all patients with admission diagnosis of STEMI admitted for primary PCI at the Isala klinieken (Zwolle, The Netherlands) were prospectively recorded. Patients who died during hospital admission were not included in this sub-study. To avoid double inclusion of patients, only the first recorded admission for STEMI during the study period was used. Patients were diagnosed with STEMI, if they had a chest pain of more than 30 min duration and electrocardiogram changes with ST segment elevation of more than $2 \mathrm{~mm}$ in at least two precordial leads and more than $1 \mathrm{~mm}$ in the limb leads. Before the primary PCI procedure, all patients received $500 \mathrm{mg}$ of aspirin and $5000 \mathrm{IU}$ of heparin intravenously. Primary PCI was performed with standard techniques if the coronary anatomy was suitable for angioplasty. PCI success was determined by the classification system of the Thrombolysis in Myocardial Infarction (TIMI) trial, in which a grade 3 blood flow indicates normal flow within the vessel, in combination with myocardial blush grades 2 and 3. ${ }^{13}$ Additional treatment with glycoprotein inhibitors IIb/IIIa or stents was to the discretion of the treating cardiologist. All patients were treated with optimized drug therapy, including angiotensin-converting enzyme inhibitors, $\beta$-blockers, aspirin and lipid-lowering drugs where appropriate.

\section{Measurements}

To study predictors and prognostic importance of prolonged hospital stay in more detail, hospital stay was categorized into tertiles. Patients who were in the highest tertile were compared to those in the two lower tertiles.

Left ventricular ejection fraction (LVEF) was measured before discharge by radionuclide ventriculography or by echocardiography, if the patient had atrial 
fibrillation. Radionuclide ventriculography was performed using the multiple-gated equilibrium method after the labeling of red blood cells of the patient with ${ }^{99 \mathrm{~m}}$ Technetium pertechnate. A General Electric 300 gamma-camera (General Electric, Milwaukee, WI, USA) with a low-energy all-purpose parallel-hole collimator was used. Global ejection fraction was calculated by a General Electric Star View computer using the fully automatic PAGE program. In patients with atrial fibrillation, standard two-dimensional and Doppler imaging was performed and stored in cineloop format by well-trained echocardiographists and reviewed by experienced cardiologists. The left ventricular end-diastolic volume (LVEDV) and left ventricular end-systolic volume (LVESV) were measured and the LVEF was calculated as:

\section{(LVEDV-LVESV)/LVEDV x 100\%}

(Simpson's rule). ${ }^{14} \mathrm{~A}$ low LVEF was defined as an ejection fraction less than or equal to $30 \%$. Follow-up information was obtained from the patient's general physician or by direct telephonic interview with the patient. Study approval was obtained from the medical ethics committee of our hospital.

\section{Statistical analysis}

Statistical analysis was carried out with the Statistical Package for the Social Sciences version 12.0.1 (SPSS Inc., Chicago, IL, USA). The analysis of variance and the Mantel-Haenszel Chi-squared test were used appropriately for continuous and categorical variables, respectively. Significant variables analyzed are reported with their respective odd ratios (ORs) and 95\% confidence intervals (CIs). Cox proportional-hazards regression models were used to estimate hazard ratios of clinical variables with regard to survival at 1 year. Multivariable analyses were carried out with the Cox models for all-cause mortality and with a logistic regression model to assess risk of low LVEF. For all analyses, statistical significance was assumed when the twotailed probability value was less than 0.05 .

\section{RESULTS}

During the study period, a total of 5030 patients with STEMI were admitted and treated with primary PCI in our hospital. A total of 2386 patients (47\%) were excluded, because they were often transported back to the referring hospital the day after primary PCI. Of the remaining 2644 patients, 96 patients (3.6\%) died during hospital admission, and were also excluded from the analyses. Finally, in 225 patients $(8.8 \%)$ no exact data of hospital discharge were available. So, the final study population consisted of 2323 patients. 
Table 1. Comparison between patients with the highest tertile ( $>6$ days) of hospital stay and the lower tertiles, in 2323 patients who survived until discharge after primary PCI for ST-elevation myocardial infarction $^{\mathrm{a}}$

\begin{tabular}{lccc}
\hline \hline Variable & Hospital stay & & \\
\cline { 2 - 4 } & $<6$ days & $>6$ days & P value \\
\hline Number & 1526 & 797 & \\
Female & 21 & 28 & 0.001 \\
Age $(\mathrm{yr} \pm$ SD) & $60.2 \pm 11.8$ & $63.3 \pm 11.4$ & 0.001 \\
History of: & & & \\
$\quad$ Myocardial infarction & 8.2 & 13.7 & 0.001 \\
$\quad$ Coronary bypass surgery & 2.4 & 4.1 & 0.02 \\
PCI & 6.4 & 7.0 & 0.54 \\
$\quad$ Stroke & 2.4 & 3.4 & 0.16 \\
$\quad$ Hypertension & 26.8 & 28.2 & 0.48 \\
$\quad$ Diabetes & 9.8 & 11.2 & 0.28 \\
$\quad$ Hyperlipidemia & 22.1 & 19.0 & 0.10 \\
$\quad$ Family coronary heart disease & 43.3 & 46.7 & 0.12 \\
Smoking & 52.1 & 43.6 & 0.001 \\
Killip Class $>$ 1 & 4.5 & 15.5 & 0.001 \\
Ischemic time, $\mathrm{h} \pm$ SD & $4.5 \pm 2.7$ & $4.8 \pm 3.0$ & 0.04 \\
Anterior wall location & 38.2 & 48.4 & 0.001 \\
Multivessel disease & 46.6 & 65.0 & 0.001 \\
TIMI 0 pre-PCI & 61.1 & 70.2 & 0.001 \\
TIMI 3 post-PCI & 92.7 & 83.9 & 0.001 \\
Collaterals & 48.8 & 44.9 & 0.15 \\
\hline \hline
\end{tabular}

PCI, percutaneous coronary intervention; SD, standard deviation; TIMI, thrombolysis in myocardial infarction. ${ }^{\mathrm{a}} \mathrm{All}$ values are $\%$ or mean with standard deviation.

\section{Baseline characteristics}

Of the 2323 included patients, mean age was 61.3 years (standard deviation: 11.7) and 536 patients (23\%) were women. Mean admission stay was 6.7days (standard deviation: 6.6). A total of 797 patients (34\%) had a hospital stay for more than 6 days, and this group (highest tertile of hospital stay) of patients was compared with the other patients. Differences in baseline characteristics between patients with a hospital stay of more than 6 days and those with a hospital stay of 6 days or less are summarized in Table 1. Patients with longer hospital stay were older, more often female, and had more often a history of previous myocardial infarction, coronary artery bypass grafting or smoking. On admission, patients in the highest tertile of hospital stay had a higher Killip Class and a longer ischemic time and were more affected by anterior wall infarction. In addition, multivessel coronary artery disease was more often observed at the angiography, as made before primary PCI. 
Table 2. Outcome in patients within the highest tertile ( $>6$ days) of hospital stay and the lower tertiles, in 2323 patients who survived until discharge after primary PCI for ST-elevation MI

\begin{tabular}{llcl}
\hline \hline Variable & Hospital stay & \\
\cline { 2 - 4 } & $<6$ days & $>6$ days & P value \\
\hline Number & 1526 & 797 & \\
Peak CK (U/1) & $1834 \pm 1638$ & $2495 \pm 2012$ & 0.001 \\
& & & \\
Mean LVEF, \% \pm SD & $47.9 \pm 10.4$ & $43.7 \pm 12.4$ & 0.001 \\
Major bleeding & 1.4 & 5.9 & 0.001 \\
Outcome after 30 days: & & & \\
Death & 1.1 & 0.8 & 0.40 \\
Re-MI & 3.7 & 5.0 & 0.12 \\
Stroke & 0.1 & 0.8 & 0.004 \\
PCI & 4.5 & 8.5 & 0.001 \\
CABG & 1.7 & 16.4 & 0.001 \\
Outcome after 1 year: & & & \\
Death & 2.9 & 3.6 & 0.32 \\
Death/re-MI & 6.0 & 8.4 & 0.03 \\
Stroke & 0.5 & 1.3 & 0.03 \\
PCI & 14.0 & 18.6 & 0.004 \\
CABG & 6.4 & 24.2 & 0.001 \\
\hline \hline
\end{tabular}

CABG, coronary artery bypass grafting; LVEF, left ventricular ejection fraction; MI, myocardial infarction; $\mathrm{PCI}$, percutaneous coronary intervention; SD, standard deviation; $\mathrm{CK}$, creatine kinase.

\section{Outcome}

Outcome data in patients with and without a prolonged hospital stay are summarized in Table 2. Those with a prolonged stay had a higher enzymatic infarction size and a lower ejection fraction. Patients in the highest tertile length of hospital stay had more often a low LVEF ( $\leq 30 \%$ ), with the unadjusted OR 3.4 (95\% CI $2.5-4.7)$ as compared with the lower tertiles. A total of 73 patients (3.1\%) died between hospital discharge and 1 year after admission. Several clinical characteristics were associated with increased mortality, including low LVEF and TIMI flow less than 3 after primary PCI. Mean hospital length of stay in patients who died within 1 year was 8.9 days (standard deviation: 11.0) compared to 6.6 (standard deviation: 6.5) in those who survived $(\mathrm{P}<0.001)$. Survival curves of patients with a hospital stay less than 6 days and those with a stay of more than 6 days are depicted in Figure 1. Patients in the highest tertile had a comparable risk of 1-year mortality [OR $=1.3(95 \%$ CI $0.8-2.0)$ ] compared to those in the other tertiles. 


\section{Mortality (\%)}

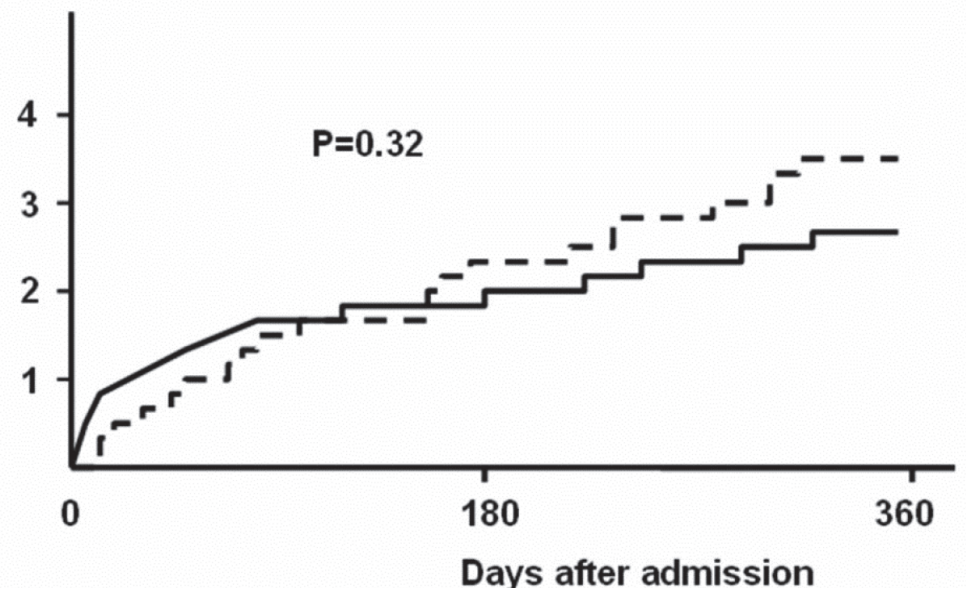

Figure 1. One-year mortality curves of patients with hospital stay of more than 6 days $(\mathrm{N}=797)$ versus those with hospital stay of less than 6 days $(\mathrm{N}=1526)$.

\section{Multivariable analyses}

In Table 3 multivariable analyses of potential predictors of prolonged hospital stay are shown. Age, female sex, infarction location, previous myocardial infarction, signs of heart failure on admission, the presence of multivessel disease, and TIMI flow 0 before PCI were independent statistically significant predictors of prolonged hospital stay. After adjusting for differences in age, sex, infarction location, Killip Classification on admission, multivessel disease, previous myocardial infarction and TIMI flow postPCI, the highest length of hospital stay tertile was still associated with a low ejection fraction [OR 2.06 (95\%CI 1.54-2.76)]. After adjusting for differences in age, sex, infarction location, Killip Classification on admission, multivessel disease, previous myocardial infarction and TIMI flow post-PCI, patients with prolonged hospital stay were not associated with an increased risk of 1-year mortality [OR 1.13 (95\%CI $0.67-$ 1.90)]. Even when adjusted for differences in LVEF, those with prolonged hospital stay did not have a higher risk of 1-year mortality [(OR 1.70, (95\% CI 0.84-3.47)]. 
Table 3. Multivariable analyses of the Risk (OR) of prolonged hospital stay ${ }^{\mathrm{a}}$

\begin{tabular}{llll}
\hline \hline Variable & OR & $95 \%$ CI & P value \\
\hline Age (/yr) & 1.01 & $1.00-1.020$ & 0.046 \\
Males & 0.71 & $0.56-0.89$ & 0.004 \\
Killip Class $>1$ & 4.02 & $2.80-5.76$ & 0.001 \\
Anterior location & 1.87 & $1.53-2.29$ & 0.001 \\
Ischemic time (/h) & 1.027 & $0.99-1.06$ & 0.13 \\
Previous myocardial infarction & 1.45 & $1.01-1.96$ & 0.047 \\
Previous bypass surgery & 1.27 & $0.72-2.22$ & 0.41 \\
Smoking & 0.81 & $0.65-1.00$ & 0.50 \\
Multivessel disease & 2.10 & $1.70-2.59$ & 0.001 \\
TIMI 0 before PCI & 1.81 & $1.46-2.25$ & 0.001 \\
\hline \hline
\end{tabular}

OR, odds ratio; PCI, percutaneous coronary intervention; TIMI, thrombolysis in myocardial infarction; CI, confidence interval.

${ }^{a}$ Adjusted for differences in the other variables.

\section{DISCUSSION}

This analysis shows that after primary PCI for STEMI, patients with longer hospital stay are older, more often female, have more often a history of previous myocardial infarction and signs of heart failure on admission, and have more frequent TIMI flow 0 before PCI. The strongest predictor of prolonged hospital stay was heart failure on admission.

Improved therapy of STEMI has resulted in a significant reduction of length of hospital stay from more than 6 weeks in the 1950s to 1 week in the thrombolysis era to nowadays discharge at day 4 or earlier in low-risk patients treated with primary PCI. $^{5-12}$

In most studies with regard to the feasibility of early discharge after primary PCI, characteristics and significance of longer stay patients remain underexposed.

In some studies, factors that avoid a safe early discharge have been identified and translated in risk scores. ${ }^{6,7}$ De Luca et al. ${ }^{7}$ revealed that age, anterior wall location, Killip Class, ischemic time, postprocedural TIMI flow and multivessel disease were independent predictors of 30-day mortality. Patients with a low-risk score $(\leq 3)$ were eligible for discharge within $48-72 \mathrm{~h}$ with a mortality risk up to $0.2 \%$ at 10 days. 
Our analysis also reveals the importance of preprocedural TIMI flow in the infarctionrelated vessel. Therefore (pre-hospital) medical treatment to increase the appearance of an already open infarction-related vessel before angiography should be encouraged. ${ }^{15}$

The occurrence of bleeding remains a matter of concern, and is in our study associated with prolonged hospital stay. In earlier studies both hemorrhagic events and thrombocytopenia have been associated with early and late mortality. ${ }^{16,17}$ Possibly, the thrombin inhibitor, bivalirudin, can reduce major bleeding. ${ }^{18}$ However, the effect of bivalirudin before catheterization (as given in the ambulance) is not yet investigated and the costs of it are considerable higher.

The existence of multivessel disease was also a strong predictor of longer hospital stay in our analysis. Probably, additional revascularization procedures may have caused the prolonged hospital stay. However, the hemodynamic significance of nonculprit lesions is frequently overestimated (40\%) and, compared to a more conservative strategy, an early ischemia-guided invasive strategy does not result in a reduction of total major adverse cardiac events at 6 months. ${ }^{19}$

In our analysis, we did not find a survival disadvantage for longer stay patients, despite a significantly lower ejection fraction. This is a remarkable finding, but it should be noted that prognosis of patients with low ejection fraction after primary PCI has been improved nowadays due to optimal medical therapy. ${ }^{20}$

\section{Study limitations}

Several limitations of our study have to be noted. The study concerned a cohort of patients who were included during 13 years. Within this time period PCI procedures and medication have changed.

In addition, we compared patients with a hospital stay of 6 days or less with those who were admitted for 6 days or more. Particularly in low-risk patients, for whom an early discharge at day 3 is safe and feasible, 6 days is a relatively long admission period.

We did not investigate whether patients who were eligible for early discharge really left the hospital before day 4 or not. We did not record the reasons for prolonged hospital stay. In addition, we had no data on morbidity during follow-up, cause of death, or whether patients were admitted in nursing homes or not.

Patients with prolonged hospital stay are a heterogenous subset, consisting of patients waiting for additional treatment in a generally good condition and other patients who 
are in a bad condition, in combination with a relatively small group of longer stay patients, these facts may have influenced the non-significant outcome in 1-year survival. We intentionally excluded patients who died during admission because the study aimed to investigate outcome of longer-stay patients.

At the time of patient inclusion, assessment of novel biomarkers such as N-terminalpro-brain natriuretic peptide (NT-proBNP) was not performed. Recent data have shown that it may provide valuable short-term prognostic information in patients with acute coronary syndrome. ${ }^{21}$ Whether measurements of NT-proBNP values can be related to hospital length of stay is not yet investigated. We were not able to assess everything, because many variables were not collected. Nevertheless, this should not have changed our main conclusions, that prolonged admission is associated with higher enzymatic infarction size and lower ejection fraction, and that prolonged admission is not independent associated with 1-year mortality.

\section{CONCLUSION AND CLINICAL IMPLICATIONS}

Our study shows an independent association between enzymatic infarction size and low left ventricular ejection fraction in patients undergoing primary PCI for STEMI and length of hospital stay. Prolonged hospital stay was, however, not associated with increased 1-year mortality. Of the predictors of prolonged hospital stay that can be changed, TIMI flow before PCI and occurrence of major bleeding may be of importance. 


\section{REFERENCES}

1. Spencer FA, Lessard D, Gore JM, Yarzebski J, Goldberg RJ. Declining length of hospital stay for acute myocardial infarction and post discharge outcome. Arch Intern Med 2004;164:733740 .

2. Newby LK, Califf RM, Guerci A, Weaver WD, Col J, Horgan JH, et al., for the GUSTO investigators. Early discharge in the thrombolytic era: an analysis of criteria for uncomplicated infarction from the global utilization of streptokinase and t-PA for occluded coronary arteries (GUSTO) trial. J Am Coll Cardiol 1996;27:625-632.

3. Silber S, Albertsson P, Avilés FF, Camici PG, Colombo A, Hamm C, et al. Guidelines for percutaneous coronary interventions. The Task Force for Percutaneous Coronary Interventions of the European Society of Cardiology. Eur Heart J 2005;26:804-847.

4. Kushner FG, Hand M, Smith SC, King SB, Anderson JL, Antman EM, et al. 2009 Focused updates: ACC/AHA Guidelines for the management of patients with ST-elevation myocardial infarction (Updating the 2004 guideline and 2007 focused update) and ACC/AHA/SCAI guidelines on percutaneous coronary intervention (updating the 2005 guideline and 2007 focused update): A report of the American College of Cardiology Foundation/ American Heart Association task force on practice guidelines. Circulation 2009;120;2271-2306.

5. Grines CL, Marsalese DL, Brodie B, Griffin J, Donohue B, Costantini CR, et al., for the PAMIII investigators. Safety and cost-effectiveness of early discharge after primary angioplasty in low risk patients with acute myocardial infarction. J Am Coll Cardiol 1998;5:967-972.

6. Halkin A, Singh M, Nikolsky E, Grines CL, Tcheng JE, Garcia E, et al. Prediction of mortality after primary percutaneous coronary intervention fore acute myocardial infarction: the CADILLAC risk score. J Am Coll Cardiol 2005;45:1397-1405.

7. De Luca G, Suryapranata H, van 't Hof AWJ, de Boer MJ, Hoorntje JCA, Dambrink JHE, et al. Prognostic assessment of patients with acute myocardial infarction treated with primary angioplasty: implications for early discharge. Circulation 2004;109;2737-2743.

8. Heggunje PS, Harjai KJ, Stone GW, Mehta RH, Marsalese DL, Boura JA, et al. Procedural success versus clinical risk status in determining discharge of patients after primary angioplasty for acute myocardial infarction. J Am Coll Cardiol 2004;44:1400-1407.

9. Jirmar R, Widimsky P, Capek J, Hlinomaz O, Groch L. Next day discharge after successful primary angioplasty for acute ST elevation myocardial infarction. Int. Heart J 2008;49:653-659.

10. Branca G, Capodanno D, Capranzano P, Barbagallo R, Seminara D, Licciardello G, et al. Early discharge in acute myocardial infarction after clinical and angiographic risk assessment. $\mathrm{J}$ Cardiovasc Med 2008;9:858-861.

11. Kotowycz MA, Cosman TL, Tartaglia C, Afzal R, Pal Syal R, Natarajan MK. Safety and feasibility of early hospital discharge in ST-segment elevation myocardial infarction. A prospective and randomized trial in low-risk primary percutaneous coronary intervention patients (the SAFE-Depart Trial) Am Heart J 2010;159:117.e1-117e6.

12. Laarman GJ, Dirksen M. Early discharge after primary percutaneous coronary intervention. Heart 2010:96:584-587.

13. Henriques JPS, Zijlstra F, van 't Hof AWJ, de Boer MJ, Dambrink JHE, Gosselink ATM, et al. Angiographic assessment of reperfusion in acute myocardial infarction by myocardial blush grade. Circulation 2003;107:2115-2119.

14. Schiller NB, Shah PM, Crawford M, DeMaria A, Devereux R, Feigenbaum H, et al. Recommendation for quantification of the left ventricle by two-dimensional echocardiography. American Society of Echocardiography Committee on Standards, Subcommittee of Quantitation of Two-Dimensional Echocardiograms. J Am Soc Echocardiogr 1989;2:358-367.

15. van 't Hof AWJ, ten Berg J, Heestermans T, Dill T, Funck RC, van Werkum W, et al., on behalf of the ongoing tirofiban in myocardial infarction evaluation (On-Time) 2 study group. 
Prehospital initiation of tirofiban in patients with ST-elevation myocardial infarction undergoing primary angioplasty (On-Time 2): a multicentre, double-blind, randomised controlled trial. Lancet 2008;372:537-546.

16. Eikelboom JW, Mehta SR, Anand SS, Xie C, Fox KAA, Yusuf S. Adverse impact of bleeding on prognosis in patients with acute coronary syndromes. Circulation 2006;114:774-782.

17. Manoukian SV, Feit F, Mehran R, Voeltz MD, Ebrahimi R, Dangas GD, et al. Impact of major bleeding on 30-day mortality and clinical outcomes in patients with acute coronary syndromes: an analysis from the ACUITY Trial. J Am Coll Cardiol 2007;49:1362-1368.

18. Mehran R, Lansky AJ, Witzenbichler B, Guagliumi G, Peruga JZ, Brodie BR, et al. Bivalirudin in patients undergoing primary angioplasty for acute myocardial infarction (HORIZONS-AMI): 1-year results of a randomised controlled trial. Lancet 2009;374:1149-1159.

19 Dambrink JHE, Debrauwere JP, van 't Hof AWJ, Ottervanger JP, Gosselink ATM, Hoorntje JCA, et al. Non culprit lesions detected during primary PCI: Treat invasively or follow the guidelines?. EuroIntervention 2010;8:968-975.

20. Ottervanger JP, Ramdat Misier AR, JHE Dambrink, de Boer MJ, Hoorntje JCA, Gosselink ATM, et al., on behalf of the Zwolle myocardial infarction study group. Mortality in patients with left ventricular ejection fraction $\leq 30 \%$ after primary percutaneous coronary intervention for ST-elevation myocardial infarction. Am J Cardiol 2007;100:793-797.

21. Heeschen C, Hamm CW, Mitrovic V, Lantelme NH, White HD, for the platelet receptor inhibition in ischemic syndrome management (PRISM) investigators. N-Terminal pro-B-Type natriuretic peptide levels for dynamic risk stratification of patients with acute coronary syndromes. Circulation 2004;110:3206-3212. 



\section{CHAPTER 3}

\section{Safety and feasibility of next day discharge after primary percutaneous coronary intervention for acute myocardial infarction}

D.A.A.M. Schellings, A. Adiyaman

A. Elvan, J.C.A. Hoorntje,

H. Suryapranata, J.P. Ottervanger

A.W.J. van 't Hof 

ABSTRACT

Background. Low-risk PPCI patients could be discharged after 3 days and even earlier as suggested by several studies. However, data concerning next day discharge in these patients is limited. We aimed to investigate the safety and feasibility of next day hospital discharge in low-risk patients who underwent primary percutaneous coronary intervention (PPCI) for acute myocardial infarction (AMI).

Methods. In this prospective single-center study, low-risk PPCI patients were defined as having a Zwolle Risk Score (ZRS) $\leq 3$ and a successful PCI procedure. Patients were discharged within 36 hours after admission and were planned for follow-up visits by specialized nurses in the outpatient clinic at the third and fourth day after PPCI. We evaluated the occurrence of major adverse cardiac events (MACEs), 30-day readmission rates and 1-year survival and compared clinical outcome to matching controls, who received traditional care.

Results. In total 231 patients were included (17\% female), with a mean $( \pm \mathrm{SD})$ age of $56 \pm 9.4$ years. Mean ZRS was $1.3 \pm 1.1$, indicating a low-risk population. Patients were discharged after a mean of $1.3 \pm 0.5$ days. Mean nuclear left ventricular ejection fraction 1 week after AMI was 59\% (range 34-86\%). No MACEs occurred within 30 days of PPCI and readmission rate was $3.0 \%$. One-year survival was $100 \%$. Compared to the short-stay patients, controls experienced a significantly longer hospital stay, although clinical outcome was similar.

Conclusion. In low-risk PPCI patients, next day discharge is safe and feasible. This may improve quality of life and reduce healthcare expenses.

\section{INTRODUCTION}

Since the introduction of primary percutaneous coronary intervention (PPCI) as first choice treatment strategy for ST-elevation myocardial infarction (STEMI), length of hospital stay decreased considerably. ${ }^{1}$ Meanwhile, several studies revealed that early discharge in low-risk PPCI patients is safe, feasible ${ }^{2-9}$ and cost effective ${ }^{2,9}$, without impairment of quality of life or compliance, when adequate follow-up is arranged. ${ }^{2,5}$ In these studies admission duration varied from 24 to $96 \mathrm{~h}$, with a majority of patients discharged within 2 to 4 days after PPCI. Present guidelines pose that it is reasonable to discharge low-risk patients after 3 days, but optimum length of hospital stay is not recommended. ${ }^{10,11}$ Given the fact that risk stratification as well as treatment has been improved, optimizing length of hospital stay after PPCI is a challenging part of patient 
management. We therefore studied the safety and feasibility of a next day discharge protocol, for low-risk STEMI patients treated with PPCI, based on the validated Zwolle Risk Score (ZRS) ${ }^{9}$

\section{METHODS}

\section{Eligible patients}

In this prospective single-center study, patients eligible for participation in the next day discharge protocol had ST-elevation myocardial infarction and were successfully treated with PPCI. Procedural success was assessed by the treating cardiologist and defined as an uncomplicated procedure with restoration of flow with a sufficient myocardial blush (thrombolysis in myocardial infarction [TIMI] 3 flow) in the area of the infarction-related vessel.

\begin{tabular}{|c|c|c|c|c|c|}
\hline Killip class & Points & Risk Score & \multicolumn{3}{|c|}{ RR $[95 \% \mathrm{Cl}]$ of death by $30-\mathrm{D}$} \\
\hline 1 & 0 & $0-1$ & 0.03 & [ 0.008 & - 0.13 ] \\
\hline 2 & 4 & 2 & 0.09 & [ 0.002 & - 0.37 ] \\
\hline $3-4$ & 9 & 3 & 1.04 & {$\left[\begin{array}{ll}0.44 \\
0\end{array}\right.$} & $-2.45]$ \\
\hline \multicolumn{2}{|l|}{ TIMI flow post } & 4 & 1.40 & {$[0.5$} & - 3.89 ] \\
\hline 3 & 0 & 5 & 2.48 & {$[0.96$} & - 6.42 ] \\
\hline 2 & 1 & 6 & 2.52 & [ 0.75 & - 8.46 ] \\
\hline $0-1$ & 2 & 7 & 5.99 & [ 1.98 & -18.1 \\
\hline \multicolumn{2}{|l|}{ Age } & $\geq 8$ & 32.1 & {$[18.6$} & $-55.8]$ \\
\hline$<60$ & 0 & & & & \\
\hline$\geq 60$ & 2 & & & & \\
\hline \multicolumn{2}{|c|}{ 3-vessel disease } & & & & \\
\hline No & 0 & & & & \\
\hline Yes & 1 & & & & \\
\hline \multicolumn{2}{|c|}{ Anterior infarction } & & & & \\
\hline No & 0 & & & & \\
\hline Yes & 1 & & & & \\
\hline \multicolumn{2}{|c|}{ Ischemia time ( $>4$ hours) } & & & & \\
\hline No & 0 & & & & \\
\hline Yes & 1 & & & & \\
\hline TOTAL SCORE & 16 & & & & \\
\hline
\end{tabular}

Figure 1. The Zwolle Risk Score (left panel) and the relative risk (RR) of 30-day mortality for each score (right panel). CI, confidence interval; STEMI, ST-elevation myocardial infarction; TIMI, thrombolysis in myocardial infarction. 
All procedures were performed via the femoral artery (Seldinger technique). Use of stents and additional treatment with medication was at the discretion of the treating cardiologist. In addition, only patients with a Zwolle Risk Score $\leq 3$ were eligible for this study. This score, assessed by a point system, has shown to be able to identify a large group of patients at very low risk who may safely be discharged early after PPCI. ${ }^{9}$ Very-low-risk patients are those with a score $\leq 3$ (mortality rate of $0.1 \%$ at 2 days and $0.2 \%$ between 2 and 10 days, Figure 1). Finally, after discharge, eligible patients had to live within $30 \mathrm{~min}$ travel time of the hospital, because of intensive outpatient follow-up in the first days. The study (registration number ISRCTN15017070) complies with the Declaration of Helsinki, the research protocol was approved by the ethics committee of the Isala hospital and all participants gave informed consent for current and future data analysis.

\section{Next day discharge protocol}

After successful PPCI, the patient was visited by a specialized nurse of the cardiac rehabilitation department within the first 24 hours after admission. This nurse informed the patient about the implications and consequences of having a myocardial infarction and provided extensive discharge instructions, including life style changes, medication use, how to recognize acute cardiac and PCI related symptoms and how to act when symptoms occur. In addition, the patient received telephone numbers at which 24 hours a day a specialized nurse and/or an attending physician from the cardiology department could be reached.

Depending on the admission time, patients were discharged within 24 to $36 \mathrm{~h}$ after PPCI. The first and second day after discharge (day 3 and day 4 after PPCI), patients visited the cardiac rehabilitation department or cardiac emergency room (weekends only) and were evaluated by the nurse or attending physician. During these outpatient clinical visits, an ECG was performed and blood samples were taken. Also, physical examination including blood pressure, cardiac and pulmonary auscultation, as well as groin inspection was performed. If necessary, medication was adjusted. All patients were treated with a $\beta$-blocker, aspirin, clopidogrel, statins and if appropriate ACEinhibition.

After 1 week, left ventricular ejection fraction was assessed by radionuclide ventriculography by using the multiple gated equilibrium method following the labeling of red blood cells of the patient with ${ }^{99 \mathrm{~m}} \mathrm{Tc}$-pertechnate. A General Electric 300 gammacamera with a low-energy all-purpose parallel-hole collimator was used. Global ejection fraction was calculated by a General Electric Star View computer, using the fully automatic PAGE program. 
After 1 week patients also participated in the rehabilitation program which is focused on education and actively involves patients to enhance adherence to lifestyle changes and drug therapies. In addition, patients could take part in a supervized exercisetraining program. After 4 weeks patients visited the cardiologist at the outpatient cardiology department. In Figure 2, the protocol is depicted schematically.

\section{Short Stay Protocol}

Day 1

$<24 \mathrm{~h}$

Day 2

$>24 \mathrm{~h},<48 \mathrm{~h}$.

Day $3+4$

$>48 \mathrm{~h}$.

1 week

$3+6+12$ weeks

\section{Admission after pPCl}

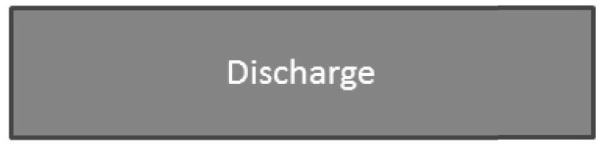

Outpatient department:

blood sampling, ECG and physical

examination

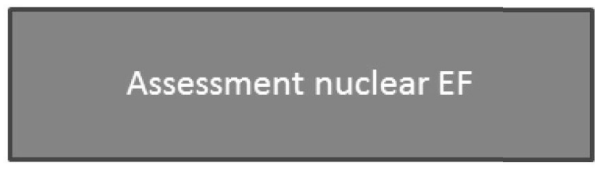

Outpatient visit cardiologist

Figure 2. Representation of the short-stay protocol. PPCI, indicates primary percutaneous coronary intervention; $\mathrm{EF}$, ejection fraction. 


\section{Main outcome measurement}

We evaluated the occurrence of major adverse cardiac events (MACEs) defined as death, recurrent myocardial infarction (reMI), urgent target vessel revascularization (TVR) and (potentially) life threatening arrhythmias defined as ventricular fibrillation (VF) or ventricular tachycardia (VT), occurring during 30-day follow-up. Patients, who experienced any MACEs in-hospital, logically were excluded from participation in the short-stay protocol. Also readmission rates, number of visits to the emergency ward for any cause at 30-day follow-up and survival at 1-year follow-up were assessed. Additionally, main outcome measures (death, reMI, urgent TVR) of the early discharged patients were compared to a matching cohort of patients who were included in the Zwolle myocardial infarction registry, during the same period of time and who received traditional care.

\section{Statistical analysis}

All variables are presented as means \pm standard deviation (SD) or as numbers with percentages, where appropriate. Normality of distribution was assessed and if not normally distributed, medians were additionally reported. We used Chi-squared tests for categoric variables, and non-parametric tests for paired observations of contineous variables.

Control patients were matched for age, (maximum difference of 5 years), gender and ZRS. A two-sided $\mathrm{P}$ value of $\leq 0.05$ was considered to be statistically significant. Statistical analysis was performed using SPSS statistical software version 24.

\section{RESULTS}

Between 2003 and 2012, 231 patients were included. Baseline characteristics of the patients are shown in Table 1. Most patients were males (83\%), with a mean age (SD) of 56 \pm 9.4 (range 30.6-83.3) years. A history of cardiovascular disease was present in a minority of patients $(6.9 \%)$, and $86.7 \%$ of patients had $\geq 1$ cardiovascular risk factors. Mean ZRS was 1.3 $\pm 1.1(0-3)$, reflecting a low-risk patient population.

Patients were discharged after a mean of $1.3 \pm 0.5$ days (Median 1, inter quartile range [IQR] 1-2). Mean left ventricular ejection fraction 1 week after AMI could be assessed in 225 patients $(97.4 \%$ ), and was $59 \pm 8.2 \%$ (range $34-86 \%$ ). 
Table 1. Baseline characteristics of 231 primary PCI patients included in the short-stay protocol

\begin{tabular}{lc}
\hline \hline Age (years) mean $\pm \mathrm{SD}$ & $56 \pm 9.4$ \\
Male gender & $83 \%$ \\
Current smoking & $51 \%$ \\
Diabetes mellitus & $7 \%$ \\
Hypertension & $29 \%$ \\
Hypercholesterolemia & $23 \%$ \\
Family history of CAD & $48 \%$ \\
Previous MI & $5.6 \%$ \\
Previous CABG & $0.4 \%$ \\
Previous PCI & $6.5 \%$ \\
\hline \hline
\end{tabular}

$\mathrm{SD}$, standard deviation; $\mathrm{CAD}$, coronary artery disease; MI, myocardial infarction; CABG, coronary artery bypass grafting; PCI, percutaneous coronary intervention.

Table 2. Outcome data of 231 primary PCI patients included in the short-stay protocol, compared to outcome data of the 231 patients included in the control group

\begin{tabular}{lccc}
\hline \hline Variable & ${\text { Case }(\%)^{\mathrm{a}}}^{\mathrm{a}}$ & ${\text { Control }(\%)^{\mathrm{a}}}^{\mathrm{a}}$ & P value \\
\hline Zwolle Risk Score, mean \pm SD & $1.3 \pm 1.1$ & $1.3 \pm 1.1$ & $>0.99$ \\
Anterior infarction location & 24.7 & 25.1 & 0.91 \\
Three-vessel disease & 0.4 & 6.5 & $<0.001$ \\
Ischemic time $>$ 4 h & 36.4 & 28.1 & 0.06 \\
TIMI grade 3 flow post primary PCI & 98.3 & 95.7 & 0.27 \\
Days in hospital, mean \pm SD & $1.27 \pm 0.5$ & $3.03 \pm 4.35$ & $<0.001$ \\
Mean left ventricular EF $(\%) \pm \mathrm{SD}$ & $59 \pm 8.2$ & $\mathrm{NA}$ & \\
MACEs (30 days) & 0 & 0.87 & 0.24 \\
Visit emergency ward (within 30 days) & 4.8 & $\mathrm{NA}$ & \\
Hospital re-admission (within 30 days) & 3.0 & $\mathrm{NA}$ & $>0.99$ \\
30-day survival & 100 & 99.6 & 0.012 \\
One-year survival & 100 & 97.2 & \\
\hline \hline
\end{tabular}

SD indicates standard deviation, EF; ejection fraction, MACEs; major adverse cardiac events, NA; (data) not available.

${ }^{a}$ Were appropriate.

At 30 days after PPCI, no MACEs occurred. In addition 18 patients (7.8\%) visited the hospital. Seven of them (3.0\%) had to be readmitted for several reasons. Six of these patients had chest pain without signs of myocardial ischemia, and 1 patient suffered pneumonia and had to be transferred to another department.

Of these 18 patients who visited the hospital, 11 patients (4.8\%) could be discharged after a few hours stay at the emergency ward, particularly because of chest pain 
without signs of myocardial ischemia at that visit (7 patients), limited groin hematoma, not requiring intervention ( 2 patients) or dizziness ( 2 patients). One-year survival was $100 \%$.

Compared to the matched controls, the short-stay PPCI patients had less often threevessel disease but tended to have longer ischemic time. In addition, admission duration in the study patients was significantly shorter compared to the matched controls ( $1.27 \pm 0.5$ vs. $3.03 \pm 4.35$ days).

However, no differences in MACEs were observed. Of the controls, 2 patients $(0.87 \%)$ experienced reMI and needed urgent TVR within 30 days after admission.

Among the control patients, 83 (36\%) left the hospital after 2 days. In Table 2 the outcome data are displayed.

\section{DISCUSSION}

Our study reveals that next day discharge of low-risk PPCI patients, based on protocolized care is safe and feasible, with excellent short- and long-term outcome. Application of routine risk assessment and a structured discharge strategy, could potentially further decrease length of hospital stay, possibly improving quality of life, and reducing consumption of clinical health care resources.

\section{Safety}

The main drawback of discharging STEMI patients very early is the possible occurrence of major adverse, potentially lethal, cardiac events that are traditionally associated with acute myocardial infarction. Keeping the patient under observation in the hospital for a longer period of time can prevent these potential complications. However, since PPCI has become the first choice treatment strategy, short- and longerterm prognosis improved, paralleled by a decrease in length of stay in hospital, which makes early discharge of low-risk patients appealing. ${ }^{10,11}$ At present, standard continuous rhythm monitoring after uncomplicated PPCI is performed for approximately $24 \mathrm{~h}$. After this, rhythm monitoring is mostly discarded and the further procedure in patient management largely depends on (hospital) organization. However, safety constitutes the key element of early hospital discharge and starts with good risk stratification. 


\section{Risk assessment and early discharge}

One of the first larger trials in the field of risk stratification for early discharge of PPCI patients, was the primary angioplasty in myocardial infarction II (PAMI II) study, where it was demonstrated that low-risk patients, according to the PAMI II criteria (age $\leq 70$ years, left ventricular ejection fraction $>45 \%$, one- or two-vessel disease, successful PCI and no persistent arrhythmias), who received accelerated care and who were discharged at day 3 , had similar outcome compared to patients receiving traditional care. In this study occurrence of mortality, unstable angina, reMI, stroke and heart failure at 6 months was similar in both groups. ${ }^{2}$ Additionally, several smaller sized studies, confirmed the safety of early discharge in comparison with traditional care. However, most low-risk patients were discharged particularly after 48-72 h. ${ }^{2-6}$ Recently, two larger scale studies reported favorable outcome in low-risk patients who were discharged within or at 2 days. ${ }^{7,8}$ Jones et al. reported a prospective analysis of 2779 PPCI patients. Of these patients, 49\% met very early discharge criteria (i.e. LVEF $>40 \%$, TIMI III flow, stable cardiac rhythm and hemodynamics stability up to $48 \mathrm{~h}$ ), $85 \%$ of these low-risk patients were discharged at 2 days $(40 \%$ of the study population). There was no difference in 30-day outcome in terms of readmission rates and all-cause mortality, with even a lower occurrence of MACEs in the early discharge group compared with patients with a longer admission period. Noman and colleagues ${ }^{8}$ reported discharge data of 2448 PPCI patients. A total of 1542 patients $(63 \%)$ were discharged within 2 days of admission and 906 patients after 2 days. Data on the occurrence of MACEs and non-MACEs related readmission were not reported. Although retrospectively studied, they found no mortality difference between both groups during a mean follow up of 584 days.

Although several risk stratification strategies have been applied in short-stay studies, to our point of view particularly a risk model that incorporates procedural variables, may be preferable. Such a model is the validated Zwolle Risk Score (ZRS).

The Safe-Depart Trial, a smaller sized prospective study that randomly assigned lowrisk patients to early (within $72 \mathrm{~h}$ ) discharge or traditional care was based on risk stratification by the ZRS. ${ }^{5}$ In both groups there were no differences in re-hospitalization, patient treatment compliance or quality of life, with zero mortality in both groups at 6 weeks follow-up.

In our study, survival was also $100 \%$ up to 1 -year follow-up with mean admission duration of only 1.3 days, which was significantly shorter, compared to admission duration of the controls. For the best of our knowledge, we report a study population with one of the shortest admission durations, in a patient cohort with prospective 
follow-up. Most patients had a nearly normal left ventricular ejection fraction at 1week post procedure. These results reveal the prognostic importance of peri-procedural data, which seems closely related with infarction size.

\section{Feasibility}

Although early discharge of low-risk PPCI patients is feasible, a structured discharge policy is not present in many hospitals, given the international differences in mean admission duration for STEMI patients and the fact that hospitals significantly vary in admission duration of low-risk patients. ${ }^{1,7,12-14}$ In addition, it is estimated that at least 60 to $70 \%$ of all PPCI patients would be eligible for early discharge. ${ }^{8,9}$

However, many conditions that are not related to postprocedural outcome may influence hospital discharge policy, and may keep PPCI patients admitted to the hospital for a longer period of time than necessary. ${ }^{14}$ Also, patients who are repatriated early from the PCI performing center to the referring hospital, and patients admitted at weekends tend to have longer admission duration. ${ }^{15}$ As proposed in this current report, patient logistics could be considerably optimized by protocolized care based on early and effective risk stratification.

Whether shortening of hospital stay would really decrease the burden of health care costs, remains underexposed, since most short-stay studies confine their follow-up data to mortality and MACEs and pay less attention to social circumstances and patient compliance.

However, as shown in our present report, most study patients who made an appeal to healthcare early after discharge by visiting the cardiac emergency department, could be reassured. Probably, the participation of GPs in the short-stay protocol could further prevent 'unnecessary' hospital visits. Therefore, early discharge may help to contain health care costs while preserving or even improving quality of care.

\section{Limitations}

In this report, we give insight into a real life implementation of a fast-track discharge protocol, with the largest cohort of patients who were discharged the next day after PPCI at present and who were followed-up prospectively.

Nevertheless, we are aware of the fact that several important limitations have to be noted. We did not randomize patients to conventional or fast track hospital care. As a consequence, the patient population was highly selective. In addition we extensively investigated the short-stay cases, whereas the availability of clinical outcome variables of the control patients who came from our infarction registry, was limited to survival and the occurrence of reMI and/or urgent TVR. Of course, discharge policy depends on much more variables than low ZRS and occurrence of a limited compilation of adverse 
events. Furthermore, the study population is small in relation to the study period. This can be explained by the fact that our clinic performs multiple other studies. However we included 25-30 patients structural, every year. Therefore, data from larger cohorts from multiple heart centers are needed before this protocol can be widely implemented. However, this does not affect our main findings.

At present biomarkers play a role in early diagnosis and have an important prognostic value in STEMI patients. ${ }^{16}$ Recently, we demonstrated that baseline NT-proBNP and ZRS had comparable and synergistic prognostic value in identifying PPCI patients at low mortality risk who could be eligible for discharge after $48 \mathrm{~h}^{17}$ Based on 'low NTproBNP' or 'low ZRS', probably the number of PPCI patients eligible for early discharge will increase. ${ }^{17,18 .}$

Whether adjustment of ZRS by NT-proBNP really could improve a next day discharge policy, deserves future investigation.

Despite excellent prognostic outcome, it must be emphasized that good patient counseling by a specialized nurse has to be warranted in order to guarantee sufficient attention to patient compliance, life-style, quality of life and psychological aspects.

\section{CONCLUSION}

Next day discharge (within 24-36 h after PPCI) in selected low-risk STEMI patients based on protocolized care is safe and feasible and could be a cost-saving alternative compared to standard care. 


\section{REFERENCES}

1 Chin CT, Weintraub WS, Dai D, Mehta RH, Rumsfeld JS, Anderson HV, Messenger JC, Kutcher MA, Peterson ED, Brindis RG, Rao SV. Trends and predictors of length of stay after primary percutaneous coronary intervention: a report from the Cath-PCI registry. Am Heart $\mathrm{J}$ 2011;162: 1052-1061.

2. Grines CL, Marsalese DL, Brodie B, Griffin J, Donohue B, Costantini CR, Balestrini C, Stone G, Wharton T, Esente P, Spain M, Moses J, Nobuyoshi M, Ayres M, Jones D, Mason D, Sachs D, Grines LL, O'Neill W. Safety and cost-effectiveness of early discharge after primary angioplasty in low risk patients with acute myocardial infarction. PAMI -II investigators. Primary angioplasty in myocardial infarction. J Am Coll Cardiol 1998;5:967-972.

3. Branca G, Capodanno D, Capranzano P, Barbagallo R, Seminara D, Licciardello G, Tamburino C. Early discharge in acute myocardial infarction after clinical and angiographic risk assessment. J Cardiovasc Med (Hagerstown) 2008;9:858-861.

4. Jirmar R, Widimsky P, Capek J, Hlinomaz O, Groch L. Next day discharge after successful primary angioplasty for acute ST elevation myocardial infarction. An open randomized study 'Prague-5'. Int Heart J 2008;49:653-659.

5. Kotowycz MA, Cosman TL, Tartaglia C, Afzal R, Syal RP, Natarajan MK. Safety and feasibility of early hospital discharge in ST-segment elevation myocardial infarction - A prospective and randomized trial in low risk primary percutaneous coronary intervention patients (The Safe -Depart Trial). Am Heart J 2010;159:117.e1-e6.

6. Laarman GJ, Dirksen MT. Early discharge after primary percutaneous coronary intervention. Heart 2010;96:584-587.

7. Jones DA, Rathod KS, Howard JP, Gallagher S, Antoniou S, De Palma R, Guttmann O, Cliffe S, Colley J, Butler J, Ferguson E, Mohiddin S, Kapur A, Knight CJ, Jain AK, Rothman MT, Mathur A, Timmis AD, Smith EJ, Wragg A. Safety and feasibility of hospital discharge 2 days following primary percutaneous intervention for ST-segment elevation myocardial infarction. Heart 2012;98: 1722-1727.

8. Noman A, Zaman AG, Schechter C, Balasubramaniam K, Das R. Early discharge after primary percutaneous coronary intervention for ST-elevation myocardial infarction. EHJ:Acute cardiovascular care 2013;2:262-269.

9. De Luca G, Suryapranata H, van 't Hof AWJ, de Boer MJ, Hoorntje JCA, Dambrink JHE, Gosselink ATM, Ottervanger JP, Zijlstra F.Prognostic assessment of patients with acute myocardial infarction treated with primary angioplasty: implications for early discharge. Circulation 2004;109:2737-2743.

10. The Task Force on the management of ST-segment elevation myocardial infarction of the European Society of Cardiology (ESC). Steg PhG, James SK, Atar D, Badano LP, BlömstromLundqvist C, Borger MA, Di Mario C, Dickstein K, Ducrocq G, Fernandez-Aviles F, Gershlick AH, Giannuzi P, Halvorsen S, Huber K, Juni P, Kastrati A, Knuuti J, Lenzen MJ, Mahaffey $\mathrm{KW}$, Valgimigli M, van 't Hof A, Widimsky P, Zahger D. ESC guidelines for the management of acute myocardial infarction in patients presenting with ST-segment elevation. available at: www.escardio.org/guidelines. Eur Heart J 2012;33:2569-2619.

11. O' Gara PT, Kushner FG, Ascheim DD, Casy jr. DE, Chung MK, de Lemos JA, Ettinger SM, Fang JC, Fesmire FM, Franklin BA, Granger CB, Krumholz HM, Linderbaum JA, Morrow DA, Newby LK, Ornato JP, Ou N, Radford MJ, Tamis-Holland JE, Tommasso CL, Tracy CM, Woo YJ, Zhao DX. 2013 ACCF/AHA Guideline for the management of ST-elevation myocardial infarction: a report of the American College of Cardiology Foundation/ American Heart Association Task Force on Practice Guidelines. Circulation 2013;127:e362-e425 
12. Kaul P, Newby LK, Fu Y Mark DB, Califf RM, Topol EJ, Aylward P, Granger CB, Van de Werf F, Armstrong PW. International differences in evolution of early discharge. Lancet 2004; 363:511-517.

13. Barchielli A, Balzi D, Marchionni N, Carraba N, Margheri M, Santoro GM, Olivotto I, Buiatti E; AMI-Florence Working Group. Early discharge after acute myocardial infarction in the current clinical practice. Community data from the AMI-Florence Registry, Italy. Int J Cardiol 2007;114:57-63.

14. Claeys MJ, Sinnaeve PR, Convens C, Dubois P, Boland J, Vranckx P, Gevaert S, Coussement P, Beauloye C, Renard M, Vrints C, Evrard P. Inter-hospital variation in length of hospital stay after ST-elevation myocardial infarction: results from the Belgian STEMI registry. Acta Cardiol 2013;68: 235-239.

15. Kotowycz MA, Syal RP, Afzal R, Natarajan MK. Can we improve length of hospitalization in ST elevation myocardial infarction patients treated with primary percutaneous coronary intervention? Can J Cardiol 2009;25:585-588.

16. Heeschen $\mathrm{C}$, Hamm CW, Mitrovic V, Lantelme NH, White HD, for the platelet receptor inhibition in ischemic syndrome management (PRISM) investigators. N-terminal Pro-B-Type natriuretic peptide levels for dynamic risk stratification of patients with acute coronary syndromes. Circulation 2004; 110:3206-3212.

17. Schellings DA, Adiyaman A, Giannitsis E, Hamm C, Suryapranata H, Ten Berg JM, Hoorntje JC, Van 't Hof AW. Early discharge after primary percutaneous coronary intervention: the added value of N-terminal pro-brain natriuretic peptide to the Zwolle Risk Score. JAHA 2014;3:e001089.

18. Ganovska E, Arrigo M, Helanova K, Littnerova S, Sadoune M, Kubena P, Pavlusova M, Jarkovsky J, Gottwaldova J, Kala P, Dastych M, Ishihara S, Van Aelst LNL, Cohen-Solal A, Gayat E, Spinar J, Parenica J, Mebazaa A, on behalf of the GREAT Network. Natriuretic peptides in addition to Zwolle score to enhance safe and early discharge after acute myocardial infarction: A prospective observational cohort study. Int J Cardiol 2016;215:527-531 


\title{
CHAPTER 4
}

\section{Early discharge after primary percutaneous coronary intervention: the added value of $\mathrm{N}$-terminal pro-brain natriuretic peptide to the Zwolle Risk Score}

\author{
D.A.A.M. Schellings, A. Adiyaman \\ E. Giannitsis, C. Hamm, \\ H. Suryapranata, J.M. ten Berg \\ J.C.A. Hoorntje, A.W.J. van 't Hof
}

Journal of the American Heart Association

2014;3:e001089

Doi: 10.1161/JAHA.114.001089 

ABSTRACT

Background. The Zwolle Risk Score (ZRS) identifies ST-elevation myocardial infarction (STEMI) patients treated with primary percutaneous coronary intervention (PPCI), eligible for early discharge. We aimed to investigate whether baseline Nterminal pro-brain natriuretic peptide (NT-proBNP) is also able to identify these patients and could improve future risk strategies.

Methods and Results. PPCI patients included in the On-TIME 2 study were candidates $(\mathrm{N}=861)$. We analysed if ZRS and baseline NT-proBNP predicted 30-day mortality and assessed the occurrence of major adverse cardiac events (MACEs) and major bleeding. ROC curve analysis was used to assess discriminative accuracy for ZRS, NT-proBNP and their combination. After multiple imputation, 845 patients were included. Both ZRS $>3$ (HR 9.42, P<0.001) and log NT-proBNP (HR 2.61, P<0.001) values were associated with 30-day mortality. On multivariate analysis, both the ZRS (HR 1.41, 95\%CI 1.27-1.56, P<0.001) and log NT-proBNP (HR 2.09, 95\%CI 1.59-2.74, $\mathrm{P}<0.001$ ) independently predicted death at 30 days. The area under the curve for 30 day mortality for combined ZRS/NT-proBNP was 0.94 (95\%CI $0.90-0.99$ ), with optimal predictive values of a $Z R S \geq 2$ and a NT-proBNP value of $\geq 200 \mathrm{pg} / \mathrm{ml}$. Using these cut-off values, $64 \%$ of the study population could be identified as very low risk with zero mortality at 30 days follow-up and low occurrence of MACEs and major bleeding between 48 hours and 10 days (1.3\% and $0.6 \%$, respectively).

Conclusion. Baseline NT-proBNP identifies a large group of low-risk patients who may be eligible for early (48-72 h) discharge, whereas optimal predictive accuracy is reached by the combination of both baseline NT-proBNP and ZRS.

\section{INTRODUCTION}

In low-risk patients with ST-elevation myocardial infarction (STEMI), treated with primary percutaneous coronary intervention (PPCI), early discharge has been proven to be safe and feasible with good cost effectiveness. ${ }^{1-6}$

In order to identify PPCI patients, eligible for early discharge, the Zwolle Risk Score (ZRS) has been developed. This validated score, assessed by a point system, was able to identify a large group of patients at low mortality risk, who could be discharged between 48 and $72 \mathrm{~h}$ after PPCI. ${ }^{7}$

For several years, the biomarkers BNP and N-terminal pro-brain natriuretic peptide (NT-proBNP) have been frequently used, especially in the diagnosis and prognosis of 
heart failure (HF). Interestingly, these biomarkers also predict major adverse cardiac events and mortality both early and late after STEMI and non-STEMI. ${ }^{8-14}$

We studied whether baseline NT-proBNP levels could identify PPCI patients at low risk, who may be eligible for early discharge, above and beyond the ZRS.

\section{METHODS}

\section{Patients}

Our population consists of patients with diagnosis of STEMI admitted for PPCI who were included in the Ongoing Tirofiban in Myocardial Infarction Evaluation (OnTIME) 2 trial, ${ }^{15}$ a prospective, multicenter placebo-controlled, randomized, clinical trial. The rationale, design and primary results of On-TIME 2 have been previously described. ${ }^{15,16}$ The trial is registered under No. ISRCTN06195297.

Briefly, enrollment was from June 2006 to November 2007. Eligible patients were 21-85 years of age with symptoms of acute myocardial infarction (MI) of more than 30 minutes, but less than 24 hours, and ST-segment elevation of more than $1 \mathrm{mV}$ in two adjacent ECG leads.

Exclusion criteria were severe renal dysfunction (glomerular filtration rate (GFR) $<30$ $\mathrm{ml} / \mathrm{min}$ or serum creatinine $>200 \mathrm{mmol} / \mathrm{l}(>2.5 \mathrm{mg} / \mathrm{dl})$, therapy-resistant cardiogenic shock (systolic blood pressure $\leq 80 \mathrm{mmHg}$ for $>30 \mathrm{~min}$ ), persistent severe hypertension (systolic pressure $>180 \mathrm{mmHg}$ or diastolic pressure $>110 \mathrm{mmHg}$ ), or a contraindication to anticoagulation or increased risk of bleeding. Also, patients with a left bundle branch block, pregnant and/or breastfeeding women, and patients with a life expectancy of less than 1 year were excluded. From each patient, a written informed consent for participation in both the On-TIME 2 study and future data analysis was obtained. The study protocol was approved by all local ethics committees (institutional review boards) involved.

\section{PROCEDURES}

\section{Treatment}

All patients were planned to undergo PPCI and were initially treated according to the On-TIME 2 study protocol and randomly assigned to (pre-hospital) treatment with tirofiban $\left(25 \mu \mathrm{g} / \mathrm{kg}\right.$ bolus and $0.15 \mu \mathrm{g} \cdot \mathrm{kg}^{-1} \cdot \mathrm{min}^{-1}$ maintenance infusion for 18 hours) or 44 
placebo. PPCI was performed with standard techniques if the coronary anatomy was suitable for angioplasty. Additional treatment with stents and devices was to the discretion of the treating cardiologist. All patients were treated with optimal drugtherapy, including angiotensin-converting enzyme inhibitors, $\beta$-blockers, aspirin and a statin. Final discharge and admission duration was to the discretion of the treating cardiologist, irrespective of NT-proBNP values or ZRS.

\section{Measurements}

NT-proBNP plasma levels were measured (Roche, Central Hematology Laboratory, University of Heidelberg, Germany) in each patient on admission, after sheath insertion before PPCI was performed. For each patient the ZRS was calculated. This score, assessed by a point system, has shown to be able to identify a large group of patients at very low risk who may safely be discharged early after PPCI. ${ }^{7}$ Very-low-risk patients are those with a score $\leq 3$ (mortality rate of $0.1 \%$ at 2 days and $0.2 \%$ between 2 and 10 days, Figure 1).

\section{Endpoints}

The primary endpoint in this study was death from any cause at 30 days. Secondary endpoints were non-fatal MACEs and major bleeding until 10 days after admission as potentially lethal events that would interfere with the patients' eligibility for early (between 48 and $72 \mathrm{~h}$ ) and safe discharge. MACE was defined as recurrent myocardial infarction (RMI), urgent target vessel revascularization and malignant cardiac arrhythmias (ventricular tachycardia [VT] or ventricular fibrillation [VF]) occurring later than $24 \mathrm{~h}$ after PPCI.

RMI was defined as a new increase of creatine kinase (CK)/myocardial band that was 3 or more times the upper limit of normal, present in two different blood samples and accompanied by chest pain or ECG changes. VT (sustained or non-sustained) was defined as a sequence of three or more ventricular beats, with a frequency $>100$ beats/min and was reported at the discretion of the physician.

Major bleeding was defined as either intracranial bleeding or overt bleeding with a decrease in hemoglobin $\geq 5 \mathrm{~g} / \mathrm{dl}(\geq 3.1 \mathrm{mmol} / \mathrm{l})$ or a decrease in hematocrit $>15 \%$.

\section{Statistical analysis}

Patients were divided into percentiles of NT-proBNP levels at the time of admission and according to their ZRS. We compared the predictive accuracy of the ZRS, NTproBNP and combined NT-proBNP / ZRS, using receiver operating characteristic (ROC) curves. A total of 74 patients had missing values on ZRS and 36 on NTproBNP at baseline (three patients had missing values on both). Assuming data were 
missing at random, a multiple missing value imputation procedure was applied in which the values of the NT-proBNP and the values of the elements of the ZRS were imputed in case they were missing (PROC MI; SAS version 9.2; SAS Institute Inc., Cary, NC, USA). The ZRS score was calculated from the individually imputed scores.

The following predictor variables were used for the multiple imputation: randomization to tirofiban or placebo, Killip Class, gender, age, a history of diabetes, smoking, anterior infarction location, TIMI post procedure, ischemic time, heart rate, cardiac troponin baseline, cardiac troponin 18-24 h, cardiac troponin 72-96 h, NT-proBNP baseline, NT-proBNP 18-24 h, NT-proBNP 72-96 h, peak CK, cumulative ST deviation 30-180 min post PPCI, death after 30 days, vessel disease (single-vessel disease, two-vessel disease, three-vessel disease or left main disease), duration of hospital stay and glomerular filtration rate.

\begin{tabular}{|c|c|c|c|c|c|}
\hline \multirow{2}{*}{$\begin{array}{l}\text { Killip class } \\
1\end{array}$} & \multirow{2}{*}{$\begin{array}{l}\text { Points } \\
0\end{array}$} & \multirow{2}{*}{$\begin{array}{l}\text { Risk Score } \\
0-1\end{array}$} & \multicolumn{3}{|c|}{$\mathrm{RR}[95 \% \mathrm{Cl}]$ of death by $30-\mathrm{D}$} \\
\hline & & & 0.03 & [ 0.008 & - 0.13 ] \\
\hline 2 & 4 & 2 & 0.09 & [ 0.002 & - 0.37 ] \\
\hline $3-4$ & 9 & 3 & 1.04 & {$\left[\begin{array}{ll}0.44 \\
0\end{array}\right.$} & $-2.45]$ \\
\hline \multicolumn{2}{|c|}{ TIMI flow post } & 4 & 1.40 & {$\left[\begin{array}{l}0.5 \\
0\end{array}\right.$} & - 3.89 ] \\
\hline 3 & 0 & 5 & 2.48 & [ 0.96 & - 6.42 ] \\
\hline 2 & 1 & 6 & 2.52 & {$\left[\begin{array}{ll}0.75 \\
0\end{array}\right.$} & - 8.46 ] \\
\hline $0-1$ & 2 & 7 & 5.99 & [ 1.98 & - 18.1$]$ \\
\hline \multicolumn{2}{|l|}{ Age } & $\geq 8$ & 32.1 & [ 18.6 & $-55.8 \quad]$ \\
\hline$<60$ & 0 & & & & \\
\hline$\geq 60$ & 2 & & & & \\
\hline \multicolumn{2}{|c|}{ 3-vessel disease } & & & & \\
\hline No & 0 & & & & \\
\hline Yes & 1 & & & & \\
\hline \multicolumn{2}{|c|}{ Anterior infarction } & & & & \\
\hline No & 0 & & & & \\
\hline Yes & 1 & & & & \\
\hline \multicolumn{2}{|c|}{ Ischemia time ( $>4$ hours) } & & & & \\
\hline No & 0 & & & & \\
\hline Yes & 1 & & & & \\
\hline
\end{tabular}

Figure 1. The Zwolle Risk Score (left panel) and the relative risk (RR) of 30-day mortality for each score (right panel). CI, confidence interval; STEMI, ST-elevation myocardial infarction; TIMI, thrombolysis in myocardial infarction. 
We generated 10 datasets and the results of all statistical analyses were pooled across the 10 data sets using the corresponding pooling procedure in SPSS or SAS. We calculated the SD of imputed variables in the baseline table by multiplying the estimated SE by the square root of $\mathrm{N}$.

The correlation between NT-proBNP and ZRS was calculated using Spearman's correlation coefficient. Multivariate Cox's regression analysis was used to estimate the influence of NT-proBNP and ZRS on 30-day mortality. We adjusted for randomization (tirofiban or placebo), gender, age, renal function (GFR, $\mathrm{ml} / \mathrm{min}$ ), and body mass index (BMI) in a backward Cox's regression with a $\mathrm{P}$ value of 0.05 for entry or exit of the variables in the model. All statistical analyses were performed using SPSS (version 19; SPSS, Inc., Chicago, IL, USA). A two-sided $\mathrm{P}$ value of $\leq 0.05$ was considered statistically significant. To perform an analysis using ZRS and NT-proBNP together, we calculated weighted scores for each as follows:

$$
(\beta 1 \times \mathrm{ZRS})+(\beta 2 \times \ln \mathrm{NT}-\text { proBNP}),
$$

where $\beta 1$ and $\beta 2$ denote $\beta$ coefficients for the ZRS and log NT-proBNP obtained from the multivariate Cox's regression model. Because NT-proBNP was not normally distributed we used logarithmically transformed values. We used ROC-curves to define optimal cut-off values in estimating mortality outcomes for ZRS, NT-proBNP and the combination of both. We calculated the pooled areas under the curve (AUC) and $95 \%$ confidence intervals (CIs) by averaging over the 10 AUCs from the imputed data sets using Rubin's rule. ${ }^{17}$ AUCs were compared in SAS using PROC Logistic and the results were pooled across imputations using Rubin's rule in order to obtain Wald statistics and corresponding P values. In Rubin's rule, the overall estimate is the average of the individual estimates, and the overall SE is a function of the withinimputation variance and the between-imputation variance. The cut-off scores were obtained from the mean scores across the 10 datasets, which gave the highest specificity in combination with $100 \%$ sensitivity (e.g., zero mortality).

In order to calibrate the prediction models, we used logistic regression models. The raw scores of ZRS and NT-proBNP separately, ZRS and NT-proBNP together, and the linear combination of ZRS and NT-proBNP, respectively, were entered into a logistic regression model with 30-day mortality as the dependent variable. This was done for each of the imputed datasets using the pooling procedure in SPSS. Because we have 10 imputed data sets, this gives $10 \mathrm{P}$ values per analysis. If a $\mathrm{P}$ value is small, this is indicative of a lack of fit of the model. All statistical analyses were performed using SPSS (version 19) or SAS (version 9.2). 


\section{RESULTS}

During the study period, 984 patients were admitted with the diagnosis of STEMI. A total of 861 patients underwent PPCI. Baseline characteristics of the whole study population have been previously reported..$^{15}$ Thirty-day follow-up was present in 845 patients of whom 738 patients had a valid value for both the ZRS and baseline NTproBNP. Based on analysis with imputation of missing data, the ZRS was calculated from baseline characteristics at presentation and ranged from 0 points to 15 points (mean $\pm \mathrm{SD}$ of $2.34 \pm 2.14$ points). Of the 845 patients, 679 patients $(80 \%)$ were in the very-low ZRS group (previously defined as ZRS $\leq 3$ ). The baseline NT -proBNP values in the total cohort ranged from 9 to $33927 \mathrm{pg} / \mathrm{ml}$ (mean $\pm \mathrm{SD}$ of $599 \pm 1883$ ), with a median of $138 \mathrm{pg} / \mathrm{ml}$. Median time from onset of ischemic symptoms to PPCI was 167 $\min$ (mean \pm SD of $238 \pm 252 \mathrm{~min}$ ). The $25^{\text {th }}$ and $75^{\text {th }}$ percentile values of NT-proBNP were 60 and $355 \mathrm{pg} / \mathrm{ml}$, respectively. In Table 1, baseline characteristics according to the NT-proBNP percentiles are given for patients below, respectively, above the $60^{\text {th }}$ percentile of NT-proBNP values $($ NT-proBNP value $=198)$. We chose this cut-off point because all fatal cases had a NT-proBNP value above the $60^{\text {th }}$ percentile. In comparison to the lower percentiles, patients above the $60^{\text {th }}$ percentile were older; more often had diabetes, hypertension, a history of previous angina and a history of previous myocardial infarction. In addition, patients with a NT-proBNP above the $60^{\text {th }}$ percentile had a higher systolic blood pressure, higher Killip Class, higher hemoglobin level, higher levels of troponin and a higher ZRS.

At 30 days of follow-up, 21 patients had died. Mortality in patients with ZRS $<6$ was significantly lower in comparison with those with $\mathrm{ZRS} \geq 6(1.1 \%$ versus $28.6 \%$; $\mathrm{P}<0.001)$.

Among the patients with ZRS $\leq 3$ (previously defined as a very low-risk group), 30-day mortality was $1.0 \%$ ( $0.1 \%$ at 2 days and $0.6 \%$ between 2 and 10 days). In patients with NT-proBNP levels below the $90^{\text {th }}$ percentile, mortality was significantly lower in comparison with NT-proBNP levels above the $90^{\text {th }}$ percentile $(0.7 \%$ vs. $19.0 \%$, $\mathrm{P}<0.001$ ). In the 21 mortality cases, median NT-proBNP was $2171 \mathrm{pg} / \mathrm{ml}$ (ranging from $213-33.927 \mathrm{pg} / \mathrm{ml}$; interquartile range 1512-3620). We found a significant correlation between ZRS and NT-proBNP (Spearman's correlation of 0.419, P<0.001). In Figure 2, 30-day mortality by quartiles of NT-proBNP and the Zwolle Risk Score is depicted. In uni- and multivariate analysis, both baseline NT-proBNP and ZRS were strongly predictive for 30-day mortality. After adjustment for renal function, BMI $\left(\mathrm{kg} / \mathrm{m}^{2}\right)$, gender, age and randomization to tirofiban or placebo, the main results of the multivariate analysis did not differ from the univariate results. 
Table 1. Baseline characteristics of the included patients in the imputed dataset $(\mathrm{N}=845)$ according to the 60th percentile of baseline NT-proBNP

\begin{tabular}{lccc}
\hline \hline Variable & $\begin{array}{l}0-60^{\text {th }} \text { percentile } \\
(\mathrm{N}=507)\end{array}$ & $\begin{array}{c}60-100^{\text {th }} \text { percentile } \\
(\mathrm{N}=338)\end{array}$ & P value \\
\hline Age (years) mean \pm SD & $58.66 \pm 10.54$ & $67.02 \pm 11.13$ & $<0.001$ \\
Male gender & $427 / 507(84.2 \%)$ & $215 / 338(63.6 \%)$ & $<0.001$ \\
Current smoking & $272 / 506(53.8 \%)$ & $137 / 336(40.8 \%)$ & $<0.001$ \\
Diabetes mellitus & $37 / 506(7.3 \%)$ & $53 / 338(15.7 \%)$ & $<0.001$ \\
Hypertension & $129 / 507(25.4 \%)$ & $153 / 338(45.3 \%)$ & $<0.001$ \\
Hypercholesterolemia & $121 / 506(23.9 \%)$ & $101 / 338(29.9 \%)$ & 0.054 \\
Family history & $211 / 503(41.9 \%)$ & $129 / 335(38.5 \%)$ & 0.320 \\
Prior angina & $42 / 505(8.3 \%)$ & $62 / 336(18.5 \%)$ & $<0.001$ \\
Previous MI & $30 / 506(5.9 \%)$ & $39 / 337(11.6 \%)$ & 0.003 \\
Previous PTCA & $35 / 507(6.9 \%)$ & $35 / 338(10.4 \%)$ & 0.075 \\
Previous CABG & $7 / 507(1.4 \%)$ & $5 / 338(1.5 \%)$ & $>0.99$ \\
Previous CVA & $7 / 507(1.4 \%)$ & $8 / 338(2.4 \%)$ & 0.288 \\
Systolic blood pressure mean $\pm \mathrm{SD}$ & $128.03 \pm 22.15$ & $134.70 \pm 26.52$ & $<0.001$ \\
Diastolic blood pressure mean $\pm \mathrm{SD}$ & $76.34 \pm 14.19$ & $76.92 \pm 16.22$ & 0.588 \\
Killip Class $>1$ & $15 / 507(3.0 \%)$ & $26 / 338(7.7 \%)$ & 0.002 \\
Hemoglobin (mmol/l) mean $\pm \mathrm{SD}$ & $9.31 \pm 4.12$ & $9.76 \pm 10.13$ & 0.001 \\
Troponin $(\mu \mathrm{m} / \mathrm{l})$ mean $\pm \mathrm{SD}$ & $0.17 \pm 0.63$ & $0.68 \pm 1.77$ & $<0.001$ \\
Zwolle Risk Score mean $\pm \mathrm{SD}$ & $1.76 \pm 1.57$ & $3.21 \pm 2.53$ & $<0.001$ \\
\hline \hline
\end{tabular}

All values are denoted as mean $\pm \mathrm{SD}$ or absolute numbers and their percentages of the total group, where appropriate. $\mathrm{CABG}$, coronary artery bypass grafting; CVA, cerebrovascular accident; $\mathrm{MI}$, myocardial infarction; NT-proBNP, N-terminal pro-brain natriuretic peptide; PTCA, percutaneous transluminal coronary angioplasty.

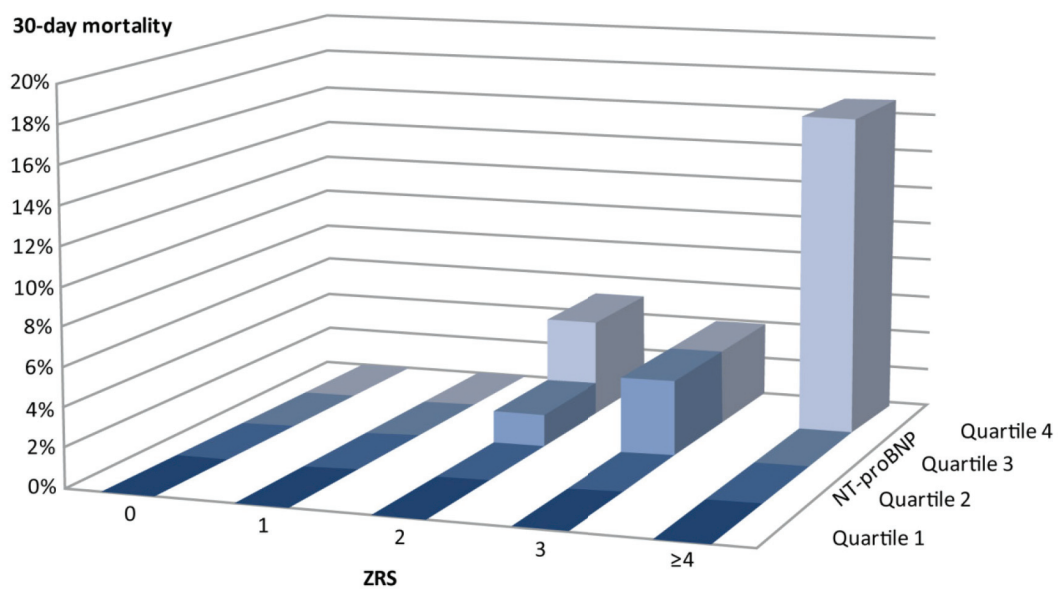

Figure 2. Thirty-day mortality (\%) by quartiles of NT-proBNP and the Zwolle Risk Score (ZRS) in ST-elevation myocardial infarction patients after primary percutaneous intervention. NT-proBNP, $\mathrm{N}$-terminal pro-brain natriuretic peptide. 


\section{Predictive accuracy for 30-day mortality of ZRS, baseline NT-proBNP and combined use}

We compared the predictive accuracy for 30-day mortality of the ZRS, baseline NTproBNP and combined use of baseline NT-proBNP/ZRS by means of ROC curves (Figure 3). The weighted linear combination of baseline NT-proBNP and ZRS, with the weights obtained from the multivariate Cox's regression model, demonstrated the best discriminatory accuracy in predicting 30-day mortality, with an AUC of 0.94 (95\%CI 0.90-0.99). Interestingly, the AUC for baseline NT-proBNP was larger than the AUC for the ZRS, $(0.91$ [95\%CI 0.86-0.96] and 0.87 [95\% CI 0.79-0.95], respectively) although the difference was not significant; $\mathrm{P}=0.34$ ). The AUC for the weighted linear combination of ZRS/NT-proBNP was higher when compared with ZRS (0.94 vs. 0.87 [95\%CI 0.79-0.95]; $\mathrm{P}=0.023$ ), and when compared with NTproBNP ( 0.94 vs. 0.91 [95\%CI $0.86-0.96$ ]; $\mathrm{P}=0.028)$. The results of the calibration of the models were good: the Chi-square for the Hosmer and Lemeshow's goodness-offit test was not significant, with all $\mathrm{P}$ values greater than $10 \%$.

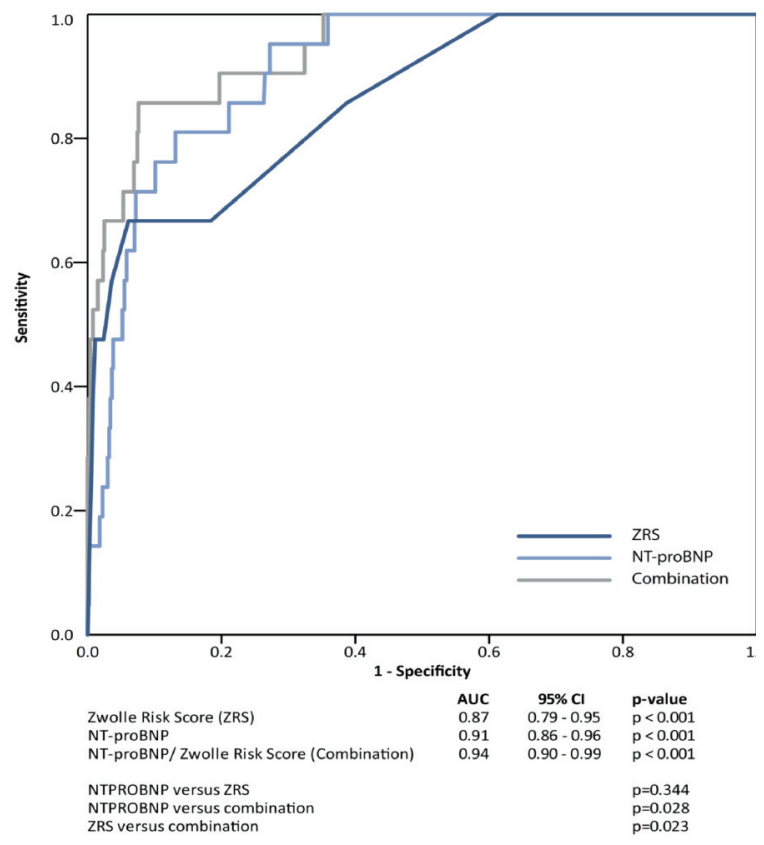

Figure 3. ROC Curves of NTproBNP and the Zwolle Risk Score in assessing 30-day mortality after primary percutaneous intervention in ST-elevation myocardial infarction patients. AUC indicates area under the curve; CI, confidence interval; NT-proBNP, N-terminal pro-brain natriuretic peptide; ROC, receiver operating characteristic. 
Table 2. Cut-off values for ZRS, NT-proBNP and combination of ZRS/NT-proBNP

\begin{tabular}{llll}
\hline \hline & Cut-off value & Sensitivity & Specificity (95\%CI) \\
\hline ZRS & $<2$ & 1.00 & $0.39(0.35-0.42)$ \\
NT-proBNP & $<200 \mathrm{pg} / \mathrm{ml}$ & 1.00 & $0.62(0.58-0.65)$ \\
Combination & ZRS $<2$ & 1.00 & $0.70(0.67-0.73)$ \\
(serial) & or & & \\
& NT-proBNP $<200 \mathrm{pg} / \mathrm{ml}$ & & \\
\hline \hline
\end{tabular}

$\begin{array}{lllll}\text { P values between specificities: } & \text { ZRS -NT-proBNP: } & \mathrm{Chi}^{2}=113.65, & \mathrm{df}=2, & \mathrm{P}<0.001 . \\ & \text { ZRS-Combination: } & \mathrm{Chi}^{2}=256, & \mathrm{df}=2, & \mathrm{P}<0.001 . \\ & \text { NT-proBNP-Combination: } \mathrm{Chi}^{2}=65, & \mathrm{df}=2, & \mathrm{P}<0.001 .\end{array}$

When we excluded the 110 patients with imputed values, the results were comparable to the results of the imputed data set. The AUC for Zwolle Risk Score was 0.84 (95\% CI $0.75-0.94)$ as compared to $\mathrm{AUC}=0.87$ (95\%CI $0.79-0.95)$ in the imputed data set. The AUC for NT-proBNP was $0.92(95 \% \mathrm{CI} 0.87-0.97)$ as compared to AUC $=0.91$ (95\%CI 0.86-0.96) in the imputed data set and AUC for the combination of ZRS and NT-proBNP was $0.94(95 \% \mathrm{CI} 0.89-0.99)$ as compared to $\mathrm{AUC}=0.94(95 \% \mathrm{CI}$ $0.94-0.99)$ in the imputed data set.

Subsequently, we determined optimal predictive values for ZRS and NT-proBNP and the serial combination of the two tests, based on $100 \%$ sensitivity (and thus $100 \%$ survival), with the aim to identify a large group low-risk patients, suitable for very early discharge. In Table 2, cut-off values with optimal predictive accuracy are given. It is shown that NT-proBNP $<200 \mathrm{pg} / \mathrm{ml}$ was able to classify $60 \%$ of the study population as very low risk, with zero mortality. In a serial test combination of both ZRS and NT-proBNP, this was as high as $68 \%$.

Based on this serial test combination we created a decision rule implying that low-risk patients, eligible for early discharge, are those with ZRS $<2$ or baseline NT-proBNP $<200 \mathrm{pg} / \mathrm{ml}$.

\section{Feasibility and safety of early discharge in low-risk patients according to the decision rule}

MACEs within 2 days after admission occurred significantly less frequently in low-risk patients than in the higher-risk group (32 [5.6\%] of 575 vs. 29 [10.7\%] of 270 $\mathrm{P}=0.007)$. Major bleeding occurred in 8 versus 6 patients, respectively $(1.4 \%$ vs. $2.2 \%$, $\mathrm{P}=0.39$ ). Of the 32 low-risk patients experiencing MACEs within 2 days after PPCI, 13 patients (40.6\%) had RMI and/or target vessel revascularization and 19 (59.4\%), had 
VT resulting in VF in one patient. Patients experiencing MACEs and major bleeding, totaling 37 patients, would be excluded for potential early discharge. Thus, 538 patients would have been eligible for very early discharge at $48 \mathrm{~h}$ after PPCI. This accounts for $64 \%$ of the study population. Between $48 \mathrm{~h}$ and 10 days after PPCI, $1.7 \%$ experienced an adverse event. MACEs occurred in $7(1.3 \%)$ patients and major bleeding occurred in $3(0.6 \%)$. In 1 patient both events occurred. Therefore, 9 (1.7\%) readmissions within 10 days after PPCI would have been expected.

Of the patients with MACEs, two developed a malignant cardiac arrhythmia requiring cardioversion or defibrillation (one patient at day 5 and the other patient at day 8 after PPCI). Because these events would have been potentially lethal in an outpatient setting, we looked at these patients in detail and noticed severe noncardiac comorbidity before VT/VF occurred in one patient. The other patient who was in a clinical good condition, had unexpected VF without signs of RMI or HF despite low ZRS (1 point) and baseline NT-proBNP $(20 \mathrm{pg} / \mathrm{ml})$ and a left ventricular ejection fraction $>35 \%$. This patient was discharged after placement of an implantable cardioverter defibrillator (ICD).

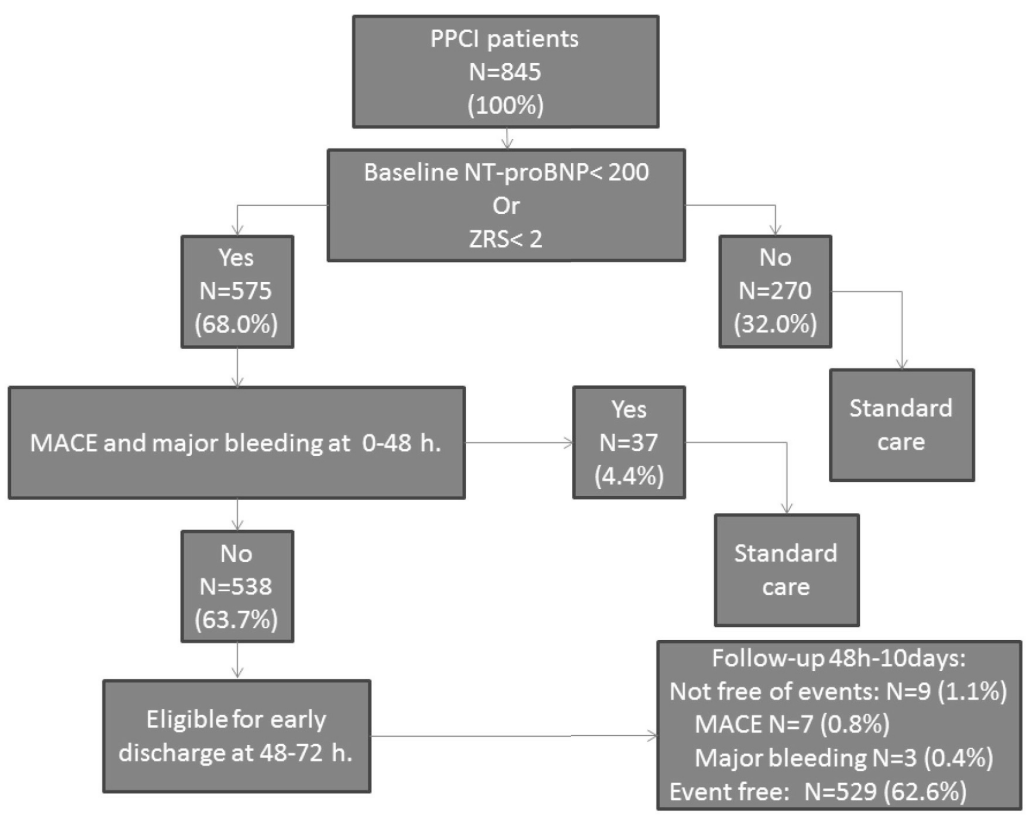

Figure 4. Feasibility of early discharge in 845 PPCI patients based on ZRS $<2$ or NT-proBNP $<200 \mathrm{pg} / \mathrm{ml}$. MACE, major adverse cardiac event; NT-proBNP, N-terminal pro-brain natriuretic peptide; PPCI, primary percutaneous coronary intervention; ZRS, Zwolle Risk Score. 
MACEs or major bleeding later than 10 days after PPCI occurred in $5(0.9 \%)$ of the low-risk patients, but these events probably could not have been prevented by initially longer hospitalization. In conclusion, based on the occurrence of MACEs and major bleeding, 538 patients (64\% of the study population) could have been discharged $48 \mathrm{~h}$ after PPCI, without mortality, and with low frequency of MACEs $(1.3 \%$ of low-risk patients eligible for very early discharge) and/or major bleeding $(0.6 \%$ of low-risk patients eligible for very early discharge, see Figure 4).

\section{DISCUSSION}

Our study reveals that baseline NT-proBNP values predict 30-day mortality in patients with STEMI, treated with PPCI independently and even more strongly than ZRS alone. However, optimum predictive value was reached by a serial test combination, where NT-proBNP $(<200 \mathrm{pg} / \mathrm{ml})$ or ZRS $(<2)$ were able to identify a large group of patients (68\% of the study population), with zero mortality at 30-day follow-up. Approximately $64 \%$ of the patients in our population would probably have been eligible for early discharge, with very low risk of MACEs (including malignant ventricular arrhythmias) and bleeding during the first 10 days after admission.

\section{Early discharge after PPCI}

Since the introduction of PPCI, length of stay in hospital for patients with STEMI has been reduced considerably. Present guidelines now recommend that it is reasonable to discharge low-risk PPCI patients early (after approx. $72 \mathrm{~h}$ ), providing rehabilitation and follow-up are properly arranged. ${ }^{18}$

Although several studies have shown that early discharge, particularly within 48-72 h, is safe, feasible and cost effective in uncomplicated PPCI patients, ${ }^{1-6}$ large randomized trials, applying a structured risk strategy prospectively, are still scarce.

Traditionally, STEMI has been associated with severe cardiac complications, such as heart failure, malignant ventricular arrhythmias, mechanical complications and of course reinfarction resulting from target segment-related reocclusion or acute stent thrombosis. In addition, several non-cardiac complications such as severe (groin) bleeding, thrombo-embolic complications or contrast agent-mediated nephropathy may occur. The possible occurrence of any of the complications mentioned above necessitates close monitoring at a coronary care unit for the first 24 to 48 hours of admission. In this setting, efforts to assess the moment and safety of discharge are often postponed until the moment that the patient can be moved to the cardiology ward. 


\section{Risk stratification}

In the current PPCI era, several risk strategies to identify STEMI patients eligible for early discharge have been proposed. ${ }^{1,5,7}$ The validated and accepted ZRS incorporates procedural factors and baseline clinical patients characteristics, without the use of timeconsuming imaging modalities. This relatively simple tool was efficient in identifying $74 \%$ of the PPCI patients at a very low mortality risk $(0.2 \%)$ within 2 to10 days. Approximately $61 \%$ of these patients would be eligible for discharge at $48-72 \mathrm{~h}^{7}$ In our study, baseline NT-proBNP was also strongly predictive for 30-day mortality, with a higher hazard ratio than the ZRS in multivariate analysis. Moreover baseline NTproBNP had a highly predictive accuracy with an AUC higher (although not reaching significance) than for the ZRS. Previous studies already suggested that in STEMI patients, NT-proBNP, drawn within $24 \mathrm{~h}$ of the onset of chest pain, is more accurate in predicting mortality at 9 months than the Thrombolysis in Myocardial Infarction (TIMI) risk score. ${ }^{12}$ Even the final PCI result in terms of TIMI flow and occurrence of the no-reflow phenomenon could be predicted by baseline levels of BNP or NTproBNP. ${ }^{19,20}$

In contrast with our previous report, ${ }^{7}$ we did not accept any mortality when defining cut-off values, given that mortality is unacceptable when searching for a reduction in hospital stay. Furthermore, we found a slightly higher mortality rate between 2 and 10 days $(0.6 \%$ versus $0.2 \%)$ for ZRS $\leq 3$. We therefore set the cut-off level at a ZRS of $<2$. None of the fatal cases in the study population had low baseline NT-proBNP (all $>200$ $\mathrm{pg} / \mathrm{ml}$ ), and the mean NT-proBNP for fatal cases was as high as $4606 \mathrm{pg} / \mathrm{ml}$.

At present it has been suggested that in just $30-40 \%$ of low-risk PPCI patients, discharge within 4 days is really effectuated. ${ }^{21,22}$ This may be improved by an additional simple baseline NT-proBNP determination. Given our study results and the fact that biomarkers are more widely implemented at present, one could question wether ZRS could be replaced by simple baseline NT-proBNP assessment. Alternatively, risk stratification could be optimized by the combination of ZRS and NT-proBNP, and a larger group of patients could be targeted for early and safe discharge, as we have shown in our results.

\section{Safety issue}

Since the introduction of the ZRS, PPCI techniques and accompanying peri-procedural pharmacological treatment have been further improved. This has led to a decrease in ischemic time, higher rates of TIMI III flow before and after PPCI, improvement of myocardial blush grades ${ }^{15,23,24}$ and a decrease of major bleeding. ${ }^{25}$ As a consequence, more patients will potentially be eligible for leaving the hospital safely, at an early stage. 
Although the risk of mortality is an important factor in the identification of PPCI patients, when assessing for eligibility for early discharge, non-fatal MACEs, major bleeding and malignant ventricular arrhythmias are conditions to be accounted for. This diversity of contraindications can neither be predicted by ZRS, nor by baseline NTproBNP, but as we have shown, the frequencies of MACEs and major bleeding are very low in patients with baseline NT-proBNP $<200 \mathrm{pg} / \mathrm{ml}$ or ZRS $<2$. Moreover, these simple cut-off values could facilitate early discharge of a large group of patients, at the cost of only few readmissions.

\section{Limitations}

First of all the sample size for a study of this sort is relatively small as well as the number of deaths. These small numbers may limit the strength of the conclusions.

Moreover several limitations in our methods have to be noted: Although in every patient baseline NT-proBNP values were assessed by protocol, the ZRS was calculated afterward.

However, all patients and outcome measures were monitored longitudinally. NTproBNP levels were drawn at variable periods after onset of symptoms. This variability is accounted for by the ZRS, which is partially based on ischemic time. Based on the exclusion criteria, patients with higher Killip Class, elderly patients and young women were not included in the study.

We imputed missing values in order to have either a complete ZRS (74 patients) or NT-proBNP (36 patients). The reason for this was that when we would exclude the patients with a missing value on ZRS and/or NT-proBNP, we would miss 4 of 21 cases of death. When we excluded the 110 patients with imputed values, the results were comparable to the results of the imputed dataset.

Although we succeeded in demonstrating the predictive accuracy and additional value of the assessment of baseline NT-proBNP values, we did not effectuate hospital discharge after $48 \mathrm{~h}$. Also we did not study the effect of real hospital length of stay on 30 -day mortality, although most patients $(80 \%)$ were at low mortality risk according to the ZRS.

Prospective validation is therefore warranted in future studies, using the presently defined cut-off values. Furthermore, the predictive value of consecutive NT-proBNP levels, during and after PPCI, should be evaluated in order to optimize early discharge policy in successfully treated STEMI patients. 


\section{CONCLUSION}

Baseline NT-proBNP is highly predictive for short-term mortality in PPCI patients and identifies a large group of very-low-risk patients (i.e., zero mortality at 30 days). These patients are potentially eligible for early discharge (48 h after successful PPCI), with very low rate of non-fatal MACEs and major bleeding up to 10 days after admission. Optimal predictive accuracy is reached by the combination of both ZRS $<2$ and baseline NT-proBNP $<200 \mathrm{pg} / \mathrm{ml}$. 


\section{REFERENCES}

1. Grines CL, Marsalese DL, Brodie B, Griffin J, Donohue B, Costantini CR, Balestrini C, Stone G, Wharton T, Esente P, Spain M, Moses J, Nobuyoshi M, Ayres M, Jones D, Sachs D, Mason D, Grines LL, O'Neill W. Safety and cost-effectiveness of early discharge after primary angioplasty in low risk patients with acute myocardial infarction. PAMI -II investigators. Primary angioplasty in myocardial infarction. J Am Coll Cardiol 1998;5:967-972.

2. Branca G, Capodanno D, Capranzano P, Barbagallo R, Seminara D, Licciardello G, Tamburino C. Early discharge in acute myocardial infarction after clinical and angiographic risk assessment. J Cardiovasc Med (Hagerstown) 2008;9:858-861.

3. Jirmar R, Widimsky P, Capek J, Hlinomaz O, Groch L. Next day discharge after successful primary angioplasty for acute ST elevation myocardial infarction. An open randomized study 'Prague-5'. Int Heart J 2008;49:653-659.

4. Kotowycz MA, Cosman TL, Tartaglia C, Afzal R, Syal RP, Natarajan MK. Safety and feasibility of early hospital discharge in ST-segment elevation myocardial infarction- A prospective and randomized trial in low risk primary percutaneous coronary intervention patients ( The Safe -Depart Trial). Am Heart J 2010;159:117.e1-e6.

5. Laarman GJ, Dirksen MT. Early discharge after primary percutaneous coronary intervention. Heart 2010;96:584-587.

6 Jones DA, Rathod KS, Howard JP, Gallagher S, Antoniou S, De Palma R, Guttmann O, Cliffe S, Colley J, Butler J, Ferguson E, Mohiddin S, Kapur A, Knight CJ, Jain AK, Rothman MT, Mathur A, Timmis AD, Smith EJ, Wragg A. Safety and feasibility of hospital discharge 2 days following primary percutaneous intervention for ST-segment elevation myocardial infarction. Heart 2012;98: 1722-1727.

7. De Luca G, Suryapranata H, van 't Hof AWJ, de Boer MJ, Hoorntje JCA, Dambrink JHE, Gosselink ATM, Ottervanger JP, Zijlstra F. Prognostic assessment of patients with acute myocardial infarction treated with primary angioplasty: implications for early discharge. Circulation 2004;109:2737-2743.

8. Heeschen C, Hamm CW, Mitrovic V, Lantelme NH, White HD, for the platelet receptor inhibition in ischemic syndrome management (PRISM) investigators. N-Terminal Pro-B-Type natriuretic peptide levels for dynamic risk stratification of patients with acute coronary syndromes. Circulation 2004;110:3206-3212.

9. Omland T, Aakvaag A, Bonarjee VV, Caidahl K, Lie RT, Nilsen DW, Sundsfjord JA, Dickstein K. Plasma brain natriuretic peptide as an indicator of left ventricular systolic function and longterm survival after acute myocardial infarction. Comparison with plasma atrial natriuretic peptide and N-terminal proatrial natriuretic peptide. Circulation 1996;93:1963-1969.

10. Tapanainen JM, Lindgren KS, Makikallio TH, Vuolteenaho O, Leppaluoto J, Huikuri HV. Natriuretic peptides as predictors of non-sudden and sudden cardiac death after acute myocardial infarction in the beta-blocking era. J Am Coll Cardiol 2004;43:757-763.

11. Mega JL, Morrow DA, De Lemos JA, Sabatine MS, Murphy SA, Rifai N, Gibson CM, Antman EM, Braunwald E. B-type natriuretic peptide at presentation and prognosis in patients with STsegment elevation myocardial infarction: an ENTIRE-TIMI-23 substudy. J Am Coll Cardiol 2004:44:335-339.

12. Khan SQ, Quinn P, Davies JE, Ng LL. N-terminal pro-B-type natriuretic peptide is better than TIMI risk score at predicting death after acute myocardial infarction. Heart 2008;94:40-43.

13. Ang D, Wei L, Kao M, Lang C, Struthers A. A comparison between B-type natriuretic peptide, global registry of acute coronary events (GRACE) score and their combination in ACS risk stratification. Heart 2009;95:1836-1842. 
14. Richards AM, Nicholls MG, Espiner EA, Lainchbury JG, Troughton RW, Elliot J, Frampton C, Turner J, Crozier IG, Yandle TG. B-type natriuretic peptides and ejection fraction for prognosis after myocardial infarction. Circulation 2003;107:2786-2792.

15. Van 't Hof AWJ, ten Berg JM, Heestermans T, Dill T, Funck RC, van Werkum W, Dambrink JHE, Suryapranata H, van Houwelingen G, Ottervanger JP, Stella P, Giannitsis E, Hamm C. Prehospital initiation of tirofiban in patients with ST-elevation myocardial infarction undergoing primary angioplasty (On-Time 2): a multicentre, double-blind, randomised controlled trial. Lancet 2008;372:537-546.

16. Van 't Hof AWJ, Hamm C, Rasoul S, Guptha S, Paolini JF, ten Berg JM, on behalf of the OnTIME 2 investigators. Ongoing tirofiban in myocardial infarction evaluation (On-TIME) 2 trial: rationale and study design. EuroInterv 2007;3:371-380.

17. Rubin DB. Multiple Imputation for Nonresponse in Surveys. J. Wiley \& Sons, New York, 1987.

18. The Task Force on the management of ST-segment elevation myocardial infarction of the European Society of Cardiology (ESC). ESC guidelines for the management of acute myocardial infarction in patients presenting with ST-segment elevation. www.escardio.org/guidelines.

19. Grabowski M, Filipiak KJ, Karpinski G, Wretowski D, Rdzanek Z, Horszczaruk GJ, Kochman J, Rudowski R, Opolski G. Serum B-type natriuretic peptide levels on admission predict not only short-term death but also angiographic success of procedure in patients with acute STelevation myocardial infarction treated with primary PCI. Am Heart J 2004;148:655-662.

20. Hong SN, Ahn Y, Hwang SH, Yoon NS, Lee SR, Moon JY, Kim KH, Hong YJ, Park HW, Kim $\mathrm{JH}$, Jeong MH, Cho JG, Park JC, Kang JC. Usefulness of preprocedural N-terminal pro-brain natriuretic peptide in predicting angiographic no-reflow phenomenon during stent implantation in patients with ST-segment elevation acute myocardial infarction. Am J Cardiol 2007;100:631634.

21. Kaul P, Newby LK, Fu Y, Mark DB, Califf RM, Topol EJ, Aylward P, Granger CB, Van de Werf F, Armstrong PW. International differences in evolution of early discharge. Lancet 2004;363:511-517.

22. Barchielli A, Marchionni N, Carraba N, Margheri M, Santoro GM, Olivotto I, Buiatti E. AMIFlorence Working Group. Early discharge after acute myocardial infarction in the current clinical practice. Community data from the AMI-Florence Registry, Italy. Int J Cardiol 2007; 114:57-63.

23. Heggunje PS, Harjai KJ, Stone GW, Mehta RH, Marsalese DL, Boura JA, O'Neill WW, Grines CL. Procedural success versus clinical risk status in determining discharge of patients after primary angioplasty for acute myocardial infarction. J Am Coll Cardiol 2004;44:1400-1407.

24. Svilaas T, Vlaar PJ, van der Horst IC, Diercks GF, de Smet BJ, van den Heuvel AF, Anthonio RL, Jessurun GA, Tan ES, Suurmeijer AJ, Zijlstra F. Thrombus aspiration during primary percutaneous coronary intervention. N Engl J Med 2008;358:557-567.

25. Mehran R, Lansky AJ, Witzenbichler B, Guagliumi G, Peruga JZ, Brodie BR, Dudek D, Kornowski R, Hartmann F, Gersh BJ, Pocock SJ, Wong SC, Nikolsky E, Gambone L, Vandertie L, Parise H, Dangas GD, Stone GW. Bivalirudin in patients undergoing primary angioplasty for acute myocardial infarction (HORIZONS-AMI): 1-year results of a randomised controlled trial. Lancet 2009;374:1149-1159. 


\title{
CHAPTER 5
}

\section{NT-proBNP during and after primary PCI for improved scheduling of early hospital discharge}

\author{
D.A.A.M. Schellings, A.W.J van 't Hof \\ J.M. ten Berg, A. Elvan \\ E. Giannitsis, C. Hamm \\ H. Suryapranata, A. Adiyaman
}

Netherlands Heart Journal

2016;Dec 9 [Epub ahead of print] 

ABSTRACT

Background. The Zwolle Risk Score (ZRS) identifies primary percutaneous coronary intervention (PPCI) patients at low mortality risk, eligible for early discharge. Recently, this score was improved by adding baseline N-terminal pro-brain natriuretic peptide (NT-proBNP). However, the optimal timepoint for NT-proBNP measurement is unknown.

Methods. PPCI patients in the On-TIME 2 study were candidates. The ZRS and NTproBNP levels on admission, at 18-24 h, at 72-96 h, and the change in NT-proBNP from baseline to $18-24 \mathrm{~h}$ (delta NT-proBNP) were determined.

We investigated whether addition of the different NT-proBNP measurements to the ZRS improves the prediction of 30-day mortality. Based on cut-off values reflecting zero mortality at 30 days, patients who potentially could be discharged early were identified and occurrence of MACEs and major bleeding until 10 days was registered.

Results. 845 patients were included. On multivariate analyses, NT-proBNP at baseline (HR 2.09, 95\%CI 1.59-2.74, P<0.001), at 18-24 h (HR 6.83, 95\%CI 2.94-15.84), and at $72-96 \mathrm{~h}$ (HR 3.32, 95\% CI 1.22-9.06) independently predicted death at 30 days. Addition of NT-proBNP to the ZRS improved prediction of mortality, particularly at $18-24 \mathrm{~h}$ (net reclassification index $29 \% \mathrm{P}<0.0001$, integrated discrimination improvement $17 \% \mathrm{p}<0.0001)$. Based on ZRS $(<2)$ or NT-proBNP at $18-24 \mathrm{~h}(<2500$ $\mathrm{pg} / \mathrm{ml}) 75 \%$ of patients could be targeted for early discharge at $48 \mathrm{~h}$, with expected readmission rates of $1.2 \%$ due to MACEs and/or major bleeding.

Conclusions. NT-proBNP at different timepoints improves prognostication of the ZRS. Particularly at $18-24 \mathrm{~h}$ post PPCI, the largest group of patients that potentially could be discharged early was identified.

\section{INTRODUCTION}

Primary percutaneous coronary intervention (PPCI) substantially improved outcome in patients with ST-elevation myocardial infarction (STEMI), which has been paralleled by a decrease in hospital length of stay. ${ }^{1-3}$ In addition several studies have demonstrated that most low-risk PPCI patients are eligible candidates for early discharge. $^{4-11}$

The Zwolle Risk Score (ZRS) is a simple tool designed to identify PPCI patients who can be safely discharged within $72 \mathrm{~h}$, based on their 30-day mortality risk. ${ }^{11}$ In patients with a score $\leq 3$ (low risk) the mortality rate was $0.1 \%$ at 2 days and $0.2 \%$ between 2 and 10 days and early discharge between $48-72 \mathrm{~h}$ could be applied in slightly more 
than $60 \%$ of patients (Figure 1) Recently we demonstrated that the predictive accuracy of the ZRS was improved by adding baseline NT-proBNP. ${ }^{12}$ In this report we studied the value of NT-proBNP measurement at different timepoints over and beyond the ZRS.

\section{METHODS}

\section{Patients}

Our study population consists of patients with the diagnosis of STEMI admitted for PPCI, who were included in the Ongoing Tirofiban in Myocardial Infarction Evaluation (On-TIME) 2 trial. $^{13}$ The rationale, design and primary results of this multicenter placebo controlled, randomized clinical trial have been previously described. ${ }^{13,14}$

\begin{tabular}{|c|c|c|c|c|c|}
\hline \multirow{2}{*}{$\begin{array}{l}\text { Killip class } \\
1\end{array}$} & \multirow{2}{*}{$\begin{array}{l}\text { Points } \\
0\end{array}$} & \multirow{2}{*}{$\begin{array}{l}\text { Risk Score } \\
0-1\end{array}$} & \multicolumn{3}{|c|}{ RR $[95 \% \mathrm{Cl}]$ of death by $30-\mathrm{D}$} \\
\hline & & & 0.03 & [ 0.008 & - 0.13 ] \\
\hline 2 & 4 & 2 & 0.09 & {$[0.002$} & - 0.37 ] \\
\hline $3-4$ & 9 & 3 & 1.04 & {$\left[\begin{array}{ll}0.44 \\
\end{array}\right.$} & $-2.45]$ \\
\hline TIMI flow post & & 4 & 1.40 & {$\left[\begin{array}{ll}0.5 \\
0\end{array}\right.$} & - 3.89$]$ \\
\hline 3 & 0 & 5 & 2.48 & [ 0.96 & - 6.42 ] \\
\hline 2 & 1 & 6 & 2.52 & {$\left[\begin{array}{ll}0.75 \\
\end{array}\right.$} & - 8.46 ] \\
\hline $0-1$ & 2 & 7 & 5.99 & [ 1.98 & - 18.1$]$ \\
\hline Age & & $\geq 8$ & 32.1 & {$[18.6$} & $-55.8]$ \\
\hline$<60$ & 0 & & & & \\
\hline$\geq 60$ & 2 & & & & \\
\hline \multicolumn{6}{|l|}{ 3-vessel disease } \\
\hline No & 0 & & & & \\
\hline Yes & 1 & & & & \\
\hline \multicolumn{6}{|c|}{ Anterior infarction } \\
\hline No & 0 & & & & \\
\hline Yes & 1 & & & & \\
\hline \multicolumn{6}{|c|}{ Ischemia time ( $>4$ hours) } \\
\hline No & 0 & & & & \\
\hline Yes & 1 & & & & \\
\hline TOTAL SCORE & 16 & & & & \\
\hline
\end{tabular}

Figure 1. Zwolle Risk Score (left panel) and the relative risk (RR) of 30-day mortality for each score (right panel). CI indicates confidence interval; STEMI, ST-elevation myocardial infarction; TIMI, Thrombolysis in Myocardial Infarction. 
Briefly, enrollment was from June 2006 to November 2007. Eligible patients were aged 21 to 85 years with symptoms of acute myocardial infarction of more than 30 minutes but less than 24 hours and ST-segment elevation of more than $1 \mathrm{mV}$ in two adjacent electro-cardiograph (ECG) leads.

Exclusion criteria were severe renal dysfunction (glomerular filtration rate $[\mathrm{GFR}]<30$ $\mathrm{ml} / \mathrm{min}$ or serum creatinine $>200 \mathrm{mmol} / \mathrm{l}(>2.5 \mathrm{mg} / \mathrm{dl})$, therapy-resistant cardiogenic shock (systolic blood pressure $\leq 80 \mathrm{mmHg}$ for $>30 \mathrm{~min}$ ), persistent severe hypertension (systolic blood pressure $>180 \mathrm{mmHg}$ or diastolic blood pressure $>110 \mathrm{mmHg}$ ), or a contraindication to anticoagulation, or increased risk of bleeding. Also, patients with left bundle branch block, pregnant and/or breastfeeding women, and patients with a life expectancy of less than 1 year were excluded. Written informed consent for participation in both the On-TIME 2 study and future data analysis was obtained from each patient. All local ethics committees involved approved the study protocol.

\section{PROCEDURES}

\section{Treatment}

All patients were planned to undergo PPCI and were initially treated according to the study protocol, randomly assigned to (pre-hospital) treatment with tirofiban $(25 \mu \mathrm{g} / \mathrm{kg}$ bolus and $0.15 \mu \mathrm{g} / \mathrm{kg} / \mathrm{min}$ maintenance infusion for $18 \mathrm{~h}$ ) or placebo. PPCI was performed with standard techniques if the coronary anatomy was suitable for angioplasty. All patients were treated with optimal drug therapy. Final discharge and duration of admission was to the discretion of the treating cardiologist, irrespective of NT-proBNP values or ZRS.

\section{Measurements}

NT-proBNP plasma levels were measured in each patient on admission (after sheath insertion), at $18-24 \mathrm{~h}$ and at $72-96 \mathrm{~h}$ after PPCI.

NT-proBNP plasma levels were measured by an electrochemiluminiscence immunoassay 'ECLIA' on an Elecsys 2010 analyser (Roche, Central Hematology Laboratory, University of Heidelberg, Germany). The ZRS was calculated afterwards in each patient.

\section{Endpoints}

Endpoints were chosen by the ability to preclude early and safe discharge. We took two periods of time: at $48 \mathrm{~h}$ (after 2 days) and at $96 \mathrm{~h}$ after PPCI (after 3 days as recommended in present guidelines). ${ }^{1,2}$ 
The primary endpoint was death from any cause at 30 days after withdrawal of blood from which the NT-proBNP level was determined. Secondary endpoints were non-fatal major adverse cardiac events (MACEs) and major bleeding until 10 days after admission. MACEs were defined as recurrent myocardial infarction (RMI), urgent target vessel revascularization and malignant cardiac arrhythmias occurring later than $24 \mathrm{~h}$ after PPCI, defined as ventricular fibrillation (VF) or sustained and non-sustained ventricular tachycardia (VT). Major bleeding was defined as either intracranial bleeding or overt bleeding with a decrease in hemoglobin $\geq 5 \mathrm{~g} / \mathrm{dl}(\geq 3.1 \mathrm{mmol} / \mathrm{l})$ or a decrease in hematocrit $>15 \%$.

\section{Statistical analysis}

Patients were categorized by percentiles of NT-proBNP levels. We assessed the predictive value of the ZRS, serial NT-proBNP levels and the absolute change of NTproBNP levels from baseline to $18-24 \mathrm{~h}$ (delta NT-proBNP) for the primary endpoint. We computed and plotted receiver operating characteristic (ROC) curves. A total of 74 patients had missing values of ZRS and 36 patients did not have baseline NT-proBNP levels. Three patients had missing values of both ZRS and baseline NT-proBNP. A multiple missing value imputation procedure was applied in which the values of the NT-proBNP levels and the values of the elements of the ZRS were imputed in case they were missing.

We generated 10 datasets and the results of all statistical analyses were pooled across the 10 datasets. Multivariate Cox's regression analysis was used to estimate the influence of NT-proBNP and ZRS on 30-day mortality. We adjusted for randomization, gender, age, renal function (estimated GFR in $\mathrm{ml} / \mathrm{min}$ ), and body mass index (BMI) in a backward Cox regression with a P value of 0.05 for entry or exit of the variables in the model.

We computed the Net Reclassification Index (NRI) and the Integrated Discrimination Improvement (IDI) to evaluate models with an extra predictor relative to a model with the ZRS alone. ${ }^{15}$ The IDI combines the increase in mortality probability for those experiencing an event plus the decrease in mortality probability for those not experiencing an event. The NRI quantifies the net proportion of subjects getting correctly reclassified to low or high mortality probabilities when adding a predictor to the model using a cut-off point of $30 \%$.

To analyse models using a linear combination of ZRS and NT-proBNP, we calculated weighted scores for each as follows:

$$
(\beta 1 \times \mathrm{ZRS})+(\beta 2 \times \ln \mathrm{NT}-\text { proBNP}),
$$

where $\beta 1$ and $\beta 2$ denote $\beta$-coefficients for the ZRS and log NT-proBNP obtained from the multivariate Cox's regression model. We used ROC-curves to define optimal cut- 
off values in estimating mortality outcomes. We calculated the pooled areas under the curve (AUC) and 95\% confidence intervals by averaging over the 10 AUCs from the imputed datasets using Rubin's rule. ${ }^{16}$ The cut-off values and scores for defining possible early discharge were obtained from the mean scores across the 10 datasets, which gave the highest specificity in combination with a $100 \%$ sensitivity for the primary endpoint (e.g., zero mortality 30 days after PPCI). A two-sided P value of $\leq 0.05$ was considered to be statistically significant. The analyses were performed in SPSS version 22 and SAS version 9.3.

Table 1. Baseline characteristics of the study group

\begin{tabular}{lcc}
\hline \hline Variable & Total $(\mathrm{N}=845)$ & $\%$ \\
\hline Age (years) mean \pm SD & $62.0 \pm 11.5$ & - \\
Male gender & 642 & $(76.0)$ \\
Current smoking & 409 & $(48.4)$ \\
Diabetes mellitus & 90 & $(10.7)$ \\
Hypertension & 282 & $(33.4)$ \\
Hypercholesterolemia & 222 & $(26.3)$ \\
Family history & 340 & $(40.2)$ \\
Prior Angina & 104 & $(12.4)$ \\
Previous MI & 69 & $(8.2)$ \\
Previous PTCA & 70 & $(8.3)$ \\
Previous CABG & 12 & $(1.4)$ \\
Previous CVA & 15 & - \\
Systolic blood pressure mean \pm SD & $130.70 \pm 24.21$ & - \\
Diastolic blood pressure mean \pm SD & $76.57 \pm 15.03$ & $(4.9)$ \\
Killip Class $>1$ & 41 & - \\
Hemoglobin (mmol/l) mean \pm SD & $9.49 \pm 7.16$ & - \\
Troponin $(\mu \mathrm{g} / 1)$ mean \pm SD & $0.37 \pm 1.24$ & - \\
Zwolle Risk Score mean \pm SD & $2.34 \pm 2.13$ & - \\
Hospital stay (days) \pm SD & $4.89 \pm 5.64$ & $(6.2)$ \\
EF $<30 \%$ & 41 & $(19.8)$ \\
EF 30-40\% & 130 & $(74.0)$ \\
EF $>40 \%$ & 486 & \\
\hline \hline
\end{tabular}

All values were denoted as mean \pm standard deviation (SD) or absolute numbers and their percentages of the total group, where appropriate. MI indicates myocardial infarction; PTCA, percutaneous transluminal coronary angioplasty; $\mathrm{CABG}$, coronary artery bypass grafting; CVA, cerebrovascular accident; EF, ejection fraction. 


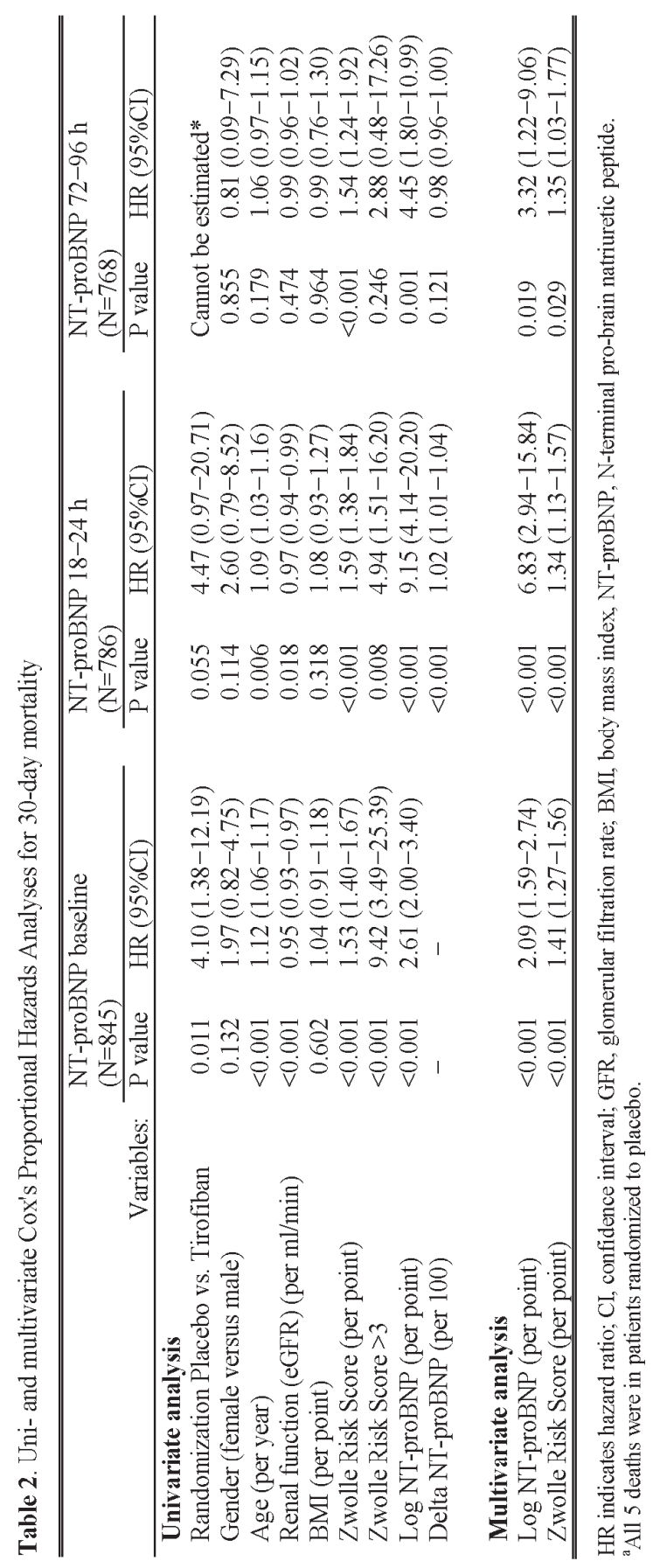




\section{RESULTS}

A total of 861 patients underwent PPCI. Complete follow-up was present in 845 patients. Baseline characteristics are shown in Table 1. The mean age was 62 years and $76 \%$ were male. Most patients had low Killip Class with post PPCI ejection fraction $>40 \%$. Mean hospital stay was 4.89 days.

Baseline NT-proBNP values ranged from 9 to $33,927 \mathrm{pg} / \mathrm{ml}$ (mean \pm SD of $599 \pm 1883$ $\mathrm{pg} / \mathrm{ml}$ ) with a median of $138 \mathrm{pg} / \mathrm{ml}$. At 18-24 h and 72-96 h, NT-proBNP was determined in 786 and 768 patients, respectively, and ranged from 45 to $20,653 \mathrm{pg} / \mathrm{ml}$ (mean $\pm \mathrm{SD}$ of $2089 \pm 2738 \mathrm{pg} / \mathrm{ml}$, median $1283 \mathrm{pg} / \mathrm{ml}$ ) and 17 to $24,119 \mathrm{pg} / \mathrm{ml}$ (mean $\pm \mathrm{SD}$ of $1618 \pm 2556 \mathrm{pg} / \mathrm{ml}$, median $860 \mathrm{pg} / \mathrm{ml}$ ), respectively.

The primary endpoint was reached in 21 patients. In uni- and multivariate analysis, ZRS and NT-proBNP measured at the different timepoints, but not delta NT-proBNP, were strongly associated with 30-day mortality (Table 2).

\section{Predictive value of ZRS and the NT-proBNP measurements on 30-day mortality}

The AUCs for ZRS and NT-proBNP at the different timepoints ranged from 0.74-0.87 and $0.87-0.94$, respectively. The AUC for delta NT-proBNP was relatively low: 0.74 (95\% CI 0.48-0.99). Adding NT-proBNP to the ZRS enlarged the AUCs at all timepoints with the largest area at 18-24 h. In addition, also the highest NRI was acquired by NT-proBNP at $18-24 \mathrm{~h}$. The integrated discrimination improved significantly after addition of NT-proBNP (Table 3).

\section{Cut-off values and potential early discharge}

Optimal cut-off values were defined (sensitivity 100\%). For NT-proBNP at 18-24 h and at $72-96 \mathrm{~h}$, these were $<2500 \mathrm{pg} / \mathrm{ml}$ and $<1050 \mathrm{pg} / \mathrm{ml}$, respectively. Interestingly, the cut-off value of the ZRS had to be $<2$. Based on the serial test combination, we created decision rules implying that low-risk patients, eligible for early discharge at 48 $\mathrm{h}$ after PPCI had to meet a ZRS $<2$ or NT-proBNP $<2500 \mathrm{pg} / \mathrm{ml}$, withdrawn at 18-24 h after PPCI (Group 1). Patients eligible for discharge at $96 \mathrm{~h}$ after PPCI had to meet a ZRS $<2$ or NT-proBNP $<1050 \mathrm{pg} / \mathrm{ml}$, withdrawn at $72-96 \mathrm{~h}$ after PPCI (Group 2).

In group 1, 639 patients met the low-risk criteria and 147 patients were at higher risk ( $75.6 \%$ and $17.3 \%$ of the total study population, respectively). 
Table 3. Prognostic accuracy of ZRS and NT-proBNP in predicting 30-day mortality at the different timepoints

\begin{tabular}{llllllll}
\hline \hline & AUC & $95 \%$ CI & $\begin{array}{l}\text { NRI } \\
(\%)\end{array}$ & $\begin{array}{l}\text { P } \\
\text { value }\end{array}$ & $\begin{array}{l}\text { IDI } \\
(\%)\end{array}$ & $\begin{array}{l}\text { P } \\
\text { value }\end{array}$ \\
\hline Baseline & ZRS & 0.87 & $0.79-0.95$ & - & - & - & - \\
& NT-proBNP & 0.91 & $0.86-0.96$ & - & - & - & - \\
& $\begin{array}{l}\text { ZRS + NT- } \\
\text { proBNP }\end{array}$ & 0.94 & $0.90-0.99$ & 9.82 & $<0.0001$ & 11.39 & $<0.0001$ \\
& & & & & & \\
$18-24 \mathrm{~h}$ & ZRS & 0.82 & $0.70-0.94$ & - & - & - & - \\
& NT-proBNP & 0.94 & $0.90-0.99$ & - & - & - & - \\
& ZRS + NT- & 0.94 & $0.88-0.99$ & 29.28 & $<0.0001$ & 17.10 & $<0.0001$ \\
& proBNP & & & & & & \\
$72-96 \mathrm{~h}$ & ZRS & 0.74 & $0.54-0.94$ & - & - & - & - \\
& $\begin{array}{l}\text { NT-proBNP } \\
\text { ZRS + NT- }\end{array}$ & 0.87 & $0.72-1.00$ & & & & \\
& proBNP & 0.87 & $0.71-1.00$ & 21.93 & 0.0046 & 7.46 & $<0.0001$ \\
\hline \hline
\end{tabular}

ZRS, Zwolle Risk Score; NT-proBNP, N-terminal pro-brain natriuretic peptide; AUC, area under the curve; $\mathrm{CI}$, confidence interval; NRI, net reclassification index; IDI , integrated discrimination improvement.

Up to $48 \mathrm{~h}$, MACEs occurred significantly more often in higher risk patients than in low-risk patients ( 7 vs. 2 patients, $\mathrm{P}<0.001$ ). Major bleeding occurred in 1 patient in both groups $(0.2 \%$ vs. $0.7 \%, \mathrm{P}=0.34)$. As a consequence, 637 patients would have been eligible for discharge at $48 \mathrm{~h}$ after PPCI. This accounts for $75 \%$ of the total study population. Between $48 \mathrm{~h}$ and 10 days after PPCI, 10 of these patients (1.2\%) experienced adverse events. MACEs occurred in 7 patients $(0.8 \%)$ and major bleeding occurred in 4 patients $(0.5 \%)$. In 1 patient both events occurred. Therefore, 10 readmissions (1.2\%) within 10 days after PPCI would have been expected (Figure 2). In Group 2, 500 low-risk patients (59\%) could be identified versus 268 patients (32\%) at higher risk, based on afore-mentioned criteria. MACEs within 10 days occurred significantly more often in the higher risk group than in the lower risk group (11/268 (4\%) vs. $4 / 500$ (0.8\%), $\mathrm{P}=0.003)$. Major bleeding occurred in 1 patient in the low-risk group $(0.1 \%)$ and in 5 patients in the higher risk group $(0.6 \%)$. Hence, readmission would have been necessary in 5 patients. Outcome of all screened patients is presented in the supplementary Figure 1. The different cut points and outcome are presented in the supplementary Table 1 and Appendix. 


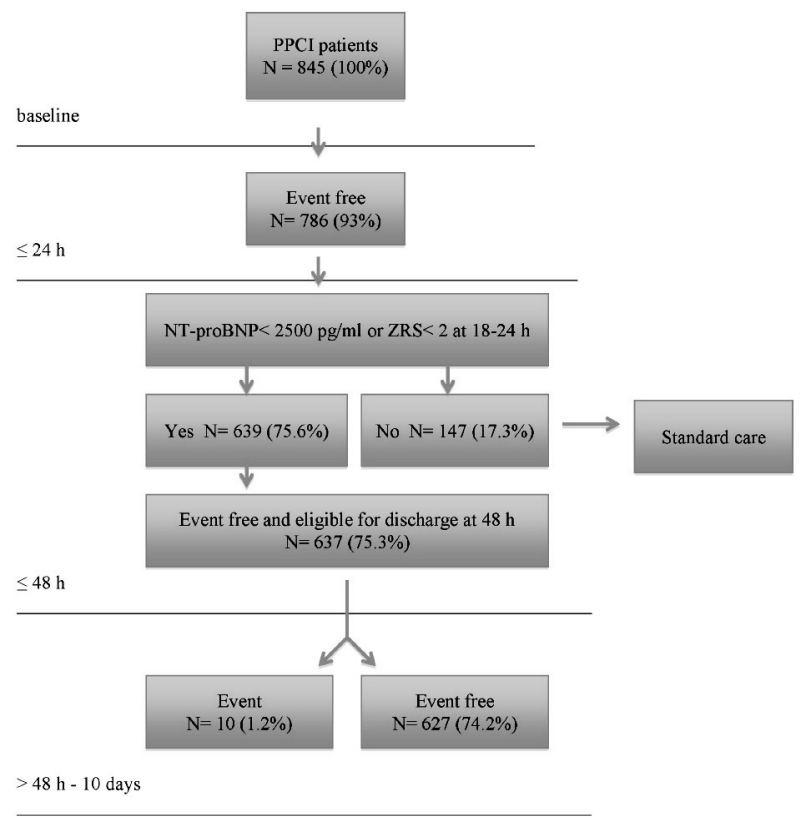

Figure 2. Feasibility of early discharge (after 2 days) in 845 PPCI patients based on ZRS $<2$ or NT-proBNP $<2500 \mathrm{pg} / \mathrm{ml}$ at $18-24 \mathrm{~h}$.

\section{DISCUSSION}

Our study demonstrates that NT-proBNP, withdrawn at different timepoints after PPCI, improves prognostication of the established ZRS and consequently may improve the scheduling of early hospital discharge.

Although the clinical outcomes in STEMI patients treated by PPCI have been improved considerably, optimizing hospital length of stay in these patients is still challenging.

Recent reports make clear that large patient groups can be discharged safely at or within $48 \mathrm{~h},{ }^{6,9,10}$ while present guidelines recommend discharge after a minimum of 3 days. ${ }^{1,2}$ In addition, a lot of international variation in hospital admission duration among low-risk PPCI patients still exists, ${ }^{3,17-19}$ assuming that the number of low-risk PPCI patients worldwide will increase because of improvement of treatment. Simultaneously, there is a need for reduction of healthcare costs. This highlights the necessity of easy tools for risk stratification, in which ideally large proportions of patients could be discharged early. 
For this purpose, De Luca et al. developed the ZRS. Important variables in this risk model are the success of coronary reperfusion and the occurrence of heart failure. These and other early adverse post PPCI events can also be predicted by NT-proBNP. ${ }^{20-22}$ Within this context, NT-proBNP can be considered to be an overlapping variable. The incremental value of adding NT-proBNP to established risk factors might be explained by the fact that biomarker measurement provides more accurate information, without observer variability.

The prognostic significance of the serial changes of plasma NT-proBNP in STEMI patients has previously been studied. ${ }^{23-25}$ It was shown that NT-proBNP increases markedly within $24 \mathrm{~h}$. At this timepoint a maximum value is reached after successful reperfusion and then usually decreases, while unsuccessful reperfusion is associated with increased NT-proBNP values at 48-96 h. ${ }^{23,25}$

Consequently, the change in NT-proBNP concentration could also be predictive. In one report, the difference between NT-proBNP at $72 \mathrm{~h}$ and baseline NT-proBNP, was superior to baseline NT-proBNP, but similar to NT-proBNP at $72 \mathrm{~h}$ in predicting shortterm adverse cardiac events. ${ }^{25}$ Interestingly, in our study the change in NT-proBNP was less predictive and cut-off values were difficult to define, since some patients had negative change in NT-proBNP (or higher values at baseline). However, measurement at two different timepoints is more laborious and would not be useful within the context of early discharge.

Based on our decision rule at $48 \mathrm{~h}$ after PPCI (ZRS $<2$ or NT-proBNP $<2500 \mathrm{pg} / \mathrm{ml}$ at $18-24 \mathrm{~h}$ ), a proportion as large as $75 \%$ of patients could be discharged early. Therefore NT-proBNP measurement at 18 to $24 \mathrm{~h}$ after PPCI may optimize length of hospital stay in low-risk patients. Furthermore, this risk strategy can also be applied to patients in non-intervention hospitals, since many patients are repatriated in the first $24 \mathrm{~h}$. This group in particular tends to be kept in hospital for a longer period of time. ${ }^{26}$

\section{Limitations}

Several limitations of our study have to be noted. Our study lacks a validation cohort to validate the serial model of ZRS en NT-proBNP. Therefore, a future randomized comparison of discharge policies should take place.

Although NT-proBNP was measured by protocol in every patient, the ZRS was calculated afterwards, so this may be considered retrospective. Although NT-proBNP has also been related to more cardiovascular risk factors than those used in the regression analysis, more potential confounders could not be included because of the number of events. Finally, the patient population was highly selective since all participants took part in a randomized trial with afore-mentioned exclusion criteria. 
Chapter 5

\section{CONCLUSION}

NT-proBNP at different timepoints improves prognostication of the ZRS. Particularly at 18-24 h post PPCI, the largest group of patients that potentially could be discharged early was identified. 


\section{APPENDIX}

$P$ values between specificities:

ZRS vs. NT-proBNP 18-24 h

ZRS vs. ZRS + NT-proBNP 18-24 h

NT-proBNP $18-24 \mathrm{~h}$ vs. ZRS+NT-proBNP 18-24 h

ZRS vs. NT-proBNP 72-96 h

ZRS vs. ZRS+NT-proBNP 72-96 h

NT-proBNP 72-96 h vs. ZRS+NT-proBNP 72-96 h
$\mathrm{P}<0.001$

$\mathrm{P}<0.001$

$\mathrm{P}<0.001$

$\mathrm{P}<0.001$

$\mathrm{P}<0.001$

$\mathrm{P}<0.001$

Supplementary Table 1. Predictive accuracy of ZRS $<2$ and NT-proBNP with cut-off values at different timepoints for the identification of PPCI patients eligible for early discharge, from best to worse (highest specificity, 100\% sensitivity)

\begin{tabular}{|c|c|c|c|c|}
\hline & AUC & $\begin{array}{l}\text { Specificity } \\
(95 \% \mathrm{CI})\end{array}$ & $\begin{array}{l}\% \text { patients } \\
\text { eligible for } \\
\text { early } \\
\text { discharge }\end{array}$ & $\begin{array}{l}\text { MACE and bleeding at } \\
10 \text { days among patients } \\
\text { eligible for early } \\
\text { discharge } \mathrm{N}(\%)\end{array}$ \\
\hline $\begin{array}{l}\text { ZRS }<2 / \text { NT-proBNP } \\
18-24 \mathrm{~h}<2500 \mathrm{pg} / \mathrm{ml}\end{array}$ & 0.94 & $0.82(0.80-0.85)$ & 75 & $10(1.6)$ \\
\hline $\begin{array}{l}\text { NT-proBNP } \\
18-24 \mathrm{~h}<2500 \mathrm{pg} / \mathrm{ml}\end{array}$ & 0.94 & $0.79(0.76-0.82)$ & 72 & $10(1.6)$ \\
\hline $\begin{array}{l}\text { ZRS }<2 / \text { NT-proBNP } \\
\text { baseline }<200 \mathrm{pg} / \mathrm{ml}\end{array}$ & 0.94 & $0.70(0.67-0.73)$ & 64 & $9(1.7)$ \\
\hline $\begin{array}{l}\text { NT-proBNP baseline } \\
<200 \mathrm{pg} / \mathrm{ml}\end{array}$ & 0.91 & $0.62(0.58-0.65)$ & 56 & $7(1.5)$ \\
\hline $\begin{array}{l}\mathrm{ZRS}<2 \text { /NT-proBNP } \\
72-96 \mathrm{~h}<1050 \mathrm{pg} / \mathrm{ml}\end{array}$ & 0.87 & $0.67(0.64-0.71)$ & 61 & $5(1.0)$ \\
\hline $\begin{array}{l}\text { NT-proBNP } \\
72-96 \mathrm{~h}<1050 \mathrm{pg} / \mathrm{ml}\end{array}$ & 0.87 & $0.56(0.52-0.59)$ & 50 & $4(0.9)$ \\
\hline ZRS $<2$ & 0.87 & $0.39(0.35-0.42)$ & 36 & $4(1.3)$ \\
\hline
\end{tabular}

ZRS, Zwolle Risk Score; NT-proBNP, N-terminal pro-brain natriuretic peptide. 


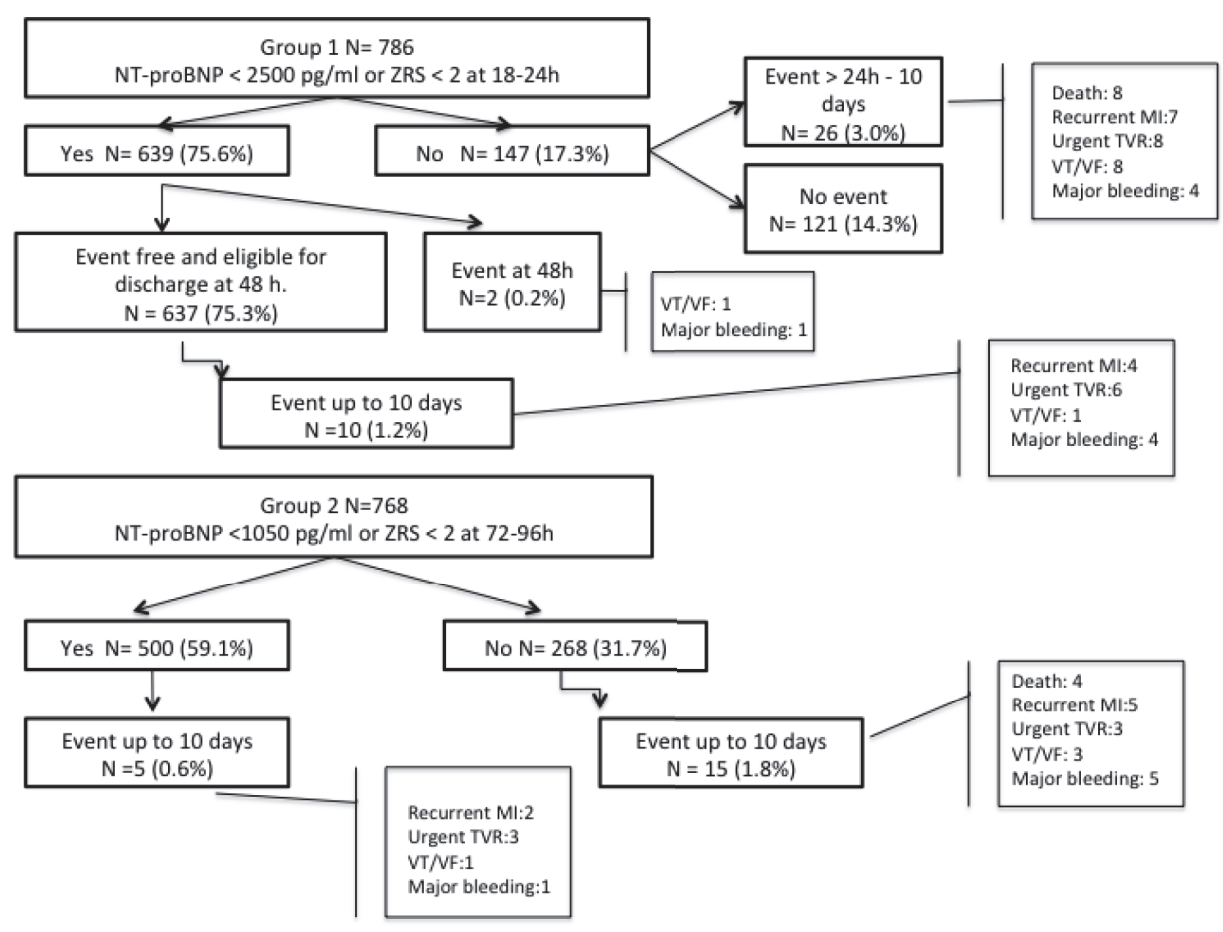

Supplementary Figure 1. Outcome of all patients screened by the decision rules. Percentages (\%) are given with reference to the study population $(\mathrm{N}=845)$. Multiple events could occur in one patient. 


\section{REFERENCES}

1. The Task Force on the management of ST-segment elevation myocardial infarction of the European Society of Cardiology (ESC). Steg PG, James SK, Atar D, et al. ESC guidelines for the management of acute myocardial infarction in patients presenting with ST-segment elevation. Available at: www.escardio.org/guidelines. Eur Heart J 2012;33:2569-619.

2. O'Gara PT, Kushner FG, Ascheim DD, et al. American College of Cardiology Foundation/American Heart Association Task Force on Practice Guidelines. 2013 ACCF/AHA Guideline for the management of ST-elevation myocardial infarction: a report of the American College of Cardiology Foundation/ American Heart Association Task Force on Practice Guidelines. Circulation 2013; 127:e362-e425.

3. Chin CT, Weintraub WS, Dai D, et al. Trends and predictors of length of stay after primary percutaneous coronary intervention: a report from the CathPCI registry. Am Heart $\mathrm{J}$ 2011;162:1052-1061.

4. Grines CL, Marsalese DL, Brodie B, et al. Safety and cost-effectiveness of early discharge after primary angioplasty in low risk patients with acute myocardial infarction. PAMI-II investigators. Primary angioplasty in myocardial infarction. J Am Coll Cardiol 1998;5:967-972.

5. Branca G, Capodanno D, Capranzano P, et al. Early discharge in acute myocardial infarction after clinical and angiographic risk assessment. J Cardiovasc Med (Hagerstown) 2008;9:858-861.

6. Jirmar R, Widimsky P, Capek J, Hlinomaz O, Groch L. Next day discharge after successful primary angioplasty for acute ST elevation myocardial infarction. An open randomized study 'Prague-5'. Int Heart J 2008;49:653-659.

7. Kotowycz MA, Cosman TL, Tartaglia C, et al. Safety and feasibility of early hospital discharge in ST-segment elevation myocardial infarction- A prospective and randomized trial in low risk primary percutaneous coronary intervention patients (The Safe-Depart Trial). Am Heart J 2010;159:117.e1-e6.

8. Laarman GJ, Dirksen MT. Early discharge after primary percutaneous coronary intervention. Heart 2010; 96:584-587.

9. Jones DA, Rathod KS, Howard JP, et al. Safety and feasibility of hospital discharge 2 days following primary percutaneous intervention for ST-segment elevation myocardial infarction. Heart 2012; 98:1722-1727.

10. Noman A, Zaman AG, Schechter C, Balasubramaniam K, Das R. Early discharge after primary percutaneous coronary intervention for ST-elevation myocardial infarction. Eur Heart J Acute Cardiovasc Care 2013;2:262-269.

11. De Luca G, Suryapranata H, van 't Hof AWJ, et al. Prognostic assessment of patients with acute myocardial infarction treated with primary angioplasty: implications for early discharge. Circulation 2004;109;2737-2743.

12. Schellings DAAM, Adiyaman A, Giannitsis E, et al. Early discharge after primary percutaneous coronary intervention: the added value of NT-proBNP to the Zwolle Risk Score. J Am Heart Assoc 2014;3:e01089

13. Van 't Hof AWJ, ten Berg JM, Heestermans T, et al. Ongoing tirofiban in myocardial infarction evaluation (On-Time) 2 study group. Prehospital initiation of tirofiban in patients with STelevation myocardial infarction undergoing primary angioplasty (On-TIME 2): a multicentre, double blind, randomised controlled trial. Lancet 2008;16;372:537-546.

14. Van 't Hof AWJ, Hamm C, Rasoul S, et al. on behalf of the On-TIME 2 investigators. Ongoing tirofiban in myocardial infarction evaluation (On-TIME) 2 trial: rationale and study design. Eurointerv 2007;3:371-380.

15. Pencina MJ, D'Agostino RB Sr, D'Agostino RB Jr. Evaluating the added predictive ability of a new marker: From area under the ROC curve to reclassification and beyond. Stat Med $2008 ; 27: 157-172$ 
16. Rubin DB. Multiple Imputation for Nonresponse in Surveys. J. Wiley \& Sons, New York, 1987.

17. Kaul P, Newby LK, Fu Y, et al. International differences in evolution of early discharge after acute myocardial infarction. Lancet 2004;363:511-517.

18. Barchielli A, Balzi D, Marchionni N, et al. AMI-Florence Working Group. Early discharge after acute myocardial infarction in the current clinical practice. Community data from the AMIFlorence Registry, Italy. Int J Cardiol 2007;114:57-63.

19. Claeys MJ, Sinnaeve PR, Convens C, et al. Inter-hospital variation in length of hospital stay after ST-elevation myocardial infarction: results from the Belgian STEMI registry. Acta Cardiol 2013; 68:235-239.

20. Jarai R, Huber $\mathrm{K}$, Bogaerts $\mathrm{K}$, et al. ASSENT-IV-PCI investigators. Plasma N-terminal fragment of the prohormone B-type natriuretic peptide concentrations in relation to time to treatment and thrombolysis in myocardial infarction (TIMI) flow: a substudy of the assessment of the safety and efficacy of a new treatment strategy with percutaneous coronary intervention (ASSENT IV-PCI) trial. Am Heart J 2010;159:131-140.

21. Blom JR, van 't Hof AWJ, Henriques JPS, et al. NT-proBNP: a marker for successful myocardial reperfusion in AMI patients treated with primary percutaneous coronary intervention. Eur J Heart Fail 2004;6:749-752.

22. Kwon TG, Bae JH, Jeong MH, et al. Korea Acute Myocardial Infarction Registry Investigators. $\mathrm{N}$-terminal pro-B-type natriuretic peptide is associated with adverse short-term clinical outcomes in patients with acute ST-elevation myocardial infarction who underwent primary percutaneous coronary intervention. Int J Cardiol 2009;133:173-178.

23. Buchner S, Debl K, Barlage S, et al. Dynamic changes in N-terminal pro-brain natriuretic peptide in acute coronary syndromes treated with percutaneous coronary intervention: a marker of ischemic burden, reperfusion and outcome. Clin Chem Lab Med 2010;48:875-881.

24. Ezekowitz JA, Théroux $\mathrm{P}$, Chang $\mathrm{W}$, et al. N-terminal pro-brain natriuretic peptide and the timing, extent and mortality in ST elevation myocardial infarction. Can J Cardiol 2006;22:393397.

25. Ezekowitz JA, Théroux P, Welsh R, et al. Insights into the change in brain natriuretic peptide after ST-elevation myocardial infarction (STEMI): why should it be better than baseline? Can J Physiol Pharmacol 2007;85:173-178.

26. Kotowycz MA, Syal RP, Afzal R, Natarajan MK. Can we improve length of hospitalization in ST elevation myocardial infarction patients treated with primary percutaneous coronary intervention? Can J Cardiol. 2009;25:585-588. 



\author{
CHAPTER 6
}

\title{
Value of serial NT-proBNP measurement in predicting non-fatal adverse events after primary PCI
}

\author{
D.A.A.M. Schellings, A.W.J. van 't Hof \\ J.M. ten Berg, A. Elvan \\ E. Giannitsis, C. Hamm \\ H. Suryapranata, A. Adiyaman
}



ABSTRACT

Aims. NT-proBNP predicts mortality in myocardial infarction patients treated with primary PCI. However, its predictive value for non-fatal adverse events is less well known. In this study we evaluated the predictive value of serial NT-proBNP measurements for the early occurrence of acute cardiovascular comorbidities in patients treated with PPCI, over and beyond the Zwolle Risk Score (ZRS).

Methods. PPCI patients included in the On-TIME 2 study were candidates. NTproBNP levels on admission, at $18-24 \mathrm{~h}$, and at $7296 \mathrm{~h}$ were measured, as was the change in NT-proBNP from baseline to $18-24 \mathrm{~h}$. Also, in each patient the ZRS was calculated. We compared the predictive value of serial NT-proBNP and ZRS for the occurrence of non-fatal adverse events at 30-day follow-up, defined as recurrent myocardial infarction, urgent target vessel revascularization, major bleeding and ventricular arrhythmias.

Results. On admission, at 18-24 h and at 72-96 h, 845, 786 and 768 patients were included, respectively. At multivariate analysis ZRS and NT-proBNP measured at 18-24 $\mathrm{h}$ and at 72-96 $\mathrm{h}$ independently predicted the composite of non-fatal events (odds ratios 1.10 to $1.14, \mathrm{P}$ values all $<0.05$ ). Although ZRS and serial NT-proBNP independently demonstrated limited predictive accuracy (AUCs all $\leq 0.70$ ), adding NTproBNP to the ZRS at $18-24 \mathrm{~h}$ could modestly improve prognostication (AUC 0.73 , 95\% CI 0.62-0.78, net reclassification improvement 19\%).

Conclusion. Non-baseline NT-proBNP measurement independently predicts the occurrence of non-fatal adverse events at 30-day follow-up after PPCI. In particular, at 18-24 h, NT-proBNP could provide more insight in identifying patients at risk for severe comorbidities.

\section{INTRODUCTION}

Despite a good outcome in most ST-elevation myocardial infarction (STEMI) patients treated with primary percutaneous coronary intervention (PPCI), good risk stratification is mandatory to optimize patient treatment and discharge policy. ${ }^{1,2}$

In recent years, several PPCI risk models have been proposed and validated, particularly to predict short-term mortality. ${ }^{3-5}$ Beside these established risk models, NT-proBNP has become an emerging biomarker that can also predict mortality after PPCI. ${ }^{6,7}$.

In previous studies we demonstrated that NT-proBNP has excellent predictive value for 30-day mortality, over and beyond the Zwolle Risk Score (ZRS). Additionally, 
combining NT-proBNP and ZRS resulted in the identification of the largest group of patients who were at very low mortality risk and who also appeared to have a low occurrence of non-fatal adverse events (AEs). ${ }^{8,9}$

However, whether NT-proBNP and ZRS could also predict non-fatal AEs in PPCI patients remained underexposed. In this study we evaluated the predictive value of NTproBNP measurement at different time points for the occurrence of non-fatal AEs at 30-day follow-up over and beyond established periprocedural risk factors as presented by the ZRS.

\section{METHODS}

\section{Patients}

Our study population consisted of patients with a diagnosis of STEMI admitted for PPCI, who were included in the Ongoing Tirofiban in Myocardial Infarction Evaluation (On-TIME) 2 trial. ${ }^{10}$ The rationale, design and primary results of the prospective, multicenter placebo-controlled, randomized On-TIME 2 clinical trial have been described previously. ${ }^{10,11}$ The trial is registered under No. ISRCTN06195297.

Briefly, enrollment was from June 2006 to November, 2007. Eligible patients were 21 to 85 years of age with symptoms of acute myocardial infarction of more than $30 \mathrm{~min}$ but less than $24 \mathrm{~h}$ and ST-segment elevation of more than $1 \mathrm{mV}$ in two adjacent electrocardiograph (ECG) leads.

Exclusion criteria were severe renal dysfunction (glomerular filtration rate $[\mathrm{GFR}]<30$ $\mathrm{ml} / \mathrm{min}$ or serum creatinine $>200 \mathrm{mmol} / 1(>2.5 \mathrm{mg} / \mathrm{dl})$, therapy-resistant cardiogenic shock (systolic blood pressure $\leq 80 \mathrm{mmHg}$ for $>30 \mathrm{~min}$ ), persistent severe hypertension (systolic blood pressure $>180 \mathrm{mmHg}$ or diastolic blood pressure $>110 \mathrm{mmHg}$ ), or a contraindication to anticoagulation, or increased risk of bleeding. Also, patients with a left bundle-branch block, pregnancy and/or breastfeeding, and patients with a life expectancy of less than 1 year were excluded. From each patient, written informed consent for participation in both the On-TIME 2 study and future data analysis was obtained. The study was conducted according to the guidelines of the Declaration of Helsinki. All local ethics committees involved approved the study protocol. 


\section{PROCEDURES}

\section{Treatment}

All patients were planned to undergo PPCI and were initially treated according to the On-TIME 2 study protocol, randomly assigned to (pre-hospital) treatment with tirofiban $(25 \mu \mathrm{g} / \mathrm{kg}$ bolus and $0.15 \mu \mathrm{g} / \mathrm{kg} / \mathrm{min}$ maintenance infusion for $18 \mathrm{~h})$ or placebo. PPCI was performed with standard techniques if the coronary anatomy was suitable for angioplasty. Additional treatment with stents and devices was to the discretion of the treating cardiologist. All patients were treated with optimal drugtherapy, including angiotensin-converting enzyme inhibitors, $\beta$-blockers, aspirin and a statin.

\section{Measurements}

NT-proBNP plasma levels were measured by an electrochemiluminiscence immunoassay 'ECLIA' on an Elecsys 2010 analyser (Roche, Central Hematology Laboratory, University of Heidelberg, Germany) in each patient on admission (after sheath insertion before PPCI was performed), at $18-24 \mathrm{~h}$ and at $72-96 \mathrm{~h}$ after PPCI. In each patient the Zwolle Risk Score (ZRS) was calculated. This score, assessed by a point system, has shown to be able to identify a large group of patients at low risk who may safely be discharged early after PPCI. Patiens were considered to be low risk when the ZRS was $\leq 3$ (mortality rate of $0.1 \%$ at 2 days and $0.2 \%$ between 2 and 10 days after PPCI). The model was built of six clinical risk factors: Killip Class, postprocedural Thrombolysis in Myocardial Infarction (TIMI) flow, Age, three-vessel disease, anterior infarction location, ischemia time $>4 \mathrm{~h}$, with maximum score of 16 points. ${ }^{5}$ Additionally, left-ventricular ejection fraction (LVEF) was measured before discharge.

\section{Endpoints}

The primary endpoint in this study was the occurrence of non-fatal AEs at 30 days after withdrawal of blood from which the NT-proBNP level was determined. AEs were defined as recurrent myocardial infarction (RMI), urgent target vessel revascularization (TVR), major bleeding (defined as clinical overt signs of hemorrhage associated with a decrease in hemoglobin of $>5 \mathrm{~g} / \mathrm{dl}$, or when hemoglobin assessment is not available, a decrease in hematocrit of $>15 \%$ ) and malignant ventricular arrhythmias defined as ventricular fibrillation (VF) or sustained and non-sustained ventricular tachycardia (VT). 


\section{Statistical analysis}

In each patient the ZRS was calculated and patients were divided into percentiles of NT-proBNP levels. Four calculation groups were created according to the availability of ZRS and NT-proBNP at the different time points: at baseline (on admission), at 18-24 $\mathrm{h}$ and at 72-96 $\mathrm{h}$ after PPCI. Also, the absolute change from baseline to $18-24 \mathrm{~h}$ after PPCI (delta NT-proBNP) was measured.

We assessed the predictive value of the ZRS, the different NT-proBNP levels and the combination of NT-proBNP/ZRS for the primary endpoint by receiver operating characteristic (ROC) curve analysis in each patient group.

In 74 patients the ZRS values were missing, and 36 patients did not have baseline NTproBNP levels. Three patients had missing values of both ZRS and baseline NTproBNP. Assuming data were missing at random, a multiple missing value imputation procedure was applied in which the values of the NT-proBNP and the values of the elements of the ZRS were imputed in case they were missing (PROC MI; SAS version 9.2). The ZRS was calculated from the individually imputed scores.

We generated 10 datasets, and the results of all statistical analyses were pooled across the 10 datasets by using the corresponding pooling procedure in SPSS or SAS. Multivariate logistic regression analysis was used to estimate the influence of NTproBNP and ZRS on non-fatal AEs at 30-day follow-up. To perform an analysis using both ZRS and NT-proBNP, we calculated weighted scores for each as follows:

$$
(\beta 1 \times \mathrm{ZRS})+(\beta 2 \times \ln \mathrm{NT}-\text { proBNP})
$$

where $\beta 1$ and $\beta 2$ denote $\beta$-coefficients for the ZRS and log NT-proBNP obtained from the multivariate Cox's regression model. Because NT-proBNP was not normally distributed, we used logarithmically transformed values. We calculated the pooled AUCs and $95 \%$ confidence intervals (CIs) by averaging over the 10 AUCs from the imputed datasets, using Rubin's rule. ${ }^{12}$ Additionally, we used two complementary measures of discrimination improvement to evaluate the performance of the model when NT-proBNP was added to the ZRS: the Net Reclassification Improvement (or Index) (NRI) and the Integrated Discrimination Improvement (IDI). The IDI combines the increase in event probability for those experiencing an event plus the decrease in event probability for those not experiencing an event. The NRI quantifies the net proportion of subjects getting correctly reclassified to low or high event probabilities when adding a predictor to the model using a cut-off point for the predicted probabilities of $10 \%$.

All statistical analyses were performed using SPSS (version 19) and SAS (version 9.2). A two-sided $\mathrm{P}$ value of $\leq 0.05$ was considered to be statistically significant. 
Table 1. Baseline characteristics of the study group

\begin{tabular}{lcc}
\hline \hline Variable & Total & $\%$ \\
& $(\mathrm{~N}=845)$ & \\
\hline Age (yrs) mean \pm SD & $62.0 \pm 11.5$ & $(76.0)$ \\
Male gender & 642 & $(48.6)$ \\
Current smoking & 409 & $(10.7)$ \\
Diabetes mellitus & 90 & $(33.4)$ \\
Hypertension & 282 & $(26.3)$ \\
Hypercholesterolemia & 222 & $(40.6)$ \\
Family history & 340 & $(12.4)$ \\
Prior angina & 104 & $(8.2)$ \\
Previous MI & 69 & $(8.3)$ \\
Previous PTCA & 70 & $(1.4)$ \\
Previous CABG & 12 & $(1.8)$ \\
Previous CVA & 15 & - \\
Systolic blood pressure mean \pm SD & $130.70 \pm 24.21$ & - \\
Diastolic blood pressure mean \pm SD & $76.57 \pm 15.03$ & $(4.9)$ \\
Killip Class $>1$ & 41 & - \\
Hemoglobin (mmol/1) mean \pm SD & $9.49 \pm 7.16$ & - \\
Troponin ( $\mu$ g/l) mean \pm SD & $0.37 \pm 1.24$ & - \\
Zwolle Risk Score mean \pm SD & $2.34 \pm 2.13$ & $(6.2)$ \\
EF $<30 \%$ & 41 & $(19.8)$ \\
EF $30-40 \%$ & 130 & $(74.0)$ \\
EF $>40 \%$ & 486 & \\
\hline \hline
\end{tabular}

All values were denoted as mean \pm standard deviation (SD) or absolute numbers and their percentages of the total group, where appropriate.

MI, myocardial infarction; PTCA, percutaneous transluminal coronary angioplasty; CABG, coronary artery bypass grafting; CVA, cerebrovascular accident; EF, ejection fraction.

\section{RESULTS}

During the study period, 984 patients were admitted for STEMI; a total of 861 patients underwent PPCI. After imputation of missing values, 30-day follow-up was present in 845 patients. Table 1 shows the baseline and periprocedural characteristics. Mean age was $62 \pm 11.5$ years and the ZRS ranged from $0-15$ points (mean \pm SD of $2.34 \pm 2.13$ points). In addition, the median time from onset of ischemic symptoms to PPCI was 167 minutes (mean \pm SD of $238 \pm 252 \mathrm{~min}$ ) and the baseline NT-proBNP values ranged from $9-33,927 \mathrm{pg} / \mathrm{ml}($ mean $\pm \mathrm{SD}$ of $599 \pm 1833$, median $138 \mathrm{pg} / \mathrm{ml}$ ). Most patients 
(74\%) had LVEF $>40 \%$ at discharge. At 30-day follow-up, 21 patients had died. Mortality analyses have been reported previously ${ }^{8,9}$

\section{Uni- and multivariate analysis}

The endpoint was reached in 102, 48 and 31 patients where NT-proBNP was measured at baseline, at 18-24 h and at 72-96 h, respectively; with most events occurring within $48 \mathrm{~h}$ after admission. At uni- and multivariate analysis, ZRS and NT-proBNP at 18-24 $\mathrm{h}$ and $72-96 \mathrm{~h}$ (but not NT -proBNP at baseline and delta NT-proBNP) independently predicted the occurrence of non-fatal AEs (Table 2).

\section{ROC curve analysis of ZRS and NT-proBNP at the different timepoints}

Baseline NT-proBNP and ZRS were assessed in 845 patients and showed poor capacity to accurately predict non-fatal AEs: AUC $0.58(95 \% \mathrm{CI} 0.52-0.64)$ and $0.62(95 \% \mathrm{CI}$ 0.54-0.66), respectively. The combination of both baseline NT-proBNP and ZRS, showed no improvement compared to ZRS only (AUC 0.61 (95\%CI 0.55-0.67)).

At 18-24 h, NT-proBNP was measured in 786 patients and ranged from 45-20,653 (mean \pm SD $2089 \pm 2738$, median $1283 \mathrm{pg} / \mathrm{ml}$ ). At this time point, the predictive capacity of NT-proBNP slightly improved compared to baseline NT-proBNP: AUC 0.70 (95\%CI 0.57-0.74). The AUC for ZRS in this patient group was $0.68(0.60-0.76)$ However, addition of NT-proBNP at 18-24 h to the ZRS demonstrated the largest AUC: 0.73 (95\%CI $0.62-0.78$ ), although the difference compared to ZRS only was not significant $(\mathrm{P}=0.14)$. Additionally, NRI and IDI were $19 \%$ and $1.7 \%$, respectively, when NT-proBNP at 18-24 $\mathrm{h}$ was added to the ZRS (P values could not be calculated). NT-proBNP at 72-96 h was measured in 768 patients and ranged from 17-24,119 (mean \pm SD $1618 \pm 2556$, median $860 \mathrm{pg} / \mathrm{ml}$ ). The AUC for NT-proBNP at this time point was 0.66 (95\%CI $0.55-0.77)$ and did not differ compared to the AUC of ZRS (0.64). Addition of NT-proBNP to the ZRS showed no improvement in 30-day event prediction compared to ZRS only (AUC 0.69, $\mathrm{P}=0.28$ ). NRI and IDI were $9 \%$ and $1.4 \%$ when NT-proBNP at $72-96 \mathrm{~h}$ was added to the ZRS.

In Table 3 the AUCs of serial NT-proBNP, ZRS and their combination for non-fatal AEs are summarized. 
Table 2. Uni- and multivariate analysis of ZRS and NT-proBNP at different time points for prediction of non-fatal events at 30-day follow-up

\begin{tabular}{|c|c|c|c|c|c|c|}
\hline \multirow[t]{2}{*}{ Timepoint } & \multirow[t]{2}{*}{ Model } & \multirow[t]{2}{*}{ Predictor } & \multirow[t]{2}{*}{ OR } & \multicolumn{2}{|c|}{$95 \% \mathrm{CI}$} & \multirow[t]{2}{*}{$P$ value } \\
\hline & & & & lower & upper & \\
\hline \multirow[t]{3}{*}{ Baseline } & univariate & ZRS & 1.14 & 1.06 & 1.24 & 0.001 \\
\hline & & NT-proBNP & 1.05 & 0.97 & 1.14 & 0.255 \\
\hline & multivariate & ZRS & 1.14 & 1.05 & 1.24 & 0.002 \\
\hline \multirow[t]{5}{*}{$18-24 \mathrm{~h}$} & univariate & ZRS & 1.26 & 1.12 & 1.41 & $<0.0001$ \\
\hline & & NT-proBNP & 1.14 & 1.06 & 1.23 & 0.0003 \\
\hline & & delta NT-proBNP & 1.16 & 1.05 & 1.28 & 0.0027 \\
\hline & multivariate & ZRS & 1.19 & 1.04 & 1.35 & 0.0104 \\
\hline & & NT-proBNP & 1.10 & 1.01 & 1.19 & 0.0289 \\
\hline \multirow[t]{4}{*}{$72-96 \mathrm{~h}$} & univariate & ZRS & 1.24 & 1.07 & 1.43 & 0.0044 \\
\hline & & NT-proBNP & 1.17 & 1.07 & 1.28 & 0.0009 \\
\hline & multivariate & ZRS & 1.15 & 0.97 & 1.36 & 0.0974 \\
\hline & & NT-proBNP & 1.14 & 1.04 & 1.25 & 0.0074 \\
\hline
\end{tabular}

OR, odds ratio; CI, confidence interval; ZRS, Zwolle Risk Score; NT-proBNP, N-terminal pro-brain natriuretic peptide.

Table 3. AUC values and 95\% CI of serial NT-proBNP, ZRS and their combination for non-fatal adverse events $(*)$ at 30-day follow-up.

\begin{tabular}{|c|c|c|c|c|}
\hline & $\begin{array}{l}\text { Baseline } \\
(\mathrm{N}=845)\end{array}$ & $\begin{array}{l}\text { Baseline - } \\
18-24 \mathrm{~h}\end{array}$ & $\begin{array}{l}18-24 \mathrm{~h} \\
(\mathrm{~N}=786)\end{array}$ & $\begin{array}{l}72-96 \mathrm{~h} \\
(\mathrm{~N}=768)\end{array}$ \\
\hline Number of events & 102 & 48 & 48 & 31 \\
\hline ZRS & $\begin{array}{l}0.62 \\
(0.56-0.67)\end{array}$ & $\begin{array}{l}0.62 \\
(0.56-0.67)\end{array}$ & $\begin{array}{l}0.68 \\
(0.60-0.76)\end{array}$ & $0.64(0.54-0.75)$ \\
\hline NT proBNP & $\begin{array}{l}0.58 \\
(0.52-0.64)\end{array}$ & $\begin{array}{l}0.64 \\
(0.55-0.74)\end{array}$ & $\begin{array}{l}0.70 \\
(0.63-0.78)\end{array}$ & $0.66(0.55-0.77)$ \\
\hline $\begin{array}{l}\text { ZRS and NT- } \\
\text { proBNP }\end{array}$ & $\begin{array}{l}0.61 \\
(0.55-0.67)\end{array}$ & $\begin{array}{l}0.70 \\
(0.62-0.78)\end{array}$ & $\begin{array}{l}0.73 \\
(0.62-0.78)\end{array}$ & $0.69(0.58-0.80)$ \\
\hline
\end{tabular}

* Re-myocardial infarction, urgent target vessel revascularization, major bleeding, ventricular tachycardia or ventricular fibrillation.

CI, confidence interval; AUC, area under the curve. 


\section{DISCUSSION}

The present study reports the predictive value of ZRS and NT-proBNP at different time points for the occurrence of non-fatal adverse events (AEs) in PPCI patients and extends our previous findings. Although ZRS and NT-proBNP at 18-24 h and at $72-96 \mathrm{~h}$ could be identified as independent predictors of AEs, independently both variables had modest prognostic accuracy. However, addition of NT-proBNP at 18-24 $\mathrm{h}$ post $\mathrm{PPCI}$ to the ZRS demonstrated a slight improvement and therefore could provide more insight into identifying patients at risk for severe comorbidities, in addition to excellent mortality prognostication as demonstrated before.

\section{Adverse events after primary PCI}

Endpoints in current PPCI risk models are mainly focussed on mortality or a composite of mortality and ischemic events. ${ }^{3-5}$ However, at present non-fatal events are a substantial part of adverse outcomes after PPCI. ${ }^{13}$

Of course these events are responsible for (severe) comorbidities, prolonged hospital stays or re-hospitalization. As a consequence, diverse risk strategies and recommendations regarding major bleeding ${ }^{14}$, use of implantable cardioverter defibrillators $(\mathrm{ICDs})^{15}$ or non-culprit vessel revascularization ${ }^{16}$ have to be taken into consideration. Therefore, PPCI patients often need to undergo multiple risk strata before tailored treatment is accomplished and appropriate discharge plans can be made.

Potentially, ZRS and NT-proBNP could help to provide a more overarching PPCI risk model where both mortality and a composite of important non-fatal AEs are taken into account.

In fact, several clinical variables associated with higher ZRS and NT-proBNP levels have also been associated with the occurrence of non-fatal AEs in PPCI patients. A TIMI flow of $<3$ and left ventricular dysfunction are predictors of stent thrombosis, the predominant cause of early RMI and urgent $\mathrm{TVR}^{17}$, whereas the risk of bleeding has been associated with baseline and periprocedural variables such as advanced age, multivessel disease, higher Killip Class, anterior infarction location and TIMI 0 flow before PCI. ${ }^{18}$ Finally, VT/VF are highly associated with infarction size and the PPCI result. $^{19}$

NT-proBNP in this context is already far from being a simple risk marker for heart failure or mortality. Several studies have shown that there are more events, including development of post PPCI no-reflow phenomenon ${ }^{20}$, angiographic success ${ }^{21,22}$ and the occurrence of contrast-induced nephropathy ${ }^{23}$, that can be predicted by NT-proBNP. 


\section{NT-proBNP and current risk models}

The applicability of NT-proBNP beyond established risk stratification of STEMI patients have been demonstrated in several PPCI studies. A sub-analysis of the APEXAMI study, revealed that baseline NT-proBNP, incorporated in a clinical risk model, improved prediction of 90-day mortality, shock or heart failure. ${ }^{24}$ Similar results were accomplished by a biomarker substudy of the PLATO trial, revealing that NT-proBNP provided additional prognostic value for cardiovascular death and RMI beyond risk scores and extend of coronary artery disease.$^{25}$ In addition, multimarker mortality-risk stratification has been proposed, where the weight of NT-proBNP was strong. ${ }^{26}$ However, how NT-proBNP and established periprocedural risk factors interact in the field of non-fatal events remained underexposed. According to the present study, measurement of NT-proBNP between 18-24 h post PPCI could help the clinician to identify patients at risk for additional severe comorbidities.

\section{Limitations}

Several limitations of our study have to be mentioned. Although in every patient NTproBNP values were assessed by protocol, the ZRS was calculated afterward, so this may be considered retrospective. Conversely, all patients were monitored longitudinally.

Based on the exclusion criteria, patients with a high Killip Class, severe renal dysfunction, elderly patients and young women, but also patients at risk for severe bleeding were not included in the study. This may have affected the results.

In addition, we were not able to provide useful cut-off points for validation. However, the current results suggest that measuring NT-proBNP provides a similar discriminative capacity to identify non-fatal AEs compared to the estabished risk factors as presented by ZRS, and that NT-proBNP would probably improve future (multi)-biomarker risk models.

\section{CONCLUSION}

Measuring non-baseline NT-proBNP independently predicts the occurrence of nonfatal adverse events at 30-day follow-up after PPCI. Particularly at 18-24 h, NTproBNP could provide greater insight in identifying patients at risk of severe comorbidities. 


\section{REFERENCES}

1. The Task Force on the management of ST-segment elevation myocardial infarction of the European Society of Cardiology (ESC). Steg PG, James SK, Atar D et al. ESC guidelines for the management of acute myocardial infarction in patients presenting with ST-segment elevation. available at: www.escardio.org/guidelines. Eur Heart J 2012;33:2569-2619.

2. O'Gara PT, Kushner FG, Ascheim DD et al. American College of Cardiology Foundation/American Heart Association Task Force on Practice Guidelines. 2013 ACCF/AHA Guideline for the management of ST-elevation myocardial infarction: a report of the American College of Cardiology Foundation/ American Heart Association Task Force on Practice Guidelines. Circulation 2013;127:e362-e425.

3. Halkin A, Singh M, Nikolsky E, Grines CL, Tcheng JE, Garcia E, Cox DA, Turco M, Stuckey TD, Na Y, Lansky AJ, Gersh BJ, O’Neill WW, Mehran R, Stone GW. Prediction of mortality after primary percutaneous coronary intervention for acute myocardial infarction. The CADILLAC Risk Score. J Am Cardiol 2005;45:1397-1405.

4. Addala S, Grines CL, Dixon SR, Stone GW, Boura JA, Ochoa AB, Pellizzon G, Kahn JK. Predicting mortality in ST elevation myocardial infarction treated with primary angioplasty. Am J Cardiol 2004;93:629-32.

5. De Luca G, Suryapranata H, van 't Hof AW, de Boer MJ, Hoorntje JC, Dambrink JH, Gosselink AT, Ottervanger JP, Zijlstra F. Prognostic assessment of patients with acute myocardial infarction treated with primary angioplasty: implications for early discharge. Circulation 2004;109:2737-43.

6. Heeschen C, Hamm CW, Mitrovic V, Lantelme NH, White HD. Platelet Receptor Inhibition in Ischemic Syndrome Management (PRISM) investigators. N-terminal pro-B-type natriuretic peptide levels for dynamic risk stratification of patients with acute coronary syndromes. Circulation 2004; 110:3206-3212.

7. Grabowski M, Fillipiak KJ, Karpinski G, Wretowski, Rdzanek Z, Horszczaruk GJ, Kochman J, Rudowski R, Opolski G. Serum B-type natriuretic peptide levels on admission predict not only short-term death but also angiographic success of procedure in patients with acute ST-elevation myocardial infarction treated with primary PCI. Am Heart J. 2004;148:655-662.

8. Schellings DAAM, Adiyaman A, Giannitsis E, Hamm C, Suryapranata H, Ten Berg JM, Hoorntje JCA, Van 't Hof AWJ. Early discharge after primary percutaneous coronary intervention: the aded value of NT-proBNP to the Zwolle Risk Score. J Am Heart Assoc 2014Nov11;3(6):e01089.

9. Schellings DAAM, Van't Hof AWJ, Ten Berg J, Elvan A, Giannitsis E, Hamm C, Suryapranata $\mathrm{H}$, Adiyaman A. NT-proBNP during and after primary PCI for improved scheduling of early hospital discharge. Neth Heart J 2016;Dec 9 [Epub ahead of print].

10. Van 't Hof AWJ, Ten Berg JM, Heestermans T et al. Ongoing tirofiban in myocardial infarction evaluation (On-Time) 2 study group. Prehospital initiation of tirofiban in patients with STelevation myocardial infarction undergoing primary angioplasty (On-TIME 2): a multicentre, double-blind, randomised controlled trial. Lancet 2008aug16;372(9638):537-546.

11. Van 't Hof AWJ, Hamm C, Rasoul S et al. on behalf of the On-TIME 2 investigators. Ongoing tirofiban in myocardial infarction evaluation (On-TIME) 2 trial: rationale and study design. Eurointerv 2007;3:371-380.

12. Rubin DB. Multiple Imputation for Non-respons in Surveys. J. Wiley \& Sons, New York, 1987.

13. Tobbia P, Brodie BR, Witzenbichler B, Metzger C, Guagliumi G, Yu J, Kellet MA, et al. Adverse event rates following primary PCI for STEMI at US and non-US hospitals: three-year analysis from the HORIZONS-AMI trial. Eurointervention 2013;22;8:1134-1142.

14. Subherwal S, Bach RG, Chen AY, Gage BF, Rao SV, Newby LK, Wang TY, Gibler WB, Ohman EM, Roe MT, Pollack CV Jr, Peterson ED, Alexander KP. Baseline risk of major 
bleeding in nonST-segment-elevation myocardial infarction: the CRUSADE (Can Rapid risk stratification of Unstable angina patients Suppress ADverse outcomes with Early implementation of the ACC/AHA Guidelines) Bleeding Score. Circulation 2009;119:1873-1882.

15. Hohnloser SH, Kuck KH, Dorian P, Roberts RS, Hampton JR, Hatala R, Fain E, Gent M, Connolly SJ, fot the DINAMIT investigators. Prophylactic use of implantable cardioverter defibrillator after acute myocardial infarction. N Eng J Med 2004;351:2481-2488.

16. Bangalore S, Toklu B, Wetterslev J. Complete versus culprit only revascularization for STsegment-elevation myocardial infarction and multivessel disease. a meta-analysis and trial sequential analysis of randomized trials.Circ Cardiovasc Interv 2015;8:e02142.

17. van Werkum JW, Heestermans AA, Zomer AC, Kelder JC, Suttorp MJ, Rensing BJ, Koolen JJ, Brueren BR, Dambrink JH, Hautvast RW, Verheugt FW, ten Berg JM. Predictors of coronary stent thrombosis: the Dutch stent thrombosis registry. J Am Coll Cardiol 2009;53:1399.

18. Hermanides RS, Ottervanger JP, Dambrink JH, de Boer MJ, Hoorntje JC, Gosselink AT, Suryapranata H, van 't Hof AW. Incidence, predictors and prognostic importance of bleeding after primary PCI for ST-elevation myocardial infarction. Eurointervention 2010;6:106-111.

19. Timmer JR, Breet N, Svilaas T, Haaksma J, Van Gelder IC, Zijlstra F. Predictors of ventricular tachyarrhytmia in high-risk myocardial infarction patients treated with primary coronary intervention. Neth Heart J 2010;18:122-128.

20. Hong SN, Ahn Y, Hwang SH, Yoon NS, Lee SR, Moon JY, Kim KH, Hong YJ, Park HW, Kim JH, Jeong MH, Gho JG, Park JC, Kang JC. Usefulness of preprocedural N-terminal pro-brain natriuretic peptide in predicting angiographic no-reflow phenomenon during stent implantation in patients with ST-segment elevation acute myocardial infarction. Am J Cardiol 2007;100:631-634.

21. Blom JR, van 't Hof AWJ, Henriques JPS, et al. NT-proBNP: a marker for successful myocardial reperfusion in AMI patients treated with primary percutaneous coronary intervention. Eur J Heart Fail 2004;6:749-752.

22. Jarai R, Huber K, Bogaerts K, Droogne W, Ezekowitz J, Granger CB, Sinnaeve PR, Ross AM, Zeymer U, Armstrong PW, Van de Werf FJ. ASSENT-IV-PCI investigators. Plasma N-terminal fragment of the prohormone B-type natriuretic peptide concentrations in relation to time to treatment and thrombolysis in myocardial infarction (TIMI) flow: a substudy of the assessment of the safety and efficacy of a new treatment strategy with percutaneous coronary intervention (ASSENT IV-PCI) trial. Am Heart J 2010;159:131-140.

23. Goussot S, Mousson C, Guenancia C, Stamboul K, Brunel P, Brunet d, Touzery C, Cottin Y, Zeller M. N-terminal fragment of pro-B-type natriuretic peptide as a marker of contrast-induced nephropathy after primary percutaneous coronary intervention for ST-segment elevation myocardial infarction. Am J Cardiol 2015;116:865-871.

24. van Diepen S, Newby LK, Lopes RD, Stebbins A, Hasselblad V, James S, Roe MT, Ezekowitz JA, Moliterno DJ, Neumann FJ, Reist C, Mahaffey KW, Hochman JS, Hamm CW, Armstrong PW, Granger CB, Theroux P, APEX-AMI investigators. Prognostic relevance of baseline proand anti-inflammatory markers in STEMI: an APEX AMI substudy. Int $J$ Cardiol 2013;168:2127-2133.

25. Velders MA, Wallentin L, Becker RC, van Boven AJ, Himmelmann A, Husted S, Katus HA, Lindholm D, Morais J, Siegbahn A, Storey RF, Wernroth L, James SK, on behalf of the PLATO Investigators. Biomarkers for risk stratification of patients with ST-elevation myocardial infarction treated with primary percutaneous coronary intervention: insights from the Platelet Inhibition and Patient Outcomes trial. Am Heart J 2015;169:879-889.

26. Damman P, Beijk MAM, Kuijt WJ, Verouden NJW, van Geloven N, Henriques JPS, Baan J, Vis MM, Meeuwissen M, van Straalen JP, Fischer J, Koch KT, Piek JJ, Tijssen JGP, de Winter RJ. Multiple biomarkers at admission significantly improve the prediction of mortality in patients undergoing primary percutaneous coronary intervention for acute ST-segment elevation myocardial infarction. J Am Coll Cardiol 2011;57:29-36. 



\title{
CHAPTER 7
}

\section{Predictive value of NT-proBNP for 30-day mortality in patients with non-ST-elevation acute coronary syndromes: a comparison with the GRACE and TIMI risk scores}

\author{
D.A.A.M. Schellings, A. Adiyaman \\ J.-H.E Dambrink, A.T.M. Gosselink \\ E. Kedhi, V. Roolvink \\ J. P. Ottervanger, A.W.J. van 't Hof
}

Vascular Health and Risk Management 2016;12:471-476 

ABSTRACT

Background. The biomarker N-terminal pro-brain natriuretic peptide (NT-proBNP) predicts outcome in patients with non-ST-elevation acute coronary syndromes (NSTEACS). Whether NT-proBNP has incremental prognostic value beyond established risk strategies is still questionable.

Purpose. To evaluate the predictive value of NT-proBNP for 30-day mortality over and beyond the Global Registry of Acute Coronary Events (GRACE) and Thrombolysis in Myocardial Infarction (TIMI) risk scores in patients with NSTE-ACS.

Methods. Patients included in our ACS registry were candidates. NT-proBNP levels on admission were measured and the GRACE and TIMI risk scores were assessed. We compared the predictive value of NT-proBNP to both risk scores and evaluated whether NT-proBNP improves prognostication by using receiver operator curves and measures of discrimination improvement.

Results. A total of 1324 patients were included and 50 patients died during follow-up. On logistic regression analysis NT-proBNP and the GRACE risk score (but not the TIMI risk score), both independently predicted mortality at 30-days. The predictive value of NT-proBNP did not differ significantly compared to the GRACE risk score (area under the curve (AUC) 0.85 vs. $0.87 \mathrm{P}=0.67$ ) but was considerably higher in comparison to the TIMI risk score (AUC $0.60 \mathrm{P}<0.001$ ). Adjustment of the GRACE risk score by adding NT-proBNP did not improve prognostication: AUC $0.86(\mathrm{P}=0.57)$, integrated discrimination improvement $0.04(\mathrm{P}=0.003)$, net reclassification improvement $0.12(\mathrm{P}=0.21)$.

Conclusion. In patients with NSTE-ACS, NT-proBNP and the GRACE risk score (but not the TIMI risk score) both have good and comparable predictive value for 30-day mortality. However, incremental prognostic value of NT-proBNP beyond the GRACE risk score could not be demonstrated.

\section{INTRODUCTION}

In patients presenting with non-ST-elevation acute coronary syndromes (NSTE-ACS) or non-ST-elevation myocardial infarction (NSTEMI), the Thrombolysis In Myocardial Infarction risk score as well as the Global Registry of Acute Coronary Events (GRACE) risk calculation have established predictive value. ${ }^{1-3}$ However, the GRACE score provides the most accurate stratification of ischemic risk, both on admission and at discharge and has become the recommended risk strategy for early patient decision making. ${ }^{4-6}$ 
Beside clinical markers of risk, key element of the GRACE score is the biomarker cardiac troponin (cTn) or high-sensitivity (hs)-cTn at present. Beyond diagnostic utility, this biomarker has also important prognostic accuracy in a directly proportional way. ${ }^{4,7}$

In addition, the biomarker brain natriuretic peptide (BNP) and its N-terminal fragment (NT-proBNP) have shown to provide prognostic information in patients with NSTEACS as well, and subsequently improve risk stratification in combination with $\mathrm{cTn}^{8}{ }^{8}$ Whether BNP has really significant incremental value to established NSTE-ACS risk models is still debatable however. ${ }^{4}$ In this report we evaluated the predictive value of baseline NT-proBNP measurement for all-cause mortality at 30-day follow-up over and beyond the established TIMI and GRACE risk scores in patients admitted with NSTE-ACS.

\section{METHODS}

\section{Population}

Between 2006 and 2014 individual data from all patients with admission diagnosis of NSTE-ACS (or NSTEMI) admitted at the Isala Heart Center (Zwolle, The Netherlands) was prospectively recorded. Patients were diagnosed with NSTE-ACS, when they met the definitions according to the European Society of Cardiology guidelines based on clinical presentation (chestpain), electrocardiogram (EKG) abnormalities or elevated cardiac enzymes (cTn or hs-cTn $>$ upper limit of normal or doubling of hs-cTn within $3 \mathrm{~h}$ ), hence inclusion criteria involved the full clinical spectrum of NSTE-ACS presentation. A written informed consent for data registration and future analysis was obtained from each patient. To avoid double inclusion of patients, only the first recorded admission for NSTE-ACS during the study period was used. Although treatment of patients was to the discretion of the cardiologist and not by protocol, all patients were treated with optimized drug-therapy including angiotensinconverting enzyme inhibitors, $\beta$-blockers, aspirin and lipid-lowering drugs where appropriate. Study approval was obtained from the medical ethic committee of the Isala Heart Center. 


\section{Measurements}

To study the predictive value of NT-proBNP for 30-day mortality over and beyond the TIMI risk score and the GRACE risk calculator, patients were divided in percentiles according to the different scores and baseline NT-proBNP values. NT-proBNP and (hs)-cTn were measured in each patient on admission by protocol. Both risk scores were calculated afterward.

The GRACE risk score was calculated by the 8 different baseline variables incorporated in the risk calculator: age, heart rate (beats per minute), systolic blood pressure, serum creatinine level, cardiac arrest at admission, ST-segment deviation on EKG, elevated cTn and congestive heart failure (Killip Class). According to the GRACE risk score, patients are classified into three risk groups. For in hospital mortality this implies: low $(\leq 108)$, intermediate $(109-140)$ and high $(>140)$ risk. www.gracescore.org

The TIMI risk score for NSTE-ACS estimates mortality based on: age $\geq 65, \geq 3$ coronary artery disease (CAD) risk factors, known CAD (stenosis $\geq 50 \%$ ), aspirin use in the past 7 days, severe angina ( $\geq 2$ episodes in $24 \mathrm{hs),} \mathrm{ST-segment} \mathrm{deviation} \geq 0.5$ $\mathrm{mm}$ and positive cardiac markers. This risk score ranges from 0 to 7 points reflecting $5 \%$ to $41 \%$ risk at 14 days of all-cause mortality, new or recurrent myocardial infarction or severe recurrent ischemia requiring urgent revascularization. ${ }^{1}$

\section{Endpoint}

The primary endpoint in this study was death from any cause at 30 days after withdrawal of blood from which the NT-proBNP level was determined.

\section{Statistical analysis}

In each patient the TIMI and GRACE risk scores were calculated. We assessed the predictive value of NT-proBNP, the GRACE risk score and the TIMI risk score for NSTE-ACS for the primary endpoint by receiver operating characteristic (ROC) curve analysis. To assess the predictive value of the NT-proBNP adjusted risk models, the linear combination of NT-proBNP and each risk model was used. To perform an analysis using the risk model and NT-proBNP together, we calculated weighted scores for each as follows:

$$
(\beta 1 \times \text { risk score })+(\beta 2 \times \ln \text { NT-proBNP }),
$$

where $\beta 1$ and $\beta 2$ denote $\beta$-coefficients for the risk score and log NT-proBNP obtained from the logistic regression model. Because NT-proBNP was not normally distributed we used logarithmically transformed values. Logistic regression analysis was performed to estimate the influence of NT-proBNP and TIMI/GRACE risk scores on 30-day mortality by calculating the change in area under the curve (AUC). 
Additionally, we used two complementary measures of discrimination improvement to evaluate the model performance when NT-proBNP was added to GRACE or TIMI risk model: the Net Reclassification Improvement (NRI) and the Integrated Discrimination Improvement (IDI). The IDI combines the increase in mortality probability for those experiencing an event plus the decrease in mortality probability for those not experiencing an event. The NRI quantifies the net proportion of subjects getting correctly reclassified to low or high mortality probabilities when adding a predictor to the model using a cut-off point for the predicted probabilities of $10 \%$. AUCs were compared in SAS using PROC Logistic. All statistical analyses were performed using SPSS (version 19) and SAS (version 9.2). A two-sided P value of $<0.05$ was considered to be statistically significant.

\section{RESULTS}

During the study period a total of 1324 patients were included. Baseline characteristics are given in Table 1. Mean age was 73 years (Standard deviation (SD) 11.6) and most patients had no history of cardiovascular disease, except for hypertension, which was present in $58 \%$ of patients. Baseline NT-proBNP levels ranged from 6.0 to 35,000 $\mathrm{pg} / \mathrm{ml}$ (mean \pm SD of $2036 \pm 4430$ ), with a median of $519 \mathrm{pg} / \mathrm{ml}$ and were available in all patients. The GRACE score could be calculated in 900 patients and ranged from 42 to 281 points (mean \pm SD of $139 \pm 42$ ), with most patients at intermediate to high risk for in-hospital mortality $\left(25^{\text {th }}\right.$ percentile score $\left.\leq 108\right)$. The TIMI score was calculated in 911 patients and ranged from 0 to 7 points (mean \pm SD of $3.1 \pm 1.4$ ). Values within the 25 percentile ranged from 0 to 2 points. As a consequence $75 \%$ of patients had values between 3 and 7 points.

In $1134(85.6 \%)$ patients, coronary angiography was performed during hospital admission. Outcome data are presented in Table 2. Most patients had obstructive coronary artery disease and $78 \%$ of these patients needed PCI or coronary artery bypass grafting. 
Table 1. Baseline characteristics of the included NSTE-ACS patients

\begin{tabular}{llc}
\hline \hline Variable & $\begin{array}{l}\text { Total } \\
(\mathrm{N}=1324)\end{array}$ & $(\%)$ \\
\hline Age (years) mean $\pm \mathrm{SD}$ & $73.1 \pm 11.61$ & 65 \\
Male gender & 861 & \\
Risk factors & & 22.3 \\
Diabetes mellitus & 295 & 26.4 \\
Smoking & 349 & 35.6 \\
Hypercholesterolemia & 471 & 33.0 \\
Family history & 437 & 57.6 \\
Hypertension & 762 & \\
History of disease & & 18.7 \\
Myocardial infarction & 247 & 18.7 \\
Percutaneous coronary intervention & 248 & 14.0 \\
Coronary artery bypass graft & 186 & 4.2 \\
Chronic renal failure & 55 & \\
\hline \hline
\end{tabular}

NSTE-ACS, non-ST-elevation acute coronary syndromes; SD, standard deviation.

Table 2. Coronary intervention data of the studied NSTE-ACS patients $(\mathrm{N}=1324)$

\begin{tabular}{lll}
\hline \hline Data on coronary intervention & $\mathrm{N}$ & $\%$ \\
\hline Coronary angiography performed & 1134 & 85.6 \\
& & \\
Time between admission and angiography $(\mathrm{h})$ & & \\
$\quad \leq 24$ & 685 & 51.7 \\
$>24-48$ & 152 & 11.5 \\
$>48$ & 288 & 21.8 \\
& & \\
Number of vessel disease & & \\
0 & 104 & 7.9 \\
1 & 336 & 25.4 \\
2 & 261 & 19.7 \\
3 & 329 & 24.8 \\
LM & 22 & 1.7 \\
LM +3 & 47 & 3.5 \\
& & \\
Treatment & & 13.8 \\
conservative & 183 & 18.2 \\
CABG & 241 & 48.8 \\
PCI & 646 & \\
\hline \hline
\end{tabular}

NSTE-ACS, non-ST-elevation acute coronary syndromes; CABG, coronary artery bypass grafting; LM, left main; PCI, percutaneous coronary intervention. 
Table 3. Logistic regression analysis of NT-proBNP, the GRACE risk score and the TIMI NSTEACS risk score for 30-day mortality prediction

\begin{tabular}{|c|c|c|c|c|c|c|c|c|c|}
\hline & & \multicolumn{8}{|c|}{ Variables in the equation } \\
\hline & & \multirow[t]{2}{*}{$\overline{\mathrm{B}}$} & \multirow[t]{2}{*}{$\mathrm{SE}$} & \multirow[t]{2}{*}{ Wald } & \multirow[t]{2}{*}{$\mathrm{df}$} & \multirow[t]{2}{*}{$\mathrm{P}$ value } & \multirow[t]{2}{*}{ OR } & \multicolumn{2}{|c|}{$95 \% \mathrm{CI}$ for OR } \\
\hline & & & & & & & & Lower & Upper \\
\hline \multirow[t]{4}{*}{ Step $1^{\mathrm{a}}$} & NT-proBNP & 0.640 & 0.215 & 8.874 & 1 & 0.003 & 1.897 & 1.245 & 2.891 \\
\hline & GRACE & 0.021 & 0.008 & 7.952 & 1 & 0.005 & 1.021 & 1.006 & 1.037 \\
\hline & TIMI & -0.201 & 0.199 & 1.023 & 1 & 0.312 & 0.818 & 0.553 & 1.208 \\
\hline & Constant & -11.209 & 1.686 & 44.183 & 1 & 0.000 & 0.000 & & \\
\hline
\end{tabular}

${ }^{\mathrm{a}}$ Variable(s) entered on step 1: NT-proBNP, GRACE risk score, TIMI risk score.

BNP, brain natriuretic peptide; CI, confidence interval; df, degree of freedom; GRACE , Global Registry of Acute Coronary Events; NSTE-ACS, non-ST-elevation acute coronary syndromes; NT, N-terminal fragment; $\mathrm{OR}$, odds ratio; SE, standard error; TIMI, thrombolysis in myocardial infarction.

Ejection fraction (EF) could be measured in 828 patients $(63 \%)$, In $9.4 \%$ of these patients, a poor left ventricular function was present $(\mathrm{EF}<30 \%)$. Most patients had EF $>40 \%(58 \%)$.

During the 30-days of follow-up, 50 patients died. On logistic regression analysis, NTproBNP and the GRACE risk score were independent predictors of 30-day mortality (Table 3).

NT-proBNP values among the patients who died, widely ranged from 51-35,000 pg/ml (mean \pm SD of $8516 \pm 9974$, median $4505 \mathrm{pg} / \mathrm{ml}$ ). The GRACE risk score in these patients ranged from 125 to 251 points (mean \pm SD of $192 \pm 33.2$, median 199 points), reflecting patients at higher in-hospital mortality risk. The TIMI score in the patients who died, ranged from 1 to 7 points (mean \pm SD of $3.6 \pm 1.4$, median 4.0 points). Both risk scores and NT-proBNP values were significantly higher in patients who died, compared to those who survived. NT-proBNP values correlated significantly with both risk models but correlation with the GRACE score was stronger than correlation with the TIMI score (Pearson correlation 0.62 and 0.33 , respectively $\mathrm{P}<0.001$ ). At ROC curve analysis NT-proBNP depicted good predictive value for 30-day mortality (AUC 0.80, range 0.73-0.87). For the GRACE score AUC was as high as $0.85(0.79-0.90)$ but the difference was not significant $(\mathrm{P}=0.67)$.

The TIMI risk score however, revealed a poor predictive value with AUC of 0.61 (0.50-0.71), which was significantly smaller in comparison to NT-proBNP and the GRACE risk score. Adding NT-proBNP to the GRACE risk score revealed no significant improvement of predictive value: AUC 0.86 vs. $0.85(\mathrm{P}=0.57)$, NRI 0.12, $(\mathrm{P}=0.21)$, IDI $0.04(\mathrm{P}=0.003)$. 


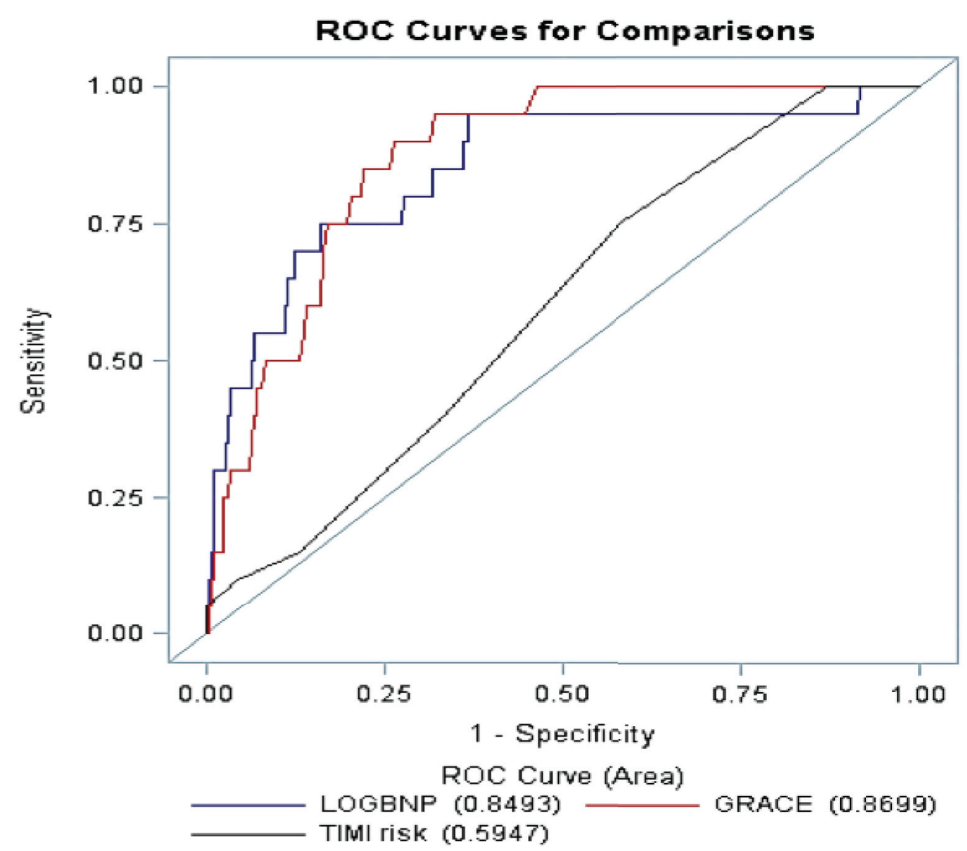

Figure 1. ROC curves for comparisons of NT-proBNP and the GRACE and TIMI-NSTE-ACS risk scores $(\mathrm{N}=692$, mortality cases $\mathrm{N}=29)$

BNP, brain natriuretic peptide; GRACE, Global Registry of Acute Coronary Events; NT, Nterminal fragment; NSTE-ACS, non-ST-elevation acute coronary syndromes; ROC, receiver operating characteristic.

However, the combination of NT-proBNP/GRACE, showed a slightly predictive improvement in comparison with NT-proBNP only (AUC 0.86 vs. $0.83, \mathrm{P}=0.03$ ). Adding NT-proBNP to the TIMI risk score, considerably improved prognostication of 30-day mortality: AUC 0.84, NRI 0.41 ( $\mathrm{P}=0.001)$, IDI 0.1 ( $\mathrm{P}<0.0001)$. Figure 1 depicts ROC curves of NT-proBNP, and the GRACE and TIMI risk scores. Because comparable analysis could not be performed in patients with missing data, these curves are based on endpoint measurement of 692 patients who had valid values for NTproBNP and both risk scores, therefore AUC values slightly differ from those found in individual analysis. 


\section{DISCUSSION}

In this study NT-proBNP at baseline and the GRACE risk calculator, had good and comparable predictive value for 30-day mortality in NSTE-ACS patients and were much more accurate than the TIMI risk score. However, adding NT-proBNP could not enhance the GRACE risk prediction of 30-day mortality.

\section{Previous findings}

Natriuretic peptides have been extensively evaluated and showed to be predictors of mortality in patients with ACS, with comparable clinical utility for B-type natriuretic peptide and NT-proBNP. ${ }^{8}$ Studies evaluating whether NT-proBNP measurement would improve risk assessment in NSTE-ACS patients beyond the established GRACE or TIMI risk scores have been previously performed. Regarding the GRACE risk score, conflicting results were noticed. Depending on different outcome measures and time points of BNP withdrawal, some reports confirmed incremental value of $\mathrm{BNP}^{9-11}$ while other reports did not or revealed only a small improvement of prognostication. ${ }^{12,13}$ The TIMI risk score however, has clearly less predictive accuracy in comparison with BNP and the GRACE score, so that incremental value of BNP to the TIMI risk score logically could be demonstrated. ${ }^{6,9,14-16}$

\section{Timing of BNP}

Although previous findings are consistent with our results, further explanation is required since BNP is predictive in ACS independently of age, EKG change and cTn concentration; all elements of the GRACE score. ${ }^{17,18}$ As a consequence it does make sense that BNP measurement should have additional value in clinical practice. Probably, time of BNP assessment and its relation with outcome measures (short versus longer time mortality) may be of influence. In patients with ACS, elevated baseline cTn concentrations or a rise of high-sensitivity cTn within a few hours is often present since elevated cTn values are of diagnostic utility and are anchored in NSTEACS definition. ${ }^{8}$

Baseline NT-proBNP however, could be within a normal range, even in patients at early mortality risk as demonstrated by our analysis, who would have been detected by the GRACE risk score. Data concerning optimal timing of BNP measurement in NSTE-ACS are limited. One of the afore-mentioned studies, that confirmed additional value of BNP to the GRACE risk score, was based on measurements at 24-96 hours. ${ }^{9}$ Furthermore, serial admission BNP measurement in NSTE-ACS has been performed. In one report, patients with chest pain were studied and NT-proBNP samples were collected 5 times within 24 hours of presentation and at discharge. Although baseline 
elevated BNP and NT-proBNP were predictive for 30-day adverse events including mortality, serial sampling showed no prognostic improvement. ${ }^{19}$ Unlike this, another study concerning a high-risk subgroup of acute myocardial infarction patients, did reveal that only the highest follow-up BNP remained associated with in-hospital death. ${ }^{20}$ Also in patients with ST elevation myocardial infarction (STEMI), nonbaseline serial BNP appears to be of optimal predictive value. ${ }^{21,22}$ Based on this knowledge, we think that the optimum time point for BNP withdrawal and its potential incremental effect on prognostication in NSTE-ACS patients deserves further investigation.

\section{Clinical implications}

Beside mortality, non-fatal major adverse cardiac events and also major bleeding, are important outcome measures that directly affect patient management and length of stay in hospital. The GRACE risk score was developed to predict death, but this score can also predict the risk of bleeding and freedom from clinical events in NSTE-ACS patients for which the GRACE investigators constructed a modified risk model that identified up to $30 \%$ of patients at low risk of death or any adverse in-hospital event. ${ }^{23}$ Whether BNP could be useful in predicting a wide variety of adverse events or the benefit of early revascularization in NSTE-ACS patients has to be determined. However, in STEMI patients, we recently found that baseline NT-proBNP could identify patients eligible for early hospital discharge, with low occurrence of adverse events at 10-day follow-up. ${ }^{24}$

\section{Limitations}

Several limitations have to be noticed. Although all outcome measures were registered prospectively, scores of both the TIMI and GRACE risk models were calculated afterward, and not by protocol so this may be considered retrospectively. As a consequence in about $1 / 3$ of patients the GRACE and/or TIMI risk scores were unknown due to missing values which may affect the results. Finally we confined outcome measures to all-cause 30-day mortality. Despite this, our results certainly contribute to better understanding of risk assessment by NT-proBNP in clinical practice, since our study cohort consisted of a 'real life', unselected NSTE-ACS patient population. 


\section{CONCLUSION}

In NSTE-ACS patients NT-proBNP and the GRACE risk score (but not the TIMI risk score) both have good and comparable predictive value for 30-day mortality. However, in our study, incremental prognostic value of NT-proBNP beyond the GRACE risk score could not be demonstrated. 


\section{REFERENCES}

1. Antman EM, Cohen M, Bernink PJ, et al. The TIMI risk score or unstable angina/non-ST elevation MI: a method for prognostication and therapeutic decision making. JAMA 2000;284:835-842.

2. Granger CB, Goldberg RJ, Dabbous O, et al; Global Registry of Acute Coronary Events Investigators. Predictors of hospital mortality in the global registry of acute coronary events. Arch Intern Med 2003;163:2345-2353.

3. Fox KA, Dabbous OH, Goldberg RJ, et al. Prediction of risk of death and myocardial infarction in the six months after presentation with acute coronary syndrome: prospective multinational observational study (GRACE). BMJ 2006;333:1091.

4. Roffi M, Patrono C, Collet J-P, et al. 2015 ESC Guidelines for the management of acute coronary syndromes in patients presenting without persistent ST-segment elevation. http://www.escardio.org/guidelines.

5. Aragam KG, Tamhane UU, Kline-Rogers E, et al. Does simplicity compromise accuracy in ACS risk prediction? a retrospective analysis of the TIMI and GRACE risk scores. PLoS One 2009;4:e7947.

6. de Araújo Gonçalves P, Ferreira J, Aguiar C, Seabra-Gomes R. TIMI, PURSUIT, and GRACE risk scores: sustained prognostic value and interaction with revascularization in NSTE-ACS. Eur Heart J 2005;26:865-872.

7. Mueller C. Biomarkers and acute coronary syndromes: an update. Eur Heart J 2014;35:552-556.

8. Thygesen K, Mair J, Mueller C, et al. Recommendations for the use of natriuretic peptides in acute cardiac care: a position statement from the study group on biomarkers in cardiology of the ESC working group on acute cardiac care. Eur Heart J 2012;33:2001-2006.

9. Garcia-Alvarez A, Regueiro A, Hernández J, et al. Additional value of B-type natriuretic peptide on discrimination of patients at risk for mortality after a non-ST-segment elevation acute coronary syndrome. Eur Heart J Acute Cardiovasc Care 2014;3:132-140.

10. Guidez T, Marechaux S, Pincon C, et al. Addition of B-type natriuretic peptide to the GRACE score to predict outcome in acute coronary syndrome: a retrospective (development) and prospective (validation) cohort-based study. Emerg Med J 2012;29:274-279.

11. Widera C, Pencina MJ, Meisner A, et al. Adjustment of the GRACE score by growth differentiation factor 15 enables a more accurate appreciation of risk in non-ST-elevation acute coronary syndrome. Eur Heart J 2012;33:1095-1104.

12. Meune C, Drexler B, Haaf P, et al. The GRACE score's performance in predicting in-hospital and 1-year outcome in the era of high-sensitivity cardiac troponin assays and B-type natriuretic peptide. Heart 2011;97:1479-1483.

13. Ang DS, Wei L, Kao MP, Lang CC, Struthers AD. A comparison between B-type natriuretic peptide, global registry of acute coronary events (GRACE) score and their combination in ACS risk stratification. Heart 2010;96:227-228.

14. Reesukumal K, Pratumvinit B. B-type natriuretic peptide not TIMI risk score predicts death after acute coronary syndrome. Clin Lab 2012;58:1017-1022.

15. Kim JH, Jeong MH, Ahn Y, et al; Other Korea acute Myocardial Infarction Registry (KAMIR) Investigators. A novel risk stratification model for patients with non-ST elevation myocardial infarction in the Korea acute myocardial infarction registry (KAMIR): limitation of the TIMI risk scoring system. Chonnam Med J 2011;47:20-26.

16. Tello-Montoliu A, Marin F, Roldán V, et al. A multimarker risk stratification approach to nonST elevation acute coronary syndrome: implications of troponin T, CRP, NT-proBNP and fibrin D-dimer. J Intern Med 2007;262:651-658.

17. de Lemos JA, Morrow DA, Bentley JH, et al. The prognostic value of B-type natriuretic peptide in patients with acute coronary syndromes. N Eng J Med 2001;345:1014-1021. 
18. Jernberg T, Stridsberg M, Venge P, Linahl B. N-terminal pro brain natriuretic peptide on admission for early risk stratification of patients with chestpain and no ST-segment elevation. J Am Coll Cardiol 2002;40:437-445.

19. Kwan G, Isakson SR, Beede J, Clopton P, Maisal AS, Fitzgerald RL. Short-term serial sampling of natriuretic peptides in patients presenting with chestpain. J Am Coll Cardiol 2007;49:11861192.

20. Pesaro AEP, Katz M, Caixeta A, et al. Prognostic value of serial brain natriuretic peptide measurements in patients with acute myocardial infarction. Cardiology 2015;131:116-121.

21. Ezekowitz JA, Théroux P, Chang W, et al. N-terminal pro-brain natriuretic peptide and the timing, extent and mortality in ST elevation myocardial infarction. Can J Cardiol 2006; 22:393397.

22. Ezekowitz JA, Théroux P, Welsh R, Bata I, Webb J, Armstrong PW. Insights into the change in brain natriuretic peptide after ST-elevation myocardial infarction (STEMI): why should it be better than baseline? Can J Physiol Pharmacol 2007;85:173-178.

23. Brieger D, Fox KA, Fitzgerald G, et al; Global registry of acute coronary events investigators. Predicting freedom from clinical events in non-ST-elevation acute coronary syndromes: The global registry of acute coronary events. Heart 2009;95:888-894.

24. Schellings DA, Adiyaman A, Giannitsis E, et al. Early discharge after primary percutaneous coronary intervention: the added value of N-terminal pro-brain natriuretic peptide to the Zwolle Risk Score. J Am Heart Assoc 2014;3:e001089. 


\title{
CHAPTER 8
}

\section{Serial N-terminal pro-brain natriuretic peptide assessments in predicting new-onset atrial fibrillation in ST-elevation myocardial infarction patients who undergo primary percutaneous coronary intervention}

\author{
E. Parlak, P. Gal \\ D.A.A.M. Schellings, R. Beukema \\ A. Adiyaman, J.M. ten Berg \\ A.W.J. van 't Hof, A. Elvan
}

Journal of Molecular Biomarkers \& Diagnosis 2015;7:268 doi: 10.4172/2155-9929.1000268 

ABSTRACT

Background. N-terminal pro-Brain Natriuretic Peptide (NT-proBNP) is associated with atrial fibrillation (AF) in the setting of acute ST-elevation myocardial infarction (STEMI), and the present study was aimed at assessing the temporal association between NT-proBNP and incident AF.

Methods. 830 patients enrolled in On-TIME 2 were included. NT-proBNP was assessed at baseline, $24 \mathrm{~h}$ and $72 \mathrm{~h}$ after admission for STEMI. Patients with new-onset $\mathrm{AF}<30$ days after STEMI were divided among three subgroups: AF on admission, AF 24-72 $\mathrm{h}$ after admission and AF $>72 \mathrm{~h}$ after admission. NT-proBNP serum levels at the three assessment intervals was used to predict the timing of $\mathrm{AF}$ with a receiver operating characteristic analysis and a binary logistic model was created to predict the $\mathrm{AF}$ at the various timings.

Results. Mean age was $62 \pm 12$ years and $76 \%$ were male. 73 patients developed incident AF, 41 developed AF on admission, 14 patients developed AF 24-72 h after admission and 18 patients developed $\mathrm{AF}>72 \mathrm{~h}$ after admission. NT-proBNP at baseline (area under the curve (AUC) 0.657, $\mathrm{P}<0.001$ ), after $24 \mathrm{~h}$ (AUC 0.829, $\mathrm{P}<0.001)$ and after $72 \mathrm{~h}(\mathrm{AUC} 0.891, \mathrm{P}<0.001)$ predicted AF. However, NT-proBNP at baseline did not predict AF on admission (AUC 0.591, $\mathrm{P}=0.058$ ). NT-proBNP after 24 $\mathrm{h}$ and $72 \mathrm{~h}$ were stronger predictors of AF compared to NT-proBNP at baseline. In regression analysis, NT-proBNP after $24 \mathrm{~h}(\mathrm{OR}: 1.220, \mathrm{P}<0.001)$ and $72 \mathrm{~h}(\mathrm{OR}: 1.290$, $\mathrm{P}<0.002$ ) showed a significant association with postinfarction AF.

Conclusion. This study shows that serial NT-proBNP plasma level assessments enhance risk stratification for incident AF in STEMI patients.

\section{INTRODUCTION}

New-onset atrial fibrillation (AF) occurs in 5-23\% of patients admitted with an acute ST- elevation myocardial infarction (STEMI) ${ }^{1-4}$ and is associated with an impaired long-term cardiovascular outcome, including a $40 \%$ increase in mortality. ${ }^{5-7}$ Therefore, predicting AF in STEMI patients can impact clinical practice by identifying patients at increased risk after STEMI. Several biomarkers have been associated with new-onset AF. ${ }^{8,9}$ A recent study showed that incident AF after STEMI can be predicted by Nterminal pro-brain natriuretic peptide (NT-proBNP) plasma level assessment. ${ }^{9}$ However, in this study, NT-proBNP was assessed somewhere during the first $72 \mathrm{~h}$ after admission and thus there are no data on the temporal relationship between serial NTproBNP plasma level assessments and mode of onset AF in STEMI patients. The aim 
of this study was to investigate if assessment of NT-proBNP plasma levels at three distinct timings enhances the risk stratification for the development of AF in STEMI patients treated with primary percutaneous coronary intervention (PPCI).

\section{Methods}

Our population consisted of patients with a STEMI, who were admitted for PPCI and included in the Ongoing Tirofiban in Myocardial Infarction Evaluation (On-TIME) 2 study, ${ }^{10,11}$ a prospective, multi-center, placebo controlled, randomized, clinical trial. The rationale, design and primary results of On-TIME 2 have been previously described. ${ }^{11}$ Briefly, enrollment was from June 2006 to November 2007. Eligible patients were aged 21-85 years with symptoms of acute myocardial infarction of more than 30 min but less than $24 \mathrm{~h}$ and ST-segment elevation of more than $1 \mathrm{mV}$ in two adjacent electrocardiograph (ECG) leads. Exclusion criteria were severe renal dysfunction (glomerular filtration rate (GFR) $<30 \mathrm{ml} / \mathrm{min}$ or serum creatinine $>200$ $\mathrm{mmol} / \mathrm{l}(>2.5 \mathrm{mg} / \mathrm{dl}$ ), therapy resistant cardiogenic shock (systolic blood pressure $\leq 80$ $\mathrm{mmHg}$ for $>30 \mathrm{~min}$ ), persistent severe hypertension (systolic pressure $>180 \mathrm{mmHg}$ or diastolic pressure $>110 \mathrm{mmHg}$ ), or a contraindication to anticoagulation or increased risk of bleeding. Also, patients with a left bundle branch block, pregnant and/or breastfeeding women, and patients with a life expectancy of less than 1 year were excluded. For the present study, patients with a history of AF were excluded. From each patient, a written informed consent for participation in the On-TIME 2 study was obtained. The local ethics committees approved the study protocol.

\section{Measurements}

NT-proBNP plasma levels were measured in each patient at baseline after sheath insertion before PPCI was performed, $24 \mathrm{~h}$ after admission and $72 \mathrm{~h}$ after admission. All plasma samples were analysed using an electrochemiluminiscence immunoassay 'ECLIA' (proBNP kit, Roche Diagnostics, Mannheim, Germany) on an Elecsys 2010 analyser. The assay had a measuring range from 0.6 to $4130 \mathrm{pg} / \mathrm{ml}$ and a functional sensitivity of $<50 \mathrm{pg} / \mathrm{ml}$. Creatine kinase-MB isoenzyme (CK-MB) plasma levels were assessed every 6 hours, until the peak CK-MB was identified.

\section{Treatment}

All patients were planned to undergo PPCI and were treated according to the On-TIME 2 study protocol, randomly assigned to (pre-hospital) treatment with tirofiban (25 $\mu \mathrm{g} / \mathrm{kg}$ bolus and $0.15 \mu \mathrm{g} / \mathrm{kg} / \mathrm{min}$ maintenance infusion for $18 \mathrm{~h}$ ) or placebo. PPCI was performed with standard techniques if the coronary anatomy was suitable for angioplasty. Additional treatment with stents and devices was to the discretion of the 
treating cardiologist. All patients were treated with optimal drug-therapy including angiotensin-converting enzyme inhibitors, $\beta$-blockers, aspirin and a statin. Final discharge and admission duration was to the discretion of the treating cardiologist, irrespective of NT-proBNP values.

\section{Endpoints}

The primary endpoint was the occurrence of AF/atrial flutter/atrial tachycardia $>30$ seconds, either on a telemetry strip or on a 12-lead ECG, in accordance with European guidelines ${ }^{12}$ within 30 days after admission. Patients were on telemetry during the first 48 hours after admission, and an ECG was performed once every $24 \mathrm{~h}$, or whenever deemed necessary. Whenever a patient experienced symptoms and was not on telemetry, an ECG was performed immediately.

\section{Statistical analysis}

Continuous variables were expressed as mean with standard deviation (SD). NTproBNP plasma values were expressed as mean with $\mathrm{SD}$, range and median value. STEMI patients who developed AF $<30$ days after admission for PPCI were categorized to the 'incident AF' group. The patients with incident AF were divided among three subgroups depending on the timing of the first AF episode. Patients who developed $\mathrm{AF}<24$ hours after admission were categorized to the 'AF on admission' subgroup. Patients who developed AF $<30$ days after admission, but $24-72 \mathrm{~h}$ after admission were additionally categorized to the 'AF 24-72 hours after admission' subgroup. Patients who developed AF $<30$ days after admission but $>72 \mathrm{~h}$ after admission were categorized to the ' $\mathrm{AF}>72 \mathrm{~h}$ after admission' subgroup, as displayed in Figure 1. Baseline characteristics were compared with a Mann-Whitney U-test in case of continuous variables and Chi-squared test in case of dichotomous or categorical data, except for previous coronary artery bypass grafting (CABG) and stroke, in which case a Fisher's exact test was used due to the number of cells with a value $<5$. Mean NT-proBNP values were compared between AF and AF free patients with a MannWhitney U-test. Receiver operating characteristic (ROC) analysis was performed to determine the area under the curve (AUC) of the three NT-proBNP plasma level assessment timings in predicting $\mathrm{AF}$ in the four groups. ROC curves were compared as described by Hanley and McNeill ${ }^{13}$ using Medcalc v13.3.1 (Medcalc Software bvba, Ostend, Belgium). The association between patient characteristics, biomarkers and incident $\mathrm{AF}$ was assessed with a binary logistic model, with variables being entered in the model. A multivariate model was created for incident AF and the AF on admission subgroup, with variables with a $\mathrm{P}$ value $<0.05$ in univariate analysis being eligible to be entered into the model. No multivariate analysis was performed in the AF 24-72 h 
after admission and $\mathrm{AF}>72 \mathrm{~h}$ after admission subgroups due to the limited number of endpoints in these subgroups. Whenever a multivariate model was created, use of study medication was also included in the multivariate model. The difference between patient age in smoking vs. non-smoking patients was assessed with a Mann-Whitney U-test. Statistical analysis was performed using IBM SPSS statistics version 20 (IBM Inc., Armonk, NY, USA). A P value of $\leq 0.05$ was considered statistically significant.

\section{RESULTS}

984 patients were admitted with the diagnosis of STEMI. A total of 861 patients underwent PPCI. Baseline characteristics of the whole study population have been previously reported. ${ }^{11}$ 30-day follow-up was present in 830 patients, who were included in the analysis. Baseline characteristics of the study population are displayed in Table 1.

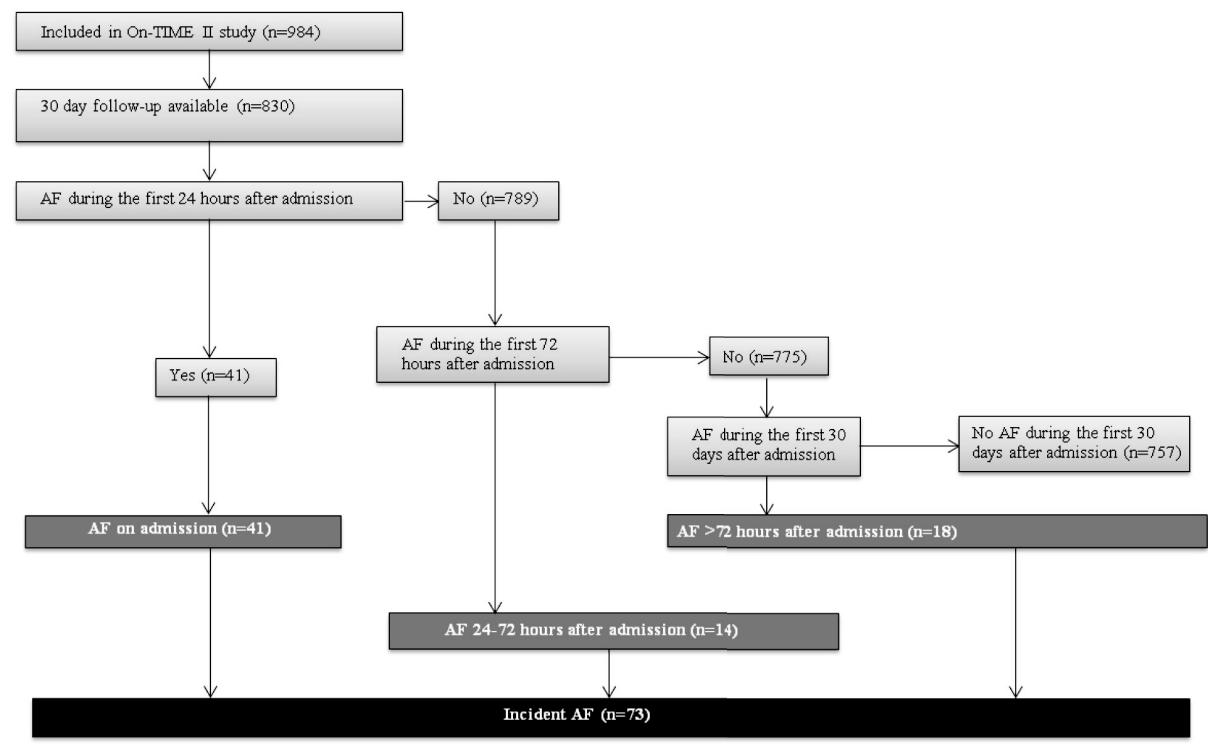

Figure 1. Flow chart of patient categorization into AF subgroups. AF: atrial fibrillation; NT-proBNP: $\mathrm{N}$-terminal pro-brain natriuretic peptide. 
Table 1. Baseline characteristics

\begin{tabular}{|c|c|c|c|c|}
\hline & $\begin{array}{l}\text { Total } \\
(\mathrm{N}=830)\end{array}$ & $\begin{array}{l}\text { AF free } \\
(\mathrm{N}=757)\end{array}$ & $\begin{array}{l}\text { Incident AF } \\
(\mathrm{N}=73)\end{array}$ & $\begin{array}{l}\mathrm{P} \\
\text { value } \\
\end{array}$ \\
\hline Age (years) & $62.1(\mathrm{SD} 11.6)$ & $61.5(\mathrm{SD} 11.5)$ & 68.4 (SD 10.9) & $<0.001$ \\
\hline Male gender & $631 / 830(76.0 \%)$ & $580 / 757(76.6 \%)$ & $51 / 73(69.9 \%)$ & 0.197 \\
\hline BMI $\left(\mathrm{kg} / \mathrm{m}^{2}\right)$ & $26.9(\mathrm{SD} 3.7)$ & 26.9 (SD 3.7) & $26.4(\mathrm{SD} 3.5)$ & 0.126 \\
\hline Current smoker & $402 / 827(48.6 \%)$ & $375 / 755(49.7 \%)$ & $27 / 72(37.5 \%)$ & 0.048 \\
\hline Diabetes & $89 / 829(10.2 \%)$ & $77 / 756(10.2 \%)$ & $12 / 73(16.4 \%)$ & 0.099 \\
\hline Hypertension & $276 / 830(33.3 \%)$ & $251 / 757(33.2 \%)$ & $25 / 73(34.2 \%)$ & 0.850 \\
\hline Hypercholesterolemia & $214 / 829(25.8 \%)$ & $195 / 756(25.8 \%)$ & $19 / 73(26.0 \%)$ & 0.965 \\
\hline Killip Class $>1$ & 96/821 (11.7\%) & 78/749 (10.4\%) & $18 / 72(25.0 \%)$ & $<0.001$ \\
\hline Previous MI & $68 / 828(8.2 \%)$ & $62 / 755(8.2 \%)$ & $6 / 73(8.2 \%)$ & 0.998 \\
\hline Previous PCI & $68 / 830(8.2 \%)$ & $65 / 757(8.3 \%)$ & $5 / 73(6.8 \%)$ & 0.661 \\
\hline Previous $\mathrm{CABG}$ & $12 / 830(1.4 \%)$ & $11 / 757(1.5 \%)$ & $1 / 73(1.4 \%)$ & $>0.99$ \\
\hline Previous stroke & $15 / 830(1.8 \%)$ & $151 / 757(2.0 \%)$ & $0 / 73(0 \%)$ & 0.634 \\
\hline Systolic BP (mmHg) & $130.9(\mathrm{SD} 24.1)$ & $131.3(\mathrm{SD} 23.8)$ & $126.2(\mathrm{SD} 24.6)$ & 0.143 \\
\hline Diastolic BP (mmHg) & 76.6 (SD 15.0) & 76.8 (SD 14.8) & $74.3(\mathrm{SD} 16.1)$ & 0.306 \\
\hline Tirofiban study medication & $406 / 830(48.9 \%)$ & $369 / 757(48.7 \%)$ & $37 / 73(50.7 \%)$ & 0.752 \\
\hline Culprit vessel & & & & 0.997 \\
\hline Culprit vessel RCA & $390 / 821(47.5 \%)$ & 355/748 (47.5\%) & $35 / 73(47.9 \%)$ & \\
\hline Culprit vessel LAD & $340 / 821(41.4 \%)$ & $310 / 748(41.4 \%)$ & $30 / 73(41.1 \%)$ & \\
\hline Culprit vessel LCx & $91 / 821(11.1 \%)$ & $83 / 748(11.1 \%)$ & $8 / 73(11.0 \%)$ & \\
\hline TIMI grade flow post $\mathrm{PCI}<3$ & $74 / 823(9.0 \%)$ & $62 / 750(8.3 \%)$ & $12 / 73(16.4 \%)$ & 0.020 \\
\hline NT-proBNP baseline (pg/ml) & 589 (SD 1896) & 517 (SD 1490) & 1339 (SD 4178) & $<0.001$ \\
\hline hs-cTnT (pg/ml) & $0.380(\mathrm{SD} 1.27)$ & $0.358(\mathrm{SD} 1.12)$ & 0.610 (SD 2.32) & 0.008 \\
\hline Peak CK-MB (U/1) & 216 (SD 197) & 207 (SD 189) & 303 (SD 245) & 0.001 \\
\hline
\end{tabular}

Data are presented as mean with their SD between parentheses or fraction with percentages where appropriate. $\mathrm{AF}$, atrial fibrillation; BMI, body mass index; MI, myocardial infarction; PCI, percutaneous coronary intervention; $\mathrm{CABG}$, coronary artery bypass grafting; $\mathrm{BP}$, blood pressure; RCA, right coronary artery; LAD, left anterior descending artery; LCx, left circumflex artery; TIMI, thrombolysis in myocardial infarction; NT-proBNP, Nterminal pro-brain natriuretic peptide; hs-cTnT, high-sensitivity cardiac troponin T; CK-MB, creatine kinase; MB, isoenzyme. $\mathrm{SD}$, standard deviation.

$\mathrm{P}$ value between $\mathrm{AF}$ free and incident AF patient groups.

\section{Atrial fibrillation}

73 patients $(8.8 \%$ ) developed $\mathrm{AF}<30$ days after STEMI, of whom 41 developed $\mathrm{AF}$ during the first $24 \mathrm{~h}$ after admission, 14 patients developed AF $24-72 \mathrm{~h}$ after admission and 18 patients developed AF $>72 \mathrm{~h}$ after admission, as displayed in Figure 1. Patients who developed AF were older (61.5 vs. 68.4 years, $\mathrm{P}<0.001$ ), less often smokers ( $49.7 \%$ vs. $37.5 \%)$, with more often a Killip Class $>1(10.4 \%$ vs. $25.0 \%, \mathrm{P}<0.001)$ and a Thrombolysis in Myocardial Infarction (TIMI) grade flow $<3$ after PCI $(8.3 \%$ vs. $16.4 \%, \mathrm{P}=0.020$ ), with a higher mean NT-proBNP plasma level at baseline (517 vs. $1339 \mathrm{pg} / \mathrm{ml}, \mathrm{P}<0.001$ ), a higher high-sensitivity cardiac troponin $\mathrm{T}$ (hs-cTnT) level 
( 0.358 vs. $0.610 \mathrm{pg} / \mathrm{ml}, \mathrm{P}=0.007)$ and a higher peak CK-MB plasma ( 207 vs. $303 \mathrm{U} / \mathrm{l}$, $\mathrm{P}=0.001$ ), as displayed in Table 1 . Table 2 displays the NT-proBNP plasma levels at all three timings.

\section{Association between NT-proBNP and incident AF}

NT-proBNP at baseline was a significant predictor of incident AF (AUC 0.657, $\mathrm{P}<0.001$ ), as displayed in Table 3. In univariate analysis, age (odds ratio (OR) 1.056, $\mathrm{P}<0.001$ ), smoking (OR 0.608, $\mathrm{P}=0.050$ ), Killip Class $>1$ (OR 2.868, $\mathrm{P}<0.001$ ), TIMI flow post $\mathrm{PCI}<3$ (OR 2.183, $\mathrm{P}=0.023$ ) and NT-proBNP at baseline (OR 1.128, $\mathrm{P}=0.010$ ) were associated with incident $\mathrm{AF}$. Of note, current smokers were significantly younger compared to non-smokers (57.2 vs. 66.7 years, $\mathrm{P}<0.001)$. Table 4 displays the univariate and multivariate analyses for incident AF. In multivariate analysis, age (adjusted OR 1.058, $\mathrm{P}<0.001$ ) and Killip Class $>1$ (adjusted OR 3.253, $\mathrm{P}<0.001)$ were significantly associated with incident $\mathrm{AF}$. Of note, in multivariate analysis, NT-proBNP at baseline was not associated with incident AF (OR 1.065, $\mathrm{P}=0.162$ ).

Table 2. NT-proBNP levels

\begin{tabular}{|c|c|c|c|c|}
\hline & Total & AF free & Not AF free & $P$ value \\
\hline \multicolumn{5}{|c|}{ NT-proBNP at baseline $(\mathrm{N}=810)$} \\
\hline mean $\pm \mathrm{SD}$ & $589(\mathrm{SD} 1896) \mathrm{pg} / \mathrm{ml}$ & $517(\mathrm{SD} 1490) \mathrm{pg} / \mathrm{ml}$ & 1339 (SD 4178) pg/ml & \multirow[t]{3}{*}{$<0.001$} \\
\hline range & $9-33927 \mathrm{pg} / \mathrm{ml}$ & $9-19095 \mathrm{pg} / \mathrm{ml}$ & $27-33927 \mathrm{pg} / \mathrm{ml}$ & \\
\hline median & $134 \mathrm{pg} / \mathrm{ml}$ & $124 \mathrm{pg} / \mathrm{ml}$ & $270 \mathrm{pg} / \mathrm{ml}$ & \\
\hline \multicolumn{5}{|c|}{ NT-proBNP after 24 hours $(\mathrm{N}=652)$} \\
\hline mean $\pm \mathrm{SD}$ & $2150(\mathrm{SD} 2810) \mathrm{pg} / \mathrm{ml}$ & 1943 (SD 2452) pg/ml & $4240($ SD 4735$) \mathrm{pg} / \mathrm{ml}$ & \multirow[t]{3}{*}{$<0.001$} \\
\hline range & $45-20653 \mathrm{pg} / \mathrm{ml}$ & $45-20653 \mathrm{pg} / \mathrm{ml}$ & $312-19497 \mathrm{pg} / \mathrm{ml}$ & \\
\hline median & $1318 \mathrm{pg} / \mathrm{ml}$ & $1244 \mathrm{pg} / \mathrm{ml}$ & $2256 \mathrm{pg} / \mathrm{ml}$ & \\
\hline \multicolumn{5}{|c|}{ NT-proBNP after 72 hours $(N=544)$} \\
\hline mean \pm SD & 1797 (SD 4289) pg/ml & 1377 (SD 2057) pg/ml & $7675(\mathrm{SD} 13568) \mathrm{pg} / \mathrm{ml}$ & \multirow[t]{3}{*}{$<0.001$} \\
\hline range & $17-25507$ & $17-25507 \mathrm{pg} / \mathrm{ml}$ & $214-24119$ & \\
\hline median & $885 \mathrm{pg} / \mathrm{ml}$ & $809 \mathrm{pg} / \mathrm{ml}$ & $3224 \mathrm{pg} / \mathrm{ml}$ & \\
\hline
\end{tabular}

Data are presented as mean with their SD between parentheses, range or median. AF, atrial fibrillation; NT-proBNP, N-terminal pro-brain natriuretic peptide. $P$ value between mean NT-proBNP values of AF free and not AF-free patients. $\mathrm{P}$ value between mean NT-proBNP values. 
Table 3. Areas under the curve of NT-proBNP for the prediction of atrial fibrillation

\begin{tabular}{|c|c|c|c|c|c|c|}
\hline & $\begin{array}{l}\text { NT-proBNP } \\
\text { at baseline }\end{array}$ & $\begin{array}{l}\mathrm{P} \\
\text { value }\end{array}$ & $\begin{array}{l}\text { NT-proBNP } \\
\text { after } 24 \mathrm{~h}\end{array}$ & $\begin{array}{l}\mathrm{P} \\
\text { value }\end{array}$ & $\begin{array}{l}\text { NT-proBNP } \\
\text { after } 72 \mathrm{~h}\end{array}$ & $\begin{array}{l}\mathrm{P} \\
\text { value }\end{array}$ \\
\hline Incident AF & $\begin{array}{l}0.657 \\
(\mathrm{SE} 0.034)\end{array}$ & $<0.001$ & N/A & & N/A & \\
\hline $\mathrm{AF}$ on admission & $\begin{array}{l}0.591 \\
\text { (SE 0.049) }\end{array}$ & 0.058 & N/A & & N/A & \\
\hline $\begin{array}{l}\text { AF } 24-72 \mathrm{~h} \\
\text { after admission }\end{array}$ & $\begin{array}{l}0.747 \\
(\text { SE } 0.060)\end{array}$ & 0.002 & $\begin{array}{l}0.829 \\
\text { (SE 0.045) }\end{array}$ & $<0.001$ & N/A & \\
\hline $\begin{array}{l}\mathrm{AF}>72 \mathrm{~h} \\
\quad \text { after admission }\end{array}$ & $\begin{array}{l}0.705 \\
\text { (SE 0.053) }\end{array}$ & 0.003 & $\begin{array}{l}0.736 \\
\text { (SE 0.061) }\end{array}$ & 0.001 & $\begin{array}{l}0.891 \\
\text { (SE 0.057) }\end{array}$ & $<0.001$ \\
\hline
\end{tabular}

Data are presented as AUC (SE). SE, standard error; AF, atrial fibrillation; NT-proBNP, N-terminal pro-brain natriuretic peptide.

$P$ values of AUC.

$P$ values between AUCs:

$\mathrm{AF}>24 \mathrm{~h}$ after admission $\mathrm{NT}$-proBNP at baseline vs. NT-proBNP after $24 \mathrm{~h}$ : $\quad$-statistic $1.177, \quad \mathrm{P}=0.239$

$\mathrm{AF}>72 \mathrm{~h}$ after admission NT-proBNP at baseline vs. NT-proBNP after $24 \mathrm{~h}$ : $\quad \mathrm{z}$-statistic $3.111, \quad \mathrm{P}=0.002$

$\mathrm{AF}>72 \mathrm{~h}$ after admission NT-proBNP at baseline vs. NT-proBNP after $72 \mathrm{~h}: \quad \mathrm{z}$-statistic $2.779, \quad \mathrm{P}=0.006$

$\mathrm{AF}>72 \mathrm{~h}$ after admission NT-proBNP after $24 \mathrm{~h}$ vs. NT-proBNP after $72 \mathrm{~h}: \quad \mathrm{z}$-statistic $0.495, \quad \mathrm{P}=0.621$

\section{Association between NT-proBNP and AF on admission}

NT-proBNP at baseline did not significantly predict AF on admission (AUC 0.591, $\mathrm{P}=0.058$ ), as displayed in Table 3. In univariate analysis, only Killip Class $>1$ was significantly associated with AF on admission (OR 2.694, $\mathrm{P}=0.010)$. NT-proBNP at baseline was not associated with $\mathrm{AF}$ on admission (OR 1.044, $\mathrm{P}=0.473$ ). In multivariate analysis, only Killip Class $>1$ was significantly associated with AF on admission (adjusted OR 2.784, $\mathrm{P}=0.008$ ). Table 5 displays the univariate and multivariate analyses for AF on admission.

\section{Association between NT-proBNP and AF 24-72 h after admission}

NT-proBNP at baseline was a significant predictor of AF $24-72 \mathrm{~h}$ after admission (AUC 0.747, $\mathrm{P}=0.002$ ). NT-proBNP after $24 \mathrm{~h}$ also significantly predicted AF 24-72 $\mathrm{h}$ after admission (AUC 0.829, $\mathrm{P}<0.001$ ). There was no significant difference in AUC between NT-proBNP at baseline and NT-proBNP after $24 \mathrm{~h}$ (z-statistic 1.177, $\mathrm{P}=0.239$ ), as displayed in Table 3. In univariate analysis, age (OR 1.117, $\mathrm{P}<0.001$ ), Killip Class $>1$ (OR 3.341, $\mathrm{P}=0.045$ ), TIMI grade flow $<3$ (OR 4.476, $\mathrm{P}=0.013$ ), NTproBNP plasma level at baseline (OR 1.186, $\mathrm{P}=0.002)$ and after $24 \mathrm{~h}(\mathrm{OR} 1.220$, $\mathrm{P}<0.001$ ), hs-cTnT plasma level (OR 1.027, $\mathrm{P}=0.001$ ) and peak $\mathrm{CK}-\mathrm{MB}$ plasma level (OR 1.213, $\mathrm{P}=0.047$ ) were significantly associated with $\mathrm{AF} 24-72 \mathrm{~h}$ after admission. Table 6 displays the univariate analysis for AF 24-72 h after admission. 


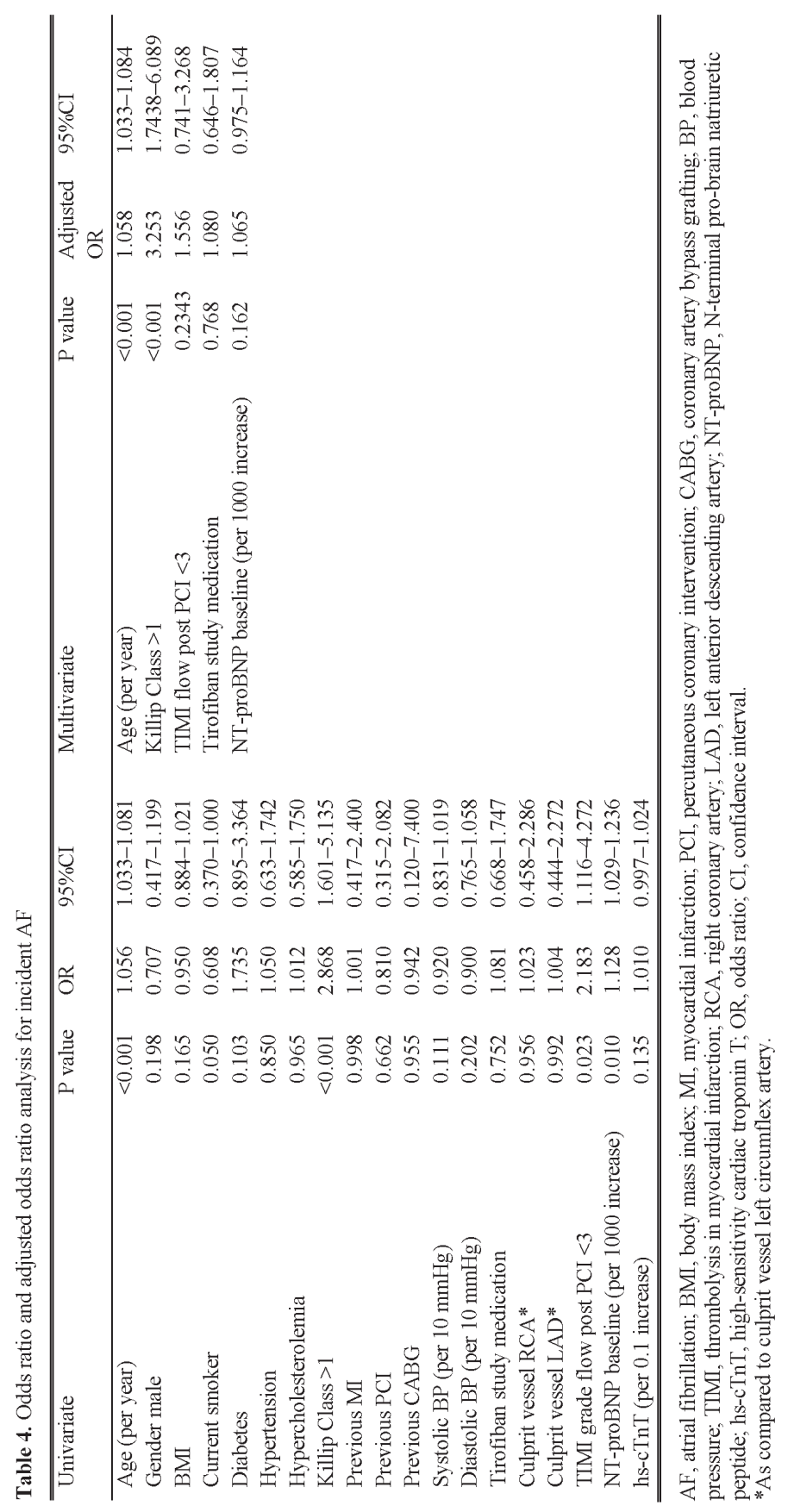




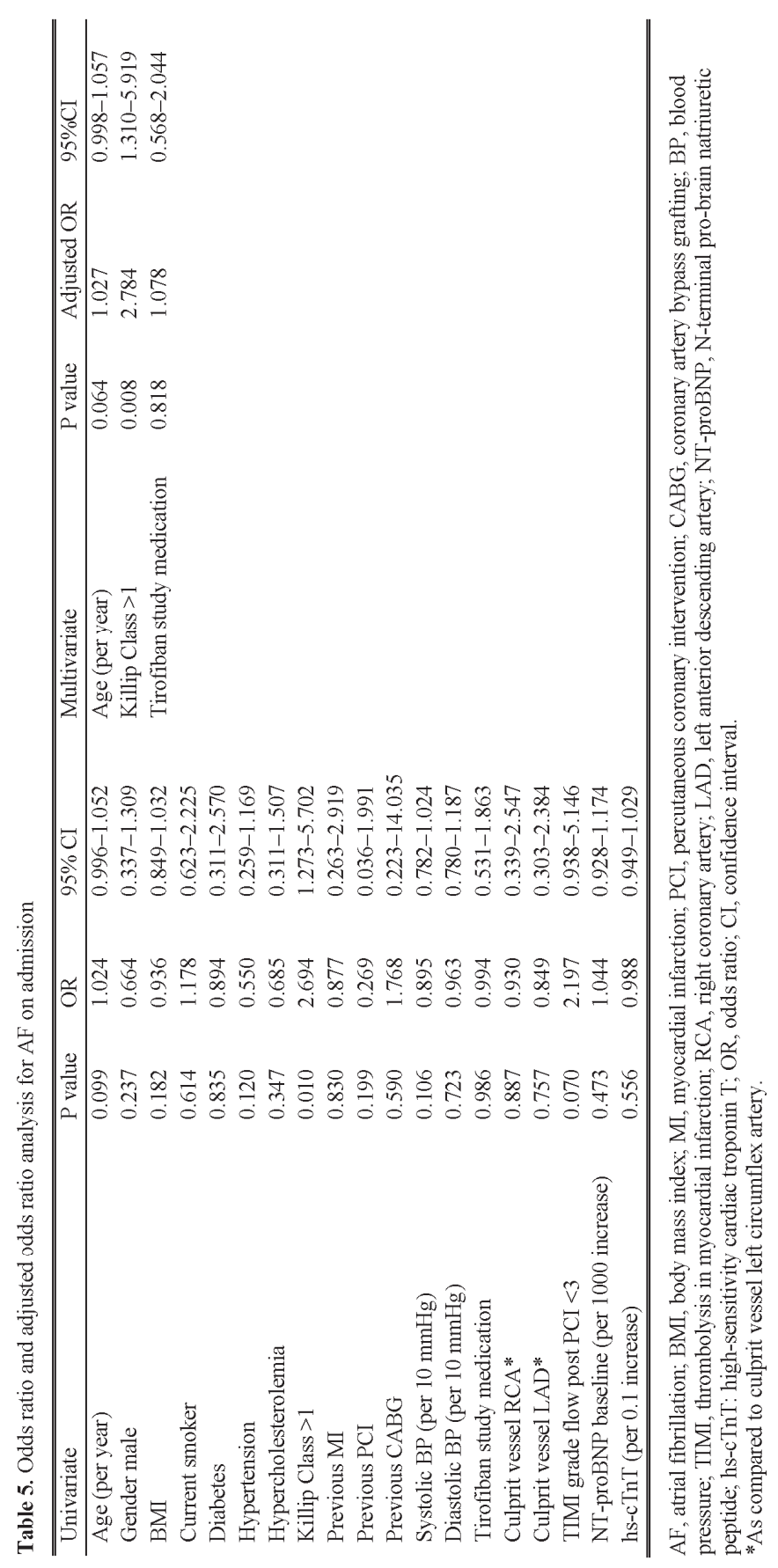


Table 6. Odds ratio analysis for AF 24-72 $\mathrm{h}$ after admission

\begin{tabular}{lrll}
\hline \hline Univariate & P value & OR & 95\%CI \\
\hline Age (per year) & $<0.001$ & 1.117 & $1.050-1.188$ \\
Gender male & 0.287 & 0.548 & $0.182-1.657$ \\
BMI & 0.287 & 0.916 & $0.778-1.077$ \\
Current smoker & 0.055 & 0.285 & $0.079-1.030$ \\
Diabetes & 0.208 & 2.302 & $0.629-8.419$ \\
Hypertension & 0.206 & 1.981 & $0.687-5.707$ \\
Hypercholesterolemia & 0.686 & 0.767 & $0.212-2.777$ \\
Killip Class $>1$ & 0.045 & 3.341 & $1.025-10.895$ \\
Previous MI & 0.878 & 0.852 & $0.110-6.619$ \\
Systolic BP (per 10 mmHg) & 0.702 & 1.044 & $0.839-1.298$ \\
Diastolic BP (per 10 mmHg) & 0.317 & 0.827 & $0.570-1.199$ \\
Tirofiban study medication & 0.324 & 0.575 & $0.191-1.730$ \\
Culprit vessel RCA* & 0.756 & 1.401 & $0.166-11.792$ \\
Culprit vessel LAD* & 0.558 & 1.877 & $0.228-15.465$ \\
TIMI grade flow post PCI $<3$ & 0.013 & 4.476 & $1.365-14.682$ \\
NT-proBNP baseline (per 1000 increase) & 0.002 & 1.186 & $1.063-1.324$ \\
NT-proBNP 24 h (per 1000 increase) & $<0.001$ & 1.220 & $1.112-1.340$ \\
hs-cTnT (per 0.1 increase) & 0.001 & 1.027 & $1.011-1.043$ \\
Peak CK-MB (per 100 increase) & 0.047 & 1.213 & $1.003-1.467$ \\
\hline \hline
\end{tabular}

AF, atrial fibrillation; BMI, body mass index; MI, myocardial infarction; PCI, percutaneous coronary intervention; CABG, coronary artery bypass grafting; BP, blood pressure; TIMI, thrombolysis in myocardial infarction; RCA, right coronary artery; LAD, left anterior descending artery; NT-proBNP, N-terminal pro-brain natriuretic peptide; hs-cTnT, high-sensitivity cardiac troponin T; OR, odds ratio; CI, confidence interval.

*As compared to culprit vessel left circumflex artery.

\section{Association between NT-proBNP and AF $>72$ h after admission}

NT-proBNP at baseline (AUC 0.705, $\mathrm{P}=0.003$ ), after $24 \mathrm{~h}(\mathrm{AUC}$ 0.736, $\mathrm{P}=0.001)$ and after $72 \mathrm{~h}$ (AUC $0.891, \mathrm{P}<0.001$ ) significantly predicted $\mathrm{AF}>72 \mathrm{~h}$ after admission, as displayed in Table 3. NT-proBNP after 24 hours was a significantly stronger predictor of AF $>72$ hours after admission compared to NT-proBNP at baseline (z-statistic 3.111, $\mathrm{P}=0.002$ ). Furthermore, NT-proBNP after $72 \mathrm{~h}$ was a significantly stronger predictor of $\mathrm{AF}>72 \mathrm{~h}$ after admission compared to NT-proBNP at baseline (z-statistic 2.779, $\mathrm{P}=0.006$ ). There was no significant difference in AUC between NT-proBNP after $24 \mathrm{~h}$ and NT-proBNP after $72 \mathrm{~h}$ in the prediction of AF (z-statistic 0.495, $\mathrm{P}=0.621$ ), as displayed in Table 3. In univariate analysis, age (OR 1.094, $\mathrm{P}<0.001$ ), current smoking (OR 0.203, $\mathrm{P}=0.012$ ), history of diabetes ( $\mathrm{OR} 3.392, \mathrm{P}=0.024$ ), 
(OR 3.147, P=0.049) NT-proBNP after $24 \mathrm{~h}(\mathrm{OR} 1.193, \mathrm{P}<0.001)$ and after $72 \mathrm{~h}(\mathrm{OR}$ $1.290, \mathrm{P}<0.001$ ) and peak $\mathrm{CK}-\mathrm{MB}$ plasma level (OR 1.230, $\mathrm{P}=0.014)$ were significantly associated with $\mathrm{AF}>72 \mathrm{~h}$ after admission. In univariate analysis, NTproBNP at baseline was not associated with $\mathrm{AF}>72 \mathrm{~h}$ after admission (OR 1.070, $\mathrm{P}=0.539$ ). Of note, current smokers were significantly younger compared to nonsmokers ( 57.0 vs. 66.2 years, $\mathrm{P}<0.001)$. Table 7 displays the univariate analysis for $\mathrm{AF}$ $>72 \mathrm{~h}$ after admission.

Table 7. Odds ratio analysis for $\mathrm{AF}>72 \mathrm{~h}$ after admission

\begin{tabular}{lrrl}
\hline \hline Univariate & P value & OR & $95 \%$ CI \\
\hline Age (per year) & $<0.001$ & 1.094 & $1.041-1.150$ \\
Gender male & 0.909 & 1.068 & $0.347-3.286$ \\
BMI & 0.941 & 1.005 & $0.885-1.141$ \\
Current smoker & 0.012 & 0.203 & $0.058-0.706$ \\
Diabetes & 0.024 & 3.392 & $1.177-9.770$ \\
Hypertension & 0.142 & 2.016 & $0.790-5.141$ \\
Hypercholesterolemia & 0.083 & 2.302 & $0.896-5.915$ \\
Killip Class $>1$ & 0.121 & 2.458 & $0.789-7.652$ \\
Previous MI & 0.661 & 1.397 & $0.314-6.217$ \\
Previous PCI & 0.049 & 3.147 & $1.006-9.848$ \\
Systolic BP (per 10 mmHg) & 0.262 & 0.891 & $0.728-1.090$ \\
Diastolic BP (per 10 mmHg) & 0.256 & 0.832 & $0.606-1.143$ \\
Tirofiban study medication & 0.141 & 2.103 & $0.781-5.661$ \\
Culprit vessel RCA* & 0.949 & 1.052 & $0.223-4.960$ \\
Culprit vessel LAD* & 0.936 & 0.937 & $0.191-4.595$ \\
TIMI grade flow post PCI <3 & 0.681 & 0.653 & $0.085-4.987$ \\
NT-proBNP baseline (per 1000 increase) & 0.539 & 1.070 & $0.862-1.329$ \\
NT-proBNP 24 h (per 1000 increase) & $<0.001$ & 1.193 & $1.088-1.308$ \\
NT-proBNP 72 h (per 1000 increase) & $<0.001$ & 1.290 & $1.151-1.447$ \\
hs-cTnT (per 0.1 increase) & 0.513 & 0.970 & $0.884-1.063$ \\
Peak CK-MB (per 100 increase) & 0.014 & 1.230 & $1.044-1.450$ \\
\hline \hline
\end{tabular}

AF, atrial fibrillation; BMI, body mass index; MI, myocardial infarction; PCI, percutaneous coronary intervention; CABG, coronary artery bypass grafting; BP, blood pressure; TIMI, thrombolysis in myocardial infarction; RCA, right coronary artery; LAD, left anterior descending artery; NT-proBNP, N-terminal pro-brain natriuretic peptide; hs-cTnT, high-sensitivity cardiac troponin T; OR, odds ratio; CI, confidence interval.

*As compared to culprit vessel left circumflex artery. 


\section{DISCUSSION}

This study reports the temporal association between serial NT-proBNP plasma level assessments at different timings after admission and the development of AF in the setting of STEMI. Of note, NT-proBNP plasma level at baseline was not associated with incident $\mathrm{AF}$ in multivariate analysis and did not predict $\mathrm{AF}$ on admission. NTproBNP at baseline did predict AF $24-72 \mathrm{~h}$ and $>72 \mathrm{~h}$ after admission. However, NTproBNP plasma level assessment 24 and $72 \mathrm{~h}$ after admission were stronger predictors of $\mathrm{AF}>72 \mathrm{~h}$ after admission compared to NT-proBNP at baseline.

\section{NT-proBNP and incident AF}

The association between NT-proBNP and AF has been previously reported in the general population ${ }^{14}$ and previous studies have reported an association between NTproBNP and incident AF. ${ }^{9,15}$ Presumably, the increased LV diastolic pressure that results in an increase of NT-proBNP plasma level also results in an increased atrial stretch, inflammation and myocardial ischemia, which play a key role in the development of AF. ${ }^{16,17}$ This study is in accordance with these studies. However, in this study, NT-proBNP assessments were performed at three distinct timings.

\section{NT-proBNP at baseline}

This study indicates that although NT-proBNP plasma level assessment at baseline is a significant predictor of AF, the accuracy is only 0.657. However, in multivariate analysis, NT-proBNP at baseline was not associated with incident AF. Furthermore, NT-proBNP at baseline was not associated with AF on admission. The incidence of AF is thought to be influenced by atrial pressure, and thus heart failure. NT-proBNP levels substantially rise in a semi-acute fashion in acute heart failure. Possibly, the baseline assessment of NT-proBNP does not reflect the acutely elevated atrial pressure and clinical manifestations of heart failure at that moment. Furthermore, other factors such as the time to hospital admission and differences in the PPCI procedure may induce heterogeneity in patients, reducing the overall predictive value of NT-proBNP.

\section{Incident AF after STEMI and hs-cTnT}

In-hospital incident AF after STEMI has been associated with an increased left ventricular diastolic dysfunction, atrial oxidative stress and end diastolic pressure, which may increase atrial stretch and atrial pressure. ${ }^{16,18,19}$ Furthermore, atrial dysfunction, atrial ischemia, pericarditis, congestive heart failure due to ischemia, atrial reverse remodeling and enhanced sympathetic tone may also play an important role in $\mathrm{AF}$ in the setting of STEMI. ${ }^{20-24}$ An increased sympathetic tone in STEMI patients is 118 
associated with worse outcome after 2 years. ${ }^{25}$ Incident AF is associated with a higher rate of death, re-infarction, cardiogenic shock and ventricular arrhythmias, and therefore, identification of potentially high-risk patients is important. ${ }^{5,6}$ In accordance with previous studies in the healthy population ${ }^{26}$ and in STEMI patients, ${ }^{9}$ age has a strong association with the development of new-onset AF. Of note, previous studies did not report an association between hs-cTnT and AF. ${ }^{9}$ Although incident AF was not associated with hs-cTnT in univariate analysis in our present analysis, AF $>24 \mathrm{~h}$ after admission was significantly associated with hs-cTnT plasma level. Since hs-cTnT was assessed during the first $72 \mathrm{~h}$ after admission in the literature, perhaps an analysis with strict serial hs-cTnT assessment timings and peak hs-cTnT assessment may elucidate this association.

\section{Implications on current clinical practice}

This study changes the perspective on the association between NT-proBNP and AF in STEMI patients since NT-proBNP at baseline is a weak predictor of AF, and was not associated with $\mathrm{AF}$ in multivariate analysis. This suggests that the predictive characteristics of NT-proBNP plasma level assessment may alter in the days after admission, resulting in the observation that NT-proBNP $24 \mathrm{~h}$ and $72 \mathrm{~h}$ after admission were stronger predictors of AF. Therefore, NT-proBNP assessed $24 \mathrm{~h}$ or $72 \mathrm{~h}$ after admission, and not NT-proBNP at baseline, could serve as biomarker in assessing risk of incident AF in STEMI patients treated with PPCI.

\section{Limitations}

The current study is a substudy of the On-TIME 2 study and therefore, a predefined power assessment was not made for the relation of NT-proBNP and incident AF, and multivariate analysis in the AF 24-72 $\mathrm{h}$ and $>72 \mathrm{~h}$ after admission subgroups could not be performed. Therefore, this study did not determine if the association between NTproBNP and AF was independent for other variables, such as infarction size and Killip Class. Although all variables were prospectively registered, the present study is a posthoc cross-sectional analysis. All patients were kept on telemetry for at least $48 \mathrm{~h}$, but thereafter, an ECG was performed once daily. This may have caused several AF episodes not to have been documented, and therefore have influenced the outcome of this study. Furthermore, analysis was limited to those having complete data sets. 


\section{CONCLUSION}

This study shows that serial NT-proBNP plasma levels, especially determined 24 to 72 $\mathrm{h}$ after admission, may help to enhance risk stratification of patients at risk of developing incident AF in the setting of STEMI. Baseline values of NT-proBNP did not predict $\mathrm{AF}$ on admission in the present study. 


\section{REFERENCES}

1. Goldberg RJ, Seeley D, Becker RC, Brady P, Chen ZY, et al. Impact of atrial fibrillation on the in-hospital and long-term survival of patients with acute myocardial infarction: a communitywide perspective, Am Heart J 1990;119:996-1001.

2. Pedersen OD, Bagger H, Kober L, Torp-Pedersen C, et al. The occurrence and prognostic significance of atrial fibrillation/-flutter following acute myocardial infarction. TRACE Study group. TRAndolapril Cardiac Evalution, Eur Heart J 1999;20:748-754.

3. Pizzetti F, Turazza FM, Franzosi MG, Barlera S, Ledda AA. Incidence and prognostic significance of atrial fibrillation in acute myocardial infarction: the GISSI-3 data. Heart 2001;86:527-532.

4. Wann LS, Curtis AB Ellenbogen KA, Estes NA, Ezekowitz MD, et al. 2011 ACCF/AHA/HRS focused update on the management of patients with atrial fibrillation (update on dabigatran): a report of the American College of Cardiology Foundation/American Heart Association Task Force on practice guidelines. J Am Coll Cardiol 2011;57:1330-1337.

5. Schmitt J, Duray G, Gersh BJ, Hohnloser SH. Atrial fibrillation in acute myocardial infarction: a systematic review of the incidence, clinical features and prognostic implications. Eur Heart $\mathrm{J}$ 2009;30:1038-1045.

6. Jabre P, Roger VL,Murad MH, Chamberlain AM, Prokop L, et al. Mortality associated with atrial fibrillation in patients with myocardial infarction: a systematic review and meta-analysis. Circulation 2011;123:1587-1593.

7. Gal P, Parlak E, Demirel F, Elvan A, Adiyaman A, Ten Berg J, et al. Prognostic significance of incident atrial fibrillation following STEMI depends on the timing of atrial fibrillation. Neth Heart J 2015;23:430-435.

8. Gal P, Parlak E, Schellings DA, Beukema R, Ten Berg J, et al. Association of serial high sensitivity troponin $\mathrm{T}$ with onset of atrial fibrillation in ST elevation myocardial infarction patients undergoing primary percutaneous coronary intervention. Eur Heart J Acute Cardiovasc Care 2016;5:22-42.

9. Parashar S, Kella D, Reid KJ, Spertus JA, Tang F, et al. New-onset atrial fibrillation after acute myocardial infarction and its relation to admission biomarkers (from the TRIUMPH registry). Am J Cardiol 2013;112:1390-1395.

10. van 't Hof AW, Hamm C, Rasoul S, Guptha S, Paolini JF, et al. Ongoing tirofiban in myocardial infarction evaluation (On-TIME) 2 trial: rationale and study design. EuroIntervention 2007;3:371-380.

11. Van 't Hof AW, Ten Berg J, heestermans T, Dill T, Funck RC, et al. Prehospital initiation of tirofiban in patients with ST-elevation myocardial infarction undergoing primary angioplasty (On-TIME 2): a multicentre, double-blind, randomised controlled trial. Lancet 2008;372:537546.

12. Calkins H, Kuck KH, Cappato R, Brugada J, Camm AJ, et al. 2012 HRS/EHRA/ECAS Expert Consensus Statement on Catheter and Surgical Ablation of Atrial Fibrillation: recommendations for patient selection, procedural techniques, patient management and follow-up, definitions, endpoints, and research trial design. Europace 2012;14:528-606.

13. Hanley JA and McNeil BJ. A method of comparing the areas under receiver operating characteristic curves derived from the same cases. Radiology 1983;148:839-843.

14. Patton KK, Ellinor PT, Heckbert SR, Christenson RH, DeFillipi C, et al. N-terminal pro-B-type natriuretic peptide is a major predictor of the development of atrial fibrillation: the Cardiovascular Health Study Circulation 2009;120:1768-1774.

15. Asanin M, Stankovic S, Mrdovic I, Matic D, Savic L, et al. B-type natriuretic peptide predicts new-onset atrial fibrillation in patients with ST-segment elevation myocardial infarction treated by primary percutaneous coronary intervention. Peptides 2012;35:74-77. 
16. Celik S, Erdol C, Baykan M, Kaplan S, Kasap H. Relation between paroxysmal atrial fibrillation and left ventricular diastolic function in patients with acute myocardial infarction. Am J Cardiol 2001;88:160-162, A5.

17. Park J, Joung B, Uhm JS, Young Shim C, Hwang C, et al. High left atrial pressures are associated with advanced electroanatomical remodeling of left atrium and independent predictors for clinical recurrence of atrial fibrillation after catheter ablation, Heart Rhythm 2014;11:953-960.

18. Shelton RJ, Clark AL, Goode K, Rigby AS, Cleland JG. The diagnostic utility of N-terminal pro-B-type natriuretic peptide for the detection of major structural heart disease in patients with atrial fibrillation. Eur Heart J 2006;27:2353-2361.

19. Xie W, Clark AL, Goode K, Rigby AS, Cleland JG. Mitochondrial oxidative stress promotes atrial fibrillation. Sci Rep 2015 Jul;5:11427 doi: 10.1038/srep11427.

20. Crenshaw BS, Ward SR, Granger CB, Stebbins AL, Topol EJ, et al. Atrial fibrillation in the setting of acute myocardial infarction: the GUSTO-I experience. Global Utilization of Streptokinase and TPA for Occluded Coronary Arteries. J Am Coll Cardiol 1997;30:406-413.

21. Corradi D, Callegari S, Maestri R, Benussi S, Alfieri O. Structural remodeling in atrial fibrillation. Nat Clin Pract Cardiovasc Med 2008;5:782-796.

22. Zicha S, Tsuji Y, Shiroshita-Takeshita A, Nattel S. Beta-blockers as antiarrhythmic agents. Handb Exp Pharmacol 2006;235-266.

23. D'Ascia SL, D'Ascia C, Marino V, Lombardi A, Santulli R, et al. Cardiac resynchronisation therapy response predicts occurrence of atrial fibrillation in non-ischaemic dilated cardiomyopathy. Int J Clin Pract 2011;65:1149-1155.

24. Santulli G, D'Ascia SL, D'Ascia C. Development of atrial fibrillation in recipients of cardiac resyn-chronization therapy: the role of atrial reverse remodelling. Can $\mathrm{J}$ Cardiol 2012;28:245e17; author reply e17-8.

25. Santulli G, Campanile A, Spinelli L, Assante di Panzillo E, Ciccarelli M, et al. G proteincoupled receptor kinase 2 in patients with acute myocardial infarction. Am J Cardiol 2011;107:1125-1130.

26. Lloyd-Jones DM, Wang TJ, Leip EP, Larson MG, Levy D, et al. Lifetime risk for development of atrial fibrillation: the Framingham Heart Study. Circulation 2004;110:1042-1046. 


\title{
CHAPTER 9
}

Association of serial high-sensitivity troponin $\mathrm{T}$ with onset of atrial fibrillation in ST-elevation myocardial infarction patients undergoing primary percutaneous coronary intervention

\author{
P. Gal, E. Parlak \\ D.A.A.M. Schellings, R. Beukema \\ J.M. ten Berg, A. Adiyaman
}

A.W.J. van 't Hof, A. Elvan

European Heart Journal: Acute Cardiovascular Care 2016;5:33-42

doi: $10.1177 / 2048872615570220$ 

ABSTRACT

Aims. Previous reports claimed that high-sensitivity troponin $\mathrm{T}$ (HsTnT) is not associated with atrial fibrillation (AF) in the setting of acute ST-elevation myocardial infarction (STEMI) and primary percutaneous coronary intervention. However, the association of serial HsTnT levels and new-onset AF is unknown. Therefore we assessed the temporal association between HsTnT levels and post-infarction AF.

Methods and Results. 830 patients enrolled in On-TIME 2 were included. HsTnT was assessed at baseline, $24 \mathrm{~h}$ and $72 \mathrm{~h}$ after admission for STEMI. New-onset AF episodes were divided among three subgroups: AF during the first $24 \mathrm{~h}$ of admission, AF 24-72 $\mathrm{h}$ after admission and $\mathrm{AF}>72 \mathrm{~h}$ after admission. ROC analysis and binary logistic regression were performed. Mean age was $62 \pm 12$ years and $76 \%$ were male. Seventythree patients developed new-onset AF: 41 patients developed AF during the first $24 \mathrm{~h}$ of admission, 14 patients developed AF 24-72 h after admission and 18 patients developed $\mathrm{AF}>72 \mathrm{~h}$ after admission. HsTnT at baseline was associated with new-onset $\mathrm{AF}$ (area under curve (AUC) 0.596, $\mathrm{P}=0.008$ ), but not with $\mathrm{AF}$ during the first $24 \mathrm{~h}$ of admission (AUC: 0.539, $\mathrm{P}=0.414$ ). HsTnT after $24 \mathrm{~h}(\mathrm{AUC}$ 0.792, $\mathrm{P}=0.001$ ) and after $72 \mathrm{~h}$ (AUC: 0.884, $\mathrm{P}<0.001$ ) were associated with $\mathrm{AF} 24-72 \mathrm{~h}$ and $>72 \mathrm{~h}$ after admission. HsTnT after $24 \mathrm{~h}$ and $72 \mathrm{~h}$ were stronger predictors of $\mathrm{AF}$ compared to $\mathrm{HsTnT}$ at baseline. In regression analysis, age (odds ratio (OR) 1.056, $\mathrm{P}<0.001$ ), Killip Class $>1$ (OR: 2.694, $\mathrm{P}=0.010)$ and HsTnT after $24 \mathrm{~h}(\mathrm{OR}: 1.012, \mathrm{P}=0.017)$ and after $72 \mathrm{~h}(\mathrm{OR}: 1.035, \mathrm{P}<0.001)$ showed the strongest association with post-infarction AF.

Conclusion. Serial HsTnT plasma levels are associated with post-infarction, new-onset $\mathrm{AF}$.

\section{INTRODUCTION}

New-onset atrial fibrillation (AF) occurs in $5-23 \%$ of patients admitted due to STelevation myocardial infarction (STEMI) ${ }^{1-4}$ and is associated with impaired long-term cardiovascular outcome, including a $40 \%$ increase in mortality. ${ }^{5,6}$ A recent study showed that new-onset AF after STEMI was not related to high-sensitivity troponin $\mathrm{T}$ HsTnT) plasma levels. ${ }^{7}$ However, HsTnT was assessed somewhere during the first 72 $\mathrm{h}$ after admission and thus no data was reported on the relationship between timing of HsTnT plasma level assessment and timing of onset of AF in the setting of STEMI. The aim of this study was to investigate if assessment of HsTnT plasma levels at three distinct timings enhances the risk stratification of patients developing $\mathrm{AF}$ after a primary percutaneous coronary intervention (PPCI) in STEMI patients. 


\section{METHODS}

Our population consisted of patients with a STEMI, who were admitted for PPCI and included in the Ongoing Tirofiban in Myocardial Infarction Evaluation (On-TIME) 2 study, ${ }^{8,9}$ a prospective, multicenter, placebo-controlled, randomized, clinical trial. The rationale, design and primary results of On-TIME 2 have been previously described. ${ }^{9}$ Briefly, enrollment was from June 2006 to November 2007. Eligible patients were aged 21-85 years with symptoms of acute myocardial infarction of more than $30 \mathrm{~min}$ but less than $24 \mathrm{~h}$ and ST-segment elevation of more than $1 \mathrm{mV}$ in two adjacent electrocardiograph (ECG) leads. Exclusion criteria were severe renal dysfunction (glomerular filtration rate $<30 \mathrm{ml} / \mathrm{min}$ or serum creatinine $>200 \mathrm{mmol} / \mathrm{l}(>2.5 \mathrm{mg} / \mathrm{dl}$ ), therapy-resistant cardiogenic shock (systolic blood pressure $\leq 80 \mathrm{mmHg}$ for $>30 \mathrm{~min}$ ), persistent severe hypertension (systolic pressure $>180 \mathrm{mmHg}$ or diastolic pressure $>110 \mathrm{mmHg}$ ), or a contraindication to anticoagulation or increased risk of bleeding. Also, patients with a left bundle branch block, pregnant and/or breastfeeding women, and patients with a life expectancy of less than 1 year were excluded. For the present study, patients with a history of AF were excluded. From each patient, a written informed consent for participation in the On-TIME 2 study was obtained. The local ethics committees approved the study protocol.

\section{Treatment}

All patients were planned to undergo PPCI and were treated according to the On-TIME 2 study protocol, randomly assigned to (pre-hospital) treatment with tirofiban (25 $\mu \mathrm{g} / \mathrm{kg}$ bolus and $0.15 \mu \mathrm{g} / \mathrm{kg} / \mathrm{min}$ maintenance infusion for $18 \mathrm{~h}$ ) or placebo. PPCI was performed with standard techniques if the coronary anatomy was suitable for angioplasty. Additional treatment with stents and devices was to the discretion of the treating cardiologist. All patients were treated with optimal drug-therapy including angiotensin-converting enzyme inhibitors, $\beta$-blockers, aspirin and a statin. Final discharge and admission duration was to the discretion of the treating cardiologist, irrespective of HsTnT values.

\section{Measurements}

HsTnT plasma levels were measured in each patient at baseline after sheath insertion before PPCI was performed, $24 \mathrm{~h}$ after admission and $72 \mathrm{~h}$ after admission. All plasma samples were analyzed in a core laboratory (Heidelberg, Germany), using the $4^{\text {th }}$ generation HsTnT assay by Roche (Roche group, Basel, Switzerland), with a lower limit of detection of $0.010 \mathrm{pg} / \mathrm{ml}$ and a $10 \% \mathrm{CV}$ of 0.035 . 


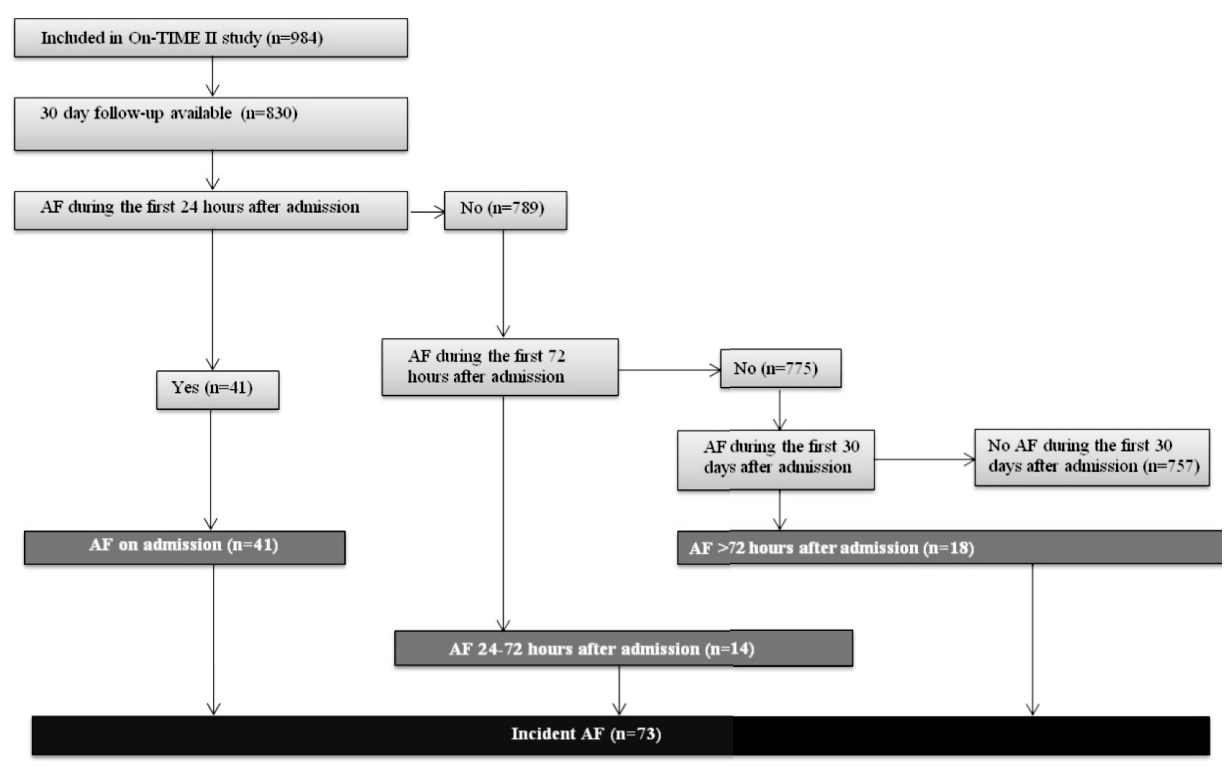

Figure 1. Flow chart of patient categorization into AF subgroups. AF, atrial fibrillation.

\section{Endpoints}

The primary endpoint was the occurrence of AF/atrial flutter/atrial tachycardia $>30$ seconds, either on a telemetry strip or on a 12-lead ECG, in accordance with European guidelines within 30 days after admission. Patients were on telemetry during the first 48 hours after admission, and an ECG was performed once every $24 \mathrm{~h}$, or whenever deemed necessary. Whenever a patient experienced symptoms and was not on telemetry, an ECG was performed immediately.

\section{Statistical analysis}

Of all patients included in the On-TIME 2 study, patients with 3 HsTnT plasma level assessments were included. Continuous variables were expressed as mean with standard deviation (SD). HsTnT plasma values were expressed as mean with SD, range and median value. Patients who had their first episode of $\mathrm{AF}<30$ days after admission were categorized to the 'new-onset $A F$ ' group. Patients who had their first AF episode 
on the first day of admission were categorized to the 'AF during the first $24 \mathrm{~h}$ of admission' subgroup. Patients who developed AF 24-72 h after admission were categorized to the 'AF 24-72 $h$ after admission' subgroup. Patients who developed AF $<30$ days after admission but $>72$ hours after admission were categorized to the ' $A F$ $>72 \mathrm{~h}$ after admission' subgroup, as displayed in Figure 1. Baseline characteristics were compared with a Mann-Whitney U-test in case of continuous variables and Chisquared test in case of dichotomous or categorical data, except when the number of cells with a value of $<5$ exceeded $20 \%$, in which case a Fisher's exact test was used. HsTnT plasma level assessments were performed at baseline, $24 \mathrm{~h}$ after admission and $72 \mathrm{~h}$ after admission. Receiver operating characteristic (ROC) analysis was performed to determine the area under the curve (AUC) of the three HsTnT plasma level assessment timings in predicting $\mathrm{AF}$ in the three groups. ROC curves were compared as described by Hanley and McNeill ${ }^{10}$, using Medcalc v13.3.1 (Medcalc Software bvba, Ostend, Belgium). The association between patient characteristics, biomarkers and new-onset AF was assessed with a binary logistic model, with variables being entered in the model. A multivariate model was created for the new-onset AF group and the AF during the first $24 \mathrm{~h}$ of admission subgroup, with variables with a $\mathrm{P}$ value of $<0.05$ in univariate analysis being eligible to be entered into the model. No multivariate analysis was performed in the AF 24-72 h after admission and AF $>72 \mathrm{~h}$ after admission subgroups due to the limited number of endpoints in these subgroups. Whenever a multivariate model was created, use of study medication was also included in the multivariate model. Statistical analysis was performed using IBM SPSS statistics version 20 (IBM Inc., Armonk, NY, USA). A P value of $\leq 0.05$ was considered statistically significant.

\section{RESULTS}

Nine hundred and eighty-four patients were admitted with the diagnosis of STEMI. A total of 861 patients underwent PPCI. Baseline characteristics of the whole study population have been previously reported. ${ }^{9}$ 30-day follow-up was present in 830 patients who were included in the analysis. Baseline characteristics of the study population are displayed in Table 1 and medication use on admission is displayed in the supplemental Table 1. 
Table 1. Baseline characteristics

\begin{tabular}{|c|c|c|c|c|}
\hline & $\begin{array}{l}\text { Total } \\
(\mathrm{N}=830)\end{array}$ & $\begin{array}{l}\text { AF free } \\
(\mathrm{N}=757)\end{array}$ & $\begin{array}{l}\text { New-onset AF } \\
(\mathrm{N}=73)\end{array}$ & $\begin{array}{l}\mathrm{P} \\
\text { value }\end{array}$ \\
\hline Age (years) & $62.1 \pm 11.6$ & $61.5 \pm 11.5$ & $68.4 \pm 10.9$ & $<0.001$ \\
\hline Male gender & $631 / 830(76.0 \%)$ & $580 / 757(76.6 \%)$ & $51 / 73(69.9 \%)$ & 0.197 \\
\hline $\operatorname{BMI}\left(\mathrm{kg} / \mathrm{m}^{2}\right)$ & $26.9 \pm 3.7$ & $26.9 \pm 3.7$ & $26.4 \pm 3.5$ & 0.126 \\
\hline Current smoker & $402 / 827(48.6 \%)$ & $375 / 755(49.7 \%)$ & $27 / 72(37.5 \%)$ & 0.048 \\
\hline Diabetes & $89 / 829(10.2 \%)$ & $77 / 756(10.2 \%)$ & $12 / 73(16.4 \%)$ & 0.099 \\
\hline Hypertension & $276 / 830(33.3 \%)$ & $251 / 757(33.2 \%)$ & $25 / 73(34.2 \%)$ & 0.850 \\
\hline Hypercholesterolemia & $214 / 829(25.8 \%)$ & $195 / 756(25.8 \%)$ & $19 / 73(26.0 \%)$ & 0.965 \\
\hline Killip Class $>1$ & $96 / 821(11.7 \%)$ & 78/749 (10.4\%) & $18 / 72(25.0 \%)$ & $<0.001$ \\
\hline Heart rate on admission & $72.1 \pm 12.6$ & $71.8 \pm 12.2$ & $75.0 \pm 16.0$ & 0.227 \\
\hline Previous MI & $68 / 828(8.2 \%)$ & $62 / 755(8.2 \%)$ & $6 / 73(8.2 \%)$ & 0.998 \\
\hline Previous PCI & $68 / 830(8.2 \%)$ & $65 / 757(8.3 \%)$ & $5 / 73(6.8 \%)$ & 0.661 \\
\hline Previous CABG & $12 / 830(1.4 \%)$ & $11 / 757(1.5 \%)$ & $1 / 73(1.4 \%)$ & $>0.99 *$ \\
\hline Previous stroke & $15 / 830(1.8 \%)$ & $151 / 757(2.0 \%)$ & $0 / 73(0 \%)$ & $.634^{*}$ \\
\hline Systolic BP (mmHg) & $130.9 \pm 24.1$ & $131.3 \pm 23.8$ & $126.2 \pm 24.6$ & 0.143 \\
\hline Diastolic BP (mmHg) & $76.6 \pm 15.0$ & $76.8 \pm 14.8$ & $74.3 \pm 16.1$ & 0.306 \\
\hline Tirofiban study medication & $406 / 830(48.9 \%)$ & $369 / 757(48.7 \%)$ & $37 / 73(50.7 \%)$ & 0.752 \\
\hline Culprit vessel & & & & 0.997 \\
\hline Culprit vessel RCA & $390 / 821(47.5 \%)$ & $355 / 748(47.5 \%)$ & $35 / 73(47.9 \%)$ & \\
\hline Culprit vessel LAD & $340 / 821(41.4 \%)$ & $310 / 748(41.4 \%)$ & $30 / 73(41.1 \%)$ & \\
\hline Culprit vessel LCx & $91 / 821(11.1 \%)$ & $83 / 748(11.1 \%)$ & $8 / 73(11.0 \%)$ & \\
\hline Number of diseased vessels & & & & 0.227 \\
\hline Single vessel & $447 / 830$ & $416 / 757$ & $31 / 73$ & \\
\hline Dual vessel & $238 / 830$ & $211 / 757$ & $27 / 73$ & \\
\hline Triple vessel & $137 / 830$ & $123 / 757$ & $14 / 73$ & \\
\hline Left main & $8 / 830$ & $7 / 757$ & $1 / 73$ & \\
\hline TIMI grade flow post $\mathrm{PCI}<3$ & $74 / 823(9.0 \%)$ & $62 / 750(8.3 \%)$ & $12 / 73(16.4 \%)$ & 0.020 \\
\hline NT-proBNP baseline (pg/ml) & $589 \pm 1896$ & $517 \pm 1490$ & $1339 \pm 4178$ & $<0.001$ \\
\hline HScTnT (pg/ml) & $0.380 \pm 1.27$ & $0.358 \pm 1.12$ & $0.610 \pm 2.32$ & 0.008 \\
\hline Peak CK-MB (U/1) & $216 \pm 197$ & $207 \pm 189$ & $303 \pm 245$ & 0.001 \\
\hline
\end{tabular}

Data are presented as mean with $\pm \mathrm{SD}$ or fraction with percentages where appropriate. $\mathrm{AF}$, atrial fibrillation; $\mathrm{BMI}$, body mass index; MI, myocardial infarction; PCI: percutaneous coronary intervention; CABG, coronary artery bypass grafting; BP, blood pressure; RCA, right coronary artery; LAD, left anterior descending artery; LCx, left circumflex artery; TIMI, thrombolysis in myocardial infarction; NT-proBNP, N-terminal pro-brain natriuretic peptide; HScTnT, high-sensitivity cardiac troponin T; CK-MB, creatine kinase MB isoenzyme.

$\mathrm{P}$ value between $\mathrm{AF}$ free and new-onset AF patient groups. * Fisher's exact test. 


\section{Incidence of atrial fibrillation}

Seventy-three patients $(8.8 \%)$ developed new-onset AF $<30$ days after STEMI. AF was present on the first ECG in 22 patients, 29 patients developed AF during the first $24 \mathrm{~h}$ after admission. Thus, 41 patients developed AF during the first $24 \mathrm{~h}$ after admission. Furthermore, 14 patients developed AF 24-72 h after admission and 18 patients developed $\mathrm{AF}>72 \mathrm{~h}$ after admission, as displayed in Figure. 1. Patients who developed AF were older ( 61.5 vs. 68.4 years, $\mathrm{P}<0.001)$, less often smokers $(49.7 \%$ vs. $37.5 \%$, $\mathrm{P}=0.048)$, with more often a Killip Class $>1(10.4 \%$ vs. $25.0 \%, \mathrm{P}<0.001)$ and a Thrombolysis in Myocardial Infarction (TIMI) grade flow $<3$ after PCI ( $8.3 \%$ vs. $16.4 \%, \mathrm{P}=0.020$ ), with a higher mean NT-proBNP plasma level (517 vs. $1339 \mathrm{pg} / \mathrm{ml}$, $\mathrm{P}<0.001)$, a higher HsTnT level $(0.358$ vs. $0.610 \mathrm{pg} / \mathrm{ml}, \mathrm{P}=0.007)$ and a higher peak CK-MB plasma (207 vs. $303 \mathrm{U} / 1, \mathrm{P}=0.001$ ), as displayed in Table 1. Patients with AF were using $\beta$-blockers $(16.9 \%$ vs. $27.4 \%, \mathrm{P}=0.025)$ and oral antidiabetics $(7.1 \%$ vs. $16.4 \%, \mathrm{P}=0.005$ ) significantly more often than patients without $\mathrm{AF}$, as displayed in the online supplemental Table 1. Table 2 displays the HsTnT plasma levels at all three timings.

\section{Association between HsTnT and new-onset AF}

HsTnT at baseline was significantly associated with new-onset AF (AUC 0.594, $\mathrm{P}=0.010$ ), as displayed in Table 3. In univariate analysis, age (odds ratio (OR) 1.056, $\mathrm{P}<0.001$ ), smoking (OR 0.608, $\mathrm{P}=0.050$ ), Killip Class $>1$ (OR 2.868, $\mathrm{P}<0.001$ ), TIMI flow post $\mathrm{PCI}<3$ (OR 2.183, $\mathrm{P}=0.023$ ) and NT-proBNP (OR 1.128, $\mathrm{P}=0.010$ ) were associated with new-onset AF. Of note, current smokers were significantly younger compared to non-smokers (57.2 vs. 66.7 years, $\mathrm{P}<0.001)$. HsTnT was not associated with new-onset $\mathrm{AF}$ in univariate analysis ( $\mathrm{OR} 1.010, \mathrm{P}=0.135)$. In multivariate analysis, age (adjusted OR 1.058, $\mathrm{P}<0.001$ ) and Killip Class $>1$ (adjusted OR 3.253, $\mathrm{P}<0.001)$ were significantly associated with new-onset AF. Table 4 displays the univariate and multivariate analyses for new-onset AF.

\section{Baseline HsTnT and AF during the first $24 \mathrm{~h}$ of admission}

$\mathrm{HsTnT}$ at baseline was not significantly associated with AF during the first $24 \mathrm{~h}$ of admission (AUC 0.532, $\mathrm{P}=0.502$ ), as displayed in Table 3. In univariate analysis, only Killip Class $>1$ was significantly associated with AF during the first $24 \mathrm{~h}$ of admission (OR 2.694, $\mathrm{P}=0.010$ ). HsTnT at baseline was not associated with AF during the first 24 $\mathrm{h}$ of admission (OR $0.988, \mathrm{P}=0.556$ ). In multivariate analysis, only Killip Class $>1$ was significantly associated with AF during the first $24 \mathrm{~h}$ of admission (adjusted OR 2.784, $\mathrm{P}=0.008$ ). Table 5 displays the univariate and multivariate analyses. 
Table 2. HsTnT levels

\begin{tabular}{|c|c|c|c|c|}
\hline & $\begin{array}{l}\text { Total } \\
(\mathrm{N}=830)\end{array}$ & $\begin{array}{l}\text { AF free } \\
(\mathrm{N}=757)\end{array}$ & $\begin{array}{l}\text { New-onset AF } \\
(\mathrm{N}=73)\end{array}$ & $P$ value \\
\hline \multicolumn{5}{|c|}{ HsTnT at baseline (pg/ml) } \\
\hline Mean \pm SD & $0.380 \pm 1.275$ & $0.358 \pm 1.125$ & $0.610 \pm 2.319$ & 0.008 \\
\hline Range & $0.009-18.620$ & $0.009-12.870$ & $0.009-8.620$ & \\
\hline Median & 0.041 & 0.036 & 0.061 & \\
\hline \multicolumn{5}{|c|}{ HsTnT after $24 \mathrm{~h}(\mathrm{pg} / \mathrm{ml})$} \\
\hline Mean \pm SD & $3.367 \pm 3.304$ & $3.164 \pm 3.144$ & $5.414 \pm 4.122$ & $<0.001$ \\
\hline Range & $0.009-27.800$ & $0.009-27.800$ & $0.437-18.290$ & \\
\hline Median & $2.450 \mathrm{pg} / \mathrm{ml}$ & 2.350 & 4.270 & \\
\hline \multicolumn{5}{|c|}{ HsTnT after $72 \mathrm{~h}(\mathrm{pg} / \mathrm{ml})$} \\
\hline Mean \pm SD & $2.330 \pm 2.154$ & $2.168 \pm 1.988$ & $4.594 \pm 3.001$ & $<0.001$ \\
\hline Range & $0.009-17.730$ & $0.009-17.730$ & $1.050-14.330$ & \\
\hline Median & 1.845 & 1.700 & 3.940 & \\
\hline
\end{tabular}

Data are presented as mean $\pm \mathrm{SD}$, range or median. AF, atrial fibrillation; HsTnT, high-sensitivity troponin $\mathrm{T}$. $\mathrm{P}$ value between mean HsTnT values of AF free and new-onset AF patient groups is presented.

Table 3. Receiver operator characteristic of HsTnT in the prediction of new-onset atrial fibrillation

\begin{tabular}{|c|c|c|c|c|c|c|}
\hline & $\begin{array}{l}\text { HsTnT } \\
\text { at baseline }\end{array}$ & $\begin{array}{l}\mathrm{P} \\
\text { value }\end{array}$ & $\begin{array}{l}\text { HsTnT } \\
\text { after } 24 \mathrm{~h}\end{array}$ & $\mathrm{P}$ value & $\begin{array}{l}\text { HsTnT } \\
\text { after } 72 \mathrm{~h}\end{array}$ & $\mathrm{P}$ value \\
\hline New-onset AF & $0.594 \pm 0.035$ & 0.010 & & & & \\
\hline $\begin{array}{l}\text { AF during the first } \\
24 \mathrm{~h} \text { of admission }\end{array}$ & $0.532 \pm 0.047$ & 0.502 & & & & \\
\hline $\begin{array}{l}\text { AF } 24-72 \mathrm{~h} \text { after } \\
\text { admission }\end{array}$ & $0.747 \pm 0.071$ & 0.002 & $0.789 \pm 0.053$ & 0.001 & & \\
\hline $\begin{array}{c}\mathrm{AF}>72 \mathrm{~h} \text { after } \\
\text { admission }\end{array}$ & $0.589 \pm 0.057$ & 0.195 & $0.799 \pm 0.053$ & $<0.001$ & $0.884 \pm 0.049$ & $<0.001$ \\
\hline
\end{tabular}

Data are presented as $\mathrm{AUC} \pm \mathrm{SEM}$.

AF, atrial fibrillation; HsTnT, high-sensitivity troponin T; SEM, standard error of the mean.

$P$ values between AUCs:

AF 24-72 $\mathrm{h}$ after admission; HsTnT at baseline vs. HsTnT after $24 \mathrm{~h}$ :

$\mathrm{AF}>72 \mathrm{~h}$ after admission; HsTnT at baseline vs. HsTnT after $24 \mathrm{~h}$ :

Z-statistic $0.655, \quad \mathrm{P}=0.513$.

$\mathrm{AF}>72 \mathrm{~h}$ after admission; $\mathrm{HsTnT}$ at baseline vs. HsTnT after $72 \mathrm{~h}$ :

Z-statistic 4.080, $\quad \mathrm{P}<0.001$.

Z-statistic 4.478, $\quad \mathrm{P}<0.001$.

$\mathrm{AF}>72 \mathrm{~h}$ after admission; HsTnT after $24 \mathrm{~h}$ vs. HsTnT after $72 \mathrm{~h}$ :

Z-statistic $0.521, \quad \mathrm{P}=0.602$ 


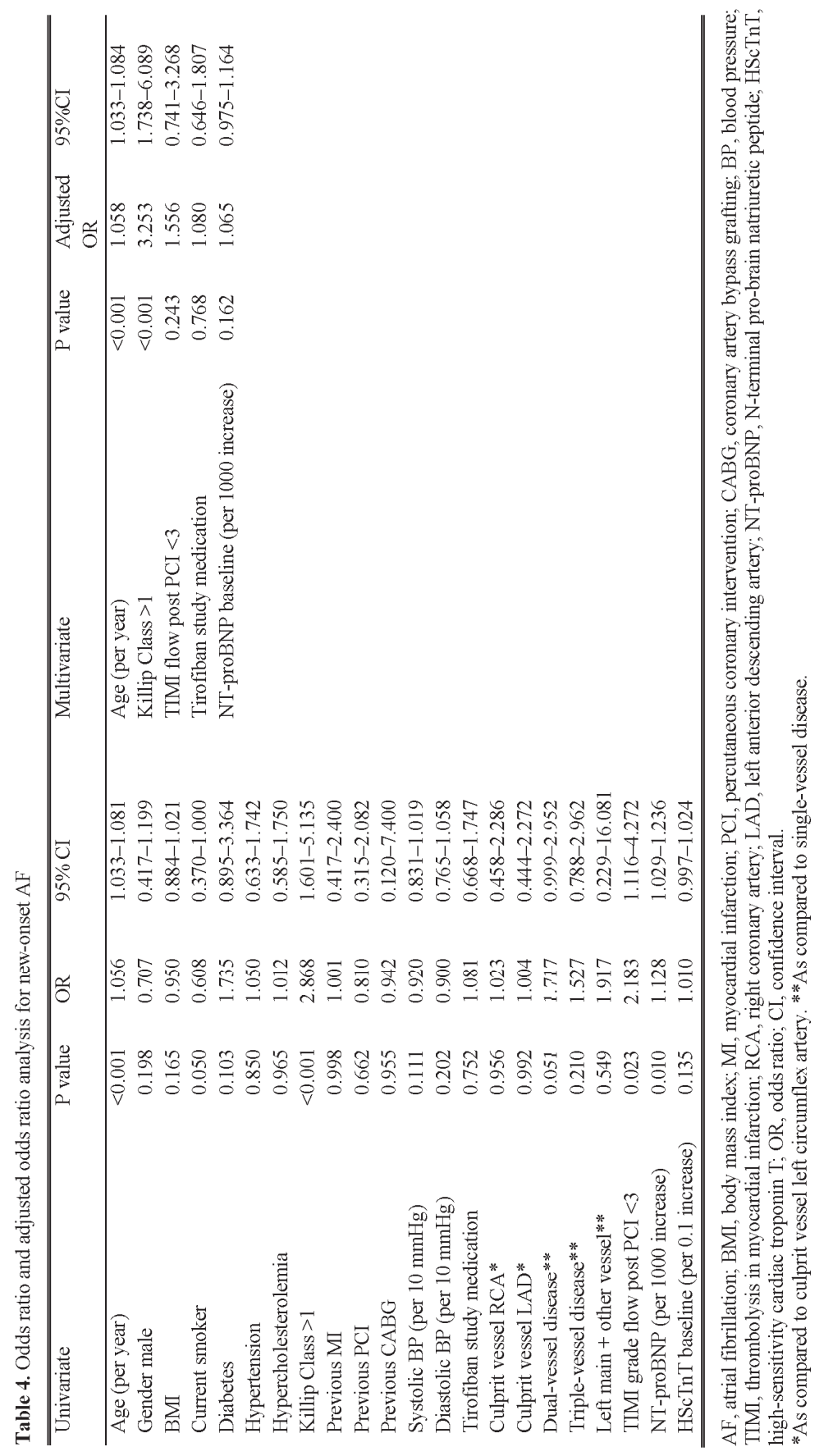




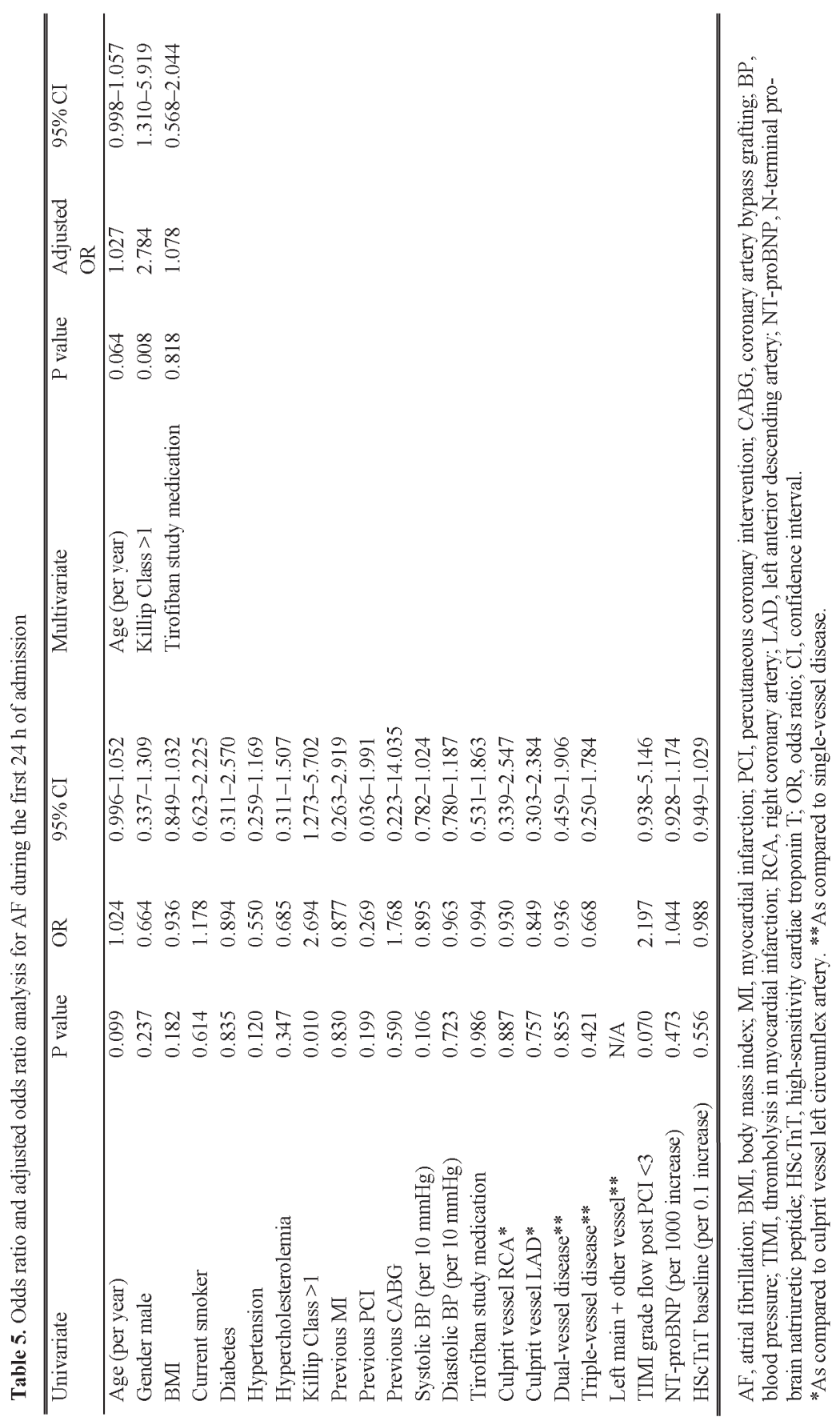




\section{Serial HsTnT levels and AF 24-72 h after admission}

HsTnT at baseline was associated with AF 24-72 h after admission (AUC 0.747, $\mathrm{P}=0.002$ ). HsTnT after $24 \mathrm{~h}$ was also significantly associated with AF 24-72 h after admission (AUC 0.789, $\mathrm{P}=0.001$ ). HsTnT after $24 \mathrm{~h}$ did not show a stronger association with AF 24-72 $\mathrm{h}$ after admission, compared to HsTnT at baseline (zstatistic $0.655, \mathrm{P}=0.513$ ), as displayed in Table 3 . In univariate analysis, age (OR 1.117, $\mathrm{P}<0.001$ ), Killip Class $>1$ (OR 3.341, $\mathrm{P}=0.045$ ), TIMI grade flow $<3$ (OR 4.476, $\mathrm{P}=0.013$ ), left main vessel disease (OR 14.964, $\mathrm{P}=0.022$ ), NT-proBNP plasma level (OR 1.186, $\mathrm{P}=0.002)$ HsTnT at baseline (OR 1.027, $\mathrm{P}=0.001)$ and after $24 \mathrm{~h}(\mathrm{OR}$ 1.012, $\mathrm{P}=0.017$ ) and peak $\mathrm{CK}-\mathrm{MB}$ plasma level ( $\mathrm{OR}$ 1.213, $\mathrm{P}=0.047$ ) were significantly associated with AF 24-72 h after admission. Table 6 displays the univariate analysis for AF 24-72 h after admission.

Table 6. Odds ratio and adjusted odds ratio analysis for AF $24-72 \mathrm{~h}$ after admission

\begin{tabular}{lccl}
\hline \hline Univariate & P value & OR & $95 \%$ CI \\
\hline Age (per year) & $<0.001$ & 1.117 & $1.050-1.188$ \\
Gender male & 0.287 & 0.548 & $0.182-1.657$ \\
BMI & 0.287 & 0.916 & $0.778-1.077$ \\
Current smoker & 0.055 & 0.285 & $0.079-1.030$ \\
Diabetes & 0.208 & 2.302 & $0.629-8.419$ \\
Hypertension & 0.206 & 1.981 & $0.687-5.707$ \\
Hypercholesterolemia & 0.686 & 0.767 & $0.212-2.777$ \\
Killip Class $>1$ & 0.045 & 3.341 & $1.025-10.895$ \\
Previous MI & 0.878 & 0.852 & $0.110-6.619$ \\
Systolic BP (per 10 mmHg) & 0.702 & 1.044 & $0.839-1.298$ \\
Diastolic BP (per 10 mmHg) & 0.317 & 0.827 & $0.570-1.199$ \\
Tirofiban study medication & 0.324 & 0.575 & $0.191-1.730$ \\
Culprit vessel RCA* & 0.756 & 1.401 & $0.166-11.792$ \\
Culprit vessel LAD* & 0.558 & 1.877 & $0.228-15.465$ \\
TIMI grade flow post PCI $<3$ & 0.013 & 4.476 & $1.365-14.682$ \\
Dual-vessel disease** & 0.056 & 3.348 & $0.970-11.562$ \\
Triple-vessel disease** & 0.584 & 1.612 & $0.292-8.899$ \\
Left main + other vessel** & 0.022 & 14.964 & $1.478-151.53$ \\
NT-proBNP (per 1000 increase) & 0.002 & 1.186 & $1.063-1.324$ \\
HScTnT at baseline (per 0.1 increase) & 0.001 & 1.027 & $1.011-1.043$ \\
HScTnT 24 h (per 0.1 increase) & 0.017 & 1.012 & $1.002-1.023$ \\
Peak CK-MB (per 100 increase) & 0.047 & 1.213 & $1.003-1.467$ \\
\hline \hline
\end{tabular}

AF, atrial fibrillation; BMI, body mass index; MI, myocardial infarction; PCI, percutaneous coronary intervention; CABG, coronary artery bypass grafting; BP, blood pressure; TIMI, thrombolysis in myocardial infarction; RCA, right coronary artery; LAD, left anterior descending artery; NT-proBNP, N-terminal pro-brain natriuretic peptide; HScTnT, high-sensitivity cardiac troponin T; OR, odds ratio; CI, confidence interval.

*As compared to culprit vessel left circumflex artery. **As compared to single-vessel disease. 
Table 7. Odds ratio and adjusted odds ratio analysis for $\mathrm{AF}>72 \mathrm{~h}$ after admission

\begin{tabular}{lccc}
\hline \hline Univariate & P value & OR & $95 \%$ CI \\
\hline Age (per year) & $<0.001$ & 1.094 & $1.041-1.150$ \\
Gender male & 0.909 & 1.068 & $0.347-3.286$ \\
BMI & 0.941 & 1.005 & $0.885-1.141$ \\
Current smoker & 0.012 & 0.203 & $0.058-0.706$ \\
Diabetes & 0.024 & 3.392 & $1.177-9.770$ \\
Hypertension & 0.142 & 2.016 & $0.790-5.141$ \\
Hypercholesterolemia & 0.083 & 2.302 & $0.896-5.915$ \\
Killip Class $>1$ & 0.121 & 2.458 & $0.789-7.652$ \\
Previous MI & 0.661 & 1.397 & $0.314-6.217$ \\
Previous PCI & 0.049 & 3.147 & $1.006-9.848$ \\
Systolic BP (per 10 mmHg) & 0.262 & 0.891 & $0.728-1.090$ \\
Diastolic BP (per 10 mmHg) & 0.256 & 0.832 & $0.606-1.143$ \\
Tirofiban study medication & 0.141 & 2.103 & $0.781-5.661$ \\
Culprit vessel RCA* & 0.949 & 1.052 & $0.223-4.960$ \\
Culprit vessel LAD* & 0.936 & 0.937 & $0.191-4.595$ \\
TIMI grade flow post PCI $<3$ & 0.681 & 0.653 & $0.085-4.987$ \\
Dual-vessel disease** & 0.015 & 5.258 & $1.381-20.023$ \\
Triple-vessel disease** & 0.003 & 7.892 & $2.011-30.975$ \\
Left main + other vessel** & $\mathrm{N} / \mathrm{A}$ & & \\
NT-proBNP (per 1000 increase) & 0.539 & 1.070 & $0.862-1.329$ \\
HScTnT at baseline (per 0.1 increase) & 0.513 & 0.970 & $0.884-1.063$ \\
HScTnT 24 h (per 0.1 increase) & $<0.001$ & 1.018 & $1.010-1.027$ \\
HScTnT 72 h (per 0.1 increase) & $<0.001$ & $1.035 \mathrm{~S}$ & $1.015-1.055$ \\
Peak CK-MB (per 100 increase) & 0.014 & 1.230 & $1.044-1.450$ \\
\hline \hline
\end{tabular}

$\mathrm{AF}$, atrial fibrillation; BMI, body mass index; MI, myocardial infarction; PCI, percutaneous coronary intervention; CABG, coronary artery bypass grafting; BP, blood pressure; TIMI, thrombolysis in myocardial infarction; RCA, right coronary artery; LAD, left anterior descending artery; NT-proBNP, N-terminal pro-brain natriuretic peptide; HScTnT, high-sensitivity cardiac troponin T; OR, odds ratio; CI, confidence interval.

*As compared to culprit vessel left circumflex artery. **As compared to single-vessel disease.

\section{Serial HsTnT levels and AF $>72 \mathrm{~h}$ after admission}

Baseline HsTnT was not associated with AF $>72 \mathrm{~h}$ after admission (AUC 0.589, $\mathrm{P}=0.195)$. HsTnT after $24 \mathrm{~h}(\mathrm{AUC} 0.799, \mathrm{P}<0.001)$ and after $72 \mathrm{~h}$ (AUC 0.884, $\mathrm{P}<0.001)$ were associated with $\mathrm{AF}>72 \mathrm{~h}$ after admission, as displayed in Table 3. HsTnT after $24 \mathrm{~h}$ (z-statistic 4.080, $\mathrm{P}<0.001)$ and after $72 \mathrm{~h}$ (z-statistic 4.478, $\mathrm{P}<0.001$ ) were significantly stronger predictors of $\mathrm{AF}>72 \mathrm{~h}$ after admission, compared to HsTnT at baseline. There was no significant difference in AUC between HsTnT after $24 \mathrm{~h}$ and $\mathrm{HsTnT}$ after $72 \mathrm{~h}$ in the prediction of AF (z-statistic 0.521, $\mathrm{P}=0.602$ ), as displayed in Table 3. In univariate analysis, age (OR 1.094, $\mathrm{P}<0.001)$, current smoking (OR 0.203, $\mathrm{P}=0.012$ ), history of diabetes ( $\mathrm{OR} 3.392, \mathrm{P}=0.024$ ), previous percutaneous coronary 
intervention ( $\mathrm{OR}$ 3.147, $\mathrm{P}=0.049)$, dual $(\mathrm{OR}$ 5.258, $\mathrm{P}=0.015)$ and triple-vessel disease (OR 7.892, $\mathrm{P}=0.003)$, HsTnT after $24 \mathrm{~h}(\mathrm{OR} 1.018, \mathrm{P}<0.001)$ and after $72 \mathrm{~h}(\mathrm{OR} 1.035$, $\mathrm{P}<0.001)$ and peak $\mathrm{CK}-\mathrm{MB}$ plasma level (OR 1.230, $\mathrm{P}=0.014)$ were significantly associated with $\mathrm{AF}>72 \mathrm{~h}$ after admission. In univariate analysis, HsTnT at baseline was not associated with $\mathrm{AF}>72 \mathrm{~h}$ after admission (OR 0.970, $\mathrm{P}=0.513$ ). Of note, current smokers were significantly younger compared to non-smokers (57.0 vs. 66.2 years, $\mathrm{P}<0.001$ ). Table 7 displays the univariate analysis for $\mathrm{AF}>72 \mathrm{~h}$ after admission.

\section{DISCUSSION}

This study is to the best of our knowledge the first study that reports the temporal association between HsTnT plasma level assessments at different timings after admission and the development of AF in the setting of STEMI. In line with previous studies, HsTnT at baseline was not associated with new-onset AF and AF during the first $24 \mathrm{~h}$ of admission in univariate analysis. In contrast to previous studies, HsTnT was significantly associated with onset of AF $24-72 \mathrm{~h}$ and $>72 \mathrm{~h}$ after STEMI.

\section{New-onset AF after STEMI}

In-hospital, new-onset AF after STEMI has been associated with an increased left ventricular diastolic dysfunction, which negatively impacts atrial stretch and atrial pressure. $^{11,12}$ Furthermore, atrial dysfunction and ischemia, pericarditis, congestive heart failure due to ischemia and enhanced sympathetic tone may also play an important role in the genesis of postinfarction $\mathrm{AF} .^{13-15}$ New-onset $\mathrm{AF}$ is associated with a higher rate of death, re-infarction, cardiogenic shock and ventricular arrhythmias, and therefore, identification of potentially high-risk patients is important and may impact clinical decision making. ${ }^{5,6}$ Previous studies already reported that newonset $\mathrm{AF}$ is most prevalent during the first $24 \mathrm{~h}$ after admission. ${ }^{16}$ In line with previous studies in the healthy population ${ }^{17}$ and in STEMI patients, ${ }^{7}$ patient age has a strong association with the development of new-onset AF. Furthermore, the association between Killip Class, ${ }^{18}$ TIMI flow after PPCI, number of diseased vessels ${ }^{19}$ and AF has also been previously described. Furthermore, AF patients used $\beta$-blockers and oral antidiabetic agents significantly more often compared to non-AF patients. Hypertension and diabetes are known risk factors of $\mathrm{AF}^{20}$ which may potentially explain this difference. Finally, NT-proBNP was significantly associated with newonset AF, which is in line with previous studies in both the healthy general population $^{21}$ and in STEMI patients. ${ }^{7}$ 


\section{HsTnT and new-onset AF}

One study showed HsTnT was associated with AF in stroke patients. ${ }^{22}$ However, other studies did not find an association between HsTnT and AF in STEMI patients. ${ }^{7,23}$ In the study by Parashar and colleagues, ${ }^{7} \mathrm{HsTnT}$ was assessed in the first $72 \mathrm{~h}$ after admission, and all AF episodes were included, without defining the exact time of onset as in our present study. HsTnT after STEMI shows a typical rise and fall. Therefore, there may have been a difference in HsTnT plasma levels due to the timing of the assessment, and this may have obscured the association between HsTnT and AF. In the other study, ${ }^{23}$ only seven patients developed AF, indicating this study may have been underpowered to identify an association between HsTnT and AF. Nevertheless, the present study is partially in line with these findings, showing that HsTnT at baseline is not significantly associated with new-onset AF and AF during the first $24 \mathrm{~h}$ of admission in univariate analysis. However, in contrast to the previous studies, the present study shows a strong association between HsTnT and new-onset AF 24-72 h and $>72 \mathrm{~h}$ after admission.

\section{HsTnT and infarction size}

Cardiac troponin $\mathrm{T}$ is a regulatory protein that controls the calcium-mediated interaction of actin and myosin. ${ }^{24}$ Besides its diagnostic characteristics, ${ }^{25}$ a previous study assessed HsTnT daily during the first $96 \mathrm{~h}$ after admission and reported that all timings of HsTnT assessment, except at baseline, were significantly associated with infarction size on magnetic resonance imaging. ${ }^{26}$ Possibly, a larger infarction size is associated with new-onset AF through elevated intracardiac pressures, though further study regarding the exact mechanism is necessary. A previous study ${ }^{27}$ of STEMI patients did not report an association between infarction size and AF. However, since this study was performed in 1992, none of the patients underwent PPCI, which may have influenced the outcome of this study.

\section{Limitations}

The current study is a substudy of the On-TIME 2 study and therefore, a predefined power assessment was not made for the relation of HsTnT and new-onset AF and multivariate analysis in the AF 24-72 $\mathrm{h}$ and $>72 \mathrm{~h}$ after admission subgroups could not be performed. Patients may have suffered asymptomatic AF episodes prior to the STEMI, which may have influenced the results for AF during the first $24 \mathrm{~h}$ after admission. Although all variables were prospectively registered, the present study is a post-hoc cross-sectional analysis. All patients were kept on telemetry for at least $48 \mathrm{~h}$, but thereafter, an ECG was performed daily. This may have caused several AF episodes not to have been documented. AF may be associated with pericarditis, but in 
this study, no routine echocardiography was performed for pericarditis. Patients were not followed up after completion of the study after 30 days.

\section{CONCLUSION}

This study shows HsTnT plasma levels are associated with new-onset AF in the setting of STEMI. 


\section{Appendix}

Supplemental Table 1. Medication use before admission

\begin{tabular}{lcccr}
\hline \hline & $\begin{array}{l}\text { Total } \\
(\mathrm{N}=830)\end{array}$ & $\begin{array}{l}\text { AF free } \\
\mathrm{N}=757)\end{array}$ & $\begin{array}{l}\text { New-onset AF } \\
(\mathrm{N}=73)\end{array}$ & P value \\
\hline Aspirin & $135 / 830(16.3 \%)$ & $120 / 757(15.9 \%)$ & $15 / 73(20.5 \%)$ & 0.299 \\
Clopidogrel & $14 / 830(1.7 \%)$ & $12 / 757(1.6 \%)$ & $2 / 73(2.7 \%)$ & 0.464 \\
ACE inhibitor & $114 / 830(17.7 \%)$ & $100 / 757(13.2 \%)$ & $14 / 73(19.2 \%)$ & 0.157 \\
Angiotensin II blocker & $58 / 830(7.0 \%)$ & $55 / 757(7.3 \%)$ & $3 / 73(4.1 \%)$ & 0.312 \\
B-blocker & $148 / 830(17.8 \%)$ & $128 / 757(16.9 \%)$ & $20 / 73(27.4 \%)$ & 0.025 \\
Calcium blocker & $54 / 830(6.5 \%)$ & $48 / 757(6.3 \%)$ & $6 / 73(8.2 \%)$ & 0.534 \\
Diuretics & $98 / 830(11.8 \%)$ & $87 / 757(11.5 \%)$ & $11 / 73(15.1 \%)$ & 0.366 \\
Oral antidiabetics & $65 / 830(66 \%)$ & $54 / 757(7.1 \%)$ & $12 / 73(16.4 \%)$ & 0.005 \\
Insulin & $20 / 830(2.4 \%)$ & $19 / 757(2.5 \%)$ & $1 / 73(1.4 \%)$ & 0.544 \\
Oral anticoagulants & $4 / 830(0.5 \%)$ & $4 / 757(0.5 \%)$ & $0 / 73(0 \%)$ & $>0.99 *$ \\
Statin & $147 / 830(17.7 \%)$ & $132 / 757(17.4 \%)$ & $15 / 73(20.5 \%)$ & 0.506 \\
\hline \hline
\end{tabular}

ACE, angiotensin converting enzyme. *Fisher's exact test.

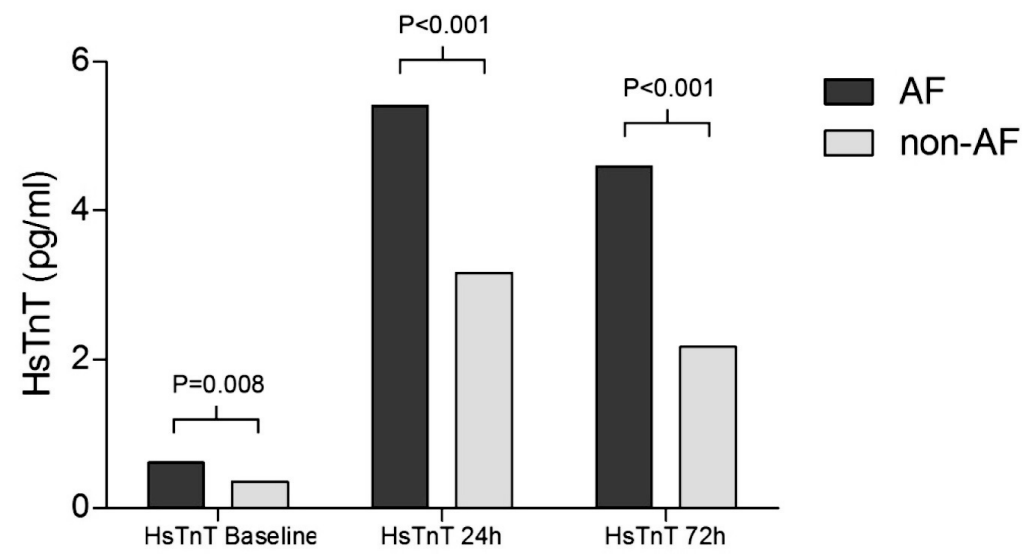

Supplemental Figure 1 Key findings. This figure displays the association between HsTnT and $\mathrm{AF}$ in STEMI patients. HsTnT, high-sensitivity troponin T; AF, atrial fibrillation. $\mathrm{P}$ values between $\mathrm{AF}$ and non-AF groups. 


\section{REFERENCES}

1. Goldberg RJ, Seely, D, Becker RC, et al. Impact of atrial fibrillation on the in-hospital and longterm survival of patients with acute myocardial infarction: a community-wide perspective. Am Heart J 1990;119:996-1001.

2. Pedersen OD, Bagger H, Kober L, et al. The occurrence and prognostic significance of atrial fibrillation/-flutter following acute myocardial infarction. TRACE Study group. TRAndolapril Cardiac Evalution. Eur Heart J 1999;20:748-754.

3. Pizzetti F, Turazza FM, Franzosi MG, et al. Incidence and prognostic significance of atrial fibrillation in acute myocardial infarction: the GISSI-3 data. Heart 2001;86:527-532.

4. Wann LS, Curtis, AB, Ellenbogen KA, et al. 2011 ACCF/AHA/HRS focused update on the management of patients with atrial fibrillation (update on dabigatran): a report of the American College of Cardiology Foundation /American Heart Association Task Force on practice guidelines J Am Coll Cardiol 2011;57:1330-1337.

5. Schmitt J, Duray G, Gersh BJ, et al. Atrial fibrillation in acute myocardial infarction: a systematic review of the incidence, clinical features and prognostic implications. Eur Heart $\mathrm{J}$ 2009;30:1038-1045.

6. Jabre P, Roger VL, Murad MH, et al. Mortality associated with atrial fibrillation in patients with myocardial infarction: a systematic review and meta-analysis. Circulation 2011;123:1587-1593.

7. Parashar S, Kella D, Reid KJ, et al. New-onset atrial fibrillation after acute myocardial infarction and its relation to admission biomarkers (from the TRIUMPH registry). Am J Cardiol 2013;112:1390-1395.

8. van 't Hof AW, Hamm C, Rasoul S, et al. Ongoing tirofiban in myocardial infarction evaluation (On-TIME) 2 trial: rationale and study design, EuroIntervention 2007;3:371-380.

9. Van't Hof AW, Ten Berg J, Heestermans T, et al. Prehospital initiation of tirofiban in patients with ST-elevation myocardial infarction undergoing primary angioplasty (On-TIME 2): a multicentre, double-blind, randomised controlled trial. Lancet 2008;372:537-546.

10. Hanley JA and McNeil BJ. A method of comparing the areas under receiver operating characteristic curves derived from the same cases. Radiology 1983;148:839-843.

11. Shelton RJ, Clark AL, Goode K, et al. The diagnostic utility of N-terminal pro-B-type natriuretic peptide for the detection of major structural heart disease in patients with atrial fibrillation. Eur Heart J 2006;27:2353-2361.

12. Celik S, Erdol C, Baykan M, et al. Relation between paroxysmal atrial fibrillation and left entricular diastolic function in patients with acute myocardial infarction. Am J Cardiol 2001Jul;88(2):160-162, A5.

13. Crenshaw BS, Ward SR, Granger CB, et al. Atrial fibrillation in the setting of acute myocardial infarction: the GUSTO-I experience. Global Utilization of Streptokinase and TPA for Occluded Coronary Arteries. J Am Coll Cardiol 1997;30:406-413.

14. Corradi D, Callegari S, Maestri R, et al. Structural remodeling in atrial fibrillation. Nat Clin Pract Cardiovasc Med 2008;5:782-796.

15. Zicha S, Tsuji Y, Shiroshita-Takeshita A, et al. Beta-blockers as antiarrhythmic agents. Handb Exp Pharmacol 2006;235-266.

16. Consuegra-Sanchez L, Melgarejo-Moreno A, Galcera-Tomas J, et al. Short- and long-term prognosis of previous and new-onset atrial fibrillation in ST-segment elevation acute myocardial infarction. Rev Esp Cardiol (Engl Ed) 2015 Jan;68(1):31-8. doi: 10.1016/j.rec.2014.03.017. Epub 2014 Aug 11.

17. Lloyd-Jones DM, Wang TJ, Leip EP, et al Lifetime risk for development of atrial fibrillation: the Framingham Heart Study. Circulation 2004;110:1042-1046. 
18. Beukema RJ, Elvan A, Ottervanger JP, et al. Atrial fibrillation after but not before primary angioplasty for ST-segment elevation myocardial infarction of prognostic importance. Neth Heart J 2012;20:155-160.

19. Sherwood MW, Morrow DA, Scirica BM, et al. Early dynamic risk stratification with baseline troponin levels and 90-minute ST-segment resolution to predict 30-day cardiovascular mortality in ST-segment elevation myocardial infarction: analysis from CLopidogrel as Adjunctive ReperfusIon TherapY (CLARITY)-Thrombolysis in Myocardial Infarction (TIMI) 28. Am Heart J 2010;159:964-971 e1.

20. Huxley RR, Lopez FL, Folsom AR, et al. Absolute and attributable risks of atrial fibrillation in relation to optimal and borderline risk factors: the Atherosclerosis Risk in Communities (ARIC) study. Circulation 2011;123:1501-15018.

21. Patton KK, Ellinor PT, Heckbert SR, et al. N-terminal pro-B-type natriuretic peptide is a major predictor of the development of atrial fibrillation: the Cardiovascular Health Study. Circulation 2009;120:1768-1774.

22. Beaulieu-Boire I, Leblanc N, Berger L, et al. Troponin elevation predicts atrial fibrillation in patients with stroke or transient ischemic attack. J Stroke Cerebrovasc Dis 2013;22:978-983.

23. Asanin M, Stankovic S, Mrdovic I, et al. B-type natriuretic peptide predicts new-onset atrial fibrillation in patients with ST-segment elevation myocardial infarction treated by primary percutaneous coronary intervention. Peptides 2012;35:74-77.

24. Adams JE 3rd, Abendschein DR, Jaffe AS. Biochemical markers of myocardial injury. Is MB creatine kinase the choice for the 1990s? Circulation 1993;88:750-763.

25. Steg PG, James SK, Atar D, et al. ESC Guidelines for the management of acute myocardial infarction in patients presenting with ST-segment elevation. Eur Heart J 2012;33:2569-2619.

26. Giannitsis E, Steen H, Kurz K, et al. Cardiac magnetic resonance imaging study for quantification of infarct size comparing directly serial versus single time-point measurements of cardiac troponin T. J Am Coll Cardiol 2008;51:307-314.

27. Nielsen FE, Andersen HH, Gram-Hansen P, et al. The relationship between ECG signs of atrial infarction and the development of supraventricular arrhythmias in patients with acute myocardial infarction. Am Heart J 1992;123:69-72. 

CHAPTER 10

Effect of pre-hospital tirofiban administration on mortality in relation to NT-proBNP level in patients undergoing primary PCI: Insight from the On-TIME 2 trial

\author{
E. Fabris, S. Kilic \\ D.A.A.M. Schellings, J.M. ten Berg \\ M.W. Kennedy, C. Hamm \\ G. van Houwelingen, E. Giannitsis \\ E. Kolkman, J.P. Ottervanger \\ A.W.J. van 't Hof
}





\section{ABSTRACT}

Aims. We undertook an exploratory analysis of the On-TIME 2, a placebocontrolled, double-blind, randomized trial, in order to evaluate the association between NT-proBNP levels and long-term (5-years) mortality and to investigate the effect of pre-hospital tirofiban administration on mortality in relation to NTproBNP levels.

Methods and Results. 984 STEMI patients undergoing primary percutaneous coronary intervention (PCI), were randomized to either in ambulance tirofiban or placebo. NT-proBNP levels were evaluated on admission before angiography (baseline) and 18-96 h thereafter (post-PCI). There were 918 (93.3\%) patients with NT-proBNP values available at baseline and $865(87.9 \%)$ post-PCI. Patients with baseline NT-proBNP values above the median had higher 30 -day $(5.1 \%$ vs. $0.2 \%$, $\mathrm{P}<0.001), 1$-year $(7.0 \%$ vs. $0.7 \%, \mathrm{P}<0.001)$ and 5 -year $(20.3 \%$ vs. $4.9 \%, \mathrm{P}<0.001)$ mortality as compared to patients with values below the median. At multivariate analysis, elevated admission NT-proBNP was an independent predictor for 5-year mortality (Odds Ratio 2.75; 95\%CI 1.41-5.73, $\mathrm{P}=0.003$ ). Patients with elevated baseline NT-proBNP levels who received early tirofiban treatment had a significant lower mortality compared to patients treated with placebo at 30-days ( $2.7 \%$ vs. $7.5 \%, \mathrm{P}=0.021)$ and 1 -year $(4.5 \%$ vs. $9.4 \%, \mathrm{P}=0.043)$. At 5 -years, a lower but non-significant mortality rate was maintained in the treatment group ( $18 \%$ vs. $22.4 \%, \mathrm{P}=0.265$ ).

Conclusions. In STEMI patients, elevated baseline NT-proBNP levels independently predict long-term mortality. In patients with elevated baseline NTproBNP levels, early pre-hospital treatment with tirofiban significantly reduces 30day and 1-year mortality, suggesting that high-risk patients may derive particular benefit. This hypothesis should be confirmed in other studies.

\section{INTRODUCTION}

Urgent restoration of perfusion to the myocardium supplied by the infarction-related artery is the primary therapeutic objective in ST-elevation myocardial infarction (STEMI), as it improves survival ${ }^{1}$. Primary percutaneous coronary intervention (PCI) combined with effective antiplatelet therapy is the preferred treatment strategy in STEMI. ${ }^{2}$ In order to increase the rates of mechanical reperfusion and so reduce ischemic complications, large interest has focused on adjunctive administration of pharmacological therapy and its timing of administration. 
Glycoprotein IIb/IIIa inhibitors (GPIs) are the most powerful class of antiplatelet therapies, and their adjunctive effects have been shown in several randomized trials. ${ }^{3}$ In addition, early GPI administration in patients undergoing primary angioplasty for STEMI has been associated with significantly higher rates of pre-procedural epicardial recanalisation and ST-segment resolution. ${ }^{4-8}$ However, the benefit of these drugs is less certain in patients at lower risk for ischemic events or those presenting later ${ }^{9,10}$ and large randomized trials, conducted to explore the benefits from adjunctive GPIs in addition to clopidogrel administration, showed conflicting results. ${ }^{6,11-13}$ Among STEMI patients undergoing primary PCI, the greatest benefit in mortality reduction from GPI usage has been shown in patients with higher-risk profiles ${ }^{14}$. Therefore, identification of additional subgroups of patients who may have particular benefit from GPI administration is of paramount importance to further improve outcomes.

N-terminal pro-B-type natriuretic peptide (NT-proBNP), an established biomarker, has been shown to be released from myocardium following acute myocardial infarction ${ }^{15}$ and elevated levels have been associated with poor outcome in patients with acute coronary syndrome (ACS). ${ }^{16-21}$ Therefore, we undertook an exploratory analysis of the Ongoing Tirofiban In Myocardial infarction Evaluation 2 (On-TIME 2) trial, a placebo-controlled, double-blind, randomized trial, in order to investigate (1) the association between NT-proBNP levels and long-term mortality, (2) the effect of early tirofiban administration on mortality in relation to NT-proBNP levels in patient with STEMI undergoing primary PCI.

\section{Methods}

\section{Study design}

The On-TIME 2 trial (ISRCTN06195297) was an international, multicenter, prospective, placebo-controlled, double-blind, randomized trial. The rationale and design of the study have been previously described. ${ }^{22}$ In brief, the study population consisted of patients with STEMI who were candidates for primary PCI treatment. Eligible patients were men and women, 21 to 85 years of age, with symptoms of acute myocardial infarction (MI) for $>30$ min but $<24 \mathrm{~h}$, and ST-segment elevation of $>1 \mathrm{mV}$ in two adjacent electrocardiogram leads. Exclusion criteria were known severe renal dysfunction, therapy-resistant cardiogenic shock, persistent severe hypertension, and an increased risk of bleeding. Also excluded were patients with a left bundle branch block and patients with a life expectancy of $<1$ year. Written informed consent was obtained by an intensive care nurse in the ambulance or, in a minority of the patients, by a 
physician in the referral center. The study protocol was approved by all local ethics committees involved.

\section{Randomization and treatment}

Patients were randomly assigned to pre-hospital treatment with either high bolus dose of tirofiban $(25 \mu \mathrm{g} / \mathrm{kg}$ bolus and $0.15 \mu \mathrm{g} / \mathrm{kg} / \mathrm{min}$ maintenance infusion for $18 \mathrm{~h})$ or placebo. In the ambulance or referring center, all patients also received a bolus of 5000 IU of unfractionated heparin intravenously together with aspirin $500 \mathrm{mg}$ intravenously and a $600 \mathrm{mg}$ loading dose of clopidogrel orally. Before PCI, additional unfractionated heparin (2500 IU) was only given if the activated clotting time was less than $200 \mathrm{~s}$.

Coronary angiography and PCI were performed according to each institution's guidelines and standards. Additional treatment with thrombus aspiration was left at the discretion of the treating cardiologist.

\section{Blood samples for NT-proBNP measurement}

Blood samples were taken on admission before angiography (baseline) and 18-96 h thereafter (post-PCI). NT-proBNP was measured by a sandwich immunoassay on a fully automated analyzer (NT-proBNP ELECSYS 2010, Roche Diagnostics, Mannheim, Germany). The NT-proBNP levels were assessed both as continuous values and dichotomized with median value as cut-off.

\section{Mortality outcome}

In order to investigate (1) the association between NT-proBNP levels and short- and long-term mortality, and (2) the effect of early tirofiban on mortality in relation to NTproBNP levels, the mortality endpoints of this exploratory study were set at 30 days, 1 year and 5 years. Death was defined as all-cause mortality.

\section{Bleeding outcome}

As previously described, ${ }^{6}$ bleeding was assessed using the TIMI criteria. ${ }^{23}$ Major bleeding was defined as clinical overt signs of hemorrhage associated with a decrease in hemoglobin of $>5 \mathrm{~g} / \mathrm{dl}$ (or when hemoglobin assessment is not available, a decrease in hematocrit of $>15 \%$ ). For patients undergoing coronary artery bypass graft surgery, the rate of surgical re-exploration for bleeding and the postoperative volume of blood loss were also evaluated. Follow-up information was derived from visits to the outpatient clinic or from telephone contact at the 30-day follow-up. 
Table 1. Baseline characteristics of the patients receiving placebo vs. tirofiban

\begin{tabular}{lccc}
\hline \hline Variable & $\begin{array}{c}\text { Placebo } \\
(\mathrm{N}=454)\end{array}$ & $\begin{array}{l}\text { Tirofiban } \\
(\mathrm{N}=464)\end{array}$ & P value \\
\hline Age $(\mathrm{yrs})$, mean $\pm \mathrm{SD}$ & $62.0 \pm 11.8$ & $61.5 \pm 11.7$ & 0.504 \\
Male gender & $340 / 454(74.9 \%)$ & $355 / 464(76.5 \%)$ & 0.567 \\
Current smoking & $223 / 449(49.7 \%)$ & $208 / 463(44.9 \%)$ & 0.152 \\
Diabetes mellitus & $51 / 454(11.2 \%)$ & $55 / 463(11.9 \%)$ & 0.760 \\
Body mass index $\left(\mathrm{kg} / \mathrm{m}^{2}\right)$, mean $\pm \mathrm{SD}$ & $26.7 \pm 4.0$ & $26.8 \pm 3.4$ & 0.506 \\
Hypertension & $152 / 454(33.5 \%)$ & $156 / 464(33.6 \%)$ & 0.964 \\
Hypercholesterolemia & $112 / 453(24.7 \%)$ & $132 / 463(28.5 \%)$ & 0.195 \\
Killip Class $>1$ & $24 / 453(5.3 \%)$ & $17 / 463(3.7 \%)$ & 0.234 \\
Prior myocardial infarction & $34 / 453(7.5 \%)$ & $43 / 463(9.3 \%)$ & 0.331 \\
Prior CABG & $9 / 454(2.0 \%)$ & $8 / 464(1.7 \%)$ & 0.772 \\
Prior PCI & $36 / 454(7.9 \%)$ & $47 / 464(10.1 \%)$ & 0.245 \\
Anterior infarction location & $168 / 407(41.3 \%)$ & $173 / 407(42.5 \%)$ & 0.722 \\
Time to intervention* & $167(128-261)$ & $165(125-235)$ & 0.371 \\
Heart rate $>100$ & $26 / 450(5.8 \%)$ & $24 / 461(5.2 \%)$ & 0.705 \\
Systolic blood pressure $<100$ & $37 / 450(8.2 \%)$ & $28 / 459(6.1 \%)$ & 0.214 \\
\hline \hline
\end{tabular}

*From onset of symptoms to intervention in minutes, median $\left(25^{\text {th }}-75^{\text {th }}\right.$ interquartile ranges).

\section{Statistical analysis}

Continuous data were expressed as mean $\pm \mathrm{SD}$ or median with interquartile range. Categorical data were expressed as percentages. Categorical variables were analyzed with the Chi-squared test or Fischer's exact test, and continuous variables with the Mann-Whitney U-test (2-sided). Values of $\mathrm{P}<0.05$ were considered statistically significant. We performed multivariate logistic regression analyses on mortality with NT-proBNP below or above the median as the predictor of main interest and baseline characteristics (age, gender, smoking, BMI, diabetes, hypertension, hypercholesterolemia, prior myocardial infarction, prior PCI, admission heart rate, systolic blood pressure, anterior infarct location, ischemic time, post-PCI TIMI flow (less than 3 versus 3), and Killip Class (I versus II, III or IV) as confounders. All analyses were performed according to the intention-to-treat principle. Statistical analysis was performed with PASW Statistics 18 (SPSS Inc., Chicago, IL, USA). 


\section{RESULTS}

\section{Study population}

The ON-TIME 2 trial recruited a total of 984 patients who were randomized to either placebo or tirofiban treatment. The baseline clinical characteristics for patient receiving placebo or tirofiban were comparable and are presented in Table 1. There were 918 (93.3\%) patients with samples available for NT-proBNP at admission (baseline) and $865(87.9 \%)$ post-PCI.

There was no significant difference in NT-proBNP levels between patients randomized to tirofiban or to placebo as a continuous variable $(626 \pm \mathrm{SD} 1850$ vs. $646 \pm \mathrm{SD} 2054$ $\mathrm{ng} / \mathrm{l}, \mathrm{P}=0.11$, in tirofiban vs. placebo group, respectively) nor as a binary variable dichotomized according to the median value $(48.9 \%$ vs. $51.1 \%, \mathrm{P}=0.51$, in tirofiban vs. placebo group, respectively).

Baseline clinical characteristics of patients according to baseline NT-proBNP level below or above the median are shown in Table 2. Several characteristics were significantly different in the two patient cohorts. Patients with baseline NT-proBNP level above the median were older, more frequently female, presented higher rate of diabetes, hypertension, history of myocardial infarction, history of PCI, Killip Class $>1$, had a higher baseline heart rate and a longer time to intervention as compared to patient with baseline NT-proBNP levels below the median; who conversely had a lower BMI and were less frequently smokers.

Table 2. Baseline characteristics of patients with a baseline NT-proBNP level $\leq$ median vs. > median.

\begin{tabular}{lccr}
\hline \hline Variable & $\begin{array}{l}\text { NT-proBNP level } \\
\text { smedian }\end{array}$ & $\begin{array}{l}\text { NT-proBNP level } \\
>\text { median }\end{array}$ & P value \\
\hline Age (yrs) mean \pm SD & $57.3 \pm 9.9$ & $66.3 \pm 11.8$ & $<0.001$ \\
Male gender & $384 / 459(83.7 \%)$ & $311 / 459(67.8 \%)$ & $<0.001$ \\
Current smoking & $246 / 456(53.9 \%)$ & $185 / 456(40.6 \%)$ & $<0.001$ \\
Diabetes mellitus & $42 / 458(9.2 \%)$ & $64 / 459(13.9 \%)$ & 0.024 \\
Body mass index $\left(\mathrm{kg} / \mathrm{m}^{2}\right)$ mean $\pm \mathrm{SD}$ & $27.2 \pm 3.8$ & $26.4 \pm 3.6$ & 0.009 \\
Hypertension & $113 / 459(24.6 \%)$ & $195 / 459(42.5 \%)$ & $<0.001$ \\
Hypercholesterolemia & $111 / 457(24.3 \%)$ & $133 / 459(29.0 \%)$ & 0.109 \\
Killip Class $>1$ & $10 / 458(2.2 \%)$ & $31 / 458(6.8 \%)$ & $<0.001$ \\
Prior myocardial infarction & $25 / 458(5.5 \%)$ & $52 / 458(11.4 \%)$ & 0.001 \\
Prior CABG & $6 / 459(1.3 \%)$ & $11 / 459(2.4 \%)$ & 0.221 \\
Prior PCI & $31 / 459(6.8 \%)$ & $52 / 459(11.3 \%)$ & 0.016 \\
Anterior infarct location & $164 / 409(40.1 \%)$ & $177 / 405(43.7 \%)$ & 0.297 \\
Time to intervention* & $152(122 ; 203)$ & $193(136 ; 292)$ & $<0.001$ \\
Heart rate $>100$ & $15 / 456(3.3 \%)$ & $35 / 455(7.7 \%)$ & 0.004 \\
Systolic blood pressure $<100$ & $32 / 453(7.1 \%)$ & $33 / 456(7.2 \%)$ & 0.919 \\
\hline \hline
\end{tabular}

* From onset of symptoms to intervention in minutes, median $\left(25^{\text {th }}-75^{\text {th }}\right.$ interquartile ranges $)$. 


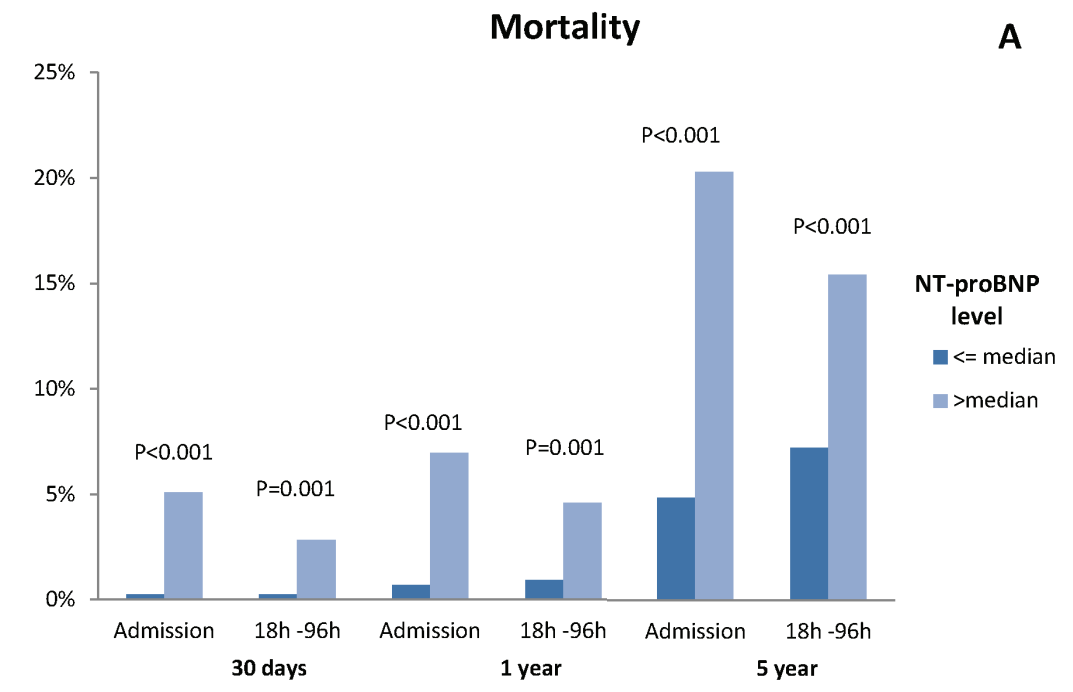

\section{5-year Mortality}

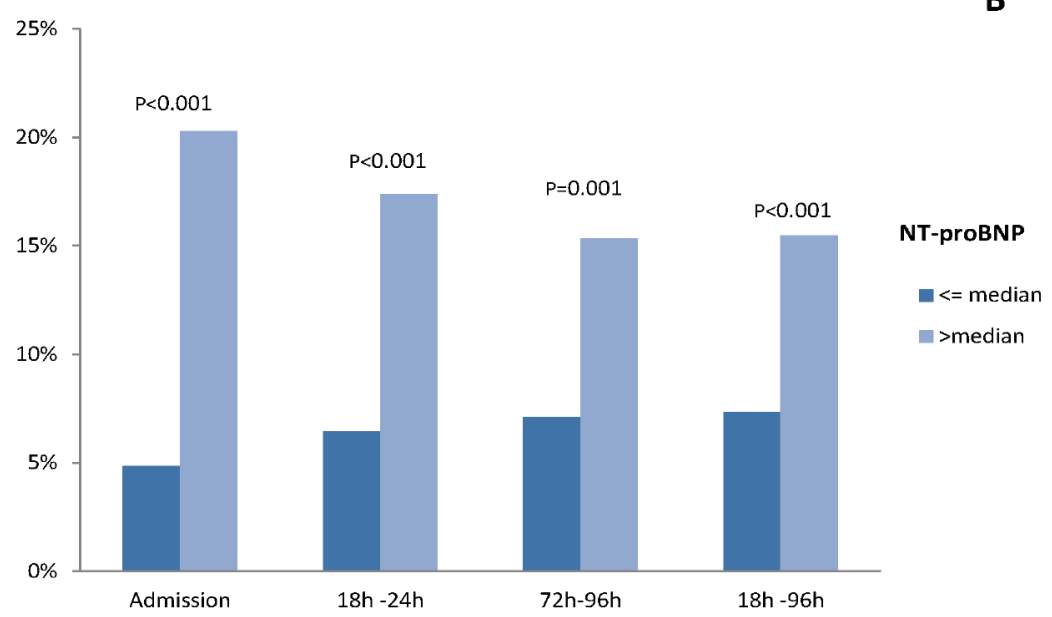

Figure 1. NT-proBNP and mortality outcomes. (A) 30-day, 1-year and 5-year mortality in relation to NT-proBNP levels above or below the median, collected before angiography (baseline) and after PCI (18-96 h). (B) 5-year mortality according to NT-proBNP level collected a several time points after PCI. 


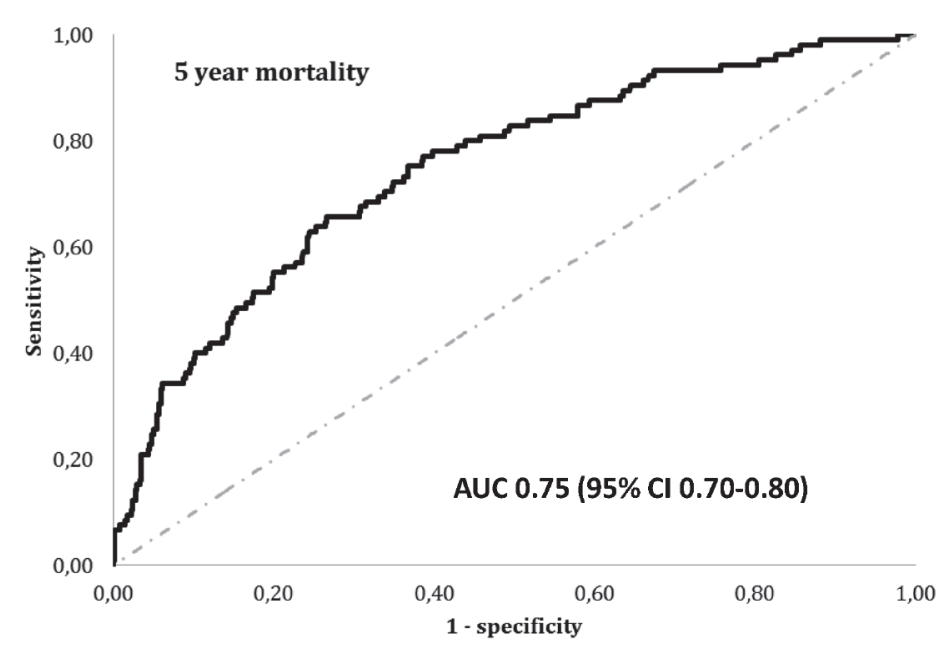

Figure 2. Receiver operating characteristics curve (ROC) for NT-proBNP at admission for 5-year mortality. AUC, area under the curve.

\section{Baseline NT-proBNP and mortality}

Patients with baseline NT-proBNP level above the median presented higher 30-day (5.1\% vs. $0.2 \%, \mathrm{P}<0.001)$, 1 -year $(7.0 \%$ vs. $0.7 \%, \mathrm{P}<0.001)$ and 5 -year $(20.3 \%$ vs. $4.9 \%, \mathrm{P}<0.001)$ mortality compared to patients with baseline NT-proBNP value below the median (Fig. 1A).

Additionally, NT-proBNP values post-PCI were also strongly related to mortality: patients with NT-proBNP levels above the median had a significant higher mortality at 30 -days $(3.0 \%$ vs. $0.2 \% \mathrm{P}=0.001)$, at 1 -year $(4.8 \%$ vs. $0.9 \% \mathrm{P}=0.001)$ and at 5 -year $(15.5 \%$ vs. $7.3 \% \mathrm{P} \leq 0.001)$ (Figure $1 \mathrm{~A})$; this effect on long-term mortality (5-years) was again confirmed at all sample times (Figure 1B).

Receiver operating characteristics (ROC) curve (Figure 2), showed that elevated NTproBNP levels (above the mean) at admission as a predictor for 1-year mortality had an area under the curve (AUC) of $0.84(95 \% \mathrm{CI} 0.76-0.92)$, and for 5-year mortality an AUC of 0.75 (95\%CI 0.70-0.80). Elevated NT-proBNP levels (above the median) at admission for 5-year mortality had a relative risk (RR) of 4.18 (95\%CI; 2.62-6.67), and after multivariate logistic regression analysis, an Odds Ratio (OR) of $2.75(95 \% \mathrm{CI}$ 1.41 to $5.73 ; \mathrm{P}=0.003$ ). 
Table 3. NT-proBNP levels in placebo versus tirofiban groups

\begin{tabular}{|c|c|c|c|c|c|c|}
\hline & \multicolumn{3}{|c|}{$\begin{array}{l}\text { NT-proBNP levels } \\
\text { expressed as a continuous variable }\end{array}$} & \multicolumn{3}{|c|}{$\begin{array}{l}\text { NT-proBNP levels } \\
\text { dichotomized according to the median value }\end{array}$} \\
\hline & $\begin{array}{l}\text { Placebo } \\
\text { mean } \pm \text { SD }\end{array}$ & $\begin{array}{l}\text { Tirofiban } \\
\text { mean } \pm \text { SD }\end{array}$ & $P$ value & $\begin{array}{l}\text { Placebo } \\
\text { N/total (\%) }\end{array}$ & $\begin{array}{l}\text { Tirofiban } \\
\text { N/total (\%) }\end{array}$ & $P$ value \\
\hline$\overline{\mathrm{Adm}}$ & $646 \pm 2054$ & $626 \pm 1850$ & 0.108 & $232 / 454(51.1)$ & $227 / 464(48.9)$ & 0.509 \\
\hline After PCI & $2114 \pm 2866$ & $1732 \pm 5019$ & 0.080 & $238 / 439(54.2)$ & $194 / 426(45.5)$ & 0.011 \\
\hline
\end{tabular}

\section{Effect of early administration of tirofiban on NT-proBNP levels, bleeding and mortality in relation to NT-proBNP level}

NT-proBNP. Interestingly in patients treated with pre-hospital tirofiban as compared to placebo, the NT-proBNP levels after PCI tended to be lower when considered as a continuous variable $(1732 \pm 2866$ vs. $2114 \pm 5019, \mathrm{P}=0.080)$ and were significantly lower when considered as a binary variable dichotomized with median value as cut-off (194/426, 45.5\% vs. 238/439, 54.2\%, $\mathrm{P}=0.011$ ) (Table 3).

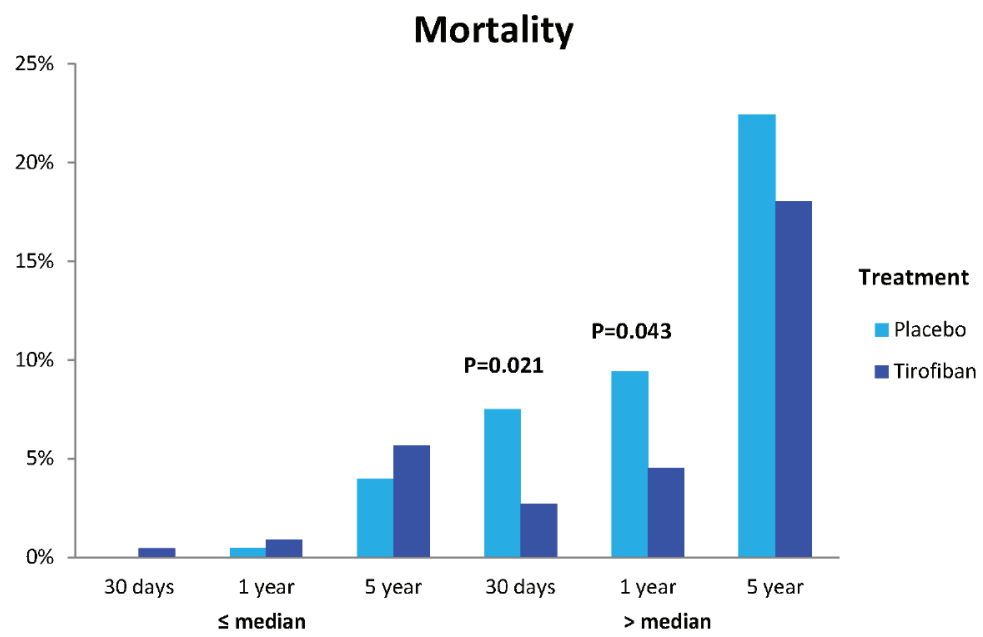

Figure 3. Effect of pre-hospital tirofiban administration on mortality in relation to NT-proBNP levels above or below the median value. Patients with baseline NT-proBNP level above the median who received early tirofiban treatment had a significant lower mortality rate at 30-days and at 1year, as compared to patients treated with placebo. 
Bleeding. Patients with NT-proBNP levels above the median at admission who received early tirofiban treatment had a similar rate of 30-days major bleeding compared to patients treated with placebo (5.8\% vs. $3.1 \%, \mathrm{P}=0.158$, for tirofiban vs. placebo group, respectively) and 30 days of minor bleeding ( $7.6 \%$ vs. $4.4 \%, \mathrm{P}=0.151$ ).

Mortality. Patients with NT-proBNP above the median at admission who received early tirofiban treatment had a significantly lower mortality at 30 -days $(2.7 \%$ vs. $7.5 \%$, $\mathrm{P}=0.021)$ and at 1 -year ( $4.5 \%$ vs. $9.4 \%, \mathrm{P}=0.043)$ compared to patients treated with placebo (Figure 3). This lower mortality rate in the treatment group was indeed maintained as far as 5-years, although at this point was associated with a nonsignificant difference ( $18 \%$ vs. $22.4 \%, \mathrm{P}=0.265)$.

\section{DISCUSSION}

In this exploratory analysis of the On-TIME 2 trial, we have shown in a group of STEMI-only patients that elevated NT-proBNP levels are an independent predictor of long-term (5-year) mortality outcome. Moreover, we have shown that in STEMI patients undergoing primary PCI who have elevated admission NT-proBNP levels, in ambulance initiation of tirofiban, significantly reduces NT-proBNP levels post PCI and improves both short- and long-term mortality outcomes compared to placebo, an important and novel finding.

We have previously reported the long-term mortality benefit of a GPI-facilitated PCI strategy $^{7}$; however, in this current analysis we provide further insight, showing that a high-risk subset of patients, as identified by higher levels of NT-proBNP upon presentation (Figure 1), represent a subgroup who derive particular benefit from early GPIs treatment in terms of reduced 30-days and 1-year mortality (Figure 3), and importantly this is without a significant increase in either major or minor bleeding complications. Previously a significant relationship between the benefits in mortality reduction from the use of GPIs and patient's risk profile has been suggested, ${ }^{14}$ the identification of patients who may incrementally benefit from GPIs administration is important in the ongoing search for a more tailored and optimized therapy for STEMI patients. Therefore, our findings may help to further refine the identification of patients likely to derive the greatest benefit from pre-hospital GPI administration.

It is widely believed that the predominant process underlying increased NT-proBNP concentrations is impairment of cardiac function, leading to increased left ventricular wall stretch with resultant synthesis and secretion of NT-proBNP. ${ }^{24,25}$ Ischemic injury 
due to coronary artery occlusion may first cause diastolic dysfunction, followed by elevation in filling pressures and associated left ventricular wall stretch resulting in the early elevation of serum NT-proBNP levels. However, elevated NT-proBNP concentrations may also result directly from cardiac ischemia, even in the absence of left ventricular dysfunction. ${ }^{26}$ Previous studies highlighted that, in STEMI patients, NT-proBNP, drawn within 24 hours of the onset of chest pain, is more accurate in predicting mortality than the Thrombolysis in Myocardial Infarction (TIMI) risk score. ${ }^{27}$ Indeed, our group recently revealed that baseline NT-proBNP values predict 30-day mortality independently and tend to have a greater discriminatory prediction than the Zwolle Risk Score. ${ }^{28}$ However, in STEMI patients the prognostic value of NTproBNP on long-term, 5-year mortality outcomes to date has never been reported.

NT-proBNP measured before primary PCI has been previously shown to be the strongest, independent predictor of suboptimal microvascular reperfusion. ${ }^{29}$

Mechanisms behind the actual association between NT-proBNP and suboptimal reperfusion remain speculative, ${ }^{29}$ however, biomarker elevation may be the expression of profound myocardial ischemia and extensive microvascular damage leading to relevant ventricular dysfunction, alternatively one could argue that primary microvascular dysfunction, by itself, may influence left ventricular wall stretch and so BNP values in the setting of acute myocardial infarction. Regardless of the mechanism, patients at risk of suboptimal microvascular reperfusion after PCI, may have particular benefit from adjunctive measures, such as early GPI administration. In fact, it has been shown that an antithrombotic therapy which is already active and effective at the time of PCI, plays a crucial role in the prevention of microvascular damage and restoration of myocardial tissue reperfusion. ${ }^{6}$

Interesting, in this study, NT-proBNP levels at baseline (before angiography) were not different with respect of the treatment strategy initiated in the ambulance. However, early tirofiban administration significantly reduced the number of patients with an NTproBNP above the median after PCI. This suggests that the time course of NT-proBNP level may be positively influenced by early tirofiban administration and could potentially be dependent on the effectiveness of microvascular reperfusion after PCI, an outcome in which early tirofiban administration has a proven role. ${ }^{6}$

Importantly, measurement of NT-proBNP has become easy-to-perform and fast; its early measurement in the ambulance setting, aimed at stratifying patients and guiding early antiplatelet therapy, could represent a possible new strategy to be tested in further studies. Finally, further prospective evaluation of high-risk subgroups identified by elevated NT-proBNP during the acute STEMI phase is warranted. 


\section{Limitations}

This is a post-hoc analysis of a randomized trial, therefore, our conclusions should be considered as exploratory. NT-proBNP levels were drawn at variable periods after onset of symptoms, therefore it has to be noted that some patients with the highest values of NT-proBNP at admission may include a sub-group of patients with a long ischemia time in which the benefit of early GPI treatment remain uncertain. ${ }^{30}$ Despite the fact that the prognostic value of NT-proBNP above the median was independent from ischemia time, further studies are warranted to evaluate the efficacy of early tirofiban administration in subgroup presenting with long ischemia time and high level of NT-proBNP. Finally, baseline NT-proBNP measurements were made at admission (before angiography) when tirofiban was already started; although the time between tirofiban administration and first NT-proBNP measurement was very short we cannot exclude a small effect of the drug on the baseline values of NT-proBNP.

\section{CONCLUSIONS}

In STEMI patients, NT-proBNP level above the median on admission independently predict long-term (5-year) mortality. Patients with elevated admission NT-proBNP levels who were treated with pre-hospital treatment with tirofiban, as compared to placebo, had significantly reduced 30-day and 1-year mortality rates. Early tirofiban administration may be particularly effective in reducing mortality in high-risk patients, as identified by higher admission levels of NT-proBNP. 


\section{REFERENCES}

1. The effects of tissue plasminogen activator, streptokinase, or both on coronary-artery patency, ventricular function, and survival after acute myocardial infarction. The GUSTO Angiographic Investigators. N Engl J Med 1993;329:1615-1622.

2. Windecker S, Kolh P, Alfonso F, et al. 2014 ESC/EACTS Guidelines on myocardial revascularization: The Task Force on Myocardial Revascularization of the European Society of Cardiology (ESC) and the European Association for Cardio-Thoracic Surgery (EACTS)Developed with the special contribution of the European Association of Percutaneous Cardiovascular Interventions (EAPCI). Eur Heart J 2014;35:2541-2619.

3. Valgimigli M, Biondi-Zoccai G, Tebaldi M, et al. Tirofiban as adjunctive therapy for acute coronary syndromes and percutaneous coronary intervention: a meta-analysis of randomized trials. Eur Heart J 2010;31:35-49.

4. De Luca G, Gibson CM, Bellandi F, et al. Early glycoprotein IIb-IIIa inhibitors in primary angioplasty (EGYPT) cooperation: an individual patient data meta-analysis. Heart 2008;94:1548-1558.

5. Herrmann HC, Lu J, Brodie BR, et al. Benefit of facilitated percutaneous coronary intervention in high-risk ST-segment elevation myocardial infarction patients presenting to nonpercutaneous coronary intervention hospitals. JACC Cardiovasc Interv 2009;2:917-924.

6. Van 't Hof AW, Ten Berg J, Heestermans T, et al. Prehospital initiation of tirofiban in patients with ST-elevation myocardial infarction undergoing primary angioplasty (On-TIME 2): a multicentre, double-blind, randomised controlled trial. Lancet 2008;372:537-546.

7. ten Berg JM, van 't Hof AW, Dill T, et al. Effect of early, pre-hospital initiation of high bolus dose tirofiban in patients with ST-segment elevation myocardial infarction on short- and longterm clinical outcome. J Am Coll Cardiol 2010;55:2446-2455.

8. Huber K, Holmes DR, Jr., van 't Hof AW, et al. Use of glycoprotein IIb/IIIa inhibitors in primary percutaneous coronary intervention: insights from the APEX-AMI trial. Eur Heart J 2010;31:17081716.

9. Stone GW, Grines CL, Cox DA, et al. Comparison of angioplasty with stenting, with or without abciximab, in acute myocardial infarction. N Engl J Med 2002;346:957-966.

10. Ellis SG, Tendera M, de Belder MA, et al. Facilitated PCI in patients with ST-elevation myocardial infarction. N Engl J Med 2008;358:2205-2217.

11. Stone GW, Witzenbichler B, Guagliumi G, et al. Bivalirudin during primary PCI in acute myocardial infarction. N Engl J Med 2008;358:2218-2230.

12. Mehilli J, Kastrati A, Schulz S, et al. Abciximab in patients with acute ST-segment-elevation myocardial infarction undergoing primary percutaneous coronary intervention after clopidogrel loading: a randomized double-blind trial. Circulation 2009;119:1933-1940.

13. Le May MR, Wells GA, Glover CA, et al. Primary percutaneous coronary angioplasty with and without eptifibatide in ST-segment elevation myocardial infarction: a safety and efficacy study of integrilin-facilitated versus primary percutaneous coronary intervention in ST-segment elevation myocardial infarction (ASSIST). Circ Cardiovasc Interv 2009;2:330-338.

14. De Luca G, Navarese E, Marino P. Risk profile and benefits from Gp IIb-IIIa inhibitors among patients with ST-segment elevation myocardial infarction treated with primary angioplasty: a meta-regression analysis of randomized trials. Eur Heart J 2009;30:2705-2713.

15. Gill D, Seidler T, Troughton RW, et al. Vigorous response in plasma N-terminal pro-brain natriuretic peptide (NT-BNP) to acute myocardial infarction. Clin Sci (Lond) 2004;106:135-139.

16. de Lemos JA, Morrow DA, Bentley JH, et al. The prognostic value of B-type natriuretic peptide in patients with acute coronary syndromes. N Engl J Med 2001;345:1014-1021. 
17. Heeschen C, Hamm CW, Mitrovic V, Lantelme NH, White HD. N-terminal pro-B-type natriuretic peptide levels for dynamic risk stratification of patients with acute coronary syndromes. Circulation 2004;110:3206-3212.

18. James SK, Lindahl B, Siegbahn A, et al. N-terminal pro-brain natriuretic peptide and other risk markers for the separate prediction of mortality and subsequent myocardial infarction in patients with unstable coronary artery disease: a Global Utilization of Strategies To Open occluded arteries (GUSTO)-IV substudy. Circulation 2003;108:275-281.

19. Galvani M, Ottani F, Oltrona L, et al. N-terminal pro-brain natriuretic peptide on admission has prognostic value across the whole spectrum of acute coronary syndromes. Circulation 2004;110:128134.

20. Grabowski M, Filipiak KJ, Karpinski G, et al. Serum B-type natriuretic peptide levels on admission predict not only short-term death but also angiographic success of procedure in patients with acute ST-elevation myocardial infarction treated with primary angioplasty. Am Heart J 2004;148:655-662.

21. Hong SN, Ahn Y, Hwang SH, et al. Usefulness of preprocedural N-terminal pro-brain natriuretic peptide in predicting angiographic no-reflow phenomenon during stent implantation in patients with ST-segment elevation acute myocardial infarction. Am J Cardiol 2007;100:631634.

22. van 't Hof AW, Hamm C, Rasoul S, Guptha S, Paolini JF, Ten Berg JM. Ongoing tirofiban in myocardial infarction evaluation (On-TIME) 2 trial: rationale and study design. EuroIntervention 2007;3:371-380.

23. Rao AK, Pratt C, Berke A, et al. Thrombolysis in Myocardial Infarction (TIMI) Trial--phase I: hemorrhagic manifestations and changes in plasma fibrinogen and the fibrinolytic system in patients treated with recombinant tissue plasminogen activator and streptokinase. J Am Coll Cardiol 1988;11:1-11.

24. Bjorklund E, Jernberg T, Johanson P, et al. Admission N-terminal pro-brain natriuretic peptide and its interaction with admission troponin $\mathrm{T}$ and ST segment resolution for early risk stratification in ST elevation myocardial infarction. Heart 2006;92:735-740.

25. Richards AM, Nicholls MG, Yandle TG, et al. Plasma N-terminal pro-brain natriuretic peptide and adrenomedullin: new neurohormonal predictors of left ventricular function and prognosis after myocardial infarction. Circulation 1998;97:1921-1929.

26. Goetze JP, Christoffersen C, Perko M, et al. Increased cardiac BNP expression associated with myocardial ischemia. Faseb J 2003;17:1105-1107.

27. Khan SQ, Quinn P, Davies JE, Ng LL. N-terminal pro-B-type natriuretic peptide is better than TIMI risk score at predicting death after acute myocardial infarction. Heart 2008;94:40-43.

28. Schellings DA, Adiyaman A, Giannitsis E, et al. Early discharge after primary percutaneous coronary intervention: the added value of N-terminal pro-brain natriuretic peptide to the Zwolle Risk Score. J Am Heart Assoc 2014;3:e001089.

29. Verouden NJ, Haeck JD, Kuijt WJ, et al. Comparison of the usefulness of N-terminal pro-brain natriuretic peptide to other serum biomarkers as an early predictor of ST-segment recovery after primary percutaneous coronary intervention. Am J Cardiol 2010;105:1047-1052.

30. Heestermans T, van 't Hof AW, ten Berg JM, et al. The golden hour of prehospital reperfusion with triple antiplatelet therapy: a sub-analysis from the Ongoing Tirofiban in Myocardial Evaluation 2 (On-TIME 2) trial early initiation of triple antiplatelet therapy. Am Heart J 2010;160:1079-1084. 

CHAPTER 11

\section{Summary \\ and}

General discussion 



\section{Summary of the thesis}

In CHAPTER 1, it is shown that risk stratification in acute myocardial infarction is an important subject that has been extensively studied before. As a consequence, several risk models for both STEMI and NSTEMI patients have been developed and validated. Because infarction size and procedural outcome are important risk variables, novel biomarkers, particularly NT-proBNP, demonstrated prognostic value in acute myocardial infarction (AMI) patients as well. However, at present knowledge of the value of NT-proBNP beyond established risk stratification is limited.

Risk stratification is also mandatory for the scheduling of hospital discharge, an issue that was taken into account by the development of the Zwolle Risk Score (ZRS). STEMI patients treated by primary PCI at low mortality risk were eligible candidates for early hospital discharge, at approximately 72 hours after admission. However, at present, PPCI patients could probably be discharged earlier; but, studies on next day discharge strategies are very limited and the value of measuring NT-proBNP in this context is unclear.

Finally, the significance of new-onset atrial fibrillation during admission in PPCI patients was discussed, and the need for improved risk strategies for early recognition of these patients was emphasized.

Based on the above-mentioned considerations, the general aims of the research presented in this thesis were three-fold:

1. To improve risk assessment in AMI patients in the present biomarker era.

2. To improve discharge policy in STEMI patients treated with PPCI.

3. To improve identification of STEMI patients treated with PPCI at risk for new-onset AF.

Aims 1 and 2 were accomplished by NT-proBNP measurements beyond established risk stratification, as provided by the ZRS. This convenient bedside primary PCI risk score has been validated before. Besides excellent 30-day mortality prognostication, the ZRS also has an established value for scheduling early hospital discharge (after 72 h). However, in previous reports the predictors and effects of prolonged length of stay in hospital in the PPCI era remained underexposed. In CHAPTER 2, we demonstrated that 'longer stay patients' are mostly those patients who have signs of heart failure due to larger infarction size, and as a consequence have lower left ventricular ejection 
fraction. Although low left ventricular ejection fraction was associated with prolonged hospital stay (OR 2.06), longer and shorter stay PPCI patients had comparable 1-year mortality risk. This was in contrast to the outcome in STEMI patients in the thrombolysis era, where prolonged hospital stay was a strong predictor for short- and longer-term mortality.

Given the fact that infarction size and, consequently, procedural PPCI success has important predictive value, we demonstrated in CHAPTER 3, that the ZRS and protocoled care could provide an excellent risk strategy for identifying PPCI patients who can be safely discharged within 24 to 36 hours after admission. Beside zero mortality cases at 30-day and even 1-year follow-up, the occurrence of major adverse events or (severe) co-morbidities was very low and did not differ significantly compared to a matching cohort of PPCI patients who received conventional care. However, in this study the patient cohort was small and highly selective and as a consequence, the percentage of 'real world' PPCI patients at low mortality risk who could be targeted for early hospital discharge was unknown. In addition, NT-proBNP was not measured. To address these issues, we performed a sub-analysis of the OnTIME 2 study in CHAPTER 4. In this study the 30-day follow-up data of 845 consecutive PPCI patients were available and NT-proBNP was measured by protocol, whereas the ZRS was calculated afterward. Both ZRS and baseline NT-proBNP independently predicted 30-day mortality and at receiver operating characteristic (ROC) curve analysis, the predictive accuracy of NT-proBNP tended to be even stronger than the ZRS. However, the linear combination of both demonstrated the best prognostic capacity (area under the curve [AUC] 0.94 CI 0.90-0.99).

Additionally, cut-off scores were defined based on $100 \%$ sensitivity (or zero mortality) and it was shown that specificity was as high as $70 \%$ when the patient had a ZRS $<2$ or NT-proBNP $<200 \mathrm{pg} / \mathrm{ml}$. Based on these cut-off values $64 \%$ of the study population could potentially be targeted for early discharge after 48 hours, with low occurrence of MACEs and major bleeding between 2 and 10 days (1.3\% and $0.6 \%$, respectively). Although these results need prospective validation, the value of NT-proBNP, besides its use in predicting mortality, was shown for improved scheduling of hospital discharge. Whether baseline or serial NT-proBNP measurements provide optimal prognostication remained unclear; it would probably be better to measure NT-proBNP post PPCI. Therefore we performed an additional analysis of the On-TIME 2 study population in CHAPTER 5, so as to define the optimum time point for NT-proBNP measurement. In 845 PPCI patients, NT-proBNP was measured at baseline, at 18-24 h and at 72-96 h after PPCI. Also, the difference between baseline and 18-24 h NTproBNP levels (delta NT-proBNP) was measured. Compared to the ZRS, NT-proBNP at the different time points (except delta NT-proBNP) demonstrated better prognostic 
accuracy for 30-day mortality with optimum AUC at 18-24 h after PPCI (AUC 0.94). The combination of NT-proBNP measured at 18-24 $\mathrm{h}$ and the ZRS did not enlarge the AUC, but additional reclassification analysis certainly demonstrated prognostic improvement. Additionally, we demonstrated that based on the cut-off values for $100 \%$ sensitivity (or zero mortality), patients who had ZRS $<2$ or NT-proBNP at 18-24 h of $<2500 \mathrm{pg} / \mathrm{ml}$ could potentially be discharged $48 \mathrm{~h}$ after PPCI, given the low occurrence of MACEs and/or major bleeding at 2 to 10 days (expected readmission rate of $1.2 \%$ ). Although the other time points also had good prognostic accuracy, at 18-24 h after PPCI the largest patient group at very low risk could be indentified ( $75 \%$ of the study population). Additionally, we gave a comprehensive insight in the occurrence of MACEs and major bleeding in both low- and higher-risk patients. However, despite these favorable results, it remained unclear whether NT-proBNP (and also ZRS) could really predict non-fatal adverse events, which are at least as important in risk stratification. In CHAPTER 6 we therefore performed an additional analysis of the OnTIME 2 patient population. It was shown that ZRS and NT-proBNP at 18-24 h and at 72-96 h (but not baseline NT-proBNP) independently predicted the composite of adverse events (re-myocardial infarction, urgent target vessel revascularization, major bleeding and the occurrence of ventricular arrhythmias) at 30-day follow-up (Odds ratios $1.10-1.14, \mathrm{P}$ values all $<0.05$ ). Although ZRS and serial NT-proBNP separately demonstrated limited predictive accuracy (AUCs all $\leq 0.70$ ), adding NT-proBNP at $18-24 \mathrm{~h}$ to the ZRS could modestly improve prognostication (AUC $0.73,95 \% \mathrm{CI}$ $0.62-0.78$, net reclassification improvement $19 \%$ ). As a consequence, NT-proBNP, particularly when measured at $18-24 \mathrm{~h}$ after PPCI, could also provide more insight in identifying patients at risk for severe co-morbidities, besides conventional risk stratification.

Apart from STEMI, a substantial number of patients are admitted with acute coronary syndromes (ACS) without ST-elevation (STE). Although this heterogeneous group of patients could benefit from early revascularization, immediate PCI is only indicated in very-high-risk patient groups. Consequently, good prognostication in non-STE-ACS is very important and could be provided by the Global Registry of Acute Coronary Events (GRACE) risk calculator or the Thrombolysis in Myocardial Infarction (TIMI) risk score for non-ST-elevation myocardial infarction (NSTEMI) or unstable angina. At present there are conflicting data, whether these risk scores (particularly the GRACE risk score) could also be improved by NT-proBNP measurement. To clarify this issue we compared the predictive value of NT-proBNP and the GRACE and TIMI risk scores for 30-day mortality as described in CHAPTER 7.

In 1324 NSTE-ACS patients, included in our ACS registry, NT-proBNP levels on admission and the GRACE risk score (but not the TIMI risk score) both independently 


\section{General discussion}

predicted death at 30-days. Moreover, NT-proBNP and the GRACE score had comparable predictive value (AUC of 0.85 and 0.87 , respectively, $\mathrm{P}=0.67$ ). However, adjustment of the GRACE score by adding admission NT-proBNP did not improve prognostication, while the combination of both was slightly better compared to NTproBNP only. Given these results, NT-proBNP is also very predictive in NSTE-ACS patients, but added value over and beyond the established GRACE risk score could not be demonstrated; this is in contrast with the TIMI risk score which turned out be to considerably less effective.

Aim 3 was accomplished by the identification of predictors of post PPCI AF and the assessment of the prognostic value of the biomarkers NT-proBNP and high-sensitivity troponin $\mathrm{T}$ (HsTnT). In CHAPTER 8 we report the temporal association between serial NT-proBNP plasma level measurements at different time points after admission and the development of AF in the setting of STEMI, in 830 PPCI patients included in the On-TIME 2 trial. In almost $9 \%$ of patients, AF occurred within 30 days after admission (incident AF). Although the established risk factors age and Killip Class were strong predictors, NT-proBNP at baseline was not associated with incident AF in multivariate analysis and did not predict AF on admission (within $24 \mathrm{~h}$ after PPCI). However, NTproBNP at baseline did predict AF $24-72 \mathrm{~h}$ and $>72 \mathrm{~h}$ after admission, but NT-proBNP plasma level assessment at $24 \mathrm{~h}$ and $72 \mathrm{~h}$ after admission were stronger predictors of $\mathrm{AF}>72 \mathrm{~h}$ after admission compared to NT-proBNP at baseline. Therefore, NT-proBNP assessed $24 \mathrm{~h}$ or $72 \mathrm{~h}$ after admission, and not NT-proBNP at baseline, could serve as biomarker in assessing the risk of incident AF in STEMI patients treated with PPCI. Although incident AF was not associated with HsTnT in univariate analysis in this study, AF $>24 \mathrm{~h}$ after admission was significantly associated with HsTnT plasma level. Since HsTnT was assessed during the first $72 \mathrm{~h}$ after admission in previous studies, perhaps an analysis with strict serial HsTnT assessment timings and peak HsTnT assessment might elucidate this association as presented in CHAPTER 9. Here, we reported the temporal association between HsTnT plasma level assessments at different timings after admission and the development of AF in the setting of STEMI. In line with previous studies, HsTnT at baseline was not associated with new-onset AF and $\mathrm{AF}$ within the first $24 \mathrm{~h}$ of admission. However, in contrast to previous studies, HsTnT measured at baseline and after $24 \mathrm{~h}$ and $72 \mathrm{~h}$ was significantly associated with onset of AF $24-72 \mathrm{~h}$ and $>72 \mathrm{~h}$ after STEMI. However, HsTnT after $24 \mathrm{~h}$ and $72 \mathrm{~h}$ were stronger predictors of AF compared with $\mathrm{HsTnT}$ at baseline.

As a consequence, also HsTnT measured after $24 \mathrm{~h}$ or $72 \mathrm{~h}$ could potentially enhance current risk stratification. 
Finally, in CHAPTER 10 we demonstrated that elevated baseline NT-proBNP levels independently predict long-term mortality (up to 5 years) in PPCI patients. In patients with elevated baseline NT-proBNP levels, early pre-hospital treatment with tirofiban significantly reduces 30-day and 1-year mortality, suggesting that NT-proBNP at baseline also identifies patients who may benefit from this treatment strategie. 



\section{GENERAL DISCUSSION}

This thesis focused on the risk stratification of patients with acute myocardial infarction (AMI) especially on those patients with ST-elevation myocardial infarction (STEMI) who are treated with primary PCI.

The main findings from the research presented in this thesis were:

- A longer hospital stay after PPCI is predicted in particular by larger infarction size and lower left-ventricular ejection fraction (LVEF). However, patients with low LVEF and longer hospital stay after PPCI have the same 1-year survival probability compared to patients who can leave the hospital earlier.

- The Zwolle Risk Score (ZRS) is a convenient and very accurate bedside PPCI risk model that provides good 30-day mortality prognostication and identification of low-risk PPCI patients eligible for next day discharge.

- The biomarker NT-proBNP and the ZRS have a comparable predictive value for 30-day mortality. However, the combined use of ZRS and NT-proBNP provides optimal predictive accuracy, especially if NT-proBNP is measured at $18-24 \mathrm{~h}$ after PPCI.

- Based on low ZRS or low NT-proBNP, large groups of patients could potentially be targeted for early discharge at $48 \mathrm{~h}$ after PPCI.

- NT-proBNP measured at 18-24 h or at 72-96 h independently predicts a composite of non-fatal adverse events at 30 days after PPCI as well.

- NT-proBNP and the GRACE risk score have comparable predictive value for 30day mortality in AMI patients without ST-elevation; however, combined use does not enhance prognostication.

- NT-proBNP and HsTnT, measured 24-72 h, are both associated with new-onset $\mathrm{AF}$ after PPCI and could serve as biomarkers in assessing risk of incident AF in PPCI patients.

- Baseline NT-proBNP also predicts long-term mortality in PPCI patients and could indentify high-risk patients who may benefit from early tirofiban treatment.

Risk stratification should be the foundation of the continuous process of patient management following AMI. Based on the patient's risk of adverse events, tailored treatment strategies can be performed and hospital discharge policy may be planned at a very early stage. In addition good risk stratification requires consistency and a thoroughly worked out strategy that can be put into practice in every patient. 


\section{Risk assessment: the past and the present}

Coronary thrombosis causing AMI has been a known cause of death since the beginning of the $19^{\text {th }}$ century. However, attention to its treatment has only been paid since the early $20^{\text {th }}$ century when it became evident that one could survive AMI. Strict bed rest for several weeks, partly promoted by G.K. Mallory's findings that necrotic myocardium needs 6 weeks to organise into a scar has been the 'state of the art' treatment for several decades. Mid $20^{\text {th }}$ century, one of the first steps toward risk assessment was taken by Samual Levine and Bernard Lown. Levine published the first book dedicated to AMI treatment and noted the importance of early detection of ventricular arrhythmias, whereas Lown pointed out that strict bed rest for several weeks could result in venous thrombosis and pulmonary embolism. Therefore Levine and Lown recommended in 1952 the 'armchair treatment', which made them pioneers in their attempt to shorten the length of hospital stay. ${ }^{1}$

In 1960s and 1970s several studies that classified low- and higher-risk AMI patients followed and demonstrated that the development of heart failure, re-infarction and ventricular arrhythmias during the first days of admission were associated with worse outcome, yet treatment options were still limited. However, with the advent of reperfusion therapy for STEMI in the mid-1980s, prognostic improvements resulted in a decline in length of stay in hospital. This trend continued with the widespread introduction of PPCI.

In this thesis we extensively highlighted the current risk factors for worse outcome after PPCI and we demonstrated that the ZRS, the recommended risk strategy at present, could provide a convenient and very accurate contribution to early patient management. Nevertheless, at present PPCI risk models have not yet become an integral part of daily routine among cardiologists.

This may be explained by the fact that in AMI patients who underwent coronary angiography or subsequently PPCI, protocoled care often intercepts high-risk patients, whereas low-risk patients are transferred back to the referring hospital or to the cardiology ward.

\footnotetext{
${ }^{1}$ Sarmento-Leite et al. Acute myocardial infarction. One century of History, Arq Bras Cardiol 2001; 77:602-610.
} 
As a matter of fact, in clinical practice, the use of risk strategies is particularly focussed on the identification of high-risk patients.

However, in this thesis it was demonstrated that, based on established risk stratification and NT-proBNP measurement, up to $75 \%$ of PPCI patients are nowadays at (very) low mortality risk. This opportunity should be taken, since most of these patients could potentially be discharged 2 days after admission and with low readmission rates.

Although safety and efficacy are the cornerstones of patient management, costeffectiveness is just as important. In contrast to AMI treatment, current guidelines provide no clear definition for when to discharge which patient. As a consequence it is estimated that $30-40 \%$ of PPCI patients could be discharged earlier when routinely used decision rules would have been applied. Furthermore, most PPCI patients leave the hospital to the discretion of the treating physician, based on different medical and logistic criteria rather than based on a structured approach.

\section{Risk assessment: the future}

Based on the afore-mentioned considerations, the findings in this thesis are intended to be the preamble to prospective validation of decision rules in PPCI patients, as suggested in CHAPTERS 4 and 5. Based on established risk factors and biomarker measurements (particularly NT-proBNP) at approximately $24 \mathrm{~h}$ after admission a very accurate risk model could be developed. Not only to predict short-term mortality, but also to detect several cardiovascular co-morbidities, major bleeding and new-onset atrial fibrillation, as demonstrated in CHAPTERS 6,8 and 9. Additionally, baseline NTproBNP could also define early treatment strategies and longer-term follow-up patient management, as suggested in CHAPTER 10.

Given the continuous improvement of treatment strategies and the rise of e-health modalities and remote monitoring technologies, patient care after PPCI outside conventional clinical settings will be more common in future. To guide this favorable development, reliable and unbiased risk stratification based on biomarkers and clinical characteristics are of great importance. 

CHAPTER 12

\section{Valorisation, Samenvatting, Dankwoord, List of publications, About the author}





\section{Valorisation}

In The Netherlands, coronary artery disease (CAD) in 2012 was responsible for more than 80,000 annual hospital admissions of more than 24 hours. As a consequence, CAD is accompanied by relatively high costs $(2.3 \%$ of the total Dutch healthcare costs in 2011), largely contributed to hospital care. In addition, 35\% of admissions are the result of acute myocardial infarction (AMI). Although length of hospital stay declined by approximately 40\% between 1995 and 2010, mean hospital stay for AMI in 2012 was 5 days in men and 6 days in women. Furthermore, it is estimated that the number of patients affected by CAD will increase from 610,000 to 840,000 between 2011 and 2030 as a result of aging and demographic growth. ${ }^{1}$

As a consequence, AMI makes that our society faces a serious healthcare issue today as well as for the future. At present, Dutch AMI patient care has been regulated very properly. STEMI patients are supposed to be transferred as soon as possible to the nearest PCI center, whereas in NSTEMI patients, particular importance is attached to risk-based decision making. This established approach has become the norm for AMI treatment. As a consequence Dutch hospitals have to provide statistics about the percentage of patients undergoing PPCI or risk-based revascularization in order to meet quality requirements. Although this policy quite rightly focuses attention on high-risk patients, lower-risk patients often go unnoticed.

In this thesis, we demonstrated that the Zwolle Risk Score (ZRS) was able to identify PPCI patients who were eligible candidates for next day discharge when protocolized outpatient care was provided. Compared to controls, short-stay patients had similar outcomes, but their stay in hospital was significantly shorter. Furthermore, it was demonstrated that ZRS and NT-proBNP measured between 18-24 h after PPCI had comparable predictive accuracy for 30-day mortality. However, combined use considerably improved discrimination of low- and higher-risk patients and could provide decision rules to target the largest patient groups (up to $75 \%$ of the study population) who would be eligible for discharge $48 \mathrm{~h}$ after admission, with very low occurrence of adverse events and readmissions. Finally, NT-proBNP and the GRACE risk score also demonstrated comparable, good predictive value in NSTEMI patients.

Although mortality risk and hospital early discharge are closely related, many other circumstances have to be taken into account. In this thesis we also demonstrated that 


\section{Valorisation}

NT-proBNP has predictive value for the occurrence of both ischemic and bleeding events. In addition, NT-proBNP and high-sensitivity troponin T (hs-TnT) may serve as biomarker for prediction and prognostication of new onset atrial fibrillation in PPCI patients.

In conclusion, this thesis established the value of NT-proBNP over and beyond current risk strategies. Despite the fact that at present low-risk AMI patients have an excellent prognosis, several standard procedures such as a stay in hospital of several days, driving disqualification for 4 weeks, initiation of rehabilitation several weeks after discharge and annual outpatient department visits are applied to many patients by protocol. Although prospective validation of our findings will have to be performed, the presented research enables the development of more accurate risk strategies in order to optimize patient management and to control healthcare expenses.

${ }^{1}$ Data derived from https://www.volksgezondheidenzorg.info, official website of the Dutch Ministry of Health, Welfare and Sport. 


\section{Samenvatting}

De algemene achtergrond en doelstellingen van de studies in dit proefschrift zijn uiteengezet in HoOFDSTUK 1. Om patiënten met een acuut myocardinfarct effectief en veilig te kunnen behandelen is het van groot belang een goed onderscheid te maken tussen laag en hoger risico patiënten. Hier is de afgelopen jaren uitgebreid onderzoek naar gedaan, hetgeen geleid heeft tot de ontwikkeling van diverse modellen waarmee het sterfte risico van patiënten met een acuut myocard infarct kan worden ingeschat.

Belangrijke variabelen in de modellen ontwikkeld voor patiënten met ST-elevatie myocard infarct (STEMI) zijn infarctgrootte en het resultaat van de primaire percutane coronaire interventie (PPCI). Recente studies hebben echter aangetoond dat (nieuwe) biomarkers zoals NT-proBNP ook een sterk voorspellende waarde hebben binnen deze patiënten categorie.

De kennis omtrent de meerwaarde van deze biomarkers naast bestaande risicomodellen is echter nog beperkt.

Een goede risicoinschatting is ook van belang als het gaat om opnameduur en ontslagbeleid. Dit thema werd nader belicht bij de ontwikkeling van de Zwolle Risico Score (ZRS), waarbij peri-procedurele variabelen ook een belangrijke plaats innemen. Laag risico STEMI patiënten die werden behandeld met PPCI zouden na 72 uur veilig uit het ziekenhuis kunnen worden ontslagen. Heden ten dage kunnen deze patiënten waarschijnlijk wel veel eerder het ziekenhuis verlaten, maar het aantal studies naar zeer vroeg ontslag (24-36 uur na PPCI) is echter nog zeer beperkt, waarbij de me erwaarde van NT-proBNP bepalingen nog onbekend is. Tot slot wordt in HOOFDSTUK 1 benadrukt dat het ontwikkelen van nieuw atrium fibrilleren (AF de novo) een belangrijke (prognostische) impact heeft op PPCI patiënten. Ook hier is onbekend in hoeverre biomarkers een bijdrage kunnen leveren aan een tijdige risico inschatting. Op grond van deze constateringen stelt het onderzoek, gepresenteerd in dit proefschrift, zich ten doel de risico inschatting van patiënten met een acuut myocard infarct te verbeteren en daarmee het ontslagbeleid te optimaliseren in het huidige tijdperk waarin biomarkers een steeds belangrijkere plaats verwerven binnen de diagnostiek en behandeling van patiënten met een acuut myocardinfarct.

In HOOFDSTUK 2 wordt eerst een inventarisatie gemaakt van de voorspellers van (verlengde) opname duur na PPCI en de prognostische betekenis hiervan. In deze studie wordt aangetoond dat patiënten die langer opgenomen zijn, grotere infarcten doormaken, een lagere ejectie fractie hebben en dientengevolge vaker hartfalen hebben. Hoewel een lagere ejectiefractie sterk geassocieerd is met een langere opnameduur, is 
de 1 jaars-sterfte voor patiënten met een langere of kortere opnameduur in het onderzochte cohort gelijk.

In HoOFDSTUK 3 wordt een "short-stay" protocol prospectief geëvalueerd. Deze studie laat zien dat laag risico PPCI patiënten (o.b.v. de ZRS) binnen 24 tot 36 uur na opname veilig naar huis kunnen worden ontslagen. Het aantal "major adverse cardiac events" (MACE's) dat hierbij optreedt is zeer laag en verschilt niet met een referentie cohort van vergelijkbare patiënten. Bovendien is de 1 jaars overleving $100 \%$. De studie populatie is echter relatief klein en zeer selectief. De vraag is dan ook hoeveel PPCI patiënten heden ten dage werkelijk een laag sterfte risico hebben en vroeg met ontslag kunnen en in hoeverre NT-proBNP bepalingen hierbij een aanvullende waarde kunnen hebben. Om deze vragen te beantwoorden wordt in HoOFDSTUK 4 een sub-analyse gepresenteerd van de On-TIME 2 studie. Bij 845 PPCI patiënten wordt bij opname een NT-proBNP bepaling verricht en de ZRS (post PPCI) berekend. Beide hebben een sterk voorspellende en vergelijkbare waarde voor 30-dagen sterfte, waarbij de voorspellende waarde van NT-proBNP zelfs nog iets beter lijkt te zijn (statistisch niet significant). De lineaire combinatie van beide voorspellers toont echter het beste resultaat [AUC 0,94, CI 0,90-0,99]. Op basis van afkapwaardes, gebaseerd op patiënten met 30-dagen overleving (sensitiviteit $100 \%$ ofwel $0 \%$ mortaliteit), kan $68 \%$ van de studiepopulatie als zeer laag risico patiënt worden geïdentificeerd uitgaande van een ZRS $<2$ of NT-proBNP $<200 \mathrm{pg} / \mathrm{ml}$. Wanneer deze "beslisregel" zou worden toegepast om een vroeg ontslag - na 48 uur - in gang te zetten, dan zou 64\% van de studiepopulatie hiervoor in aanmerking zijn gekomen, met slechts een heel laag percentage MACE's en majeure bloedingen tot 10 dagen na ontslag (resp. 1,3\% en $0,6 \%$ ). Natuurlijk behoeven deze bevindingen een prospectieve evaluatie, maar de studie toont de meerwaarde aan van NT-proBNP naast klassieke risico variabelen, niet alleen bij inschatting van het sterfte risico, maar ook bij het in gang zetten van een veilig en effectief (vroeg-)ontslag beleid. De vraag is echter of het optimale tijdstip van NT-proBNP afname bij opname is of juist op een later tijdstip. Deze vraag wordt beantwoord in HoOFDSTUK 5; een aanvulling op HoOFDSTUK 4, waarin naast de ZRS, NT-proBNP wordt bepaald op drie tijdstippen: bij opname, 18-24 uur en 72-96 uur na opname en waarbij ook het verschil tussen NT-proBNP bij opname en na 18-24 uur (delta NT-proBNP) wordt gemeten in 845 PPCI patiënten uit de On-TIME 2 studie. Vergeleken met de ZRS, toont NT-proBNP bepaald op 18-24 uur en 72-96 uur (maar niet delta NT-proBNP) een betere voorspellende waarde, met een optimaal voorspellende waarde na 18-24 uur [AUC 0,94]. Hoewel de combinatie van ZRS en NT-proBNP 18-24 uur op basis van de AUC geen verbetering toont, wordt middels aanvullende reclassificatie berekeningen wel degelijk aangetoond dat een combinatie 
van beide variabelen (ZRS en NT-proBNP 18-24 uur) de best voorspellende waarde voor 30-dagen sterfte laat zien.

Wanneer een nieuwe beslisregel wordt opgesteld, gebaseerd op afkapwaardes, wederom uitgaande van $0 \%$ sterfte (sensitiviteit van $100 \%$ ), dan blijkt dat op basis van een ZRS $<2$ of een NT-proBNP waarde bepaald tussen 18-24 uur na opname $<2500$ $\mathrm{pg} / \mathrm{ml}, 75 \%$ van de studiepopulatie als laag risico kan worden geïdentificeerd. Deze patiëntengroep zou na 48 uur veilig naar huis kunnen worden ontslagen, met een verwacht heropname percentage van slechts $1,2 \%$ tussen het tijdstip van ontslag en 10 dagen, gebaseerd op MACE's of bloedingen.

Hoewel dus blijkt dat een laag sterfte risico, gebaseerd op bovenstaande risicostratificatie, gepaard gaat met een eveneens laag risico op (niet fatale) ongewenste uitkomsten, blijft het onduidelijk of NT-proBNP ook daadwerkelijk niet-fatale doch ongewenste uitkomsten (non-fatal adverse events) kan voorspellen. Dit wordt nader bestudeerd in HoOfDSTUK 6. Een sub-analyse van de On-TIME 2 studie. Hoewel ZRS en NT-proBNP bepaald tussen 18-24 uur en 72-96 uur na PPCI voorspellend blijken te zijn voor het samengesteld eindpunt van re-infarct, spoed re-vascularisatie, majeure bloedingen of ventriculaire ritmestoornissen na 30 dagen. [Odds ratio's 1,10-1,14], vallen de AUC's voor de bepalingen afzonderlijk tegen [alle $<0,70$ ]. De combinatie van ZRS en NT-proBNP bepaald op 18-24 uur na opname laat echter een bescheiden verbetering zien [AUC $0,73,95 \% \mathrm{BI} 0,62-0,78]$.

Een belangrijk deel van de infarct patiënten presenteert zich met een NSTEMI of NSTE- acuut coronairsyndroom (NSTE-ACS). Hoewel deze heterogene patiëntengroep meestal gebaat is bij een hartcatheterisatie (CAG), gevolgd door een revascularisatie, is een spoed interventie eigenlijk alleen geïndiceerd bij zeer hoog risico patiënten en dienen hoog risico patiënten binnen 24 uur na opname een CAG te ondergaan. Voor NSTE-ACS patiënten zijn diverse risicomodellen ontwikkeld waarvan the Global Registry of Acute Coronary Events (GRACE) risico score het meest gebruikt wordt. Daarnaast is er de Thrombolysis In Myocardial Infarction (TIMI) risk score voor NSTEMI/ instabiele angina pectoris. In Hoeverre NT-proBNP echter deze risico modellen zou kunnen verbeteren is nog enigszins onduidelijk. Dit wordt nader belicht in HOOFDSTUK 7. Hierin wordt de voorspellende waarde van NT-proBNP gemeten bij opname, vergeleken met die van de GRACE en TIMI risico scores in 1324 patiënten met NSTE-ACS. Zowel NT-proBNP als de GRACE score (maar niet de TIMI risico score) zij beide onafhankelijke voorspellers voor 30 dagen sterfte met een vergelijkbare voorspellende waarde (AUC respectievelijk 0,85 en $0,87, \mathrm{P}=0,67$ ). De GRACE score kan echter niet worden verbeterd met toevoeging van NT-proBNP, terwijl de voorspellende waarde van NT-proBNP wel licht toeneemt na toevoeging van de 


\section{Samenvatting}

GRACE score. Resumerend is NT-proBNP dus ook bij NSTEMI patiënten een krachtige voorspeller voor 30-dagen sterfte (en veel beter dan de TIMI risico score), maar een echte meerwaarde t.o.v. de GRACE score lijkt er niet te zijn.

In HoOFDSTUK 8 wordt de voorspellende waarde van NT-proBNP voor het ontwikkelen van atrium fibrilleren (AF) de novo bij PPCI patiënten bepaald. Hoewel van NT-proBNP wel is aangetoond dat het geassocieerd is met AF de novo binnen deze patiëntencategorie, is het onduidelijk of NT-proBNP ook daadwerkelijk kan bijdragen aan een verbetering van risicoinschatting. Verder is onbekend op welk tijdstip na opname, NT-proBNP het best voorspellend is. In een sub-analyse van de On-TIME 2 studie wordt bij 830 PPCI patiënten NT-proBNP bepaald bij opname, na 24-72 uur en na 72 uur. Bij 73 patiënten onstaat na 30 dagen AF (bij 41 patiënten binnen 24 uur, bij 14 patiënten na 24-72 uur en bij 18 patiënten na 72 uur).

Hoewel leeftijd en Killip Klasse bij multivariate analyse krachtige voorspellers zijn voor AF de novo, blijkt opname NT-proBNP geen voorspeller te zijn van AF de novo in de eerste 24 uur na STEMI (AUC 0,59). Ondanks dat opname NT-proBNP wel weer voorspellend is voor AF de novo op een later tijdstip ( op 24-72 uur en na 72 uur), zijn NT-proBNP bepalingen na 24 uur en na 72 uur het sterkst geassocieerd met AF de novo na 72 uur tot 30 dagen post infarct (OR resp. 1,22, $\mathrm{P}<0,001$ en $1,29, \mathrm{P}<0,002$ ). Ook uit deze studie blijkt dus dat de prognose van PPCI patiënten niet alleen betreffende sterfte maar ook betreffende het optreden van AF de novo, beter in kaart kan worden gebracht met NT-proBNP gemeten na 24 uur en niet met een opname bepaling. In navolging van NT-proBNP zou ook de biomarker high-sensitivity troponin $\mathrm{T}$ (HsTnT) voorspellend kunnen zijn voor het ontwikkelen van AF de novo in de setting van een STEMI en PPCI. Eerdere studies hebben dit vooralsnog niet laten zien. Echter, de waarde van seriële (op verschillende tijdstippen) HsTnT metingen, bij het voorspellen van post infarct $\mathrm{AF}$ is in deze setting niet eerder bestudeerd.

In Hoofdstuk 9, wordt bij 830 patiënten in de On-TIME 2 studie HsTnT gemeten bij opname, na 24 uur en na 72 uur na opname. Het tijdstip waarop AF optreedt wordt hierbij verdeeld in drie groepen: binnen 24 uur, tussen 24 en 72 uur na opname en na 72 uur - 30 dagen na opname. Op deze tijdstippen ontwikkelen resp. 41, 14 en 18 patiënten $\mathrm{AF}$ de novo. Hoewel opname HsTnT enigszins voorspellend is voor $\mathrm{AF}$ de novo op latere tijdstippen (AUC $0,60, \mathrm{P}=0,008$ ), is de voorspellende waarde voor $\mathrm{AF}$ dat de eerste 24 uur optreedt, slecht (AUC 0,54, $\mathrm{P}=0,41$ ). Dit in tegenstelling tot HsTnT bepaald na 24 uur (AUC $0,79, \mathrm{P}=0,001$ ) of na 72 uur (AUC $0,88, \mathrm{P}<0,001$ ), dat voorspellend blijkt te zijn voor zowel AF dat optreedt tussen 24-72 uur als AF dat optreedt na 72 uur. Bij multivariate regressie analyse komt dan ook naar voren dat HsTnT bepaald na 24 uur (OR 1,012, $\mathrm{P}=0,017)$ en na 72 uur (OR 1,035, $\mathrm{P}<0,001)$ het 
meest geassocieerd is met het optreden van post infarct AF in PPCI patiënten. De studie toont dus aan dat HsTnT wel degelijk een voorspeller van post infarct AF is, waarbij een bepaling na 24 uur of na 72 uur beter is dan een opname bepaling.

Tot slot wordt in HoOFDSTUK 10 aangetoond dat een verhoogd opname NT-proBNP bij STEMI patiënten behandeld met PPCI ook een onafhankelijke voorspeller blijkt te zijn van lange termijns (5-jaars) sterfte (OR 2,75; 95\%BI 1,41-5,73, $\mathrm{P}=0,003$ ). Verder lijkt NT-proBNP ook te kunnen worden ingezet als biomarker om een behandelstrategie te optimaliseren: Bij PPCI patiënten met een verhoogd opname NT-proBNP, die worden behandeld met tirofiban in een vroeg stadium (al voor opname, in de ambulance) is de 30-dagen en 1 jaarssterfte significant lager, vergeleken met de placebo groep (resp. $2,7 \%$ vs $7,5 \%, \mathrm{P}=0,021$ en $4.5 \%$ vs $9,4 \%, \mathrm{P}=0,043$ ) 



\section{Dankwoord}

\section{"Geneeskunde is een wetenschap van onzekerheid en een kunst van waarschijnlijkheid".}

Met deze woorden van de 19e eeuwse internist Sir William Osler zou al het voorgaande inhoudelijk in één ademteug vattend kunnen worden weergegeven.

Als het gaat om de tot stand koming van dit proefschrift, heb ik ervaren dat het toch nog een hele kunst is de wetenschap te behouden dat ondanks alle onzekerheden een success-volle afronding waarschijnlijk is.

Dit lange traject kon echter niet worden doorlopen zonder de hulp en steun van vele mensen die ik allen mijn dank verschuldigd ben. Een aantal personen en instanties wil ik hier echter graag persoonlijk noemen.

\section{Prof. Dr. J.C.A. Hoorntje, promotor}

Beste Jan, Ik herinner mij nog goed onze 1e ontmoeting; de sollicitatie in Zwolle in 2003. Je resideerde als opleider in een kleine kamer met uitzicht op een binnenpleintje van de Weezenlanden. Een bureau, hoge fauteuil en een - aanzienlijk lager - tweezitsbankje voor de sollicitant, vormden toen het decor waarbij het startschot werd gegeven voor een boeidende tijd. Jouw pragmatische maar goed onderbouwde benadering van de geneeskunde in het algemeen en het hartinfarct in het bijzonder sprak mij altijd aan. Daar waar complicaties vlak na een infarct werden gevreesd wees jij op het lage risico hiervan als "de Dotter" snel en goed was gelukt. Ik ben zeer verguld met het feit dat we deze zienswijze verder wetenschappelijk hebben kunnen onderbouwen met dit proefschrift als kroon op het werk. Zeer veel dank hiervoor!

\section{Dr. A. Adiyaman, copromotor}

Beste Ahmet, Wij genoten samen een deel van de opleiding in Zwolle en de wetenschap bracht ons samen. Als cardioloog in opleiding had je wetenschappelijk al een grote staat van dienst en werd je voor velen van ons een gewaardeerd aanspreekpunt aangaande hulp en advies bij analyses en interpretaties van data. Onze samenwerking leidde ertoe dat je mijn copromotor wilde worden. Grote waardering en veel dank wil ik uitspreken voor jouw scherpe en analytische denkvermogen en de moeite die je nam voor de vele "reviews" en correcties, ook bij artikelen die wat minder snel ter perse konden gaan. 


\section{Dankwoord}

Dr. A.W.J. van 't Hof, copromotor

Beste Arnoud, vice-opleider en groot wetenschapper, wiens werk de top-literatuur heeft bereikt. Zonder jouw aanwezigheid en inzet, waag ik het te betwijfelen of wij dit proefschrift ooit hadden kunnen schrijven. Je wees ons assistenten immers altijd op de noodzaak van goede data registratie ; de absolute basis voor solide wetenschappelijk werk. De inmiddels zeer omvangrijke infarctregistratie heeft velen enthousiast gemaakt voor het verrichten van wetenschappelijk onderzoek en een substantiële bijdrage geleverd aan de verbetering van de behandeling van acute coronaire syndromen. Dat hieruit voor jou een leerstoel interventie cardiologie voortvloeit is een mijns inziens logisch gevolg. Voor de wijze waarop je mij in de aanloop naar de promotie hebt begeleid zeg ik je met recht "hartelijk" dank!

Voorzitter en leden van de beoordelingscommissie, Prof. Dr. H.P. Brunner-La Rocca, Prof. Dr. H.J.G.M. Crijns, Prof. Dr. J.P.S. Henriques, Prof. Dr. A.H.E.M. Maas, Prof. Dr. G.J. Wesseling, hartelijk dank voor de beoordeling van dit proefschrift.

\section{drs. J.-D. Brugma en drs. L. Koppendraaier, paranimfen}

Beste Jan-Dietert en Laurens,

Met een apotheker en een kaakchirug aan mijn zijde hoop ik dat de verdediging geen bittere pil wordt en dat we niet te stevig aan de tand worden gevoeld. Ik dank jullie daarom alvast voor het werk dat jullie nog te doen staat.

\section{Mw. V.R.C. Derks}

Beste Vera, met het noemen van jouw naam kan ik nu niet langer wachten. Met grote toewijding heb je mijn manuscripten gereed gemaakt voor verzending en onderhield je de correspondentie met de diverse tijdschriften. Na 30 jaar ervaring ben je inmiddels een onmisbare expert in het Zwolse! Daarnaast ben je altijd een morele supporter geweest die mij het enthousiasme wist te behouden als vele uren werk met een pennenstreek teniet werden gedaan. De laatste jaren hebben we elk geaccepteerd manuscript gevierd met een etentje in de Achterhoek; een gezellige traditie die we absoluut blijven voortzetten. Vera dankjewel voor alles.

\section{Dr. A.R. Ramdat Misier}

Beste Anand, Halverwege mijn opleidingstijd nam je het opleidersstokje over en hield je de goede naam van Zwolle hoog. Je wist ons dagelijks te enthousiasmeren voor een portie onderwijs geserveerd met soep en boterhammen. Het was voor mij dan ook een leerzame periode. Jouw uitspraak "Er is maar één tijd en dat is kwaliteit", neem ik mij 
nog altijd ter harte. Mede dankzij een goede opleiding destijds kan ik mij nu inzetten voor optimale cardiologische zorg. Heel veel dank hiervoor.

\section{De Vakgroep Cardiologie Doetinchem}

drs. John van Hal, Dr. Willem Terpstra, Dr. Rutger Jansen, drs. Frank Smeele, drs. Edwin van Gorselen, drs. Sjoerd Reinders en drs. Astrid Schultz.

\section{"Ieders persoonlijke noot maakt de perfecte melodie"}

John, Wij hebben heel vaak amusante conversaties, waarbij we ons zo nu en dan afvragen hoe we van een dubbeltje een kwartje kunnen maken: daarin ben je niet te overtreffen.

Willem, Jouw karaktereigenschappen vormen de perfecte ingrediënten voor een geschikte opleider, manager en (toffe) peer bij wie iedereen zich in het ziekenhuis vertrouwd voelt.

Rutger, Aimabele dokter en uitstekend MSB bestuurder. Jij was degene die mij destijds attendeerde op de "chef plek" in Doetinchem: achteraf gezien voor mij een mijlpaal.

Frank, Medicus practicus, maar bovenal een practisch medicus die met een jachtig karakter zijn doelen niet voorbijschiet.

Edwin, Gedreven collega met vele talenten. De stelling "geluk zit in een klein (Achter)hoekje", is dè perfecte hekkensluiter: Ik zie er naar uit!

Sjoerd, Mede "vroege vogel" en - bijna - buurman, Jouw beeldvorming heeft een enorme aantrekkingskracht waarbij je plussen en minnen uiteindelijk tegen elkaar weet op te heffen. Dat wordt zeer gewaardeerd.

Astrid, De eerste vrouwelijke cardioloog (of mag ik toch zeggen cardiologe...) in Doetinchem: het werd tijd! Fijn dat je bij ons wilt blijven.

En dan de pensionado's die mij hebben zien komen (en ik heb zien gaan): Hoop jullie snel weer te zien in Maastricht.

Jos Deppenbroek, Cardioloog van het eerste uur in Doetinchem en levensgenieter, Jouw lijfspreuk " "t kump goed", houden we erin!

Henk Drost, Met mijn wetenschappelijke activiteiten ben je altijd begaan. Bewonderens-waardig is je nog immer aanwezige belangstelling voor ontwikkelingen in het vak. Hoe ouder hoe beter geldt derhalve niet exclusief voor rode wijn. 


\section{Dankwoord}

\section{Maatschap Cardiologie Zwolle}

Alle cardiologen zowel aanwezig tijdens mijn opleidingstijd als de huidige maatschapsleden dank ik hartelijk voor de vele opleidingsmomenten en de mogelijkheid om in wetenschappelijk onderzoek te participeren. In het bijzonder Prof. Dr. M.J. de Boer, Dr. J.-H. Dambrink, Dr. J.P. Ottervanger en Prof. Dr. H. Suryapranata voor hun bijdrages aan mijn eerste wetenschappelijke activiteiten en publicaties.

\section{Diagram BV}

Alle medewerkers dank ik voor hun hulp die zij de afgelopen jaren hebben geboden en voor de gastvrijheid die ik altijd mocht ervaren bij de vele bezoeken aan het Van Nahuysplein. In het bijzonder dank ik Jaap Klijn die altijd mijn vele verzoeken om extra analysis te mogen laten verrichten heeft gehonoreerd. Ook op Edwin Nibbering en Evelien Kolkman heb ik frequent een beroep kunnen doen.

\section{Dr. P. Koopmans}

Beste Petra, Als statisticus heb je een significante bijdrage geleverd aan de getalsmatige onderbouwing. Aangezien ik in de statistiek niet uitblink, heb je altijd de tijd genomen om e.e.a. uit te leggen als ik iets niet begreep. Heel veel dank voor deze plezierige samenwerking!

Verder spreek ik mijn dank uit aan alle arts-assistenten in Zwolle zowel aan de huidige generatie als aan de toenmalige assistenten en "opleidingsmaatjes" voor de klinische data registratie en collegialiteit. Daarnaast veel dank aan alle medewerkers die betrokken zijn geweest bij de behandeling van de infarct- en studiepatiënten van opname tot ontslag; zonder jullie bijdrage zou het genereren van data niet mogelijk zijn geweest.

Ook alle mede-auteurs hartelijk dank voor jullie waardevolle commentaren.

I should like to say a special word of thanks to all On-TIME 2 investigators for allowing me to perform several sub-analysis of this great study.

Thea Schenk dank ik hartelijk voor de verzorging van de lay-out van dit boekwerk en de waardevolle adviezen betreffende het juiste gebruik van de Engelse taal.

\section{Mijn (studie-) vrienden}

J.C. Banco: drs. Jan-Dietert Brugma, drs. Laurens Koppendraaier, Rutger Ligtenberg, Jeroen Levij van Vinninghe, drs. Bart Ponsioen, Rogier Sterkenburgh MSc, Wim 
Sturm, drs. Maarten Swaan: "Hoe ver uiteen gedreven, hoe wijd van deze stad, vereend zijn wij voor het leven, door 't wachtwoord..." jullie wel bekend. Maar ook studiegenoot drs. Andrew Robinson: Een leuke studietijd is essentieel om uiteindelijk een doctoraat in de wacht te kunnen slepen.

Heel veel dank voor de mooie momenten die we toen hebben beleefd en nog steeds beleven - zij het minder vaak door ieders drukke bestaan.

\section{Mijn ouders}

Lieve ouders, mijn moeder en wijlen mijn vader. Jullie hebben er altijd alles aan gedaan om mij mijn idealen te kunnen laten verwezenlijken Ik kan dan ook terugkijken op een fijne jeugd; heel veel dank hiervoor!

\section{Mijn schoonfamilie}

Jullie staan vaak voor ons en vooral voor onze jongens klaar. Heel veel dank hiervoor en voor de vele gezellige momenten die wij met elkaar beleven.

\section{Marleen}

Mijn allerliefste. Zonder jouw onvoorwaardelijke steun en engelen geduld was dit proefschrift er niet gekomen. "Schrijven is blijven zitten tot het er staat" heb je letterlijk mogen ervaren, vaak in vrije tijd waarbij andere plannen dikwijls werden doorkruist en je ook nog eens de zorg voor onze lieve jongens Pepijn en Justus op je nam. De blijk van waardering die ik hiervoor heb is enorm en moeilijk in geschreven woorden uit te drukken! 


\section{Publication list}

Schellings DA, Dambrink J-H, Hoorntje JC et al. Long-term comparison of balloon angioplasty with provisional stenting versus routine stenting in patients with non-STelevation acute coronary syndrome. Neth Heart J 2010;18(6):307-313.

Schellings DA, Ottervanger JP, Van 't Hof AW et al. Predictors and importance of prolonged hospital stay after primary PCI for ST elevation myocardial infarction. Coron Artery Dis 2011; 22(7):458-462

Schellings DA, Symersky T, Ottervanger JP et al. Clinical cardiology consultation at noncardiology departments: stepchild of patientcare? Neth Heart J 2012;20(6):260-263.

Schellings DA, Boomsma MF, Wolfhagen MJ et al. Chylopericardium with cardiac tamponade secondary to acute Epstein-Barr virus peri-myocarditis. Neth Heart J 2014;22(9):401-403.

Schellings DA, Adiyaman A, Giannitsis E et al. Early discharge after primary percutaneous coronary intervention: the added value of $\mathrm{N}$-terminal pro-brain natriuretic peptide to the Zwolle Risk Score. J Am Heart Assoc 2014;3(6):online paper.

Parlak E, Gal P, Schellings DA et al. Serial N-terminal pro-brain natriuretic peptide assessments in predicting new-onset atrial fibrillation in ST elevation myocardial infarction patients who undergo primary percutaneous coronary intervention. J Mol Biomark Diagn $2015 ; 7: 1$.

Gal P, Parlak E, Schellings DA et al. Association of serial high-sensitivity troponin T with onset of atrial fibrillation in ST-elevation myocardial infarction patients undergoing primary percutaneous coronary intervention. Eur Heart J Acute Cardiovasc Care 2016;5(1):33-42

Schellings DA, Van 't Hof AW, Ten Berg JM et al. NT-proBNP during and after primary PCI for improved scheduling of early hospital discharge. Neth Heart J 2016;9 Dec online.

Schellings DA, Adiyaman A, Dambrink J-H et al. Predictive value of NT-proBNP for 30day mortality in patients with non-ST-elevation acute coronary syndromes: a comparison with the GRACE and TIMI Risk scores. Vasc Health Risk Manag 2016;12:471-476. 


\section{About the Author}

The author was born on 1 May 1978 in Almelo and grew up in the nearby village of Ootmarsum. He attended secondary school in Almelo (Atheneum, RK scholengemeenschap Sint Canisius). In 1996 he moved to Leuven (Belgium) where he started his medical training at the University of Leuven. In 1997 the medical training was continued at the University of Groningen. In Groningen he actively participated in student life and became a member of the Groninger Studenten Corps 'Vindicat atque Polit'. In the final two years of medical training he did clinical internships at MST Enschede and at the cardiology department of ZGT Hengelo where his interest for cardiology was established. This was followed by a residency at the cardiology department of Isala Hospital, Zwolle, where he started his cardiology training in 2005 (supervisors Dr. J.C.A. Hoorntje, who was succeeded by Dr. A.R. Ramdat Misier), which he completed in 2011. In the same year he joined the association of cardiologists in Slingeland Hospital, Doetinchem, where he became a member of staff in 2013. At Slingeland Hospital he works as general cardiologist and as certified device specialist, sharing responsibility for pacemaker implantations and ICD follow-up. Recently he became one of the two medical safety officers of Slingeland Hospital.

Dirk Schellings is married to Marleen van Joolen and they have two children: Pepijn and Justus. In 2014 they found their home in Terborg at 'het Hasselshuis' a mid-19th century monumental building. The house, gardening and collecting antiques are among his favorite hobbies. 
